

\section{INSTITUTO DE PESQUISAS ENERGÉTICAS E NUCLEARES \\ Autarquia associada à Universidade de São Paulo}

Informatização e unificação dos programas de proteção radiológica: monitoramento das radiações ionizantes e sua otimização

Denise Sahyun Levy

\begin{tabular}{llllrr} 
Tese apresentada como & \multicolumn{2}{c}{ parte } & dos \\
requisitos para obtenção do & Grau & de \\
Doutor & em & Ciências & na & Área \\
de Tecnologia Nuclear - Aplicações
\end{tabular}

Orientador:

Prof. Dr. Gian Maria Agostino Angelo Sordi

Versão Original

Versão Original disponível no IPEN

São Paulo

2015 


\section{DEDICATÓRIA}

Dedico este trabalho à minha família querida: meu marido Patrick e meus filhos Alissar e Jean-Michel, que permaneceram sempre ao meu lado compartilhando minhas alegrias e angústias, me amparando nos momentos difíceis com palavras de afeto e carinho. Obrigada pelo apoio incondicional e pelo amor sem igual durante este meu percurso. 


\section{AGRADECIMENTOS}

Ao Instituto de Pesquisas Energéticas e Nucleares, pela oportunidade.

Ao meu orientador, Doutor Gian Maria Agostino Angelo Sordi, que desde o mestrado me acompanha, por me acolher mais uma vez, pela sempre disponibilidade, pela confiança em mim depositada e pelo empenho na orientação deste trabalho.

Aos amigos do IPEN que me acompanharam e me incentivaram a vencer os desafios ao longo deste percurso.

A todos aqueles que, de maneira especial, fizeram parte da minha vida nestes últimos três anos, deixo meu mais sincero agradecimento! 


\title{
INFORMATIZAÇÃO E UNIFICAÇÃO DOS PROGRAMAS DE PROTEÇÃO RADIOLÓGICA: MONITORAMENTO DAS RADIAÇÕES IONIZANTES E SUA OTIMIZAÇÃO
}

\author{
Denise Sahyun Levy
}

\section{RESUMO}

Um programa de monitoramento para fins de proteção radiológica deve mostrar como ele auxilia na obtenção e demonstração de um grau de proteção adequado e comprovar que as condições de trabalho continuam satisfatórias com o transcorrer do tempo. Para o controle operacional das exposições à radiação ionizante em qualquer local de trabalho, a Comissão Internacional de Proteção Radiológica (CIPR) recomenda um programa de proteção radiológica operacional, proporcional ao grau de risco, para garantir o gerenciamento efetivo das medidas necessárias para se satisfazer o principio da otimização. O presente trabalho de pesquisa tem como premissa o potencial das Tecnologias da Informação e Comunicação (TIC) como ferramenta para a comunicação e disseminação do conhecimento em Proteção Radiológica. 0 trabalho inclui a informatização da filosofia e técnica do monitoramento e sua otimização, unificando e inter-relacionando informações advindas de diversas publicações nacionais e internacionais, oferecendo às instalações radiativas brasileiras um veículo completo para informação e pesquisa, que permite dimensionar os esforços de otimização tornando-os eficazes e justificados. O sistema oferece ainda tópicos de discussões no intuito de ampliar o repertório dos profissionais do campo da proteção radiológica, suscitando novas reflexões a favor da segurança. Trata-se dos temas desenvolvidos nesta tese, a saber: a necessidade de um monitoramento auditor e discussões mais aprofundadas sobre as exposições potenciais. As reflexões propostas na presente tese vêm ao encontro das novas exigências internacionais, propondo ações passíveis de serem incorporadas na prática laboral. Dentro dos princípios da proteção radiológica, a implementação de um programa de monitoramento auditor permite avaliar se os critérios e ações previamente estabelecidas pelo Serviço de Proteção Radiológica são ou não atendidos, se foram implementados com eficácia e se permanecem adequados. Os fatos resultantes dos procedimentos de auditoria auxiliam a detectar deficiências no processo, possibilitando conclusões e recomendações diante de possíveis fatores desencadeadores de exposições indevidas. Por meio de exames sistemáticos das atividades realizadas em cada tipo de monitoramento, a auditoria infere segurança ao processo, respaldando o trabalhador na realização do monitoramento relacionado com a tarefa e respaldando a instalação, que empreende ações responsáveis a favor da segurança. Em relação às exposições potenciais, somente duas publicações da CIPR são expressivas e desenvolvem o assunto. Entretanto, ainda que forneçam a fundamentação teórica, são incompletas em seus exemplos. Há uma grande falta de conhecimento das probabilidades de falhas, o que atualmente constitui um vasto campo de pesquisa da proteção radiológica. A presente tese propõe, a partir de árvores de falhas, caminhos que auxiliam a quantificar probabilisticamente a ocorrência das exposições potenciais e a probabilidade de se atingir um determinado valor da dose. Acreditamos que o potencial das TIC contribuirá largamente para a disseminação da informação para as instalações radiativas, estimulando o desenvolvimento neste país de grandes extensões territoriais, onde permanece um desafio oferecer o acesso à informação ao maior número de pessoas possível, minimizando custos e maximizando resultados. 


\title{
WEB-BASED SYSTEM TO UNIFY THE RADIOLOGICAL PROTECTION PROGRAMS: IONIZING RADIATION MONITORING AND OPTIMIZATION
}

\author{
Denise Sahyun Levy
}

\begin{abstract}
A monitoring program for the purposes of radiological protection should demonstrate an adequate protection degree and prove that working conditions remain appropriate as time goes by. For operational control of exposures to ionizing radiation in any workplace, the International Comission on Radiation Protection (ICRP) recommends establishing a program of operational radiation protection, proportional to the risk, to ensure the effective management of all necessary measures to satisfy the principle of optimization. This research work focus on the potential value of Information and Communication Technologies (ICTs) to enhance communication and education on Radiological Protection throughout Brazil. The work includes the informatization of the monitoring policy and techniques, interrelating information currently scattered in several documents, providing Brazilian radioactive facilities a complete repository for research, consultation and information, which allows to size optimization efforts by technology, enabling them to be effective and justified. The content of monitoring programs involves not only the collection and interrelationship of existing information in the publications, but also new approaches from some recommendations, presenting some initiatives towards safety. In this sense, the two contents researched and expanded are: the need for an auditor monitoring and discussions on potential exposures. The recommendations proposed in this thesis meet the new international requirements stablished by the International Agency of Nuclear Energy (IAEA) and propose appropriate actions to be incorporated into labor practice. Respecting the scope of the principles of radiological protection, an auditing program permits to evaluate whether criteria and actions previously established by Radiological Protection Service are effectively implemented and remain appropriate as time goes by. The results of auditing procedures help to detect deficiencies in the process, enabling conclusions and recommendations, avoiding possible triggers of undue exposures. Through systematic examinations of activities in each type of monitoring, auditing attempt to ensure the process, supporting the employee in performing task-related monitoring and support the facility that choose responsible actions towards safety. Furthermore, regarding potential exposures, only two publications of ICRP develop expressively the issue. Even though these publications provide the fundamental theory, they are incomplete in their examples. There is still lack of knowledge of failure probabilities, which currently constitutes a broad research field in radiological protection. This research work proposes the development of fault trees, suggesting paths to quantify probabilistically the occurrence of potential exposures, as well as probabilities to reach a certain level of dose. We believe that the potential of ICT shall contribute greatly to provide information where it is needed, stimulating development in this large country where it is a strong challenge to ensure access to information to as many people as possible, minimizing costs and optimizing results.
\end{abstract}




\section{ÍNDICE DE TABELAS E FIGURAS}

Tabela 1 - Critérios de riscos: intervalo de probabilidades 52

Tabela 2 - Probabilidades anuais de ocorrência de risco

Figura 1 - Acessos ao sistema UNIPRORAD entre 20/12/13 e 19/06/14

Figura 2 - Acessos ao sistema UNIPRORAD entre 20/07/14 e 19/12/15 …..................................57

Figura 3 - Acessos ao sistema UNIPRORAD entre 20/12/14 e 19/06/15 ….............................58

Figura 4 - Acessos ao sistema UNIPRORAD entre 20/05/14 e 19/06/15 ....................................59

Figura 5 - Sistemas operacionais utilizados $-09 / 06 / 15$ a 08/07/15 ..........................................59

Figura 6 - Resoluções de tela a partir de tecnologias móveis - 09/06/15 a 08/07/15................60

Figura 7 - Programa adequado e Eficaz para um programa de Proteção Radiológica .................64

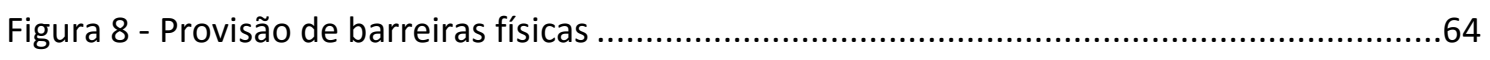

Figura 9 - Controle da contaminação de superfície e do ar .......................................................65

Figura 10 - Provisão de equipamento apropriado (portátil, móvel e fixo)..................................65

Figura 11 - Programa de monitoramento do local de trabalho ................................................6

Figura 12 - Adequação do monitoramento individual ...........................................................6

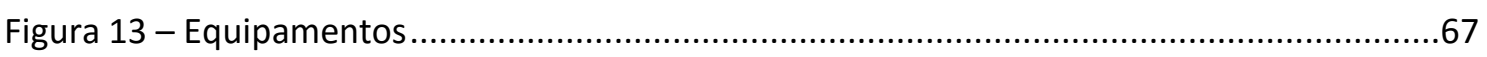

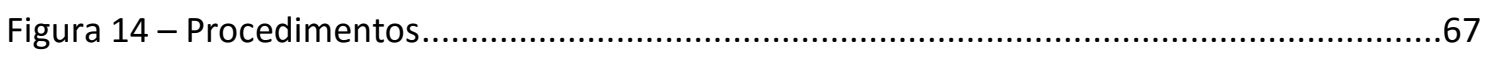

Figura 15 - Caso 1: Exposição potencial em irradiador moderno ..............................................68

Figura 16 - Caso 1: Fonte não blindada e operador entra pela porta do produto .......................68

Figura 17 - Caso 1: Operador entra e a fonte deixa a blindagem .............................................69

Figura 18 - Caso 1: Fragmento de fonte transportado para fora ..............................................69

Figura 19 - Caso 1: Monitoramento relacionado com a tarefa para radiação externa ................70

Figura 20 - Caso 2: Exposição potencial de pacientes por aparelho de radioterapia ..................70

Figura 21 - Caso 2: Falha na blindagem ............................................................................ 71

Figura 22 - Caso 2: Auditoria do monitoramento: equipamentos e procedimentos ...................71

Figura 23 - Caso 3: Exposição potencial em um cíclotron..........................................................72

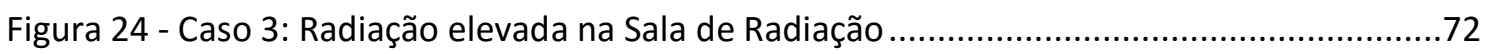

Figura 25 - Caso 3: Falha humana procedimental e/ou operacional .........................................73

Figura 26 - Caso 3: Liberação por painel diagnóstico defeituoso .............................................73

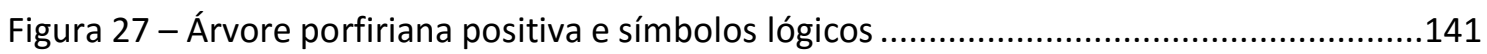

Figura 28 - Diferentes fileiras para um programa adequado e eficaz de proteção radiológica142

Figura 29 - Exemplo de árvore positiva para controle da radiação laboral ..............................143

Figura 30 - Componentes importantes na apreciação de um programa ...................................145

Figura 31- Diagrama em bloco para condução de uma operação .............................................146 


\section{SUMÁRIO}

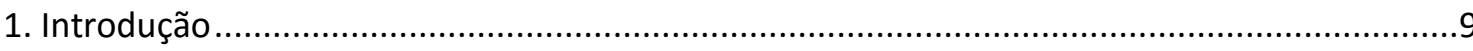

1.1 Principais entidades internacionais e nacionais pertinentes à Proteção Radiológica..........9

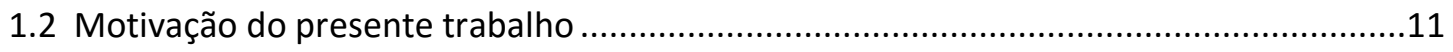

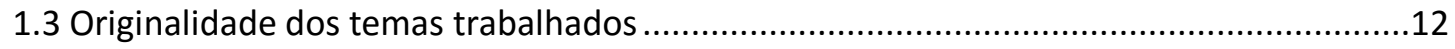

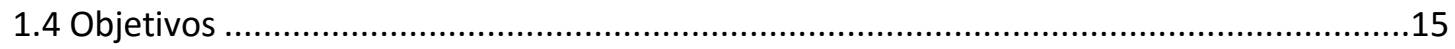

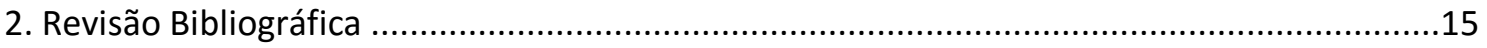

2.1 Mudanças de paradigmas em Proteção Radiológica .......................................................16

2.2 Exposições potenciais diante dos novos paradigmas ......................................................18

2.3 Evolução das Tecnologias da Informação e Comunicação no Brasil ..................................19

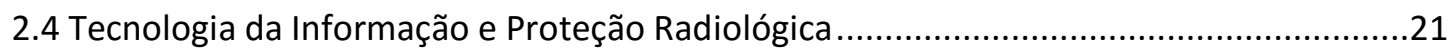

2.4.1. FORO Iberoamericano de Organismos Reguladores Radiológicos y Nucleares ........22

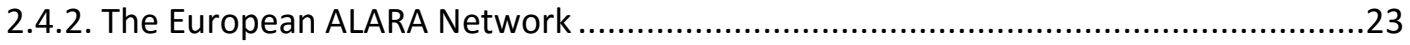

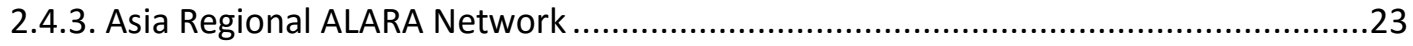

2.4.4. The European Radiation Protection Authorities Network .....................................23

2.4.5. The European Training and Education in Radiation Protection Platform .................24

2.4.6. The Regional European and Central Asian ALARA Network....................................24

2.4.7. Red de optimización de Protección Radiológica Ocupacional en America Latina.....25

2.4.8. Latin American Network for Education in Nuclear Technology ................................25

2.4.9. Unificação dos Programas de Proteção Radiológica .................................................25

3. A tecnologia informática para a disseminação da informação ..............................................26

3.1. Metodologia para desenvolvimento dos modelos de informatização.............................27

3.2. Dimensionamento do conteúdo nas Tecnologias da Informação e Comunicação ...........28

4. Programa de Monitoramento para o trabalhador em condições normais de trabalho .........29

4.1. Diferentes funções do monitoramento das radiações ionizantes ....................................30

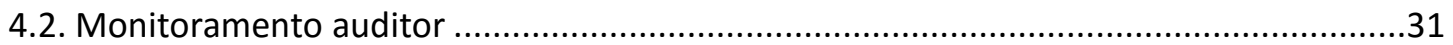

4.3. Garantia da qualidade versus função auditora do monitoramento ................................32

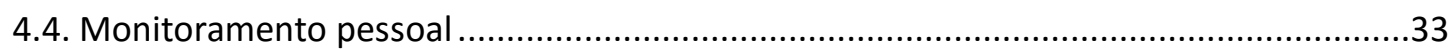

4.4.1. Monitoramento do local de trabalho para a radiação externa.................................33

4.4.2. Monitoramento do local de trabalho para contaminação de superfície ...................36

4.4.3. Monitoramento do Local de trabalho para a contaminação do ar ...........................39

4.4.4. Monitoramento individual para radiação externa .....................................................43

4.4.5. Monitoramento individual para exposição interna .................................................45

4.4.6. Monitoramento para a contaminação de pele e roupa ............................................47 
4.4.7. Monitoramento interventor . .49

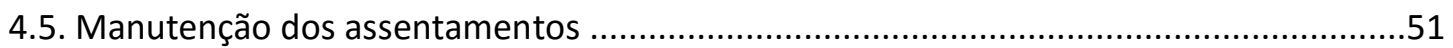

5. Exposições potenciais: recomendações e cenários envolvidos .............................................52

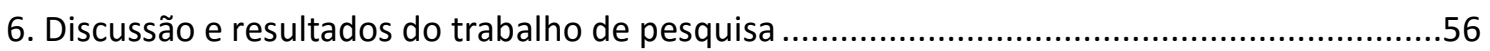

6.1. Considerações para um programa adequado e eficaz de proteção radiológica ...............64

6.2. Cenário 1 - Exposição potencial em irradiador moderno ..............................................68

6.3. Cenário 2 - Exposição potencial de pacientes por aparelho de radioterapia....................70

6.4. Cenário 3: Exposição potencial em um cíclotron ............................................................72

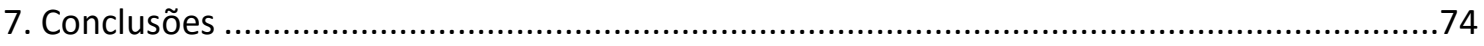

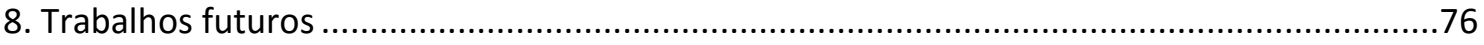

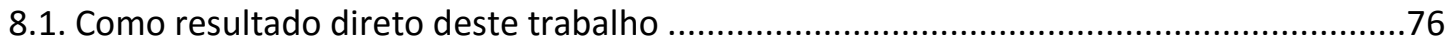

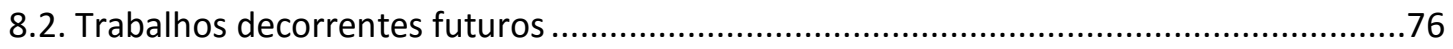

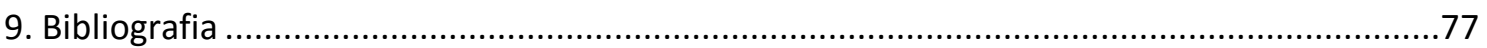

ANEXO A - Filosofia e Técnica para Monitoramento do Trabalhador para Radiação lonizante..81

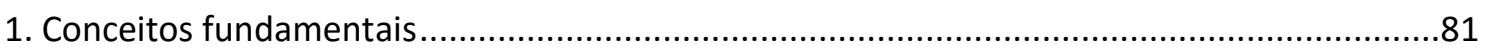

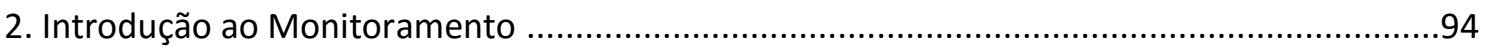

3. Monitoramento do Local de Trabalho para Radiação Externa .............................................98

4. Monitoramento do Local de Trabalho para a Contaminação de Superfície ..........................102

5. Monitoramento do Local de Trabalho para a Contaminação do Ar .....................................108

6. Monitoramento Individual para Radiação Externa.............................................................117

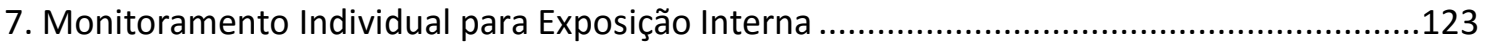

8. Monitoramento Individual para Contaminação de Pele e Roupa..........................................127

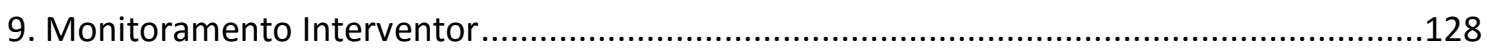

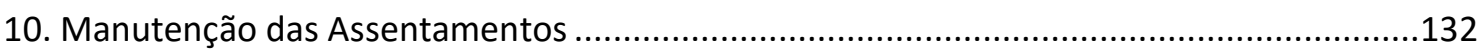

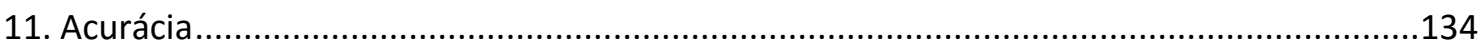

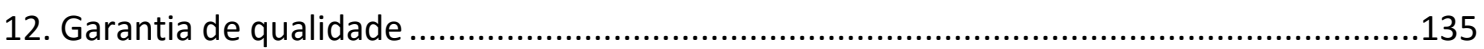

13. Procedimentos Para apreciação sistemática dos Programas de Proteção Radiológica ......137 


\section{Introdução}

\subsection{Principais entidades internacionais e nacionais pertinentes à Proteção Radiológica}

Quando uma instalação radiativa elabora o seu programa de proteção radiológica intitulado "Plano de Proteção Radiológica, PPR" ou seu "Plano de Emergência Radiológica, PER", deve levar em consideração todos os procedimentos baseados em normas, diretrizes e recomendações tanto nacionais como internacionais. Essas informações encontram-se em diversos documentos de diferentes organizações publicados ao longo das últimas décadas, a saber: Comissão Internacional de proteção Radiológica (CIPR), Organismo internacional de Energia Atômica (OIEA) e Comissão Nacional de Energia Nuclear (CNEN). No Brasil as instalações que envolvem a radiação ionizante são divididas em instalações radiativas e instalações nucleares. As instalações nucleares são aquelas que abrangem todo o ciclo do combustível nuclear, desde a mineração dos materiais nucleares, reatores tanto de potência e pesquisa e produção de radioisótopos, até o reprocessamento dos elementos combustíveis dos reatores nucleares. As instalações radiativas são aquelas que se utilizam das radiações ionizantes nas demais aplicações pacíficas da energia nuclear como na indústria, na medicina, na agricultura, na preservação do ambiente etc. Todo o ciclo do combustível nuclear, incluindo os reatores, bem como os radioisótopos, isto é, materiais radioativos, são monopólio governamental, a não ser aqueles que têm uma meia vida igual ou inferior a duas horas. Os materiais radioativos podem ser desenvolvidos e utilizados pelo público sob licença e fiscalização do governo.

A CIPR fornece recomendações visando à proteção do meio ambiente e dos indivíduos aos efeitos maléficos produzidos pela radiação ionizante. Suas recomendações estão alicerçadas nos relatórios do Comitê Científico sobre os Efeitos das Radiações Atômicas das Nações Unidas (CCERANU) e nos relatórios do Biological Effects of lonizing Radiations (BEIR) dos Estados Unidos. Estas duas entidades analisam todos os trabalhos técnico-científicos publicados internacionalmente sobre os efeitos das radiações atômicas tanto no ambiente - incluindo a fauna e flora - quanto em seres humanos e periodicamente publicam os avanços nos conhecimentos científicos a respeito do assunto, citando os trabalhos referência. Em suas publicações, a CIPR ainda fornece os motivos que levaram a expor as suas recomendações. Esta entidade atualmente já teve publicados mais de uma centena de relatórios, embora nem todos continuem vigentes. O OIEA, órgão oficial das Nações Unidas (ONU) que congrega os países que se utilizam das radiações ionizantes e que são afiliados a ela, baseando-se nas recomendações da CIPR e sua filosofia, emite as próprias recomendações. Não fornece os motivos que levaram a elas, mas fornece guias para se satisfazer as exigências constantes nas recomendações. Atualmente o OIEA possui mais de duas mil publicações sobre proteção e segurança, mas para a proteção radiológica operacional há a coleção Safety Series, com cerca de 150 publicações, nem todas vigentes, a coleção Technical Report Series e a série de documentos técnicos conhecidos como Tec-doc. Ainda, cada país afiliado à OIEA emite suas próprias normas e regulamentos, baseados nas recomendações internacionais, pois cada país possui um órgão governamental regulatório em permanente contato com o OIEA. No Brasil, a entidade governamental nacional, afiliada ao OIEA e subordinada ao Ministério de Ciência e Tecnologia, 
é a Comissão Nacional de Energia Nuclear (CNEN). Esta comissão já emitiu uma série de normas ${ }^{1}$ e resoluções para instalações radiativas do país, para que se mantenham em funcionamento programas de proteção radiológica adequados e eficazes, mas não fornece os guias para cumprilas, como faz o OIEA. Ainda que as Diretrizes Básicas de Proteção [1] em seu artigo 5.3.8 informe a temática que um Plano de Proteção Radiológica deve conter, não se encontra em uma sequência lógica, nem comenta o nível de detalhamento, o que faz com que para instalações radiativas análogas, os planos aprovados possuam descrições diferentes dos programas.

Para o controle operacional das exposições à radiação ionizante em qualquer local de trabalho, a CIPR recomenda efetuar uma avaliação radiológica inicial de todos os aspectos relacionados com a operação para identificar as fontes de exposição habituais e potenciais racionalmente previsíveis, para fazer previsões realistas das doses e para determinar as medidas de proteção radiológica necessárias para satisfazer o principio da otimização. Recomenda ainda estabelecer um programa de proteção radiológica operacional, proporcional ao grau de risco, para garantir o gerenciamento efetivo das medidas necessárias para satisfazer o principio de otimização. Um programa de monitoramento para fins de proteção radiológica deve mostrar como o monitoramento auxilia na obtenção e demonstração de um grau de proteção adequado e comprovar que as condições de trabalho continuam adequadas com o transcorrer do tempo [2; 3].

Dentre os múltiplos aspectos que englobam a proteção radiológica, será tratada nesta tese a informatização dos programas de monitoramento pessoal, isto é, do local de trabalho e individual. Visando auxiliar a instalação radiativa que necessita implementar um programa de proteção radiológica, o intuito do processo de informatização é fornecer ao público corporativo um veículo completo que possibilite a pesquisa detalhada no que concerne ao monitoramento das radiações ionizantes. Buscando satisfazer tanto às normas nacionais da CNEN [1] como as recomendações internacionais da CIPR [2] e do OIEA [3] no que dizem respeito ao assunto deste trabalho, esta pesquisa contempla definições e teorias necessárias, de forma a detalhar e interrelacionar informações hoje dispersas em várias publicações e documentos, de forma pertinente e consistente.

Este trabalho também poderá ser útil às instalações nucleares que devem confeccionar o RAS (Relatório de Análise de Segurança). Como os tipos e funções do monitoramento são os mesmos para ambas as instalações, este trabalho pode ser o princípio de um trabalho de pesquisa para a informatização dos RAS, que será sugerida como futuros trabalhos.

\footnotetext{
${ }^{1}$ Muitas das Normas da CNEN se encontram sob revisão e/ou consulta pública, podendo em futuro próximo serem publicadas como resoluções.
} 


\subsection{Motivação do presente trabalho}

As atuais tendências das Tecnologia da Informação e Comunicação (TIC) vão ao encontro das aspirações de uma sociedade globalizada, plural, inclusiva e participativa, que tem por principais características a disseminação do conhecimento e a democratização da educação. Na chamada Sociedade da Informação, onde as tecnologias são onipresentes, é preciso considerar seu impacto nas esferas social, acadêmica e laboral. O campo da proteção radiológica evolui a passos largos tendo como uma de suas principais bases as lições aprendidas do passado. 0 exemplo abaixo, que toma por referência o acidente radiológico de Soreq, em Israel [4], nos faz refletir sobre o valor da disseminação da informação de forma correta, completa, ética e abrangente no espaço laboral.

O acidente em questão ocorreu em 21 de Junho de 1990, em uma instalação de irradiação industrial de Soreq, em Israel. A instalação irradiava produtos médicos e especiarias para fins de esterilização. Para esses fins, era utilizada uma fonte radioativa intensa de ${ }^{60} \mathrm{Co}$. O operador, funcionário experiente, entrou na sala de irradiação e foi exposto de forma aguda à radiação. As consequências foram fatais. Este acidente, que poderia ter sido evitado, resultou da violação de procedimentos operacionais estabelecidos. $\mathrm{O}$ acidente teve início com uma embalagem danificada que, emperrada no sistema de transporte interno, prendeu a fonte móvel na posição de irradiação. Havia dois equipamentos à disposição do trabalhador para verificação das condições de segurança e envio de sinais de alerta. Esses equipamentos, entretanto, enviaram sinais conflitantes, cabendo ao operador a tomada de decisão. O operador era um técnico experiente, que havia sido treinado e certificado para a função e contava com mais de três anos de experiência. Ainda assim, violando os procedimentos de segurança, o operador optou por entrar na sala de irradiação. No momento do acidente a atividade total da fonte era de 12,6 PBq (340 kCi). As estimativas apontam uma dose de corpo inteiro entre 10 e $20 \mathrm{~Gy}$.

O OIEA realizou uma revisão internacional para a determinação e documentação detalhada das causas e circunstâncias do acidente, no intuito de extrair lições aprendidas a respeito das questões de segurança das instalações e gerar informações para futuras referências. A comissão concluiu que a causa direta do acidente se deu por uma conjunção de fatores que incluíam o mau funcionamento do equipamento e as ações não autorizadas empreendidas pelo operador. De acordo com o relatório do OIEA, a sequência que culminou no evento ocorrido incluiu: o congestionamento das embalagens; a falsa indicação de que a fonte havia sido recolhida; o grave erro de julgamento por parte do operador, que ignorou o alarme de radiação; a ação não autorizada do operador que optou entrar na sala de irradiação; o mau funcionamento do medidor portátil de taxa de dose; e a falha do operador para verificar o medidor de taxa de dose portátil antes de entrar na sala de irradiação, ainda que estivesse ciente que o alarme de radiação estava funcionando. Um dos pontos salientados foi quanto ao idioma do material fornecido aos trabalhadores, cuja língua materna era o hebraico. Apesar dos cursos terem sido ministrados em hebraico, as instruções de segurança, bem como o manual de instruções, estavam disponíveis apenas em inglês. Apenas uma pequena lista de rotina operacional e instruções de segurança, incluindo a do procedimento para a inserção do irradiador, haviam sido disponibilizadas em hebraico. 
A análise do caso deste acidente em Israel, um dentre os vários exemplos cabíveis, ilustra a importância dos temas trabalhados nesta tese, em todas as suas dimensões:

1. A importância da disponibilização da informação ao trabalhador de forma ampla, acessível e adequada. Um dos problemas evidenciados foi a dificuldade do acesso à informação. Para além das diretrizes básicas cotidianas que foram disponibilizadas no idioma do país, o material completo, incluindo questões específicas de procedimentos e segurança, era apenas disponibilizado em inglês.

2. A importância de uma função de auditoria, para corroborar a qualidade da função relacionada com a tarefa e a veracidade dos relatórios fornecidos. $\mathrm{O}$ bom funcionamento dos equipamentos podem auxiliar a conter situações de desvios, evitando que evoluam para incidentes ou acidentes. Ainda, muitas vezes profissionais experientes, com conhecimento da planta e dos princípios básicos de radioproteção, baseados em sua experiência prévia, podem tomar decisões equivocadas quanto à interpretação de resultados que diferem do esperado.

3. A importância de se expandir as discussões sobre as exposições potenciais de forma mais quantitativa que trazem as publicações disponíveis, identificando possíveis cenários e antevendo possíveis caminhos que podem contribuir para sua ocorrência. Muitas vezes as exposições potenciais decorrem de sequências de eventos que podem ser probabilisticamente previsíveis.

\subsection{Originalidade dos temas trabalhados}

Nos últimos anos o avanço da tecnologia tem propiciado possibilidades nunca antes imaginadas, com o crescimento exponencial da internet, a evolução e a padronização dos navegadores, a disseminação do computador dentro das empresas, indústrias e corporações como ferramenta de trabalho individual, a evolução técnica das linguagens disponíveis de programação e por fim a consolidação dos padrões de aplicações em formato WEB, onde todos os dados e funcionalidades são armazenados em um servidor, sendo o acesso possível de qualquer parte do mundo. Segundo publicações realizadas pelo Comitê Gestor da Internet no Brasil que realizou diversas pesquisas em todos os estados brasileiros, nos últimos cinco anos houve importantes avanços no uso das tecnologias da informação nas empresas brasileiras, um importante decréscimo no acesso à internet discada, um avanço significativo quanto às redes corporativas internas sem fio e maior utilização das mídias móveis, como tablets e celulares corporativos. Estes fatos demonstram a propensão do mercado corporativo de acompanhar as mais novas tendências tecnológicas mundiais e de se beneficiar o mais amplamente possível dos avanços das tecnologias de informação [5 - 9].

Com efeito, organizações de diversos países investem na informatização como ferramenta para disseminação do conhecimento. No "Simposio Internacional sobre Protección Radiológica", realizado no Peru, no dia 4 de abril de 2012, a Sessão de Capacitação e Difusão da Proteção Radiológica, ressaltou a importância das Tecnologias da Informação e Comunicação (TIC) para a disseminação do conhecimento para os países da região e apresentou iniciativas inovadoras que articulam a tecnologia da informação e a proteção radiológica [10 - 11]. No 13 Congresso Internacional da Associação Internacional de Radioproteção, realizado em Glasgow, Escócia, em maio de 2012, foram apresentados importantes projetos, desenvolvidos por pesquisadores de 
diferentes nações, como França [12] e Peru [13], além do Reino Unido [14 - 15] e Brasil [16 - 17], confirmando os esforços da comunidade internacional em articular as novas possibilidades da tecnologia da informação à radioproteção. Foram ainda criadas diversas redes de trabalho regionais, suportadas pelo Organismo Internacional de Energia Atômica [18], como recursos estratégicos para a gestão do conhecimento e disseminação da informação. Entretanto, apesar dos muitos esforços da comunidade internacional para se beneficiar da tecnologia da informação para divulgação e compartilhamento do conhecimento e da pluralidade dos temas abordados, verifica-se que tanto a nível internacional como nacional, os programas de monitoramento pessoal para as diferentes instalações que o exigem, não se encontram informatizados. Considerando que a informatização dos programas de monitoramento pode auxiliar sobremaneira as instalações radiativas, permitindo consultas complexas com tempo de resposta reduzido, este trabalho de pesquisa contempla a unificação e o inter-relacionamento da filosofia e da técnica do monitoramento das radiações ionizantes, de forma a satisfazer as exigências nacionais e internacionais para a implementação de um programa de monitoramento adequadamente dimensionado, podendo ser adaptado às diferentes instalações radiativas.

A informatização dos programas de proteção radiológica unificados e inter-relacionados é completamente original em seu campo. O trabalho de dimensionamento, disponibilização e inter-relacionamento dos programas monitoramento não foi ainda realizado no Brasil ou no exterior, apesar dos muitos esforços da comunidade internacional para se beneficiar da tecnologia da informação para divulgação e compartilhamento do conhecimento. Com relação ao conteúdo de monitoramento para fins de proteção radiológica, dentro do escopo deste trabalho², além da unificação e do inter-relacionamento das informações hoje disponíveis nas publicações vigentes, este projeto de pesquisa contempla ainda a originalidade nos modelos e metodologias de proteção radiológica, propondo a inclusão de temas que não se encontram hoje detalhados nas recomendações internacionais ou nas normas nacionais. É o caso de recomendações que são feitas, porém não desenvolvidas, tornando difícil o acesso às informações de forma completa e clara, mesmo a partir das publicações originais [2, 19 - 21].

Nesse sentido, um dos temas que foi pesquisado e expandido para além das diretrizes das publicações internacionais foi a função auditora do monitoramento. De acordo com as recomendações internacionais, o monitoramento contempla tanto a medida quanto a interpretação de resultados [22 - 23]. Apesar de prevista esta função juntamente com o monitoramento de rotina, nem as publicações internacionais ou as normas nacionais tratam com clareza os aspectos que envolveria uma auditoria. A função de rotina visa avaliar e estimar as doses do indivíduo e é executada pelo serviço de radioproteção, a partir de um modelo que descreve de forma quantitativa a relação entre as grandezas medidas e aquelas que se desejam avaliar ou estimar. Como essa é a principal função do serviço de radioproteção, a auditoria é normalmente trascurada, não Ihe sendo dada a devida ênfase. Por esta razão, este projeto de pesquisa propõe o desmembramento da função de rotina entre: função de rotina (para avaliar e estimar) e função auditora. Uma originalidade no campo da proteção radiológica, que acreditamos, auxiliará sobremaneira as instalações, possibilitando novos olhares a favor da

\footnotetext{
${ }^{2} \mathrm{O}$ trabalho envolve a informatização do programa de monitoramento pessoal, isto é, do local de trabalho e individual, contemplando todos os seus tipos e suas funções. Faz parte do escopo deste trabalho, ainda, a otimização do programa de monitoramento pessoal, fazendo uso das técnicas de ajuda para a tomada de decisão, além de introduzir um programa de auditoria de um plano de proteção radiológica.
} 
segurança nas operações de monitoramento da radiação ionizante. A função auditora tem por objetivo verificar a correta realização das tarefas de proteção radiológica atribuídas ao trabalhador, tanto no que se refere ao monitoramento relacionado com a tarefa, quanto no caso do monitoramento interventor. $\mathrm{O}$ trabalho empreendido nesta tese explica e exemplifica os passos de um monitoramento auditor para cada tipo de monitoramento relacionado à tarefa, possibilitando à instalação empreender ações a favor da segurança sem, contudo, ferir o princípio da proteção radiológica que recomenda uma atuação econômica e eficaz. A partir do estudo das especificidades dos diferentes tipos de monitoramento e das exigências e diretrizes constantes nas publicações vigentes, foi possível elaborar exemplos a partir de uma estrutura geral, que pode ser adaptada e aplicada por analogia em diferentes instalações, de acordo com a situação específica de cada uma.

Outra originalidade nos modelos e metodologias da proteção radiológica para além do atual conteúdo das publicações e normas vigentes, foram as exposições potenciais, com uma abordagem muito mais quantitativa do que disponibilizam as recomendações nacionais e internacionais. Apesar de algumas publicações da CIPR [19 - 20] recomendarem que a exposição potencial deve ser tratada juntamente com a normal, em sua publicação 76 [21] a CIPR assume que em grande parte das situações isso não é possível, uma vez que a exposição normal toma por base os limites laborais, enquanto na exposição potencial devem ser consideradas as doses mais elevadas do cenário. A publicação 76 da CIPR, em sua seção 62 , traz a seguinte consideração:

"Os métodos para a otimização da proteção radiológica variam do simples bom senso a técnicas quantitativas complexas (ver publicações 37 e 55; CIPR, 1983; 1989). A otimização da proteção às exposições potenciais, continua em grande parte, sem solução, especialmente quando as probabilidades são pequenas e as consequências são grandes (NEA/OECD, 1995) $)^{3}$. Embora este relatório equacione conceitualmente os riscos advindos das exposições normais e potenciais, é difícil a otimização formal simultânea da proteção contra os dois tipos de exposição. Entretanto, o uso de dispositivos de proteção contra exposições potenciais, de acordo com o que foi esboçado aqui, já inclui um elemento de otimização. Além disso, o risco referência utilizado neste relatório, corresponde ao risco associado às doses laborais mais elevadas em uma operação otimizada e não ao risco associado a uma dose no limite de dose laboral. Também, a proteção ótima contra exposições potenciais não é necessariamente alcançado no mesmo valor de risco da proteção ótima contra as exposições normais. Isso porque os custos da redução dos riscos advindos de exposições normais e potenciais podem ser bastante diferentes."

Embora a publicação 76 da CIPR [21] reconheça que esses dois temas deveriam ser tratados separadamente, não fornece recomendações específicas. Empreendemos, neste trabalho, uma pesquisa que possibilite introduzir as exposições potenciais de maneira muito mais quantitativa do que o fazem as recomendações internacionais e as normas nacionais.

Este trabalho de pesquisa envolve o aprofundamento deste tema com a introdução de cenários envolvidos nas exposições potenciais e caminhos para identificar as probabilidades nas

\footnotetext{
${ }^{3}$ NEA/OECD (1995) The meaning and Application of the Concept of Potential Exposure. A Report from CRPPH/CSNI/CNA/RE/RWMC Expert Group, OCDE/GD (95) 145. Organization for Economic Co-operation and Developement Nuclear Energy Agency. Le Seine Saint-Germain 12, Boulevard dês lies. F-92130, Issyles-Moulineaux, France.
} 
sequências de eventos que compõem a exposição, o que torna o trabalho completamente original no que se refere ao conteúdo das atividades de monitoramento.

\subsection{Objetivos}

A finalidade da presente tese é informatizar todas as informações pertinentes, tanto nacionais como internacionais, no campo do monitoramento pessoal da proteção radiológica, introduzindo inovações e aperfeiçoamento, conforme delineado no subtítulo 1.3.

Nesse sentido, a fim de alcançar a finalidade exposta, foram formulados três objetivos principais, a saber:

1. A informatização dos programas de monitoramento de forma a inter-relacionar as normas e recomendações dos diferentes organismos nacionais e internacionais, disponibilizando às instalações radiativas um veículo completo para pesquisa e informação que satisfaça a todas as questões que podem ser razoavelmente colocadas quando do planejamento de um programa de monitoramento.

2. A proposta de desmembramento da função de rotina, com a inclusão de uma função auditora no programa de monitoramento das radiações ionizantes, incentivando a incorporação de novas práticas a favor da segurança nas operações de monitoramento, principalmente por aquela efetuada pelo próprio trabalhador.

3. Expansão das discussões sobre as exposições potenciais, aprofundando a discussão sobre os limites de risco e possibilidades de quantificar probabilisticamente ocorrências que podem levar às exposições potenciais nas instalações radiativas, bem como fornecendo caminhos para a determinação de probabilidades nas sequências de eventos que compõem a exposição.

\section{Revisão Bibliográfica}

O presente trabalho visa a disseminação do conhecimento no que tange o monitoramento das radiações ionizantes, de forma a satisfazer tanto as normas nacionais da CNEN [1] como as recomendações internacionais da CIPR [2; 22 - 23] e do OIEA [3; 24 - 25]. Uma vez que a CIPR e - OIEA atualizaram as diretrizes básicas de proteção radiológica [2 - 3], em princípio o presente trabalho estará praticamente atualizado para as futuras normas nacionais.

Em relação ao desenvolvimento do corpo teórico deste trabalho, foi efetuado um extenso trabalho de pesquisa, que teve como principal fonte a biblioteca do IPEN e suas conveniadas. Além da vasta bibliografia pertinente disponível, esta biblioteca está também conectada com toda a documentação do Organismo Internacional de Energia Atômica OIEA, órgão oficial das Nações Unidas, ONU, e tem acesso a elas. Possui um avançado sistema de pesquisa bibliográfica que permite resgatar bibliografias técnicas em um tempo mínimo. No que concerne à pesquisa referente às Tecnologias da Informação e Comunicação para o desenvolvimento deste trabalho, ela foi realizada mediante estudo de relatórios oficiais do governo federal brasileiro, publicações científicas nacionais e internacionais e projetos notadamente reconhecidos pelo Organismo Internacional de Energia Atômica que articulam a Tecnologia da Informação à Tecnologia 
Nuclear. Os conhecimentos adquiridos permitiram o desenvolvimento do trabalho proposto levando-o aos resultados exigidos para atender à finalidade desta tese.

A revisão bibliográfica foi elemento fundamental para uma compreensão mais acurada da evolução da filosofia do monitoramento até os dias atuais, tornando possível dialogar com as diversas publicações para a estruturação do sistema de unificação dos programas de monitoramento e para o aprofundamento teórico em recomendações de fundamental importância, como o monitoramento com função auditora e as exposições potenciais.

\subsection{Mudanças de paradigmas em Proteção Radiológica}

A proteção radiológica tem por objetivo oferecer proteção aos indivíduos e ao meio ambiente contra possíveis efeitos nocivos à saúde causados pela radiação ionizante e envolve dois grupos de indivíduos distintos: a proteção ao trabalhador, aquele cuja atuação profissional envolve a radiação ionizante e contato com materiais radioativos, e a proteção ao público, que vive próximo a instalações radiativas e que pode vir a sofrer os efeitos da radiação, seja por vazamento dela através das blindagens, seja por liberação do material no ambiente.

O monitoramento é um processo contínuo, de caráter preventivo e confirmatório, que envolve trabalhadores e indivíduos do público. As técnicas de monitoramento permitem tanto alertar trabalhadores e público a respeito da presença da radiação buscando evitar uma dose excessiva, quanto estimar doses já recebidas que não puderam ser evitadas.

Entretanto, a filosofia e técnica de monitoramento como a conhecemos hoje são frutos de significativas mudanças dos paradigmas e diretrizes ao longo das últimas décadas. A seguir, apresentamos as principais evoluções destes paradigmas e diretrizes, no que tange ao monitoramento, a partir de 1955, ano em que foi liberado o uso da tecnologia nuclear para fins pacíficos.

O primeiro paradigma, hoje conhecido como Sistema de Limitação de Dose, foi enunciado nas publicações 1, 2 e 9 da CIPR e publicado em 1967 pelo OIEA em sua Série de Relatórios de Segurança n⒐ No Brasil, o tema foi disposto na Resolução CNEN/CD no 06, de 19 de junho de 1973 [26 - 31]. Na época, foram estabelecidos os Limites de Dose Máximos Permissíveis (LAMP). Considerando-se os efeitos estocásticos, porcentagens de mutações genéticas e fatores de hereditariedade, a CIPR sugeriu os LAMPs de $1,67 \mathrm{mSva}^{-1}$ para a população como um todo, 5 $\mathrm{mSva}^{-1}$ para o grupo crítico (atualmente denominado pessoa representativa). Para os trabalhadores foi determinado um LAMP de $50 \mathrm{mSva}^{-1}$, considerando os efeitos somáticos, a possibilidade da manutenção do tempo médio de vida, quando comparado com a população (isto é, a não existência de decréscimo do período de vida médio), e uma não alteração da porcentagem da incidência de cânceres com relação à população, como um todo. Para satisfazer este paradigma, foram estabelecidas duas diretrizes: a classificação das áreas de trabalho e o monitoramento das radiações ionizantes, que englobavam: (i) o monitoramento do local de trabalho, de caráter preventivo e (ii) o monitoramento individual, de caráter confirmatório [29 - 33].

Mantendo o princípio de que a toda dose é associado um risco e que não existe um limiar de exposição abaixo do qual poder-se-iam desconsiderar efeitos maléficos à saúde humana, a CIPR 
propôs modificações no sistema de limitação de dose, visando a redução das doses e aumento da proteção no ambiente de trabalho. A publicação no 22 da CIPR oficializa o princípio da otimização [34], que propunha ações para a redução das doses até atingirem limites aceitáveis, e o princípio da justificação, que proibia a introdução de atividades nas quais os riscos se sobrepunham aos benefícios efetivamente recebidos pela população. Foram suprimidos os Limites para a população como um todo, mantendo-se os limites anteriormente estabelecidos para o público e para o trabalhador. O limite do público passa a ser $1 \mathrm{mSva}^{-1}$ [35]. Dentro dessa mudança de paradigma, foi introduzido o conceito de Limites Anuais Máximos Admissíveis (LAMA). Nessa época em que o mundo passava por graves crises econômicas, um segundo paradigma foi então acrescentado: a proteção radiológica deve ser econômica e eficaz [31 - 32].

Novas diretrizes foram adotadas para satisfazer as exigências dos dois paradigmas em questão. Além do monitoramento pessoal e da classificação das áreas de trabalho, foram introduzidos os conceitos de níveis de referência e classificação dos trabalhadores. Foram estabelecidas as funções do monitoramento, a saber: função controladora (hoje intitulada função de rotina), função operacional (hoje intitulada função relacionada com a tarefa) e função interventora.

Quanto aos níveis de referência, foram introduzidos o nível de registro, nível de investigação e nível de interferência. As publicações diferem em suas recomendações quanto ao nível de registro para o monitoramento com função controladora. Enquanto o OIEA recomenda um valor não inferior a $1 \mathrm{mSva}^{-1}$, a CIPR recomenda $1 / 10$ do LAMA. Entretanto, ambos os organismos estabeleceram para o nível de investigação o valor de 3/10 do LAMA. Esses paradigmas foram internacionalmente adotados pela CNEN em 1988 [36] e vigoraram internacionalmente até o ano de 1995, com a nova publicação SS 115 do OIEA [37], quando houveram novas mudanças.

Manteve-se a premissa que qualquer dose, por menor que seja incorre em um risco e, portanto, deve ser reduzida. Quanto aos limites para os trabalhadores, foram consideradas as diferentes atividades realizadas e, portanto, não mais se justificava um limite anual único para as diversas atividades envolvendo a radiação ionizante. Para tanto, foi acrescentado mais um limite para o trabalhador: as restrições de dose. A partir de então, as restrições de dose passaram a estar vinculadas à fonte da radiação e seus valores foram estabelecidos tomando-se por base valores médios entre as maiores e menores doses de uma mesma atividade realizada em diferentes instalações [37 - 38].

Em sua publicação 75 [23], a CIPR recomenda manter o monitoramento individual para valores acima de $15 \mathrm{mSva}^{-1}$ e altera os nomes das funções de monitoramento, para função de rotina, função relacionada com a tarefa e função especial (que na presente tese trataremos por função interventora). Os limites derivados têm também sua nomenclatura alterada para níveis de referência. O nível de investigação sofre alteração e passa a ter valores diferentes para a CIPR e para o OIEA. Para a CIPR, seu valor passa a ser o nível de registro, enquanto que para o OIEA, continua sendo $3 / 10$ do limite, mas nesse caso, anual médio. Uma nova diretriz é ainda acrescentada para satisfazer os novos paradigmas: trata-se da exposição potencial [23; 37].

Em 2007 a CIPR em sua publicação 103 [2], dispôs sobre uma série de recomendações consolidando os paradigmas até então estabelecidos e detalhando suas recomendações, tais como: tipos e situações de exposição, categoria de exposição, níveis de proteção radiológica, multiplicidade e amplitude de restrições de dose e níveis de referência. Entretanto, as novas 
recomendações do OIEA foram publicadas no ano de 2011. Essa edição Interim traz propostas de grandes modificações ampliando para 10 os princípios básicos de proteção radiológica. Os capítulos mantém a estrutura das recomendações anteriores, porém os tópicos são dispostos de forma mais clara e detalhada, com um total de 52 exigências normativas. Em sua exigência no 14, por exemplo, a normativa estabelece para o monitoramento a responsabilidade do órgão regulador, as obrigações dos registrados e licenciados, dispõe sobre a verificação de conformidade, equipamento, assentamentos e como interpretar os resultados $[2,23,29]$. Posteriormente, em julho de 2014, esta edição interim tornou-se definitiva com pequenas alterações [3].

Com base no estudo das recomendações passadas e das possibilidades futuras, foi dado início à estruturação do sistema informatizado para a disseminação da informação dos programas de monitoramento da radiação ionizante.

\subsection{Exposições potenciais diante dos novos paradigmas}

As sucessivas mudanças de paradigmas ao longo dos anos refletiram na evolução das recomendações sobre as exposições potenciais. Nesse quesito, houveram mudanças significativas decorrentes dos paradigmas internacionais que foram introduzidos pela publicação 60 da CIPR e pela publicação SS 115 do OIEA [38 - 37]. Mudanças na filosofia da proteção radiológica que implicaram novas diretrizes básicas de radioproteção também no Brasil [29; 37 - 38].

Os novos paradigmas partiram do pressuposto que todos os trabalhadores devem receber doses inferiores aos 3/10 dos LAMAs, que para efeito de cálculo devem ser consideradas as horas efetivamente trabalhadas (e não as 2.000 horas previstas no ano), que devem ser mantidos os valores de $50 \mathrm{mSv}$ como limite anual de dose para corpo inteiro e que nenhum trabalhador em condições normais de trabalho - deve ultrapassar $15 \mathrm{mSva}^{-1}$. Estas considerações implicaram no estabelecimento de novas diretrizes, dentre as quais o dever de controlar as possibilidades de ocorrência e os valores previstos em casos de exposição potencial. Foi então que, ao lado dos limites conhecidos como Restrições de dose, a CIPR introduziu um Limite Anual de Risco, para o caso de exposições potenciais. Com o intuito de minimizar o detrimento provocado pelas exposições potenciais, as novas diretrizes apontavam para três linhas de pesquisa, a saber: (i) tentar diminuir a probabilidade de ocorrência da exposição potencial; (ii) tentar diminuir as doses previstas caso a exposição potencial venha a ocorrer e (iii) tentar interpor barreiras que se constituam em linhas de atraso na evolução da situação de exposição potencial [39].

As exposições potenciais foram alvo de maior detalhamento também na publicação 103 da CIPR. Anteriormente, em sua publicação 60 , a CIPR considerava dois casos para a situação de exposição: situações de práticas propostas ou já em andamento e situações de intervenção. As situações de intervenção, por sua vez, eram subdivididas em:

- $\quad$ situações que envolvem exposições a fontes naturais ou que já existiam, mas que, novas medidas de controle exigem a diminuição de suas exposições;

- situações que envolvem acidentes e emergências. Estas situações foram consideradas como fontes de exposição potencial quando tratadas nas práticas mas se elas ocorrerem demandam por uma intervenção. 
A publicação 75 definiu a exposição potencial como aquela que não é pretendida, mas que apresenta um potencial de ocorrência, ainda que não seja certa a sua realização [23]. Esta publicação informa ainda que a exposição potencial pode ser prevista e a sua probabilidade de ocorrência estimada, mas não pode ser prognosticada em detalhes. As recomendações da CIPR publicadas até então, a saber: publicação 37 e 55 sugeriam que as exposições potenciais seriam tratadas juntamente com as exposições normais [19 - 20]. Entretanto, em sua publicação 76, a CIPR foi de encontro às suas próprias recomendações anteriores, assumindo que em grande parte das situações isso não é possível, uma vez que a exposição normal toma por base os limites laborais, enquanto na exposição potencial devem ser consideradas as doses mais elevadas do cenário [21 - 23].

Na publicação 103 as situações de exposição foram divididas em três, a saber: situações de exposição planejada, situações de emergência e situações de exposição existente. Nesta publicação, a CIPR define as situações de exposição de emergência, como elas passíveis de ocorrer durante a operação de uma situação planejada ou decorrentes de ações mal intencionadas ou de qualquer outra situação inesperada, que exige ação urgente, a fim de minimizar ou evitar consequências indesejáveis [2].

Percebe-se que dentre as mudanças paradigmáticas para a proteção radiológica, ao longo das décadas, houve uma grande evolução em termos de diretrizes e de detalhamento sobre o monitoramento das radiações ionizantes. As exposições potenciais foram também alvo de atenção dos organismos internacionais, dada a sua importância. Entretanto, dentre as várias ponderações a respeito das exposições potenciais, percebe-se que não há grande detalhamento e há mesmo inconsistências entre publicações. Sabendo-se que apenas e tão somente por meios de cenários pode-se prever uma certa probabilidade de ocorrência das exposições potenciais e a probabilidade de se atingir um determinado valor da dose, a presente tese propõe detalhar e aprofundar o tema das exposições potenciais, articulando as publicações nacionais e internacionais em diferentes cenários.

\subsection{Evolução das Tecnologias da Informação e Comunicação no Brasil}

O presente estudo teve por objetivo verificar o avanço e o impacto que as TIC proporcionaram na chamada Sociedade da Informação e suas instituições, nomeadamente quanto aos aportes no cotidiano laboral. Por meio deste estudo foi possível identificar como se deu a evolução da utilização dos recursos tecnológicos diante desse novo paradigma que é a utilização da tecnologia da informática para a disseminação da informação. De acordo com publicações disponibilizadas pelo Comitê Gestor da Internet no Brasil que realiza anualmente diversas pesquisas em todos os estados brasileiros, houve um avanço significativo no uso das tecnologias de informação em grande parte das empresas brasileiras. As pesquisas lideradas pelo Comitê Gestor da Internet no Brasil fazem uso dos padrões metodológicos propostos pela "United Nations Conference on Trade and Development (UNCTAD)", Conferência das Nações Unidas sobre o Comércio e o Desenvolvimento (CNUCED), descritos no "Manual for the Production of Statistics on the Information Economy", Manual de Produção de Estatísticas Sobre a Economia da Informação, elaborados em parceria com a Organização para a Cooperação e Desenvolvimento Econômico (OCDE), pelo Instituto de Estatísticas da Comissão Europeia (EUROSTAT) e pelo "Partnership on Measuring ICT for Development", Parceria para Mensuração 
de TIC para o Desenvolvimento, uma coalizão de diversas organizações internacionais visando a harmonização de indicadores-chave em pesquisas TIC (Tecnologia da Informação e da Comunicação) [5 - 9].

Ainda no ano de $2006,14 \%$ das empresas brasileiras alegavam fazer uso do acesso discado para acessar a Internet. Nos dois anos subsequentes houve um importante decréscimo na utilização do acesso discado e no ano de 2008 apenas 5\% das empresas alegavam ainda utilizar essa tecnologia [5 - 6]. Tal fato viabilizou que as TIC atingissem mais organizações nas diversas regiões do país, uma vez que a principal diferença entre a qualidade do acesso discado e acesso banda larga está na velocidade da conexão. Desde 2008 a conexão via cabo foi a que apresentou maior crescimento, passando de $22 \%$ para 57\% em 2012 [5 - 6]. Esse crescimento se deu em praticamente todas as regiões, portes e segmentos. $\mathrm{O}$ acesso discado seguiu estável em 7\%, com predominância na região Nordeste, onde $10 \%$ das empresas declararam possuir esse tipo de conexão. Outro avanço significativo se deu pelo rápido crescimento das redes corporativas internas sem fio que contemplava apenas $14 \%$ das empresas em 2005 ; já no ano de $2009,41 \%$ das empresas brasileiras declararam possuir rede sem fio [6]. No ano de 2012, 96\% das empresas brasileiras que usam computadores declararam possuir infraestrutura de rede local - LAN (Local Area Network). Dessas organizações, $86 \%$ declaram possuir LAN com fio, e $71 \%$ mencionam a presença de LAN sem fio. Esses resultados indicam a tendência de crescimento da LAN sem fio e da estabilidade do uso da LAN com fio nas empresas brasileiras. $40 \%$ das empresas de grande porte alegam utilizar o modem 3G, que vem crescendo em função da tendência à mobilidade de conexão [7 - 8].

Já desde o ano de 2010 os dados de pesquisa apontavam que $97 \%$ das empresas brasileiras com mais de 10 funcionários já utilizavam computadores, e esse percentual aumentava para $100 \%$ em se tratando de empresas com número de funcionários igual ou superior a 50 [7]. 0 percentual médio de funcionários que faziam uso dos computadores para fins de trabalho equivalia a $45 \%$ e o percentual se manteve com o passar dos anos. Dentre as empresas brasileiras que possuíam computador, $96 \%$ tinham acesso à internet, percentagem que atingia 99\% se consideradas apenas empresas com 50 ou mais funcionários [7 - 8]. O número de computadores de mesa mantém a mesma porcentagem, entretanto, houve um crescimento na aquisição de tecnologias móveis nos dois últimos anos. Em 2011, 13\% das empresas afirmaram possuir tablets, enquanto em 2012 esse percentual aumentou para 19\%. Celulares, computadores de mesa e computadores portáteis são os principais equipamentos que constituem a infraestrutura de acesso das empresas [9]. Por isso, um aspecto avaliado na pesquisa foi o indicador de velocidade máxima para download contratada pelas empresas brasileiras.

"Em 2012, a faixa de velocidade mencionada com maior frequência foi a de 1 Mbps a 10 Mbps, presente em $48 \%$ das empresas com acesso à Internet. Isso representou um aumento de 10 pontos percentuais em relação a 2011. Também cresceram todas as faixas de velocidade acima de 1 Mbps e decresceram as faixas mais baixas, que vão de 256 Kbps até 1 Mbps. O resultado sugere um aumento de capacidade da infraestrutura de conexão das empresas." [9] 
No ano de 2010, a busca de informações e atividades de pesquisa nos locais de trabalho aparecia em terceiro lugar, atividades essas realizadas por 86\% das empresas brasileiras [7]. Em 2012 a busca por informações e serviços online na Internet já figurava em segundo lugar, dentre as atividades predominantemente realizadas por funcionários nas empresas brasileiras [9].

Esse trabalho de pesquisa proporcionou um panorama global da evolução das Tecnologias da Informação e da Comunicação (TIC) nas empresas brasileiras, a saber: proporção de empresas que utilizam computadores, número de computadores por empresa, proporção de funcionários que usam computadores ou que tenham acesso remoto ao sistema, proporção de empresas com rede (LAN, intranet, extranet), atividades realizadas por celular corporativo e outras tecnologias móveis, proporção das empresas que usam internet, proporção de funcionários com acesso à internet nos locais de trabalho, velocidade média de download fornecida pelos provedores, tipo de atividade realizada pelas empresas utilizando a internet, empresas com políticas de restrição de acesso, dentre outras informações pertinentes. Estas informações sobre o atual cenário das TIC no Brasil, de que forma as organizações trabalham com os recursos disponíveis, as tecnologias mais presentes, as principais dificuldades e tendências, foram essenciais para balizar o planejamento deste projeto.

\subsection{Tecnologia da Informação e Proteção Radiológica}

O Brasil é um país com grandes extensões territoriais e um forte desafio é assegurar o acesso à informação ao maior número de profissionais possível, minimizando custos e otimizando a produção. Sabendo que organizações de diversos países investem na informatização como ferramenta para disseminação do conhecimento, buscamos conhecer os trabalhos científicos desenvolvidos até o presente momento que fazem uso da Tecnologia da Informação para a disseminação do conhecimento no campo da Proteção Radiológica.

No "Simposio Internacional sobre Protección Radiológica", realizado no Peru, em abril de 2012, Brasil e Peru apresentaram trabalhos inovadores que fazem uso da Tecnologia da Informação e Comunicação para disseminação do conhecimento da Proteção Radiológica. Tanto o projeto brasileiro, intitulado "Tecnología informática y radioprotección: informatización de la optimización y investigación del perfil de utilización" [10], quanto o projeto peruano, intitulado "Contribución de las redes sociales para el desarrollo de La protección radiológica" [11] se expandiram e se consolidaram.

Confirmando os esforços da comunidade internacional em articular as novas possibilidades da tecnologia da informação à proteção radiológica, no 13 Congresso Internacional da Associação Internacional de Radioproteção, realizado em Glasgow, Escócia, em maio de 2012, foram apresentados diferentes projetos, com diferentes enfoques, desenvolvidos por pesquisadores de diversas nações. Os projetos envolveram capacitação de profissionais e disseminação do conhecimento. São eles:

- França: «A bottom up experience: the French RPO and qualified experts regional networks " [12];

- Peru: « Social Networking and Radiation Protection » [13];

- Reino Unido: « An e-Learning package for Radiation Protection training of Health Staff » [14] e " Distance learning course in radiation protection » [15]; 
- Brasil: «Informatization of Multi-Criteria Analysis Outranking: A Software to Improve Decision-Making in Radiological Protection Optimization Programs " [16] e "Informatization and integration of radiological protection optimization programs » [17].

No ano de 2014 as Tecnologias da Informação e Comunicação mereceram destaque na "International Joint Conference RADIO 2014", realizada de 26 a 29 de agosto em Gramado, Rio Grande do Sul. Reconhecendo a importância e o potencial das TIC na área da proteção radiológica, a mesa redonda intitulada "A Tecnologia da Informação para a Disseminação do Conhecimento em Proteção Radiológica" levou ao conhecimento do público os avanços e benefícios das TIC nos mais diferentes setores dentro da proteção radiológica, a saber: ferramentas de pesquisa e ferramentas de capacitação tanto para a indústria quanto para a área médica. Foram apresentadas as seguintes palestras:

- Redes Regionais de Educação e Treinamento na Área Nuclear, apresentada por Aucyone Augusto da Silva (IRD/ CNEN)

- Programa Emerald - BR, apresentada por Denise Yanikian Nersissian (IF/ USP)

- Unificação e Informatização dos Programas de Proteção Radiológica para Instalações Radiativas, apresentada por Denise Levy (IPEN/ USP)

Confirmando a evolução e a abrangência das TIC no atual cenário de um mundo globalizado, foram criadas nos últimos anos diversas redes para compartilhamento do conhecimento, em nível regional ou global. Essas redes recebem o apoio do Organismo Internacional de Energia Atômica e abordam diferentes aspectos relacionados à Proteção Radiológica, conforme referências a seguir.

\subsubsection{FORO Iberoamericano de Organismos Reguladores Radiológicos y Nucleares}

O Fórum Americano de Radiologia e Órgãos Reguladores Nucleares foi criado em 1997 para promover a cultura de segurança radiológica e nuclear na região latino-americana. A associação, que até o presente momento engloba Argentina, Brasil, Chile, Cuba, Espanha, México, Peru e Uruguai, visa a incorporar novos membros para a consolidação de sua estrutura organizacional e institucional. Representam esses países:

- Argentina : Autoridade Regulatória Nuclear (ARN)

- Brasil : Comissão Nacional de Energia Nuclear ( CNEN )

- Chile : Comissão de Energia Nuclear chileno ( CCHEN )

- Cuba : Centro Nacional de Segurança Nuclear ( CNSN)

- Espanha : Conselho de Segurança Nuclear (CSN)

- México : Comissão Nacional para a segurança e salvaguardas nucleares (CNSNS)

- Peru : Instituto Peruano de Energia Nuclear (IPEN )

- Uruguai: Autoridade Reguladora Nacional de Protecção Contra Radiações ( rRNA )

O Fórum propõe um ambiente, via Internet, para promover a troca de experiências e discussões conjuntas relacionadas a problemas enfrentados por todos os membros da Associação. A filosofia da rede toma por base o desenvolvimento e implementação de uma programação técnica comum que prioriza as necessidades nacionais e regionais, bem como 0 
desenvolvimento de uma rede de conhecimento sobre a radiação e segurança nuclear. Nesse sentido, a Internet permite um ambiente de trabalho que facilita o desenvolvimento de várias atividades. A rede oferece um sistema de gestão documental que possibilita a disseminação do conhecimento e a troca de informações entre os países membros [18].

\subsubsection{The European ALARA Network}

A Rede Europeia de ALARA (EAN) é uma associação europeia sem fins lucrativos criada para promover uma implementação mais ampla e uniforme do princípio ALARA para a gestão de público, paciente e exposições do trabalhador. Seu objetivo é identificar e investigar questões atuais de interesse comum para melhorar ainda mais a implementação de ALARA, promovendo a troca de informações a partir da experiência e da disseminação das boas práticas de proteção às radiações.

A EAN conta com a representatividade de organizações de 21 países europeus diferentes, que assinaram os Termos e Condições EAN .

A gestão técnica e administrativa da rede é de responsabilidade da França e Reino Unido (membros da rede) e o orçamento é gerido por um Conselho de Administração, composto por membros que apoiam financeiramente a EAN . Participam da EAN Alemanha, Áustria, Bélgica, Croácia, República Checa, Dinamarca, Finlândia, França, Alemanha, Grécia, Islândia, Irlanda, Itália, Países Baixos, Noruega, Portugal, Eslovénia, Espanha, Suécia, Suíça e Reino Unido [18].

\subsubsection{Asia Regional ALARA Network}

Com o apoio do OIEA, a Asia Region ALARA Network (ARAN) foi fundada em Daejeon, na Coréia do Sul em dezembro de 2007, visando o desenvolvimento de uma rede regional sustentável. 0 intuito da rede é facilitar a troca de informações entre os países participantes, o que inclui descobertas e prática relacionadas ao princípio de otimização da protecção radiológica. A rede visa , o intercâmbio e a integração de habilidades e competências com ênfase para a aplicação do princípio ALARA para exposições laborais em operações de rotina, contribuindo para a harmonização de objetivos, normas e práticas.

A ARAN é coordenada pelo Comitê Gestor do OIEA e Acordo de Cooperação Regional - RCA. Integram a rede 17 países: Austrália, Bangladesh, China, Índia, Indonésia, Japão, Coréia, Malásia, Mongólia, Mianmar, Nova Zelândia, Paquistão, Filipinas, Singapura, Sri Lanka, Tailândia e Vietnã [18].

\subsubsection{The European Radiation Protection Authorities Network}

Fundada em junho de 2006, esta rede está aberta a todas as autoridades reguladoras da Europa a nível operacional. A European Radiation Protection Authorities Network (ERPAN) tem como objetivo promover a comunicação entre as autoridades reguladoras dos países europeus. Nesse contexto, o trabalho da ERPAN, inclui a troca de informações, requisitos e experiências sobre o processo de métodos de autorização e inspeção na Europa e promove o principio ALARA. A rede visa à maior eficiência operacional do controle das radiações em toda a Europa, levando em consideração os diferentes sistemas de regulamentação que adotam os diversos países participantes. 
Todas as autoridades europeias reguladoras de proteção à radiação são encorajadas a participar da rede, nomeando representantes da autoridade reguladora competente de cada país. Os representantes, por sua vez, tem voz para expressar os pontos de vista da autoridade reguladora que representam, para contribuir para o debate, para se preparar para reuniões, para realizar tarefas específicas e para a disseminação de informações dentro de seu próprio país [18].

\subsubsection{The European Training and Education in Radiation Protection Platform}

O projeto da European Training and Education in Radiation Protection Platform (EUTERP) surgiu a partir do levantamento das situações envolvendo proteção radiológica nos Estados Unidos e União Europeia, após o qual foi realizado um estudo de viabilidade para um programa de trabalho e estrutura da plataforma na Internet. O objetivo desta plataforma é promover a educação e formação continuada na União Europeia, estabelecendo e reforçando laços entre projetos e organizações. Os resultados dos vários projetos são divulgados por meio da plataforma em toda a União Europeia e podem ser utilizados como futuras referências. Além disso, a plataforma oferece um órgão consultivo para a Comissão Europeia acerca de questões sobre educação e formação. Desta maneira, a EUTERP avalia o uso de material de treinamento padronizado em vários países, identificando as necessidades de formação e facilitando apoio e assistência a todos os países europeus.

Participam da gestão da EUTERP os Estados Unidos e União Europeia. São países membros: Áustria, Bélgica, Bulgária, Croácia, Chipre, República Checa, Dinamarca, Estónia, Finlândia, França, Alemanha, Grécia , Hungria, Irlanda, Itália, Letónia , Lituânia, Luxemburgo , Malta , Países Baixos, Noruega, Polônia, Portugal, Roménia, Eslováquia, Eslovénia, Espanha, Suécia, Suíça, Turquia, Reino Unido. São observadores externos à União Europeia: Belarus, Cazaquistão, Macedónia, Síria, Tajiquistão [18].

\subsubsection{The Regional European and Central Asian ALARA Network}

O objetivo da Regional European and Central Asian ALARA Network (RECAN) é apoiar o desenvolvimento de uma rede regional sustentável, facilitando a troca de informações entre países e promovendo uma abordagem integrada para a implementação prática do princípio ALARA.

As principais ações do RECAN consistem na organização de workshops (oficinas), publicação de boletins informativos e troca de informações via Internet. O site propõe ainda links para outras redes que cobrem diferentes áreas relacionadas à Proteção Radiológica.

A RECAN opera sob o controle de um Comitê Gestor (SC RECAN), que consiste em pelo menos 6 membros eleitos, representantes dos países participantes. A rede conta também com um coordenador do RECAN, um representante do OIEA, um representante da EAN e o representante nacional do país anfitrião da próxima oficina. A rede conta, até o presente momento, com a participação de mais de 20 países da Europa Central e da Ásia Central e Oriental [18]. 


\subsubsection{Red de optimización de Protección Radiológica Ocupacional en America Latina}

A Red de optimización de Protección Radiológica Ocupacional en America Latina (REPROLAM) foi criada tomando por base os interesses comuns dos países da América Latina, no que tange à aplicação e prática dos princípios de otimização, no intuito de contribuir para a melhora das infraestruturas da proteção radiológica laboral. Desta maneira, em outubro de 2010 se criou na Colômbia o comitê diretivo responsável pelo desenvolvimento da rede. O referido comitê integra especialistas da Argentina, Brasil, Costa Rica, Peru e Uruguai.

A rede tem por objetivos facilitar o intercâmbio da informação e proporcionar aos países da região um enfoque integrado do princípio de otimização da proteção radiológica. A rede visa ainda contribuir para a harmonização de políticas e práticas da proteção radiológica laboral no que se refere à otimização em diferentes enfoques: infraestrutura, usuários de fontes de radiação, apoio técnico e científico e autoridades reguladoras. $O$ esforço engloba a otimização em casos de exposição laboral para situações normais ou de emergência.

Nesse contexto, a rede visa promover a disseminação da informação, contribuindo para a integração e a cooperação, disponibilização de conhecimentos e serviços especializados [18].

\subsubsection{Latin American Network for Education in Nuclear Technology}

O objetivo da Latin American Network for Education in Nuclear Technology (LANENT) é promover, gerenciar e preservar o conhecimento relacionado à Tecnologia Nuclear, assegurando a sustentabilidade de recursos humanos na área nuclear na América Latina e Caribe. No intuito de facilitar e ampliar a cooperação no que tange treinamentos e formação em Tecnologia Nuclear, por meio da rede, os participantes identificam necessidades educacionais e avaliam as ofertas disponíveis para treinamento e capacitação. A rede permite a troca de informações, materiais de aprendizado e ferramentas virtuais para a formação, facilitando a comunicação entre instituições educacionais. É intuito da LANENT promover a colaboração entre os membros participantes e outras redes regionais ou globais de trabalho, integrando recursos para educação e treinamento. A rede visa ainda promover e disseminar os benefícios da Tecnologia Nuclear ao público, incentivando o acesso à informação aos jovens em início de carreira.

A LANENT incentiva o uso das Tecnologias da Informação e Comunicação (TIC) e encoraja o envolvimento de instituições acadêmicas, organismos governamentais e centros de pesquisa. Outras organizações que promovem a educação são passíveis de participar da rede enquanto membros colaboradores [18].

\subsubsection{Unificação dos Programas de Proteção Radiológica}

Percebe-se que tanto a nível regional quanto a nível global, os esforços de disseminação da informação e compartilhamento do conhecimento não cobrem, até o presente momento a informatização dos programas de proteção radiológica detalhadamente. Acreditando que as Tecnologias da Informação e Comunicação (TIC) podem trazer aportes significativos à indústria ou instalações que trabalham com material radiativo, a presente tese propõe a integração de uma nova rede nacional que contempla a unificação, o inter-relacionamento e a informatização dos programas de proteção radiológica, fornecendo informações completas que podem ser 
aplicadas conforme a situação de cada instalação. O sistema por nós desenvolvido, intitulado Unificação dos Programas de Proteção Radiológica (UNIPRORAD) [40]. O referido sistema teve início no ano de 2011 [41], com a pesquisa e informatização dos programas de otimização da proteção radiológica. A pesquisa empreendida nesta tese possibilitou a informatização dos programas de monitoramento pessoal, inter-relacionando os conteúdos de monitoramento e otimização. Desta maneira, deu-se início a um sistema operacional integrado que poderá futuramente ser estendido a todos os demais itens exigidos no Plano de Proteção Radiológica.

\section{A tecnologia informática para a disseminação da informação}

A disponibilização da informação de forma unificada, correta, completa e em português pode auxiliar sobremaneira as instalações a dimensionarem os esforços da otimização, de modo que eles sejam justificados e eficazes, evitando subdimensionamento ou superdimensionamento dos esforços empreendidos. Um dos princípios da proteção radiológica é que ela seja econômica e eficaz, porém isso nem sempre ocorre na prática. Quando os esforços são subdimensionados, a escassez de medidas preventivas adequadas pode levar a ações remediadoras com graves consequências, que podem variar de perdas financeiras a danos na saúde dos envolvidos. Por outro lado, o superdimensionamento dos esforços, ainda que por excesso de zelo, pode ser desnecessariamente oneroso e não justificado pelos resultados que apresentará.

Um exemplo de superdimensionamento de esforços é descrito na dissertação de mestrado intitulada "Otimização no controle dos valores de radiação nas dependências do cíclotron de 30 MeV do IPEN" [42]. Esta instalação, como qualquer instalação radiativa, está amparada por um rigoroso programa baseado nos princípios fundamentais de proteção radiológica, que possibilita o conhecimento e o controle dos valores da radiação. Havia na instalação 32 posições de monitoramento do local de trabalho para radiação externa e o monitoramento individual era realizado em todos os servidores. O referido trabalho de pesquisa envolveu um minucioso estudo sobre o monitoramento pessoal, a classificação das áreas de trabalho, os valores de referência então adotados, a classificação dos trabalhadores e um estudo das operações realizadas nas diferentes áreas de trabalho, que podiam apresentar valores de doses de radiação diferentes. Com base na classificação dosimétrica do trabalhador, segundo as recomendações internacionais da CIPR e do OIEA daquela época, foram sugeridos os locais para aplicação do princípio ALARA, novos valores de referência e valores de investigação, condizentes com a realidade da instalação. Das 32 posições de monitoramento do local de trabalho para a radiação externa com função de rotina, conseguiu-se eliminar 23 posições, portanto cerca de $72 \%$ do total e o estudo revelou a necessidade de monitoramento individual para radiação externa em apenas dois trabalhadores. Este exemplo, realizado nas dependências do próprio Instituto de Pesquisas Energéticas e Nucleares (IPEN), ilustra a importância do conhecimento dos programas de otimização e de monitoramento para a elaboração de um programa eficaz e econômico de proteção radiológica.

A disseminação da informação é uma necessidade e um desafio. O desafio envolve assegurar a acessibilidade da informação para o maior número de trabalhadores possível, minimizando custos e otimizando os resultados, neste país de grandes dimensões territoriais. 0 presente 
trabalho de pesquisa responde a esse desafio fazendo uso do valioso potencial das TIC como ferramenta para soluções inovadoras no que tange a disseminação da informação e educação do trabalhador. O poder de processamento dos servidores aliado à tecnologia dos bancos de dados relacionais permitem consultas complexas com tempo de resposta bastante reduzido a partir de qualquer conexão tradicional à Internet. A estruturação do sistema para a disseminação da informação envolveu o estudo detalhado do conteúdo dos programas de monitoramento, de forma a inter-relacionar informações hoje dispersas em várias publicações e documentos. O delineamento do conteúdo inclui conceitos, definições e teoria necessários, além da pesquisa detalhada da filosofia e técnica dos programas de monitoramento da radiação ionizante, trazendo detalhadamente as funções e tipos de monitoramento. O conteúdo, elaborado e estruturado em forma de perguntas e respostas, permite responder a todas as questões que devem ser colocadas na elaboração de um programa de monitoramento de forma a possibilitar montagem do plano de Proteção Radiológica conforme a situação específica do usuário.

\subsection{Metodologia para desenvolvimento dos modelos de informatização}

Uma vez delineado o conteúdo a partir das diversas publicações das diferentes entidades, deuse início à inteligência do sistema e à elaboração dos modelos de informatização da proteção radiológica. O projeto UNIPRORAD (Unificação dos Programas de Proteção Radiológica) está implementado em ambiente WEB, faz uso de ferramentas e recursos WEB 2.0 que permitem a estrutura organizacional necessária para os inter-relacionamentos e articulações para a adequada informatização dos programas de monitoramento da radiação ionizante [40]. Foi desenvolvida uma plataforma cuja gama de recursos e funcionalidades se adequam às necessidades do público corporativo, levando-se em consideração as possibilidades e qualidades das conexões nas diferentes regiões do país. O desafio envolveu a capacidade de criar um sistema consistente, eficaz e ao mesmo tempo flexível, permitindo que se possa adaptá-lo às futuras inovações tecnológicas. Para fins de atualização e alimentação do sistema, levando-se em consideração que a atualização de uma única norma pode incidir em dezenas de informações correlatas, os modelos de informatização permitem que as informações sejam registradas sem redundância, ou seja, qualquer informação pode ser registrada em sua forma mais atual a partir de um único registro, ainda que esteja inter-relacionada com diferentes assuntos ou referenciadas em diferentes módulos.

Os modelos de informatização foram desenvolvidos a partir da utilização combinada de várias tecnologias, tanto para o desenvolvimento quanto para questões de infraestrutura, de forma a aproveitar e potencializar ao máximo os recursos disponíveis em cada uma delas e alcançar os objetivos propostos para fins de desenvolvimento do sistema e disponibilização da informação. Em se tratando de um projeto original e com a perspectiva de longo prazo de utilização, considerou-se o padrão HTML (XHTML1 STRICT), de acordo com recomendações internacionais contidas no W3C (World Wide Web Consortium) [43]. A infraestrutura atual atende um volume médio de acesso ao serviço, condizente com a média de acessos mensais até a presente data. Para tanto, são utilizados, na presente data, servidor WEB com sistema operacional Linux e servidor de banco de dados MySQL [44]. Ainda, o modelo criado prevê a possibilidade de escalar o servidor para uma demanda maior, caso seja necessário futuramente, migrando a base de dados para um Servidor MSQL Server [45]. O projeto segue os padrões de WEB 2,0 fazendo 
utilização de CSS (linguagem computacional), permitindo que o mesmo possa ser facilmente adaptado a novas possibilidades de meios de suporte, como acesso móvel, alimentação de conteúdo e compartilhamento de informações. Há ainda uma grande preocupação com a SEO (linguagem computacional), para garantir que a informação seja indexada da melhor forma possível nos motores de busca da internet. Quanto à linguagem de desenvolvimento do lado servidor, é utilizado o PHP [46], por se tratar de uma linguagem dinâmica, flexível e de fácil manutenção. O PHP é hoje uma tecnologia amplamente difundida, documentada, com uma comunidade extensa e atuante. As tecnologias supramencionadas são programas atuais de utilização padrão para esse tipo de desenvolvimento de projeto. Outras tecnologias mais modernas, até a presente data, ainda apresentam diversos pontos de preocupação referentes à manutenção dos códigos fonte e a flexibilidade para evolução futura.

\subsection{Dimensionamento do conteúdo dos programas de monitoramento nas Tecnologias da Informação e Comunicação}

O conteúdo completo dos programas de monitoramento da radiação ionizante é vasto e complexo, compreendendo recomendações de diversas publicações, dentre as quais nem todas vigentes. $O$ conteúdo fornece uma base teórica necessária para a adequada compreensão das diferentes funções e tipos do monitoramento, além dos conceitos fundamentais e recomendações sobre as técnicas do monitoramento, a filosofia e as recomendações aplicadas aos assentamentos, à acurácia, à garantia da qualidade, às técnicas e aos procedimentos de apreciação dos programas. Para os conceitos de maior complexidade, que envolvem procedimentos e cálculos específicos, necessários para o monitoramento para a radiação externa e para a contaminação do ar, foram desenvolvidos exercícios interativos. A partir de situações fictícias que simulam cenários passíveis de ocorrerem na prática cotidiana, os exercícios possibilitam ao usuário articular o conhecimento teórico com as situações práticas, impulsionando para a formulação de novas hipóteses, promovendo o raciocínio investigativo, incentivando a tomada de decisões e possibilitando a definição de estratégias que podem, posteriormente, ser estendidas ao cotidiano laboral [40]. Feitas essas considerações, o trabalho de pesquisa e informatização foi estruturado conforme descrito a seguir e seu conteúdo encontra-se disponível na íntegra no ANEXO A da presente tese.

A partir das diretrizes fornecidas pelas publicações da CIPR, do OIEA e CNEN, foram abordados os conceitos fundamentais de exposição laboral, exposição normal e exposição potencial; atuação da Proteção Radiológica; controle das exposições laborais normais e potenciais; classificação das áreas de trabalho; implicações práticas e controles de engenharia; padrões de Proteção Radiológica; metodologia de monitoramento; níveis de referência e conservação dos assentamentos. Cada um dos temas foi desenvolvido em seus diversos aspectos. Toma-se como exemplo os diferentes tipos de níveis de referência, juntamente com os quais são abordados os níveis de investigação, intervenção, isenção e exclusão das fontes de radiação.

Um segundo item desenvolvido detalhadamente concerne à introdução ao monitoramento, que contempla os critérios introdutórios de um programa de monitoramento, introdução e justificativa de um programa, tratando também os conceitos de obrigação, tipos de monitoramento e suas funções. Nesta etapa do trabalho foram ainda discutidos a obrigação do 
monitoramento, as etapas do processo e aspectos importantes, bem como os tipos de monitoramento e suas funções.

Cada tipo de monitoramento foi desenvolvido como um capítulo à parte, de forma que a pesquisa pudesse abordar cada um deles em seus mais diversos aspectos e especificidades, de acordo com as recomendações e diretrizes do OIEA e da CIPR. Para cada tipo de monitoramento foram desenvolvidas perguntas e respostas sobre suas finalidades, objetivos e particularidades, bem como as especificidades quanto ao monitoramento de rotina e monitoramento relacionado com a tarefa em cada caso. O tema do monitoramento interventor foi discutido em dois itens, a saber: (i) princípios gerais do monitoramento interventor; e (ii) exposição interna e monitoramento interventor.

O conteúdo conta ainda com o detalhamento de importantes temas discutidos nas publicações vigentes, tais como a acurácia, a garantia de qualidade e a manutenção, retenção e descarte dos assentamentos. Foram contemplados os procedimentos para apreciação sistemática dos programas de proteção radiológica, a introdução da técnica da árvore porfiriana e a construção da árvore de porfírio aplicada aos programas de proteção radiológica. Foram pesquisados, detalhados e disponibilizados a introdução às técnicas de apreciação, o conteúdo de uma apreciação, questões quanto a equipe e planejamento, exigências de uma apreciação, revisão e relatório final. Foi apresentada e explicada ainda a árvore intitulada "Programa eficaz de Proteção Radiológica para o uso seguro de fontes de radiação na indústria, medicina, pesquisa e ensino", desenvolvida pelo OIEA [47]. Esta árvore positiva conta com o desenvolvimento passo a passo de um Programa de Proteção Radiológica. O presente trabalho de pesquisa conferiu ênfase ao detalhamento dos assuntos tratados nesta tese, a saber: controle eficaz da radiação no trabalho; programa de monitoramento do local de trabalho; planejamento e preparo para emergência eficaz.

Além do desenvolvimento de cada um dos itens supramencionados, esta ferramenta para a disseminação da informação oferece propostas de discussões a partir das diretrizes internacionais. É o caso das discussões a respeito da função auditora do monitoramento e das exposições potenciais, descritas nos capítulos a seguir, que trazem novas possibilidades e diferentes cenários, suscitando novas reflexões e proporcionando olhares mais acurados para os profissionais ligados à proteção radiológica.

\section{Programa de Monitoramento das Radiações lonizantes para o trabalhador em condições normais de trabalho}

Ainda que as condições de trabalho sejam aceitavelmente seguras e satisfatórias e os riscos à pessoa representativa seja igual ou inferior aos riscos previstos em sua vida cotidiana, deve-se comprovar que, com o passar do tempo, o sistema implantado continua suficiente e adequado. O dimensionamento do monitoramento preventivo, isto é, o monitoramento do local de trabalho, é proporcional à dose que se avalia que afetará o trabalhador, e portanto, quando a soma das doses é inferior a 1/10 de LAMA (Limite Anual Máximo Admissível), não se justifica o monitoramento e ele deve ser excluído. Há três tipos de monitoramento para o trabalhador, que não necessariamente atuam ao mesmo tempo: monitoramento do local de trabalho para 
radiação externa, monitoramento do local de trabalho para contaminação de superfície e monitoração do local de trabalho para a contaminação do ar. Da mesma forma, os três tipos de monitoramento de caráter confirmatório para o trabalhador, conhecidos pelo nome genérico de monitoramento individual, serão utilizados de acordo com a sua necessidade de implementação. São eles: monitoramento individual para radiação externa, monitoramento individual para contaminação interna e monitoramento para contaminação de pele e roupa [23; 25].

Quanto ao monitoramento preventivo para o público, busca mensurar a dose na pessoa representativa advinda de vazamentos de radiação ou descarga de materiais radioativos no ambiente. Isso se dá relacionando percentualmente as doses resultantes dos caminhos críticos e os respectivos LAMAs. Nesse caso não são considerados importantes aqueles caminhos cujas doses resultantes são inferiores a $1 / 10$ daquelas fornecidas pelo caminho crítico de maior dose e nesse caso a dose representativa deste caminho é eliminada. Não é realizado monitoramento individual para indivíduos do público, mas são analisados os diferentes caminhos críticos, e por meio do monitoramento do ambiente, podem-se avaliar as doses que receberá a pessoa representativa, sejam elas externas, isto é, decorrentes do aumento do nível de radiação, ou internas, isto é, em virtude da contaminação do ar ou fontes de alimentação [23; 35].

Os equipamentos para o monitoramento devem ser calibrados segundo padrões de confiabilidade nacionais e internacionais. $\mathrm{O}$ grau de incerteza dos monitores individuais - em um grau de confiabilidade de $95 \%$ - não devem exceder um fator de 1,5 para níveis de radiação próximos aos LAMAs, e um fator de 2 para níveis anuais inferiores a $10 \mathrm{mSv}$. Para o monitoramento em geral, os instrumentos podem apresentar erro de até $50 \%$ e os dosímetros acidentais (lendo doses em intervalo a partir de $1 \mathrm{mSv}$ a mais de $10 \mathrm{~Gy}$ ) erro de 25\% [23].

Embora a prioridade da radioproteção seja privilegiar sistemas de proteção que evitem contaminações, quando estas ocorrem, envolvendo trabalhadores e ambiente de trabalho, é necessária uma intervenção de maneira a restabelecer o nível de segurança da instalação que havia antes da ocorrência. Os rejeitos gerados pelos procedimentos de descontaminação raramente podem ser reaproveitados e devem ser adequadamente eliminados por meio de extensivos programas de tratamentos de rejeitos radioativos. Buscando minimizar as contaminações, torna-se imprescindível a formação e treinamento da equipe de operação que, no mais das vezes, pode ser realizado no próprio local de trabalho durante o desenvolvimento das tarefas. Além desses procedimentos, há que se considerar outras atividades que ultrapassam as funções das instalações, como atividades normativas e legislativas perante a prefeitura, estado ou país; atividade de planejamento de emergência junto à defesa civil dos órgãos governamentais; prestação de serviço ao público e atividades de educação à população.

\subsection{Diferentes funções do monitoramento das radiações ionizantes}

As funções do monitoramento da radiação ionizante, tais como constam nas atuais recomendações [23], são três a saber: monitoramento de rotina, monitoramento relacionado com a tarefa e monitoramento interventor. A função de rotina se aplica a operações contínuas ou voluntárias das atividades da instalação e foi idealizado para demonstrar que as condições de trabalho, inclusive os valores das doses individuais permanecem satisfatórios, para avaliar e estimar as doses dos trabalhadores e auditar o monitoramento relacionado com a tarefa e para 
atender às exigências regulatórias. A função relacionada com a tarefa se aplica a uma operação específica, para auxiliar na tomada de decisão imediata para a condução da operação e para possibilitar evitar, detectar e tomar as primeiras medidas reparadoras em caso de desvios da situação normal de trabalho. Ela é realizada pelo trabalhador, sob orientação e audição do Serviço de Proteção Radiológica. O monitoramento interventor (especial) se aplica na necessidade de uma investigação em situações, no local de trabalho, onde as informações são insuficientes para demonstrar um controle adequado. Ele foi idealizado para fornecer informações detalhadas de modo que possa elucidar qualquer problema e definir procedimentos futuros [22 - 23].

A função de rotina é realizada pelo serviço de radioproteção e tem por objetivo avaliar e estimar as doses do indivíduo. De acordo com as definições da OIEA [24], avaliar remete a um caráter preventivo e é utilizado para o monitoramento de área, em casos de uma dose previsível de ser recebida. Estimar refere-se a um caráter confirmatório, para o monitoramento individual, quando a dose já foi recebida pelo trabalhador. A função auditora - apesar de contemplada nas recomendações internacionais - não foi desenvolvida nas publicações e acaba por ser trascurada no cotidiano laboral. Uma vez que nem mesmo as publicações internacionais ou as normas nacionais separam com clareza as funções de avaliar e estimar da função de auditar, a partir das recomendações que tratam da função de rotina do monitoramento [22 - 23], discutimos as poucas informações publicadas sobre a função auditora, ampliando o repertório de informações hoje disponíveis. Para tanto, desmembramos nesta tese a função de rotina entre: função controladora (para avaliar e estimar) e função auditora, conferindo a esta última a devida ênfase. Cabe lembrar que a função auditora é de suma importância, uma vez que se presta a (i) auditar as tarefas de Proteção Radiológica realizadas pelo trabalhador, seja no monitoramento relacionado com a tarefa, seja no monitoramento interventor; e (ii) verificar se as tarefas atribuídas ao trabalhador são realizadas de forma correta e equilibrada, conforme as instruções do Serviço de Proteção Radiológica.

Neste contexto, cabe à Proteção Radiológica auditar se o monitoramento dos locais de trabalho, com função relacionada à tarefa, encontra-se em conformidade com as instruções propostas por ela ao trabalhador, considerando periodicidade, equipamentos e não conformidades. A periodicidade remete à frequência com que o monitoramento deve ser realizado. A vistoria dos equipamentos à disposição do trabalhador deve comprovar seu correto funcionamento. $A$ verificação de inconformidades leva a auditoria a buscar e avaliar suas possíveis justificativas e empreender ações corretivas, quando necessárias.

\subsection{Monitoramento auditor}

Para um monitoramento auditor eficaz, consideraremos duas etapas complementares e igualmente importantes, que contemplam o monitoramento rotineiro e o monitoramento incerto. O monitoramento auditor rotineiro é aquele que é previsto e é realizado periodicamente segundo um intervalo de tempo que pode variar de acordo com o tipo de monitoramento e deve ser sempre condizente com o volume da tarefa. Quanto às auditorias com frequência incerta, devem ser realizadas em momentos-chave dos processos e não são programadas junto ao trabalhador, uma vez que têm por finalidade a comprovação de que os procedimentos e recomendações são obedecidos no cotidiano laboral. Poder-se-ia dar como 
exemplo o uso do dosímetro individual. Uma auditoria não programada no horário que se deve fazer a leitura, com a finalidade de atestar a veracidade dos registros permite auditar os procedimentos quanto ao correto uso dos dosímetros pelo trabalhador: se o dosímetro é utilizado no trabalho que o exige e, nesse caso, se o trabalhador o porta de maneira correta, comprovando o correto uso e a veracidade dos registros dos dosímetros, seja o dosímetro de alerta, seja o dosímetro de leitura mensal para estimativa da dose.

A função auditora permite, portanto, verificar a correta realização das tarefas de Proteção radiológica atribuídas ao trabalhador, tanto no que se refere ao monitoramento relacionado com a tarefa, quanto no caso do monitoramento interventor. Ainda, a função auditora do monitoramento se aplica aos diferentes tipos de monitoramento, a saber: monitoramento para a radiação externa, monitoramento para a contaminação de superfície, monitoramento para a contaminação do ar, monitoramento individual para a radiação externa, monitoramento individual para a exposição interna e monitoramento individual para a contaminação de pele e roupa.

\subsection{Garantia da qualidade versus função auditora do monitoramento}

A função auditora do monitoramento não deve ser confundida com os procedimentos da garantia de qualidade. A garantia de qualidade para os programas de controle e monitoramento da radiação ionizante é empreendida por meio de ações sistemáticas e planejadas, necessárias para proporcionarem uma confiabilidade adequada nos resultados de programas de controle e monitoramento. Entende-se por controle da qualidade nos processos de monitoramento da radiação ionizante as ações que avaliam, em relação às exigências estabelecidas, a adequacidade dos equipamentos, instrumentos e procedimentos.

Em um programa de monitoramento da radiação ionizante a garantia de qualidade deve assegurar que os equipamentos e os instrumentos funcionem corretamente, os procedimentos foram estabelecidos e implementados corretamente, as análises são executadas corretamente, os erros sejam quantificados dentro dos limites aceitáveis e os assentamentos sejam mantidos corretos, pontualmente e disponíveis. São muitos os fatores que devem ser considerados em um projeto de um programa de garantia de qualidade para o monitoramento da radiação ionizante, dentre eles: a qualidade dos equipamentos e instrumentos, o treinamento e experiência do pessoal, a verificação dos procedimentos - pela análise de averiguação - de amostras de controle usando métodos padronizados, e a frequência de calibração e manutenção dos equipamentos e instrumentos $[1 ; 23]$.

São cuidados a serem tomados na confecção de um programa de garantia de qualidade [23] para o monitoramento da radiação ionizante:

- Que a instabilidade no sistema de medida é um aspecto importante que influi na frequência de calibração e manutenção dos equipamentos e instrumentos.

- Na necessidade de que os resultados dos programas de monitoramento sejam acompanhados por um padrão nacional.

- Com relação à classe de documentação necessária para demonstrar que a qualidade exigida foi alcançada e é mantida. 
Ainda, devem ser documentados em um programa da garantia da qualidade no monitoramento da radiação ionizante as verificações realizadas regularmente pelo controle da qualidade.

A função auditora, por sua vez, tem por finalidade certificar que as tarefas de Proteção radiológica atribuídas ao trabalhador são realizadas em conformidade com as recomendações, tanto na função relacionada à tarefa quanto na função interventora. Desta forma, o monitoramento com função auditora engloba identificar as especificidades das tarefas, equipamentos e exigências para os diferentes locais de trabalho.

\subsection{Monitoramento pessoal}

Articulamos a seguir as diferentes funções para cada tipo de monitoramento, desmembrando e especificando a função auditora para cada caso. Elas são globalmente denominadas de monitoramento pessoal.

\subsubsection{Monitoramento do local de trabalho para a radiação externa}

O monitoramento de rotina para local de trabalho para radiação externa [23] envolve o uso de medidas de inspeção regularmente repetidas e pode incluir o uso de monitores instalados para identificar o inicio de condições anormais ou de emergência. Um exemplo deste último pode ser uma falha no retorno de uma fonte de radiografia para a sua blindagem. Alguns cuidados que devem ser tomados na confecção de um programa de monitoramento de rotina para o local de trabalho para radiação externa com fins de proteção radiológica: deve ser cuidadosamente planejado, não deve ser super elaborado e deve-se levar em consideração que a geração de um grande número de resultados desnecessários é contraproducente e pode mascarar a presença de resultados úteis e significativos. O monitoramento de rotina do local de trabalho para radiação externa com fins de proteção radiológica deve ser efetuado nas posições onde permanecem os trabalhadores durante a execução das respectivas tarefas. Para determinar a frequência do monitoramento de rotina para a radiação externa, devem ser consideradas as variações do campo, conforme descritas a seguir. Quando as variações de campo de radiação só ocorrem em decorrência de alterações apreciáveis nos arranjos de blindagem, nos controles ou nos processos realizados no local de trabalho, é necessário somente um monitoramento ocasional no local para propósitos de comprovação. Quando as variações do campo de radiação são lentas e as consequências não são graves, considera-se monitoramentos periódicos, que normalmente proporcionarão informações de advertência suficientes e em tempo hábil sobre as condições de deterioração, principalmente para pontos pré-estabelecidos. Quando as variações do campo de radiação são rápidas e imprevisíveis a valores alarmantes, devem ser colocados no local de trabalho instrumentos de aviso ou usados individualmente pelos trabalhadores. No caso do campo de radiação variar rapidamente e de modo imprevisível a valores alarmantes os equipamentos devem possuir as seguintes características:

- devem ser robustos e confiáveis;

- devem apresentar respostas adequadas para o tipo e a energia da radiação que se encontra no local de trabalho;

- deve ser dada uma atenção especial na escolha e calibração de instrumentos utilizados na medida de nêutrons ou fótons de penetração pequena; 
- os instrumentos devem responder em unidades do sistema Internacional, SI, e devem ser calibrados nas grandezas operacionais da Comissão Internacional de Unidades e Medidas de Radioproteção, CIUR, geralmente, em dose equivalente ambiente ou dose equivalente direcional.

- os instrumentos antigos, graduados em unidades SI mas calibrados em dose absorvida no ar, geralmente, são adequados para medidas de fótons.

- ainda que a maioria dos instrumentos utilizados no monitoramento do local de trabalho meçam taxa de dose em vez de dose mas existem circunstâncias onde é útil um dosímetro integrador simples como um Dosímetro Termoluminescente, DTL.

No caso do monitoramento com função relacionado com a tarefa [23] para o monitoramento do local de trabalho para radiação externa, é necessário considerar as características do instrumento e as taxas de dose nas operações. É desejável que os instrumentos sejam portáteis e que se possa prever, detectar e tomar as primeiras medidas em caso de se tornar uma situação anormal. Para casos em que os campos de radiação permanecem, essencialmente constantes, geralmente é suficiente um levantamento preliminar das taxas de dose na região a ser ocupada pelos trabalhadores. Algumas vezes torna-se necessário repetir estes levantamentos antes de cada série de operações. Nos casos em que as operações interferem na taxa de dose e os campos de radiação podem variar, faz-se necessária a realização de medidas durante toda a operação. No monitoramento com função relacionada com a tarefa os locais de monitoramento devem ser escolhidos tomando por base as posições onde se pode detectar confiavelmente qualquer desvio da situação normal, procurando evitar que os trabalhadores recebam doses extras além daquelas previstas durante o trabalho normal. Nas posições de monitoramento não é necessária a presença dos trabalhadores. O monitoramento com função relacionada com a tarefa, quando realizado por equipamento fixo, passa para o controle do serviço de radioproteção e, portanto, incluído no monitoramento com função de rotina, uma vez que a radioproteção pode manter o controle por meio de uma estação repetidora das medidas. Esta atitude contribui para reduzir o volume de tarefas de radioproteção efetuadas pelo trabalhador, que tem como principal função a produção. Ainda, no monitoramento do local de trabalho para radiação externa devem ser tomados mais cuidados quando se trabalha com radiação beta ou outro tipo de penetração pequena. Isso porque manipulações realmente secundárias, como mudanças de orientação ou remoção de componente, podem causar mudanças muito grandes na taxa de dose. Como a maioria dos monitoramentos, especialmente aqueles que fornecem um aviso aos trabalhadores, estão baseados na detecção da radiação gama mais energética, estas alterações podem deixar de ser detectadas. Deve-se atentar especialmente às medidas de taxa de dose imediatamente adjacentes à superfícies ou em fontes puntiformes.

Um aspecto importante do monitoramento é a definição de bases bem estabelecidas para a interpretação dos resultados em função dos objetivos da proteção. Deve-se levar em consideração que, qualquer que seja o tipo de monitoramento, a interpretação dos resultados só se dá uma vez atingido o nível de investigação. No caso das recomendações da CIPR, o nível de investigação coincide com o nível de registro e qualquer dose registrada merece ser investigada em busca de possibilidades para otimizar a proteção. Para o monitoramento do local de trabalho para a radiação externa, a CIPR apresenta sugestões no intuito de auxiliar a interpretação dos resultados. No caso do monitoramento de rotina, quando as doses equivalentes ou efetivas recebidas são próximas a $1 / 10$ dos limites anuais, a CIPR aconselha 
supor que o trabalhador permaneça durante todo o tempo no ponto de maior dose. Se, no entanto, as doses são próximas a 3/10 dos limites anuais, recomenda-se determinar ou mesmo restringir o tempo de permanência nas áreas onde as taxas de dose são elevadas até que sejam efetuadas melhorias na proteção. A interpretação das doses avaliadas pode ser facilitada com a correta calibração dos instrumentos de medida. No que tange o monitoramento relacionado com a tarefa, é recomendado estabelecer um tempo máximo de trabalho para assegurar-se que o trabalhador não ultrapassa as doses especificadas, determinadas em função das doses recebidas nas demais tarefas executadas dentro de um mesmo período de tempo.

Uma vez compreendidas as funções de rotina e relacionada com a tarefa para a radiação externa, há que se empreender um estudo para a compreensão das diretrizes envolvidas em um monitoramento com função auditora que, embora contemplado na publicação [23], não é discutido ou especificado. Acreditamos que a função auditora no caso do monitoramento para a radiação externa, envolve obrigatoriamente auditar as características dos instrumentos utilizados; os casos em que são realizados os monitoramentos; a frequência de realização do monitoramento de acordo com cada caso; a escolha dos locais de monitoramento e os cuidados tomados quanto à radiação beta ou outro tipo de penetração pequena. Nos casos em que as taxas de dose não variam com as operações do trabalhador, o intervalo para a realização do monitoramento relacionado com a tarefa deve obrigatoriamente estar previsto no plano de trabalho. Esse intervalo varia conforme a natureza da atividade realizada. Cabe ao serviço de proteção radiológica ao final de cada período verificar primeiramente, por meio de relatórios, se o monitoramento relacionado com a tarefa foi realizado conforme previsto. É tarefa da função auditora verificar se os valores obtidos nos relatórios estão em conformidade com os valores esperados, uma vez que diferenças nos valores previstos podem indicar (i) variações não esperadas no campo de radiação ou (ii) mau funcionamento do equipamento. O processo de auditoria periódica desincentiva tomadas de decisão baseadas em suposições, tais como: assumir que uma diferença no valor esperado se deu porque o equipamento não está corretamente calibrado. A auditoria deve comprovar a veracidade das informações apresentadas no relatório e as ações tonadas em caso de resultados diferentes do esperado. Suposições baseadas na experiência prévia, sem que sejam devidamente comprovadas as causas das diferenças nas medidas violam os procedimentos de segurança e são portas abertas para desvios da situação normal. Por esta razão, deve ser efetuada em todas as auditorias previstas verificação da calibração dos instrumentos. Equipamentos portáteis podem ter suas baterias facilmente verificadas no próprio visor e pode-se fazer uso de uma pequena fonte padrão para verificar que a resposta à dose está correta. São recomendáveis duas ou três auditorias não programadas ao longo do ano.

As implicações de um monitoramento auditor seriam outras em casos em que as taxas de dose variam com as operações do trabalhador. Se tomarmos como exemplo celas para processamento do ${ }^{131}$ lodo, a previsão para variação do campo (devido ao desgaste ou deterioração das condições físicas) é da ordem de 10 anos. No caso do monitoramento com função auditora para celas de processamento de ${ }^{131}$ lodo, a auditoria poderia ser efetuada a cada 3 meses. A auditoria nesse caso contempla a verificação e comparação dos resultados com os últimos resultados obtidos e a verificação do bom funcionamento dos equipamentos. Além da auditoria programada ao longo do período, são recomendáveis auditorias incertas ao longo do ano, podendo o profissional da proteção radiológica solicitar a realização das medidas 
juntamente com o trabalhador responsável, comparando os resultados obtidos com o último registro apresentado, corroborando assim o bom funcionamento dos equipamentos ao longo do período. Em se tratando de casos em que as operações do trabalhador interferem nas taxas de dose provocadas pelos campos de radiação, a auditoria pode se dar esporadicamente, por exemplo, após um intervalo de cinco ou seis monitoramentos previstos no plano de trabalho, dependendo do radionuclídeo trabalhado e de quão lentas forem as variações previstas. Em instalações em que as variações do campo de radiação são rápidas e imprevisíveis, podendo atingir valores alarmantes, devem ser auditados os instrumentos de aviso colocados no local de trabalho e aqueles utilizados individualmente pelos trabalhadores. Disso depende a confiabilidade dos resultados apresentados pelo monitoramento relacionado à tarefa. 0 primeiro passo do monitoramento auditor é verificar os resultados obtidos com os relatórios precedentes. É importante conhecer os valores normais que os equipamentos costumam fornecer, para detectar possíveis desvios. É necessário ainda comprovar o bom funcionamento dos equipamentos. No caso dos monitores contínuos de ar, pode ser auditado por meio de simulações se os equipamentos reproduzem os resultados esperados. É possível nesses casos que o profissional auditor, juntamente pelo responsável no local de trabalho, reproduzam juntos resultados para conferir as medidas obtidas. A frequência da auditoria dependerá da frequência da operação com o material radioativo em questão. A escolha da frequência deve considerar, pois, os momentos-chave da operação. A experiência do fiscal do serviço de proteção radiológica juntamente com os resultados obtidos por meio dos relatórios auxiliariam, em cada caso, a estabelecer o ideal de frequência para o monitoramento com função auditora. Em qualquer dos casos supramencionados, cabe à Proteção Radiológica, no acompanhamento do monitoramento com função auditora para a radiação externa, providenciar o registro ou relatório de conformidades ou das irregularidades encontradas para futuras referências.

\subsubsection{Monitoramento do local de trabalho para contaminação de superfície}

A finalidade de um monitoramento de contaminação de superfície pela radiação ionizante com função de rotina é detectar uma contaminação, pois é difícil avaliar a dose individual a partir dela [23]. O método convencional é monitorar uma fração representativa das superfícies de uma área por meio de um detector específico, como por exemplo a panqueca. A frequência do monitoramento é estabelecida pela prática. Devem ser considerados os seguintes casos:

a. Monitoramentos mais frequentes - Neste caso devem-se ter pontos indicadores estratégicos como barreiras de controle e áreas com potencial elevado de contaminação.

b. Monitoramentos menos frequentes - Neste caso, deve-se, representativamente, cobrir toda a área controlada em conjunto com algumas medidas a mais fora da área.

c. Monitoramento onde existe a probabilidade de ocorrência de uma grande contaminação, onde o individuo possa transferir uma quantidade significativa de atividade para fora da área controlada num único evento - Neste caso o monitoramento convencional deve ser complementado pelo uso de monitores instalados nas saídas externas as áreas controladas. Os monitores podem ser: sondas de varreduras, monitores de pés, mãos e roupas ou portais. Estes monitores podem ser adequados para a indústria nuclear (ciclo do combustível nuclear), mas raramente são necessários nas aplicações medicas e indústrias. 
d. Uso de métodos alternativos para detecção de deteriorações lentas ou derrames - neste caso faz-se uma análise dos valores da contaminação em panos de chão, sacos de aspirador, outras superfícies nas áreas de saída, sapatos, luvas, bolsas etc. Esta analise fornece uma indicação genérica dos valores da contaminação mas não detecta a ocorrência isolada de pequenas quantidades de materiais radioativos e nem permite uma estimativa qualitativa dos valores da contaminação.

e. Instalações onde é necessária a troca de vestimentas - deve-se lembrar que são instalações que possuem áreas demarcadas com potencial para contaminação e que deve ser dada uma atenção especial no monitoramento dos trabalhadores que saem da área - Neste caso os monitores para contaminação de superfície colocados no lado limpo da sala de troca normalmente são idealizados para uso pessoal, com a finalidade de garantir que as mãos, roupas e sapatos não estejam contaminados antes que os trabalhadores deixem estes locais. Como este monitoramento é realizado após terem sido lavadas as mãos e após a remoção das sapatilhas e outras roupas de proteção especiais deve ser relacionado como uma técnica adequada de verificação da contaminação geral no local de trabalho.

f. Itens retirados das áreas demarcadas com potencial para contaminação devem ser monitorados - Neste caso quando o monitoramento de tudo que sai da área é impraticável deve-se definir as áreas e itens para os quais o monitoramento de rotina é necessário e porque o é.

g. Distinção entre contaminação fixa e removível - Neste caso devemos considerar que esta distinção não é absoluta pois a contaminação fixa pode se tornar removível, principalmente quando são aplicados processos abrasivos e ambas as formas de contaminação contribuem para a radiação externa, mas unicamente a removível pode tornar-se uma fonte de exposição interna. Em virtude de termos contaminações de superfície provocada pela radiação ionizante fixas e removíveis, possuímos as seguintes medidas de contaminação: (i) medidas diretas com sondas que detectam tanto a contaminação fixa como a removível e (ii) uso do teste de esfregaços que detecta somente a contaminação removível.

A finalidade do monitoramento de contaminação de superfície com função de rotina é detectar uma contaminação e não avaliar a dose do trabalhador, porque é muito difícil avaliar a dose deles provocada por ela. Ela se coaduna mais com a função de auditoria do monitoramento relacionado com a tarefa. Quanto à prevenção de contaminação por fontes de radiação ionizante seladas, não há necessidade do monitoramento de contaminação de superfície mas há necessidade de um programa regular de testes de fuga, conhecidos como ensaios diretos. A frequência dos ensaios depende da eficácia de contenção da fonte. Normalmente são adequados ensaios regulares de um a dois anos. A CNEN adota a frequência anual. Em fontes frágeis ou usadas em ambientes agressivos os ensaios de vazamento devem ter uma frequência maior $[1 ; 23]$.

Quanto aos ensaios indiretos, podem ser realizados nas fontes seladas de radiação ionizantes o monitoramento do recipiente que acomoda a fonte e o monitoramento dos produtos de decaimento de meia vida curta como no caso do radio, que se detecta o escape do radônio. No resultado do ensaio deve ser incluída uma declaração cautelosa que indica a natureza limitada do ensaio e, em particular, que o acesso junto à fonte pode resultar na dispersão de 
contaminação. Um programa completo de monitoramento de contaminação de superfície provocada pela radiação ionizante deve fornecer a confiança de que a possibilidade de ocorrência de uma contaminação significativa levada para fora de uma área controlada seja aceitavelmente pequena.

Quanto ao monitoramento relacionado com a tarefa, é importante ter claros os objetivos, que são: evitar a contaminação e limitar a sua dispersão. Desta forma, é útil durante ou imediatamente após um trabalho não rotineiro ou de manutenção e em contenções parciais, como no caso das capelas com exaustão. O serviço de proteção radiológica, por sua vez, mantém à disposição do trabalhador equipamentos de monitoramento e providencia o treinamento dele para a sua utilização [23].

A interpretação dos resultados para o monitoramento do local de trabalho para contaminação de superfície envolve diversas etapas. Primeiramente, a separação das medidas entre a radiação alfa e beta, uma vez que o principal risco para a radiação alfa é a inalação, embora há que se prestar atenção à possibilidade de incorporação da radiação beta. Outra etapa a ser cumprida é o estabelecimento e a aderência aos níveis de referência que, não podendo ser rigorosamente determinados, devem ser inferidos valores arbitrários inferiores aos níveis de registro do monitoramento individual. Ao se estabelecer o nível de investigação, quando os valores da contaminação podem ser mantidos inferiores ao nível de registro, devem ser consideradas as diferentes áreas de contaminação (área onde a contaminação é rara, área onde ocorrem contaminações gerais etc). Finalmente, o nível de registro deve ser estabelecido de forma que as doses e incorporações se mantenham inferiores aos limites básicos ou autorizados. Devem ser evitados registros de resultados inferiores a um valor determinado.

A referida publicação não oferece, entretanto, informações qualitativas ou quantitativas em relação à um processo de auditoria a ser empreendido pelas instalações radiativas para este tipo de monitoramento. $O$ trabalho empreendido nesta tese, contempla o estudo e discussão das possibilidades de diretrizes para que esta função possa ser incluída no monitoramento das instalações. No nosso entender, a função auditora para o monitoramento do local de trabalho para contaminação de superfície tem como função verificar se foram adequadamente cumpridos os objetivos do monitoramento relacionado com a tarefa, ou seja, evitar a contaminação e limitar a sua dispersão. Faz-se necessária a auditoria para que se possa verificar sua correta realização em situações de contenções parciais ou após trabalhos não rotineiros ou de manutenção e atestar a correta utilização dos equipamentos de monitoramento à disposição do trabalhador. Uma vez que o monitoramento da contaminação de superfície é de pouco valor para avaliar a irradiação dos trabalhadores e que os mecanismos para se avaliar as doses recebidas pelos trabalhadores são muito complexos, a função auditora contempla todo o monitoramento de rotina. Nesse caso, considerando que as ações para o controle de contaminação envolvem (i) manter à disposição dos trabalhadores os equipamentos de monitoramento devidamente calibrados em órgão credenciado pela CNEN e (ii) treinamento para a utilização dos equipamentos e dos monitores. O monitoramento com função auditora inclui verificação do correto funcionamento do equipamento e se sua utilização se dá em conformidade com os procedimentos e as recomendações. 
Normalmente, para monitorar a contaminação de superfície, são deixados à disposição do trabalhador equipamento móveis de bancada que utilizam a sonda externa do tipo panqueca. Uma vez que a frequência do monitoramento de rotina é estabelecida pela prática, a frequência do monitoramento relacionado com a tarefa deve ser estudada caso a caso, de acordo com a atividade realizada. Fazem parte do monitoramento relacionado com a tarefa, dentre outros, a verificação da contaminação de superfície (bancadas e chão) após a jornada de trabalho, a verificação da superfície externa dos recipientes destinados aos rejeitos, a verificação das superfícies nos locais onde são armazenados materiais radioativos e a verificação da superfície externa dos embalados sempre que chegam à instalação.

Supondo uma instalação na qual o monitoramento para contaminação de superfície é realizado diariamente pelo trabalhador, o serviço de proteção radiológica poderia promover um monitoramento auditor, com relação ao serviço de proteção do próprio trabalhador, com frequência semanal. Se, por outro lado, a atividade é realizada uma vez por semana, o monitoramento auditor programado pode se dar mensalmente. Apesar desse tipo de monitoramento ser pouco útil para se avaliar as doses dos trabalhadores, alterações de resultados quanto ao nível de contaminantes nas bancadas podem indicar desvios da situação desejável. Dessa forma, a primeira ação do serviço de auditoria contempla a assiduidade da tarefa e a comparação de seus resultados com aqueles obtidos no monitoramento de rotina. $\mathrm{O}$ monitoramento auditor deve contemplar a reprodutibilidade de medidas juntamente com o profissional responsável. Esta ação permite a comprovação da adequada manutenção das condições no ambiente de trabalho, bem como o bom funcionamento dos detectores e a confiabilidade dos monitores de contaminação de superfície, tanto daqueles em uso como daqueles sobressalentes. Além da auditoria programada, recomendam-se auditorias incertas nas atividades do trabalhador, para verificar se o programa de monitoramento está sendo realizado corretamente e de forma contínua pelo trabalhador. Assim sendo, o monitoramento incerto inclui auditorias não programadas, intercaladas com uma série de 3 ou 4 auditorias programadas, permitindo auditar as boas práticas do monitoramento relacionado com a tarefa e a manutenção das condições físicas do local de trabalho, como as bancadas que devem ser corretamente forradas e permanecer sem rachaduras ou desgastes que dificultariam um trabalho de descontaminação.

\subsubsection{Monitoramento do Local de trabalho para a contaminação do ar}

Quando de discute o Monitoramento do Local de trabalho para a contaminação do ar pela radiação ionizante, é preciso levar em consideração que para o projeto de um programa de monitoramento do local de trabalho para a contaminação do ar existe uma estrutura geral [22] comum a todos os tipos de monitoramento descritos neste trabalho de tese e uma estrutura mais conveniente para este tipo específico de monitoramento [23]. Deve-se então considerar a estrutura mais conveniente em suas divisões:

a. Monitoramento de alerta - para detectar e advertir o início de uma contaminação significativa presente no ar.

b. Amostragem de área - para detectar tendências e variações nas contaminações presentes no ar em todo o local de trabalho. 
c. Amostragem representativa - para quantificar a extensão da contaminação presente no ar à qual o trabalhador provavelmente estará exposto.

$\mathrm{Na}$ estrutura geral das funções [22], os monitoramentos com função de alerta e de amostragem de área seriam classificadas com função relacionada com a tarefa e a função de amostragem representativa com função de rotina, mas a amostragem de área, também, pode ser considerado como função de rotina.

O monitoramento de Alerta torna-se útil em operações ou desvios que podem causar liberações apreciáveis e inesperadas de materiais radioativos no local de trabalho. Neste caso devem ser usados equipamentos de aviso operando continuamente. Eles devem estar localizados em posições onde detectarão com confiabilidade uma liberação de material radioativo. Um exemplo é a Instalação do equipamento em/ou próximo a pontos de extração do ar em locais de trabalho e não devem ser colocados na extensão de sistemas fechados do tipo da capela com exaustão. É útil a colocação dos equipamentos para o monitoramento de alerta para o local de trabalho onde pode existir a contaminação do ar provocada por radiação ionizante, a saber: reatores; próximos a celas de processamento; áreas onde são manuseados plutônios e outros elementos transurânicos; locais onde são usadas quantidades apreciáveis de materiais sob forma não selada [23].

Para a escolha do nível de alarme e equipamento que deve ser utilizado no monitoramento de alerta para contaminação do ar devem ser considerados o valor normal de atividade presente no ar e a sua esperada variação. Há ainda a necessidade de se evitar alarmes freqüentes desnecessários (incluindo os alarmes falsos) e a necessidade de se efetuar a discriminação de contribuições que confundem como aquelas causadas pela radiação natural de fundo resultante dos produtos de decaimento do radônio. Os equipamentos utilizados são os monitores contínuos de ar providos de aviso e/ou alarme [23].

A utilidade da amostragem de área é a obtenção de dados sobre a tendência dos valores da contaminação presente no ar. Os Equipamentos utilizados são amostradores de área estáticos, com ou sem qualquer equipamento de monitoramento de alerta. $O$ número de equipamentos e a sua localização devem ser justificados e devem-se considerar o significado global da contaminação e seu grau de variação [23].

A amostragem representativa tem por finalidade colher amostras da atividade no ar respirado pelos trabalhadores e, portanto, pode ser usada para determinar a exposição recebida pelo trabalhador. A sua importância é fornecida pelo papel que desempenha no monitoramento com propósitos de controle operacional. Utilizam-se amostradores fixos em um determinado número de locais selecionados como representativos da zona de respiração dos trabalhadores. Denomina-se de ciclo completo de operações. Ela se torna importante em locais fixos de trabalho com grande ocupação e a amostra de ar, que representa a incorporação, pode ser, convenientemente, localizada próxima à zona de respiração. A amostragem representativa da contaminação do ar provocada pela radiação ionizante pode representar adequadamente a incorporação de cada trabalhador em um ciclo completo de operações [23].

Considerando a estrutura conveniente, a incorporação de materiais radioativos no monitoramento do local de trabalho para a contaminação do ar pode ser avaliada a partir dos 
resultados do monitoramento do local de trabalho tanto pela amostragem de área como representativa. Quando forem usados amostradores de área de modo rotineiro para avaliar a contaminação do ar provocado pela radiação ionizante, a quantidade incorporada pelo trabalhador pode ser determinada pela introdução de um programa de monitoramento interventor (especial), frequentemente envolvendo amostradores de ar individuais e determinados fatores de conversão. Os fatores de conversão determinados pelo monitoramento com função interventora introduzidos no monitoramento de área para a contaminação do ar não são perenes e devem ser revisados de tempo em tempo e, sempre, após qualquer alteração significativa nas operações [23].

Mesmo fazendo uso de fatores de correção no monitoramento da contaminação do ar provocado pela radiação ionizante pode haver falhas em representar adequadamente a incorporação para cada trabalhador. Tal fato pode ocorrer em situações em que as fontes de contaminação são localizadas e variáveis com o tempo, frequentemente, provocadas pela própria ação ou movimento do trabalhador. Como exemplo, poder-se-ia citar a fuga em uma cela com luvas. Situações em que a distribuição de atividade dentro do espectro de tamanhos de partículas não é uniforme, algumas partículas apresentam grande fração do LIA (Limite de Incorporação Anual) com relação às demais partículas [23].

A representatividade de uma amostra de contaminação do ar com relação ao ar inalado por um trabalhador depende da taxa de amostragem do ar, das características de seleção do tamanho das partículas suspensas no ar amostrado e da circulação do trabalhador dentro do local de trabalho [22 - 23].

Uma vez compreendidas as particularidades da estrutura geral e da estrutura mais conveniente para o monitoramento da contaminação do ar, pode-se compreender a estrutura geral com as funções do monitoramento de rotina e monitoramento relacionado com a tarefa.

O monitoramento de rotina para a contaminação do ar deve compreender as operações singulares e as operações variadas. Nas operações singulares devem ser usados amostradores de ar instalados em locais escolhidos, expressivos das zonas de respiração dos trabalhadores. Nas operações variadas deve-se efetuar amostragens nas diferentes etapas das operações e avaliar a incorporação total para cada trabalhador em um ciclo completo de operações [22 - 23].

Quanto à função relacionada com a tarefa, a técnica mais comum é fazer uso de amostradores com equipamento de detecção contínuo pois fornece um aviso nas variações súbitas dos níveis de concentração. Os monitores de ar contínuos devem ser localizados onde poderão detectar, confiavelmente, uma liberação de material radioativo. Eles são necessários em reatores de pesquisa, em locais aonde são manuseados plutônio e elementos transurânicos dentro de caixas com luvas e onde há grandes liberações de material radioativo [22 - 23].

A interpretação dos resultados das medidas provenientes da amostragem do ar, em termos de incorporação, não é simples e pode produzir erros. Os resultados podem representar adequadamente a incorporação em um ciclo completo de operações, em uma amostragem representativa. Quando se busca a determinação quantitativa da incorporação, são usados amostradores de área por meio de um programa de monitoramento interventor que frequentemente envolve amostradores de ar individuais e determinados fatores de conversão. 
O monitoramento interventor que pode ser temporariamente empregado em caso de situações normais de trabalho para verificar a adequacidade dos programas de monitoramento de rotina e validar ou melhorar os modelos envolvidos na interpretação dos dados do monitoramento. Por exemplo, uma melhor interpretação dos resultados do monitoramento do ar pode apontar ou não a necessidade de monitoramento de rotina individual para contaminação interna. Para a avaliação da incorporação para resultados singulares de amostras que duram um único turno ou menos, recomenda-se estabelecer um nível de investigação pequeno o suficiente para detectar desvios significativos e grande o bastante para não ser constantemente ultrapassado.

Uma vez que a publicação [23] contempla, porém não especifica a obrigatoriedade de auditoria do monitoramento, foi empreendido neste trabalho de pesquisa o levantamento dos pontos a serem auditados no monitoramento para a contaminação do ar. De acordo com o nosso entendimento, a função auditora implica comprovar se os trabalhadores executaram corretamente suas funções, no que tange à proteção radiológica, a saber: o correto funcionamento dos monitores, se os registros da leitura do monitor são realizados de forma adequada, se os procedimentos obedecem às leituras diárias previstas e a verificação da frequência da execução das tarefas de acordo com o cronograma de leitura estabelecido. Mais especificamente, a auditoria deve contemplar o monitoramento de alerta para detectar desvios; localização dos amostradores de ar contínuos (se foram deslocados para outro lugar e, nesse caso, suas justificativas); e verificar se os monitores de ar individuais estão sendo utilizados de acordo com o procedimento. Além disso a função auditora envolve a verificação da amostragem de área para detectar desvios. A amostragem de área é útil para se obter dados sobre a tendência dos valores de contaminação do ar. Por isso a auditoria da amostragem de área envolve duas etapas:

- verificar o perfeito estado de funcionamento dos equipamentos, a saber: os amostradores de área estáticos e/ou equipamento(s) de monitores de alerta;

- atestar que o número e localização dos amostradores está em conformidade com as recomendações da proteção radiológica, pois devem contemplar o significado global da contaminação e seu grau de variação.

As auditorias programadas, bem como as auditorias incertas, contemplam a verificação da calibração, localização e correto uso dos equipamentos. É necessário auditar nos casos em que se fazem necessários os detectores portáteis se são utilizados pelos trabalhadores. Quanto aos detectores posicionados no nível da respiração, é necessário auditar seu correto posicionamento no local de trabalho, se estão calibrados e se os resultados se mantém. A calibração dos instrumentos pode ser efetuada com auxílio de uma pequena fonte padrão para conferência de resultados das medidas obtidas. As auditorias sistemáticas permitem detectar e sanar falhas em relação aos alarmes e avisos, que devem estar sempre em conformidade com as orientações da proteção radiológica e em bom funcionamento. No mais, o monitoramento para a contaminação do ar com função auditora tem ainda por tarefa a verificação da uniformidade dos resultados dos registros. 


\subsubsection{Monitoramento individual para radiação externa}

O desenvolvimento deste subcapítulo foi baseado na publicação 75 da CIPR [23], que descreve a função do monitoramento relacionado com a tarefa, bem como o monitoramento de rotina que, segundo a publicação, deve envolver as funções de estimar e avaliar as doses, assim como a função de auditar o monitoramento relacionado com a tarefa.

É importante que as instalações tenham claros que os principais objetivos de um programa de monitoramento individual para a radiação externa são: (i) obter uma avaliação da dose ef etiva e, onde for adequada, a dose equivalente em tecidos apreciavelmente expostos, de modo que demonstre concordância com as exigências gerenciais e regulatórias; (ii) contribuir para o controle de operações e para o projeto da instalação; e (iii) no caso de sobrexposição em acidentes, fornecer informação valiosa para o inicio e auxilio de qualquer acompanhamento médico e tratamento de saúde apropriado.

Isso posto, pode-se discutir as principais questões que envolvem o monitoramento de rotina para radiação externa. Cabe ao gerente operacional a escolha dos trabalhadores que devem ser individualmente monitorados para a radiação externa, mas deve também ser examinada pelo órgão regulatório. $\mathrm{Na}$ escolha dos trabalhadores que necessitam de monitoramento individual para radiação externa devem ser considerados os seguintes fatores: o valor da dose com relação ao limites pertinentes, a probabilidade de variações nas doses e a complexidade das medidas nos procedimentos de interpretação envolvidos no programa de monitoramento.

Deverão ser monitorados individualmente os indivíduos laboralmente expostos, $\mathrm{ILE}^{4}$, desde que suas doses não possam ser determinadas de outro modo como no caso das tripulações dos voos aéreos. Devem ser dispensados os ILE que recebem doses "consistentemente pequenas" e aqueles cujas doses não excedam um valor identificado como no caso da tripulação de voos aéreos. Não devem ser monitorados, também, todos os indivíduos que recebem doses inferiores ao limite do público. Para os indivíduos que necessitam de um monitoramento individual para a radiação externa, a CIPR sugere um valor selecionado entre 5 e $10 \mathrm{mSva}^{-1}$. Acima deste valor, o monitoramento individual tornar-se-ia necessário.

A quantidade e o tipo de dosímetro individual a ser usado para a radiação ionizante externa é definida pela complexidade e heterogeneidade do campo de radiação. Por exemplo, nos campos de radiação envolvendo tanto radiação penetrante como pouco penetrante, como radiação gama e beta, deve ser usado um dosímetro com dois componentes. Em campos de radiação complexos e heterogêneos frequentemente torna-se necessário mais de um dosímetro. Em operações envolvendo manipulações muito próximas das fontes de radiação pode ser necessário o uso de um dosímetro tipo anel.

Entretanto, o monitoramento individual para exposição externa a nêutrons apresenta alguns problemas. Os limites de deteç̧ão dos monitores individuais para nêutrons geralmente são maiores do que aqueles para monitores individuais para gama. Frequentemente, os nêutrons contribuem unicamente com uma pequena fração da dose de radiação externa total causada pela exposição laboral. Nesses casos, a CIPR propõe que a avaliação da dose, usando o

\footnotetext{
${ }^{4}$ A CNEN utiliza o termo Indivíduo Ocupacionalmente Exposto (IOE).
} 
monitoramento individual de exposição a nêutrons, só seja necessária em áreas controladas onde as exposições a nêutrons provavelmente seriam uma contribuinte significativa para a dose efetiva.

Os dosímetros individuais para a radiação externa devem fornecer a dose acumulada durante o período de tempo em que o individuo está trabalhando excluindo a dose acumulada pelo dosímetro fora do serviço. As técnicas utilizadas com esta finalidade devem constar no projeto de registro do programa de monitoramento.

A função relacionada à tarefa pode se dar no caso em que possam ocorrer acidentes envolvendo Radiação Externa e, nesses casos, a avaliação da dose equivalente e efetiva para a radiação ionizante externa no monitoramento individual com função relacionada à tarefa, deve levar em consideração as recomendações que se seguem. Para acidentes de pequenas proporções ela é coberta pelo programa de monitoramento de rotina. Para acidentes com exposições elevadas em circunstâncias não intencionais deve-se incluir no programa de monitoramento uma providencia para estimar estas doses elevadas no programa rotineiro. Para acidentes com exposições elevadas ou em circunstancias deliberadas devem ser especificados mais dosímetros para as tarefas que os exigirem. Também, devem ser considerados dosímetros de leitura direta e instrumentos de taxa de dose individuais, algumas vezes com aviso sonoro.

Assim, como nos outros tipos de monitoramento, a publicação 75 da CIPR [23] não discute separadamente a função auditora do monitoramento. Por esta razão, a partir das recomendações fornecidas, este trabalho de pesquisa desenvolve e expande as discussões contemplando e aprofundando as possibilidades de um monitoramento auditor. A função auditora para monitoramento individual para radiação externa contempla ambas as funções, a saber: função de rotina e função relacionada com a tarefa. No monitoramento de rotina, devese auditar se o dosímetro é utilizado de acordo com o estabelecido pela Proteção Radiológica. Já no monitoramento relacionado com a tarefa, deve ser verificado o correto uso dos dosímetros de aviso, como por exemplo o dosímetro tipo caneta. Considerando uma situação normal de trabalho, na qual os campos são variáveis, devem ser auditados o correto funcionamento e a correta utilização dos dosímetros de aviso pessoais: o BIP, que aumenta a sonoridade e outro que integra a dose, e a caneta, que fornece leitura direta ou indireta (nesse último caso, é necessário verificar também o leitor).

A auditoria dos registros permite o acompanhamento das doses laborais e pode auxiliar a tomada de decisões. Considerando a importância dos registros de medição e detecção da radiação, a primeira ação a ser empreendida em um monitoramento auditor é a verificação dos registros e o cumprimento das exigências normativas, como:

- Verificação e comparação do registro de doses acumuladas no período de 12 meses;

- Verificação do registro do monitoramento da taxa de exposição;

- Verificação do registro de ocorrências radiológicas;

- Verificação das datas de encaminhamento para calibração do monitor de taxa de exposição.

- Comparação dos valores de doses individuais em relação às condições de radioproteção, à carga de trabalho e a natureza da manipulação dos radionuclídeos em questão. 
A verificação do correto uso dos dosímetros pode ser realizada por meio de medições conjuntas com equipamentos distintos, para verificação de resultados conflitantes, que podem indicar o mau funcionamento ou a discrepância de valores quando comparados com as doses registradas. Nesse caso, além da verificação dos registros de encaminhamentos dos monitores para a calibração, a auditoria inclui a verificação das baterias dos monitores individuais e se a medição está correta fazendo-se uso de uma pequena fonte padrão.

Casos de discrepâncias entre os registros e os resultados esperados, quando os equipamentos demonstram perfeito funcionamento, podem indicar possíveis variações nos campos de radiação. Nesse caso é preciso comunicar ao serviço de proteção radiológica para verificação das possíveis causas, tais como insuficiência no sistema de blindagem ou falhas nos procedimentos de manuseio dos radioisótopos no laboratório.

A frequência do monitoramento auditor para verificação individual da radiação externa pode ser estabelecida de acordo com o plano de trabalho de cada instalação. Em se tratando de locais de trabalho nos quais não há variações significativas nos campos de radiação, a auditoria programada poderia ser estabelecida, por exemplo, a cada cinco monitoramentos periódicos realizados pelo trabalhador.

Ainda, monitoramentos auditores não programados são aconselháveis para reforçar a importância das boas práticas cotidianas e se as exigências regulatórias são cumpridas a contento. Nesse caso, as visitas não programadas podem ainda contemplar:

- se são informadas ao serviço de proteção radiológica as doses registradas nos dosímetros individuais;

- o cumprimento em relação às permissões de acesso às áreas restritas, de acordo com as características de cada instalação. Estas áreas podem ser, por exemplo: sala de rejeitos e sala quente, nas quais têm permissão de entrada apenas funcionários diretamente envolvidos com a tarefa e pessoas autorizadas pela radioproteção;

- que os funcionários portam dosímetros individuais e que o utilizam de maneira correta, bem como auditar o correto armazenamento dos dosímetros após o uso, ou seja, se o seu armazenamento é efetuado em local apropriado, em área livre e protegido contra a umidade, para assegurar a veracidade dos resultados registrados.

\subsubsection{Monitoramento individual para exposição interna}

O monitoramento individual para exposição interna com função de rotina é realizado por medidas indiretas pela coleta e analise de amostras de excretas ou por medidas diretas da radiação emitida pelos radionuclídeos contidos nos órgãos ou tecidos internos ao corpo. Além da atividade incorporada, para estimar a dose equivalente e efetiva no monitoramento individual para exposição interna com função de rotina, é necessário conhecer a sua distribuição no instante da incorporação e também os modelos dosimétricos e biológicos padronizados necessários para calcular os coeficientes associados com a incorporação para determinar a dose equivalente e efetiva [23].

O monitoramento com função de rotina deve ser efetuado somente para os trabalhadores que estão empregados em áreas que foram demarcadas como áreas controladas, especificamente 
em relação ao controle da contaminação e onde existem variações que resultam em incorporações apreciáveis. São exemplos de operações em que a experiência demonstrou que é necessário considerar o monitoramento dos trabalhadores com função de rotina, os casos de manuseio de grandes quantidades de gases e materiais voláteis, por exemplo, trítio e seus compostos em processos de produção em grande escala, em reatores de água pesada em consequência da produção de óxidos e em processos de luminescência como pinturas. Outros exemplos são o processamento de plutônio e outros elementos transurânicos; processamento de minérios de tório e seus compostos; mineração e beneficiamento de minério de urânio com teor elevado; processamento de urânio natural e levemente enriquecido e fabricação de combustível para reatores; produção de grandes quantidades de radionuclídeos; locais de trabalho com grandes teores de radônio que excedem os níveis de ação; manuseio de grandes quantidades de ${ }^{131} 1$ para terapia.

A necessidade de se introduzir um programa de monitoramento individual interno com função de rotina pode ser determinada pelos resultados do monitoramento do local de trabalho para contaminação de superfície e do ar, pela experiência anterior em operações similares, pelo uso dos critérios específicos ou pela introdução de um programa de monitoramento individual interventor. Ele pode ser dispensado quando há condições de trabalho satisfatórias, confirmadas pelo monitoramento com função de rotina do local de trabalho.

De acordo com a CIPR, as situações que podem provocar uma contaminação interna dos trabalhadores são:

- Resultantes de eventos poucos frequentes, normalmente ao acaso.

- Variáveis, mas essencialmente contínuas, como resultado de operações normais.

- Descontínuas, mas com certa frequência, como resultado de pequenas situações anormais.

A distinção entre primeira e terceira está na frequência. Quando a frequência é próxima à mensal, coaduna-se com a terceira situação.

Para se avaliar a necessidade de um monitoramento para a contaminação interna com função de rotina para a radiação ionizante podem-se utilizar os resultados do monitoramento do ar.

Só se considera a possibilidade do monitoramento individual com doses superiores a 1/10 do LAMA e os resultados anteriores do trabalhador podem possibilitar esta avaliação. Em caso de duvida há a necessidade de se efetuar uma revisão geral das operações executadas considerando o aspecto experiência. Se a revisão confirmar que há possibilidade de incorporação acima de $1 / 10$ do LAMA é pequena, não será necessário um monitoramento individual de rotina, mas poderá ser necessário um programa de monitoramento individual interventor após a detecção da contaminação. Esta deteç̧ão da contaminação pode ser realizada pelo monitoramento do local de trabalho ou pela própria situação operacional [23].

A principal informação para se estabelecer a necessidade de um monitoramento individual para a exposição interna com função de rotina advêm dos resultados do monitoramento de ar realizado nas zonas de respiração dos trabalhadores. Se as incorporações individuais estiverem distribuídas em torno de um valor médio e o programa de monitoramento do ar for bem 
projetado e interpretado é possível prever que a incorporação não será superior a 3 vezes o valor médio estimado para o grupo. Neste caso se os resultados médios anuais para o monitoramento do ar, na zona de respiração, forem menores do que $1 / 30$ do LAMA, o monitoramento individual interno não será necessário [23].

Os resultados do monitoramento do ar, geralmente, são obtidos na corrente de ar e não nas zonas de respiração e neste caso, tipicamente, existe um fator de uma ordem de grandeza entre as medidas na corrente de ar e aquelas efetuadas próximas a zona de respiração. Em virtude disto se o resultado médio anual do monitoramento do ar for menor do que 1/100 do LAMA as incorporações dos trabalhadores não excederão os $1 / 10$ do LAMA e não será necessário o monitoramento individual interno com função de rotina [23].

Para a interpretação dos resultados, é necessário que o modelo metabólico que relaciona o resultado da medida à grandeza física deva ser compatível com o modelo metabólico utilizado para a grandeza física que define o limite ou nível de referência. Deve ainda possibilitar a interpretação dos resultados, fornecendo informações sobre taxa de excreção e quantidade de radionuclídeos depositados nos órgãos ou tecidos. Para avaliar a incorporação média a longo prazo, o monitoramento deve ser conduzido em intervalos de períodos selecionados e devem ser definidos níveis de investigação para a dose efetiva, como $6 \mathrm{mSva}^{-1} / \mathrm{n}$, sendo n o número de períodos de amostragem. Via de regra, o nível de investigação é o nível de registro, quando adotado o valor de $5 \mathrm{mSva}^{-1}$ como recomenda a CIPR.

Em se tratando do monitoramento individual para exposição interna, as medidas só podem ser obtidas in vivo por coletas de amostras biológicas ou in vitro por medidas de corpo inteiro ou parciais, dos órgãos de deposição [48].

Todos os dados são obtidos durante o monitoramento de rotina efetuado pela Proteção Radiológica. Para esse tipo de monitoramento não cabe a função relacionada com a tarefa e não caberia uma função auditora.

\subsubsection{Monitoramento para a contaminação de pele e roupa}

A contaminação da pele e da roupa pela radiação ionizante refere-se à irradiação externa e irradiação interna, se for absorvida abaixo da camada superficial da pele. É muito difícil determinar o valor das doses externas e internas provocadas pela contaminação da pele pelo fato das contaminações não serem uniformes e de ocorrem em certas partes do corpo, principalmente nas mãos. Para se sobrepor às dificuldades apresentadas na determinação das doses externas e internas ao corpo humano provocadas pela contaminação da pele e roupa, pode-se estabelecer níveis de ação ou investigação, isto é, níveis de referência ou autorizados de contaminação inferiores ao nível de registro pois neste caso não é necessário determinar doses equivalentes ou efetivas, mas unicamente efetuar a descontaminação [23].

É importante atentar ao fato de que as publicações diferem quanto ao valor recomendado para o nível de investigação para as doses individuais. O Organismo Internacional de Energia Atômica $[2,38]$ recomenda o valor de $6 \mathrm{mSva}^{-1}$, isto é, $3 / 10$ do LAMAM (Limite Anual Máximo Admissível Médio). Já o valor do nível de investigação sugerido pela Comissão Internacional de Proteção Radiológica [3] é de 1/10 do LAMA. De acordo com as recomendações internacionais, a medida 
deve ser efetuada em uma superfície de $100 \mathrm{~cm}^{2}$ para a pele e roupa, exceção feita às mãos cuja superfície deve ser de $300 \mathrm{~cm}^{2}$, ou seja, uma mão completa frente e verso.

Os principais objetivos de um monitoramento para a contaminação da pele e roupa [23] pela radiação ionizante são: demonstrar concordância com os limites pertinentes; detectar a contaminação que poderia ser transferida para fora de uma área controlada, pelo indivíduo; e no caso de sobre exposição, fornecer informação valiosa para o início e auxílio de qualquer acompanhamento médico e tratamento de saúde apropriado.

Novamente, não são discutidas ou detalhadas nas publicações as diretrizes para um trabalho auditor, trabalho esse empreendido nesta tese. Este tipo de monitoramento envolve o estudo de algumas particularidades. A determinação das doses resultantes das irradiações externa e interna é muito difícil de ser conseguida. Não há monitoramento de rotina. Em caso de confirmação da contaminação, o trabalhador deve avisar a proteção radiológica. Em caso de contaminação, serão feitas investigações posteriores para avaliar as causas. Os trabalhadores são treinados e têm o equipamento à sua disposição. Ainda assim, um programa de monitoramento auditor pode detectar falhas sistemáticas de procedimentos de manipulação, como: contaminação das mãos ao retirar as luvas, tocar em objetos e utensílios do laboratório com as luvas ou sair do laboratório para as áreas livres sem o devido monitoramento. A frequência do monitoramento com função auditora depende do tipo de atividade realizada na instalação, natureza do radionuclídeo trabalhado e número de atividades semanais previstas. É nossa sugestão que esse monitoramento seja executado juntamente com o monitoramento auditor para contaminação de superfície, uma vez que os equipamentos móveis de bancada são os mesmos utilizados para o monitoramento de pele e roupa e de superfície. Isso permitiria otimizar o trabalho de auditoria em relação à verificação dos instrumentos. Entretanto, além do equipamento móvel de bancada para a contaminação de superfície, devem ser auditados, quando for o caso, os equipamentos utilizados no monitoramento relacionado com a tarefa para a contaminação de pele e roupa, a saber:

- Monitor de pés, mãos e roupa - geralmente fixo e localizado em locais estratégicos.

- Portais - com a finalidade de detectar contaminações que escapam à precepção do trabalhador, evitando assim que sejam transferidas para outras áreas.

A auditoria programada permite verificar o bom funcionamento dos equipamentos: se o trabalhador segue os procedimentos corretamente e se os equipamentos se encontram nos lugares determinados, isto é, se não foram transferidos. Os equipamentos fixos podem ser checados fazendo-se uso de uma pequena fonte padrão que pode corroborar a veracidade das medidas obtidas. Há que se verificar igualmente os resultados gerados pelos portais e monitores fixos de pés, mão e roupa, comparando-os com (i) os resultados anteriores e (ii) com os resultados esperados. Quando há variações significativas nos registros, em relação a qualquer das duas situações, há que se verificar os relatórios de encaminhamento, registros ou contatos com o serviço de proteção radiológica seja para comunicar alterações inesperadas, sejam elas muito superiores ou muito inferiores daquelas esperadas.

Quanto aos equipamentos móveis, podem ser efetuadas medições conjuntas de forma a comparar resultados simultâneos, no intuito de verificar se os mesmos encontram-se devidamente calibrados. 
O monitoramento envolve ainda a conferência dos registros: quanto à periodicidade, valores assentados e comparação com registros anteriores, bem como a análise comparativa dos registros com a observância da prática cotidiana, que pode auxiliar a elucidar doses acima das previstas e contaminações não justificadas. Conforme supramencionado, um dos grandes problemas nas instalações é a transferência de materiais radioativos e uma auditoria incerta inibiria a não observância dos procedimentos de segurança. A auditoria não programada pode ou não coincidir com aquela do monitoramento para contaminação de superfície. Além da análise dos relatórios e conferência de medidas, visitas não programadas permitem auditar o ambiente de trabalho, no que concerne à contaminação de pele e roupa, como:

- Averiguar a existência bolsas, canetas, celulares, agasalhos ou qualquer material estranho à bancada de laboratório, bem como a presença de utensílios de alimentação ou cosméticos nas áreas de trabalho e armazenamento de materiais radioativos;

- Verificar o correto uso dos EPI, por exemplo, se são utilizados aventais com mangas longas e corretamente armazenados na sala de manipulação após o uso. Outro exemplo é o apropriado uso e descarte de máscaras e luvas após o uso. Torneiras, trincos ou interruptores não devem ser manuseados com luvas, a fim de não acarretar contaminações desnecessária. E após usadas, as luvas devem ser tiradas seguindo um correto procedimento, para evitar a contaminação das mãos do trabalhador ou dos locais próximos à área de trabalho.

- Identificar possíveis ações inadequadas quanto ao procedimento para descarte de rejeitos.

- Efetuar o monitoramento dos EPI quando não estão em uso ou quando foram descartados.

\subsubsection{Monitoramento interventor}

A finalidade de um monitoramento interventor em trabalhos envolvendo a radiação ionizante é proporcionar uma informação detalhada que elucide os problemas para a obtenção de um controle adequado. São características do monitoramento interventor objetivos bem definidos e duração limitada no tempo. Para situações anormais de trabalho, ao término do monitoramento interventor retorna-se à situação normal. Para situações normais de trabalho o monitoramento interventor termina a favor de um monitoramento de rotina, monitoramento relacionado com a tarefa ou a não necessidade de monitoramento [23].

Deve-se levar em consideração que em situações normais de trabalho o monitoramento interventor pode ser necessário no inicio da colocação em funcionamento de uma instalação; logo após alterações consideráveis realizadas nas instalações ou em procedimentos operacionais; para verificar a adequacidade dos programas de monitoramento de rotina; para validar ou melhorar os modelos envolvidos na interpretação dos dados do monitoramento. Igualmente, o monitoramento interventor pode se tornar necessário em situações anormais de trabalho, como por exemplo, logo após a observação de um resultado inesperado, como um nível de investigação ou de ação que foi excedido. Ainda, ele pode se fazer necessário em casos de acidentes, para vários propósitos, como: definir as áreas afetadas ou reconstruir as circunstâncias de um evento de modo a chegar a uma melhor estimativa de dose. Para um monitoramento interventor, devem constar nos planos de emergência radiológico (PER): os 
objetivos, peculiares às circunstâncias específicas; a quantidade de instrumentos necessários; a disponibilidade dos instrumentos durante um tempo adequado e a adequacidade dos instrumentos para os tipos, a qualidade e a intensidade dos campos de radiação que provavelmente serão encontrados $[1 ; 23]$.

Para casos de exposição externa com possibilidade de doses superiores ao limites são necessárias avaliações precisas e confiáveis da exposição. Os instrumentos dosimétricos de rotina nem sempre tem capacidade de fornecer estas informações. É justificável fornecer aos trabalhadores dosímetros especiais que fornecem informações confiáveis sobre a dose absorvida acima de cerca de $1 \mathrm{~Gy}$. Em campos de nêutrons, medidas simples da atividade induzida no corpo dos trabalhadores expostos, ${ }^{24} \mathrm{Na} \mathrm{e}^{38} \mathrm{Cl}$ podem fornecer informações úteis. Nos casos de exposição interna, torna-se necessário um monitoramento interventor quando os resultados do monitoramento do local de trabalho indicam que podem ter ocorrido incorporações apreciáveis ou quando os trabalhadores forem envolvidos em incidentes com incorporações apreciáveis de material radioativo. Testes simples de verificação da necessidade do monitoramento interno interventor podem ser realizados por medidas de contaminação na pele, na roupa e no muco nasal. Há dois métodos de medida, no monitoramento das exposições internas provocadas pela radiação ionizante, com função interventora. In vivo, pela avaliação dos radionuclídeos presentes no corpo ou nos tecidos por medidas externas, e in vitro, por meio da análise de excretas ou amostras de fluídos do corpo. Os métodos de interpretação são, basicamente, iguais àqueles do monitoramento com função de rotina [23].

Levando-se em consideração que a função interventora do monitoramento implica ações corretivas e temporárias, acreditamos que a função auditora no monitoramento interventor envolve definir o objetivo e a frequência mínima aceitável da auditoria para cada tipo de monitoramento. Quando se justifica fornecer dosímetros especiais aos trabalhadores, devem ser auditados o correto funcionamento dos dosímetros e se estão sendo obedecidos os procedimentos de quando e como devem ser usados. Em caso de irradiações frequentes, devem ser auditadas as funções relacionadas com a tarefa para o referido caso e se os dosímetros estão sendo utilizados corretamente, isto é, se o trabalhador segue os procedimentos de uso.

Quando o monitoramento interventor refere-se a uma situação de acidente e, portanto, deve constar no PER, a auditoria deve ser realizada antes de qualquer exercício de emergência ou, ao menos, uma vez ao ano. Nesse caso deve-se testar se os dosímetros estão à disposição e em perfeito funcionamento no instante que é exigido seu uso e testar a eficácia dos planos de emergência. Poder-se-ia citar como exemplo o teste de todos os sistemas de comunicação. 


\subsection{Manutenção dos assentamentos}

Os assentamentos dos programas de monitoramento da radiação ionizante devem incluir detalhes do programa, dos métodos de medida e de sua interpretação, dos resultados do monitoramento do local de trabalho e dos resultados do monitoramento individual. Os assentamentos devem estar disponíveis à gerência operacional, aos consultores de proteção radiológica e consultores médicos, ao órgão regulador, a pedido, ainda que isso não seja uma exigência reguladora e ao trabalhador a respeito de seu próprio monitoramento, a pedido. Também podem estar disponíveis para grupos de trabalhadores, desde que a gerência consulte a sua mão de obra, com a finalidade de encorajar um interesse no desempenho de suas proteções [23; 38].

Ocorre que programas de monitoramento da radiação ionizante têm potencial para gerar enormes quantidades de dados. $O$ interesse é mantê-los sob exame minucioso com a finalidade de eliminar as medidas desnecessárias do programa de monitoramento. Os dados (com as suas grandezas e unidades pertinentes claramente expressadas) devem ser apresentados ao gerente numa forma que facilite o reconhecimento de uma deterioração apreciável nas condições. Desta maneira, a quantidade a ser assentada pode ser reduzida pelo uso de um nível de registro. As doses individuais relacionadas com a tarefa devem ser incluídas nos assentamentos individuais mas não em substituição aos resultados da função de rotina durante o período de execução da tarefa. Em relação à manutenção dos registros dos monitoramentos, segundo os padrões de proteção radiológica preconizados na publicação 60 da CIPR, parágrafo 277:

"Deve ser atingido um balanço entre a complexidade de dados de entradas iniciais, que podem comprometer a acurácia e a completeza e o possível uso futuro dos registros. A validade da maioria dos registros diminui com o passar do tempo, quanto a possibilidade de se tornarem necessários. Como orientação geral e sujeito a exigências regulamentares, os registros que fornecem os resultados das avaliações das doses individuais devem ser mantido por períodos comparáveis com a sobrevivência esperada para os indivíduos". [38]

O gerente, considerando a necessidade de se demonstrar a concordância com a sua própria filosofia e com as exigências regulamentares, decide quais são os dados que devem ser conservados nos assentamentos. Deve ser evitada a necessidade de se preservar todos os resultados do monitoramento durante muitos anos. Os seus resultados junto com os dados dosimétricos referentes à função relacionada a tarefa devem ser mantidos de forma que possam ser disponibilizados prontamente quando for exigida uma reavaliação de sua interpretação.

Para propósitos de proteção radiológica, não deve ser necessária a retenção daqueles dados de monitoramento obtidos somente para gerenciamento rotineiro das operações, por mais do que alguns anos [23].

O trabalho de pesquisa empreendido nesta tese quanto à função auditora para manutenção dos assentamentos, no que tange às funções relacionadas com a tarefa, compreende a necessidade de verificação do assentamento das doses individuais de acordo com o procedimento, uma vez que nem todas as doses precisam ser assentadas. A frequência é específica a cada situação, por isso, para estabelecê-la é necessário conhecer: os valores das doses e a atividade da fonte em 
questão. A auditoria deve proceder de acordo com o que está escrito no manual de procedimento, conforme a atividade realizada. Além do conhecimento das doses, da atividade e dos procedimentos, a eficácia da auditoria para a manutenção dos assentamentos implica ainda na experiência e no bom senso do analisador. De qualquer maneira, acreditamos que não se justifica a manutenção dos resultados das auditorias após terem sido eliminados os resultados com função relacionada com a tarefa, aos quais a auditoria está diretamente relacionada.

\section{Exposições potenciais: recomendações e cenários envolvidos}

Exposição potencial é aquela que não é pretendida, mas para a qual existe um potencial de ocorrência, ainda que não seja certa a sua realização. Embora possa ser prevista e a sua probabilidade de ocorrência estimada, não pode ser prognosticada em detalhes. Apesar de algumas publicações da CIPR recomendarem $[21 ; 39]$ que a exposição potencial deve ser tratada juntamente com a normal, em sua publicação 76 a CIPR assume que em grande parte das situações isso não é possível, uma vez que a exposição normal toma por base os limites laborais, enquanto na exposição potencial devem ser consideradas as doses mais elevadas do cenário. Embora a publicação 76 reconheça que esses dois temas deveriam ser tratados separadamente, não fornece recomendações específicas [21].

Para planejar medidas de proteção ou ações de contenção, é preciso efetuar uma ampla análise das exposições potenciais, baseada na compreensão de possíveis cenários que possam representar sequências de eventos passíveis de desencadear as exposições, na estimativa da probabilidade de ocorrência dessas sequências, na estimativa das doses envolvidas e na otimização da proteção. A publicação 64 da CIPR [39], retomando as considerações da publicação 60 , reforça que os princípios básicos da radioproteção devem ser igualmente aplicados em casos de intervenções e de introdução de novas fontes, tanto para as estimativas de exposição normal quanto potencial. Isso porque grupos de indivíduos podem estar expostos a várias outras fontes simultaneamente. A publicação 64 amplia o cálculo de detrimento, acrescentando a este o fator probabilidade, uma vez que pequenas probabilidades podem gerar grandes consequências e o limite de risco individual global pode ser grande, ocasionando efeitos determinísticos. A publicação reconhece que é difícil generalizar limites ou restrições, entretanto, recomenda traçar tipos de restrições passíveis de serem dimensionados com base na experiência. O exemplo utilizado na publicação 64 da CIPR é a representação das probabilidades anuais de sequência de eventos conforme critério de riscos especificados pela Comissão para deposição de rejeito sólido, conforme descrito na TABELA 1.

Tabela 1 - Critérios de riscos: intervalo de probabilidades

\begin{tabular}{l|c}
\hline Sequência de eventos que levam a doses tratadas como parte de exposições normais & $10^{-1}$ a $10^{-2}$ \\
\hline Sequência de eventos que levam a efeitos estocásticos acima dos limites de dose & $10^{-2}$ a $10^{-5}$ \\
\hline Sequência de eventos que levam a alguns efeitos determinísticos & $10^{-5}$ a $10^{-6}$ \\
\hline Sequência de eventos que levam a doses nas quais existe probabilidade de morte & $<10^{-6}$ \\
\hline
\end{tabular}


De acordo com a publicação 64 da CIPR, o valor principal da análise de segurança é a identificação das sequências de eventos mais prováveis para possíveis implementações de melhorias na segurança. Há que se calcular as probabilidades individualmente e traçar combinações entre os possíveis cenários. Devem ser levadas em consideração as avaliações relativas às fontes, que podem desencadear diversos cenários, e a avaliação relativa ao indivíduo, que pode estar exposto aos riscos provenientes de várias fontes. Desta forma, outro ponto a ser analisado são as sequências e processos nos caminhos críticos das fontes, que podem ser comuns a várias fontes. Como em grande parte das vezes não é possível a avaliação relativa aos indivíduos, os cenários da avaliação relativa à fonte devem considerar igualmente o número de indivíduos expostos e a magnitude dos riscos envolvidos. Os princípios técnicos gerenciais envolvem: defesa-em-profundidade conforme a complexidade da fonte, projeto da instalação, garantia da qualidade, otimização da segurança, treinamento e qualificação dos indivíduos laboralmente expostos (ILE) e avaliação da segurança [39].

Assim sendo, trazemos primeiramente algumas recomendações sobre a avaliação, o planejamento e a construção do processo de otimização, no que tange a avaliação e a análise das tarefas específicas da distribuição da exposição à radiação ionizante nas atividades humanas. Exposições não pretendidas podem atingir tanto os trabalhadores como os indivíduos do público. A publicação 76 da CIPR [21] enfatiza que a cada cenário e exposição são atribuídas probabilidades de acordo com as possibilidades da exposição potencial, a saber:

1. Probabilidade de afetar indivíduos do público além dos ILE (como por exemplo entrada potencial insegura numa sala de irradiação);

2. Afetar grande número de pessoas e detrimentos além da saúde (como por exemplo inutilização de terrenos ou contaminação de alimentos);

3. Exposições que ocorrerão em futuro remoto e doses liberadas aos poucos ao longo de grande período de tempo (como por exemplo deposição de rejeito sólido em repositórios profundos).

Para fins de otimização da proteção radiológica, cada grupo da população afetado por uma fonte de radiação ionizante deve ser descrito por atributos de idade, sexo e hábitos, bem como por vários parâmetros de exposição, como doses individuais médias, mínimas e máximas, número de indivíduos expostos, dose coletiva e probabilidade de exposição potencial. Desta maneira, de acordo com a publicação 101 da CIPR [49], na construção do processo de otimização da proteção radiológica, deve-se dar atenção para evitar acidentes em qualquer exposição potencial, transferência de exposição entre os diferentes grupos e distribuição de exposições por longos períodos de tempo e para populações distantes.

Ainda de acordo com a publicação 101 da CIPR, a otimização da proteção para as situações de emergência deve ser realizada por ocasião do planejamento para identificar as opções de proteção e selecionar os valores apropriados das restrições de dose. Ela deve ser aplicada de maneira flexível para considerar as circunstâncias reais. A NN 3.01 da CNEN [1] recomenda que sejam considerados os acidentes de maior gravidade, os acidentes de maior probabilidade e todos os intermediários e com base nesses estudos, pode-se então proceder a montagem do plano de emergência radiológica (PER). Ainda quanto ao projeto inicial, a publicação 76 da CIPR atenta para o fato de que modificações do projeto inicial são passíveis de ser implementadas ao 
longo do tempo, no intuito de melhorar as condições de proteção. Estas devem ser consideradas quando da otimização da radioproteção. Entretanto, são passíveis também modificações realizadas em campo pelo operador, que podem ocasionar outros perigos que não os previstos em projeto. Estas, devem ser evitadas ou limitadas ao máximo. Todas as modificações implementadas devem assegurar o cuidado de não modificarem as condições em outras partes do projeto.

A publicação 76 da CIPR [21] introduz o critério de aceitabilidade dos limites de risco nas exposições potenciais. Se a probabilidade de efeitos maléficos for usada para determinar a aceitabilidade ou a conformidade, os limites e as restrições de dose devem ser suplementados por limites e restrições de risco, que consideram tanto a probabilidade da dose quanto os malefícios associados a esta dose.

Para a redução das doses potenciais e no sentido de limitar as probabilidades das doses de serem recebidas, a otimização deve considerar os fatores de probabilidade da exposição, a distribuição de riscos, as consequências totais no caso da exposição e os esforços de segurança [39]. A publicação 76 da CIPR reconhece que o processo de otimização pode variar do simples bom senso a procedimentos muito complexos; os custos advindos para proteção contra exposições potenciais pode ser elevado. A 76 recomenda a otimização tendo em vista situações normais e usar o risco como valor referência para avaliar consequências nas potenciais [21]. Em sua publicação 55 [20], a CIPR sugere a seguinte equação matemática para expressar o risco da exposição potencial para ser usada no processo da otimização da proteção radiológica:

$$
d R=P(D) d D P(E F F / D)
$$

onde

- $\mathrm{dR}$ representa o risco à saúde

- $P(D)$ é a densidade de probabilidade da ocorrência

- $P(D) d D$ é a probabilidade de início do evento que dá origem a uma dose entre $D$ e $D+d D$

- $P(E F F / D)$ é a probabilidade de ocorrer um efeito grave, resultante da dose $D$, no indivíduo ou descendente.

Quanto à probabilidade de ocorrer um efeito grave à saúde, na exposição potencial e a dose recebida pelo indivíduo, a CIPR [20] sugere as seguintes relações:

a. Uma relação proporcional (linear) na região estocástica até cerca de 1Sv.

b. Uma relação não proporcional para o intervalo em que podem ocorrer efeitos determinísticos, isto é, de 1-2 Sv até 5-10 Sv.

c. Probabilidade constante no intervalo de dose letal.

As recomendações desta publicação [20] apontam alguns problemas a serem considerados no processo de otimização para situações de exposição potencial. Na região determinística devese conhecer a distribuição de doses em detalhes para se poder avaliar o risco. Quando se puder atribuir probabilidades de ocorrência da situação potencial e calcular os seus impactos, deve-se considerar tanto a sua probabilidade como a sua consequência. $O$ detrimento que corresponde a uma dose coletiva não é um dado suficiente para o processo de otimização, principalmente 
quando a probabilidade é pequena e a consequência é grande. Deve-se dar importâncias diferentes aos valores esperados quando o intervalo de variação está próximo ao valor médio e quando o intervalo é muito grande com relação ao valor médio. Percebe-se que a apresentação das consequências torna-se complicada, uma vez que pode ter muitos pontos finais, incluindo efeitos agudos à saúde e interrupções, como aquela causada por evacuações das áreas.

Cada caso necessita uma análise de cenários realistas e completos, o que envolve estimativas de probabilidades e frequências das sequências passíveis de desencadearem exposições indevidas em cada caso, considerando falhas de equipamentos ou erros humanos. 0 planejamento da otimização e a correta implementação de todas as funções do monitoramento são determinantes para a redução das probabilidades de ocorrência.

Para planejar medidas de proteção ou ações de contenção, a publicação 76 da CIPR [21] sugere uma ampla análise baseada na compreensão de possíveis cenários que, realistas e completos, possam representar probabilidades e frequências das sequências passíveis de desencadearem exposições indevidas, considerando falhas de equipamentos ou erros humanos. A referida publicação em sua seção 2.4 quantifica ou referência bibliografia pertinente para que se possa mensurar a probabilidade de falhas em equipamentos eletrônicos, mecânicos e mesmo falhas relacionadas à construção civil.

Embora reconheça que é difícil quantificar a ocorrência de falhas humanas, a publicação considera fatores modeladores do desempenho (como treinamento, condições do local de trabalho e fatores de distração, dentre outros) e infere um valor de $10^{-3}$ a $10^{-2}$ para a sua ocorrência, a depender da complexidade da situação. Entretanto, as deficiências para quantificação encontram-se justamente na determinação das probabilidades de ocorrência no que tange à proteção radiológica. Considerando estes fatos, o presente trabalho de pesquisa sugere possíveis caminhos para mensurar as probabilidades de ocorrências radiológicas que poderiam levar às exposições potenciais. Para tanto, foram analisados, discutidos e quantificados os limites de risco por meio dos dados discutidos nas publicações vigentes, bem como pesquisas a outras abordagens que completam ou contrapõem as informações disponíveis nas publicações da CIPR. Fazendo uso das equações de Sordi [50], o sistema disponibiliza valores de dose máxima admissível pelos Limites de Risco relacionados à probabilidades anuais de ocorrência de risco, conforme demonstrado na TABELA 2.

Tabela 2 - Probabilidades anuais de ocorrência de risco

\begin{tabular}{l|l}
\hline Dose máxima admissível pelos Limites de Risco & Probabilidade do incidente \\
\hline $100 \mathrm{mSv}$ & $1,0 \times 10^{-2}$ \\
$110 \mathrm{mSv}$ & $1,5 \times 10^{-3}$ \\
$120 \mathrm{mSv}$ & $8,0 \times 10^{-4}$ \\
$150 \mathrm{mSv}$ & $2,6 \times 10^{-4}$ \\
$200 \mathrm{mSv}$ & $1,0 \times 10^{-4}$ \\
$500 \mathrm{mSv}$ & $1,0 \times 10^{-5}$ \\
$1000 \mathrm{mSv}$ & $2,5 \times 10^{-6}$ \\
$2000 \mathrm{mSv}$ & $1,0 \times 10^{-6}$ \\
\hline
\end{tabular}

Fonte: Sordi [50]

A partir do inter-relacionamento da TABELA 1 e TABELA 2, o autor fornece as equações para se determinar a dose máxima prevista que satisfaça os limites de risco, uma vez conhecida a 
probabilidade de uma ocorrência anormal. Uma vez em posse dessas informações, deu-se início ao trabalho de pesquisa para o desenvolvimento de cenários passíveis de fornecer caminhos para se determinar probabilidades de ocorrências anormais no que tange às fontes nas instalações radiativas. Os cenários aqui desenvolvidos são de caráter amplo e geral, de forma que possam ser estendidos e aplicados por similaridade para qualquer instalação radiativa, conforme sua situação específica. Para oferecer caminhos que auxiliem a quantificar as probabilidades das ocorrências radiológicas, sugerimos o desenvolvimento de árvores de falhas que podem evoluir para dois tipos distintos de cenários, nos quais podem se enquadrar todas as instalações radiativas.

O primeiro cenário refere-se a fontes conhecidas, como no caso dos aceleradores, cobaltoterapia ou fontes utilizadas para a esterilização de materiais cirúrgicos. Nesse caso, o direcionamento é sugerido em função do estudo das fontes, considerando seu tempo de vida, erros ocorridos, frequência de erros e tempo de funcionamento das fontes em relação aos maiores acidentes já relatados.

O segundo cenário apresenta casos relativos a uma pluralidade de fontes, não sendo possível predeterminar a quantidade de fontes ou seu tempo de uso, sendo essas informações particulares a cada instalação, como é o caso da gamagrafia. Nesse caso, sugerimos o estudo das probabilidades a partir do acidente de maior ocorrência, levando em consideração a evolução da tecnologia, lições aprendidas e erros ocorridos no passado não mais passíveis de ocorrer no futuro.

Para exemplificar o correto desenvolvimento árvores de falhas que proporcionem esses caminhos, discutiremos no capitulo 6 , a construção de árvores de falhas adequadas e eficazes, tomando por base os exemplos de exposição potencial da publicação 76 da CIPR [21], ampliando, discutindo e articulando cada cenário a partir da publicação 102 do OIEA [47], que traz as diretrizes para um programa de proteção radiológica adequado e eficaz, e do TECDOC 430 OIEA [51], que traz as recomendações, simbologias e procedimentos para o desenvolvimento da árvore porfiriana.

\section{Discussão e resultados do trabalho de pesquisa}

Acreditamos que esse trabalho de pesquisa e o detalhamento para a disseminação da informação em proteção radiológica auxilia sobremaneira as instalações. Com efeito, a análise semestral dos acessos ao programa UNIPRORAD, efetuadas entre 20/12/2013 e 19/06/2015 revelam o crescente aumento no número de acessos, conforme pode ser visualizado nos três períodos monitorados. A FIGURA 1 ilustra os dados estatísticos de acesso ao sistema entre 20/12/2013 e 19/06/2014. O relatório demonstra o acesso por parte de 130 usuários em 207 sessões e 1371 páginas visualizadas. O relatório demonstra ainda que $46 \%$ dos visitantes retornaram ao sistema. Os relatórios estatísticos do site foram obtidos por meio da ferramenta "Google Analytics", que permite comparações por meio de gráficos ou tabelas interativas, fornecendo informações sobre as principais métricas das visitas, como: número de visitantes, comportamentos frequentes, sistemas operacionais utilizados, navegadores, resolução de tela dos usuários e uso de tecnologias móveis, dentre outras. 


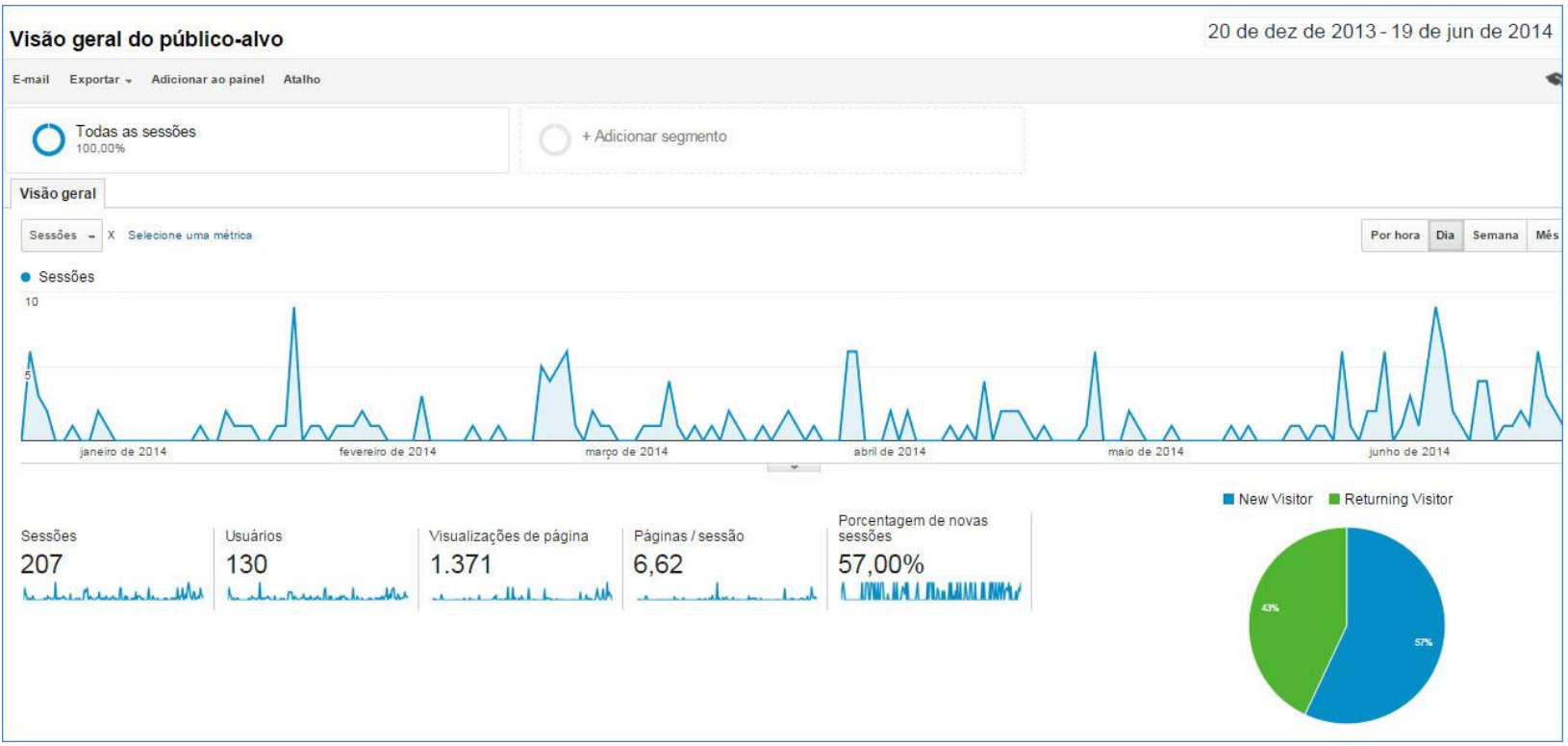

Figura 1 - Acessos ao sistema UNIPRORAD entre 20/12/13 e 19/06/14

No segundo período monitorado, o relatório revela um crescimento significativo nos acessos e visualização ao sistema, conforme demonstrado na FIGURA 2. Este segundo relatório demonstra que 583 sessões foram realizadas por 336 usuários, perfazendo um total de 6.177 páginas visitadas do sistema UNIPRORAD. A taxa de retorno ao sistema, estimada em $47 \%$, demonstra a fidelização dos usuários.

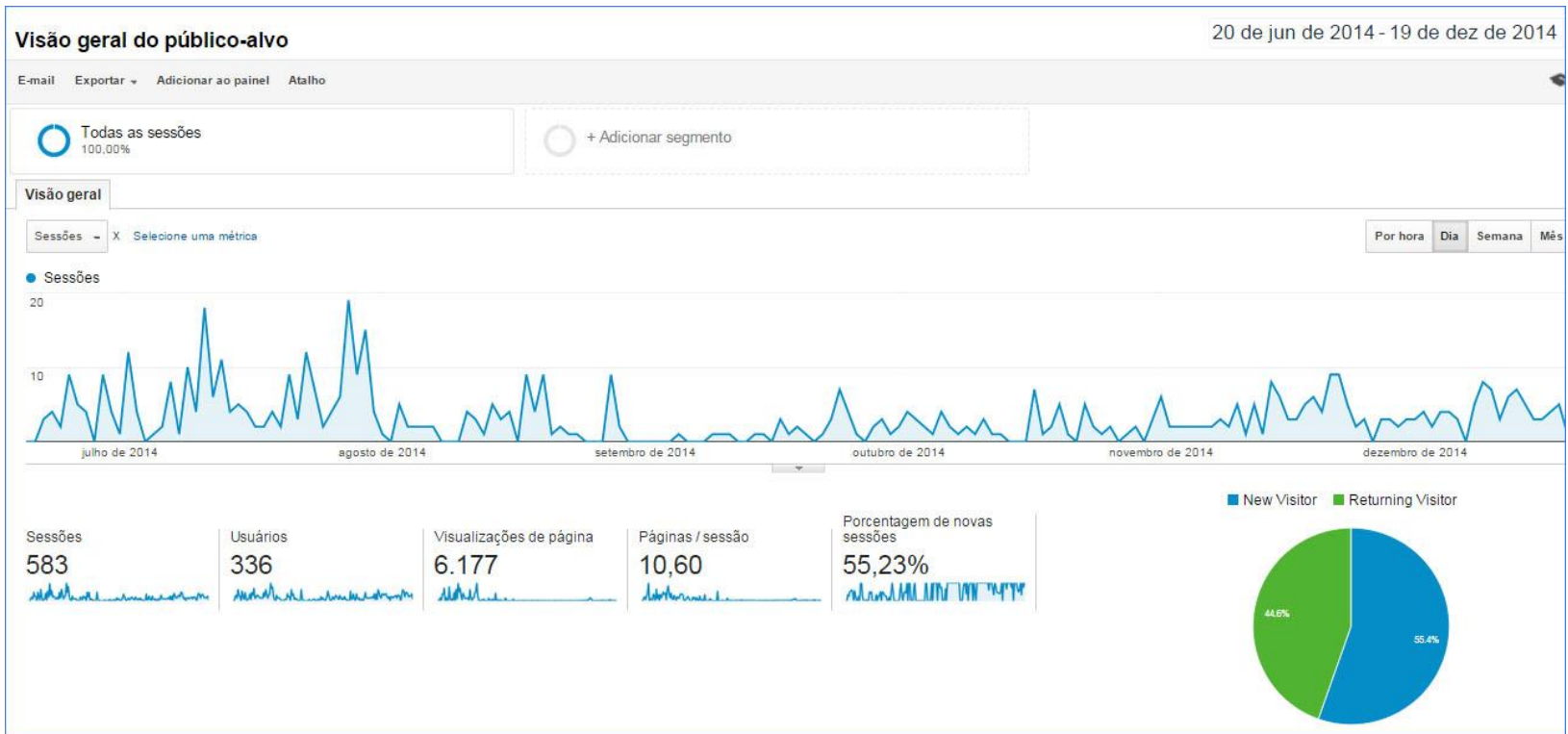

Figura 2 - Acessos ao sistema UNIPRORAD entre 20/07/14 e 19/12/15

O mais recente relatório de acesso ao sistema é apresentado na FIGURA 3. Comparando os dados estatísticos com aqueles trazidos na FIGURA 1, podemos observar um crescimento de $632 \%$ em relação ao mesmo período em relação ao número de visitantes. Os dados estatísticos sugerem uma taxa de $81 \%$ de novos visitantes durante o semestre monitorado. 


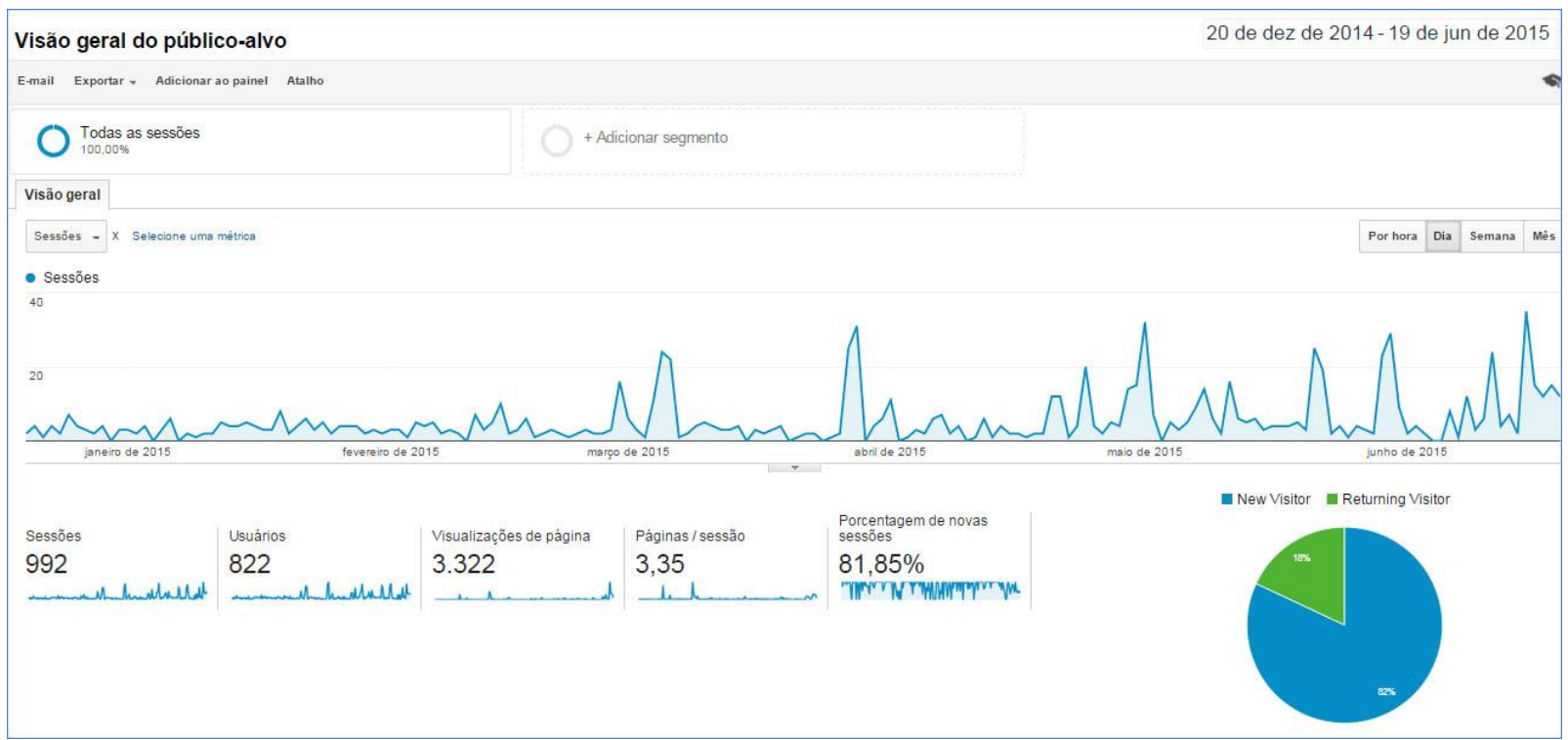

Figura 3 - Acessos ao sistema UNIPRORAD entre 20/12/14 e 19/06/15

O segundo parâmetro a ser discutido é a taxa de retorno ao site, que revela a fidelização do usuário ao sistema. Conforme demonstrado na FIGURA 3, o "Google Analytics" atesta que 822 usuários, ao longo do período, empreenderam 992 visitas ao site, visualizando um total de 3.322 páginas. Acreditamos que isso se deu porque o cuidado com as boas práticas de programação, bem como a inclusão de uma ferramenta de tradução para vários idiomas, acabaram por atribuir uma boa pontuação ao sistema UNIPRORAD nos motores de busca, por meio dos quais muitos usuários são levados ao site.

Um relatório mensal mais detalhado, conforme apresentado na FIGURA 4, permite analisar o comportamento do público alvo, introduzindo dois novos parâmetros, a saber: a taxa de rejeição e a taxa de retorno ao site. A taxa de rejeição não se refere a uma pontuação negativa ao site, mas indica o percentual de acessos a uma única página em uma mesma sessão. $O$ fato pode se dar porque o usuário achou rapidamente a informação que buscava ou porque, por meio dos motores de busca, foi levado ao site que não correspondia à sua busca. $O$ segundo parâmetro a ser discutido é a taxa de retorno ao site, que revela a fidelização do usuário ao sistema. 0 relatório mais recente fornecido pelo Analytics atesta que no intervalo de um mês 202 usuários empreenderam 377 visitas ao site, visualizando um total de 4.647 páginas. O retorno de 49,1\% dos visitantes ao site demonstra, por sua vez, o interesse do usuário pela realização de novas consultas ao sistema. Além da elevada taxa de retorno, a média de visualização, estimada em 12,33 páginas por sessão e a duração média da visita estimada em 12,37 minutos, nos levam a crer que os profissionais ligados à proteção radiológica fazem uso do site para fins de pesquisa ou busca de informações pontuais. 


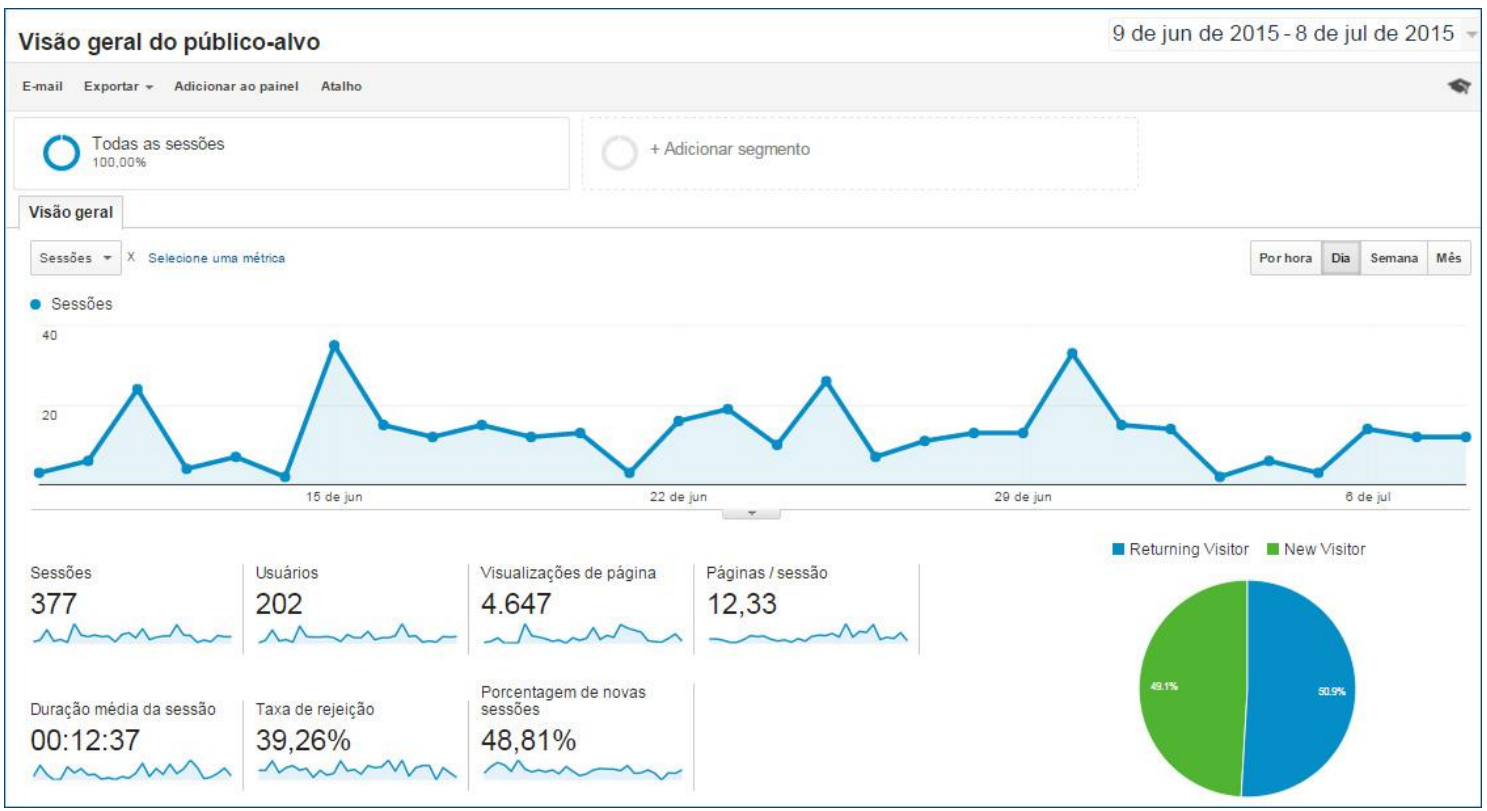

Figura 4 - Acessos ao sistema UNIPRORAD entre 09/06/15 a 08/07/15

Outro ponto que sugere a utilização do sistema UNIPRORAD para pesquisas puntiformes e necessárias é a utilização por meio de tecnologias móveis, a partir das mais diversas resoluções de tela, conforme demonstrado na FIGURA 5 e FIGURA 6 . A elevada taxa de utilização do sistema pela comunidade de radioprotecionistas corrobora a eficácia da ferramenta de pesquisa que tem por objetivo primeiro fornecer resultados para pesquisas complexas em curto espaço de tempo.

\begin{tabular}{|c|c|c|c|}
\hline & Sistema operacional & Sessōes & $\begin{array}{l}\text { Porcentagem do } \\
\text { Sessóes }\end{array}$ \\
\hline 1. & Windows & 189 & $50,13 \%$ \\
\hline & Android & 79 & $20,95 \%$ \\
\hline & Macintosh & 59 & $15,65 \%$ \\
\hline 4. & (not set) & 33 & $8,75 \%$ \\
\hline 5. & iOs & 13 & | $3,45 \%$ \\
\hline 6. & Linux & 3 & $0,80 \%$ \\
\hline & Windows Phone & 1 & $0,27 \%$ \\
\hline
\end{tabular}

Figura 5 - Sistemas operacionais utilizados - 09/06/15 a 08/07/15 


\begin{tabular}{|c|c|c|c|}
\hline & Resolução de tela & Sessōes & $\begin{array}{l}\text { Porcentagem do } \\
\text { Sessốes }\end{array}$ \\
\hline & $360 \times 640$ & 36 & $37,50 \%$ \\
\hline & $1280 \times 752$ & 16 & $16,67 \%$ \\
\hline & $320 \times 534$ & 12 & $12,50 \%$ \\
\hline & $320 \times 568$ & 12 & $12,50 \%$ \\
\hline & $480 \times 800$ & & $9,38 \%$ \\
\hline & $384 \times 640$ & 5 & $5,21 \%$ \\
\hline & $1920 \times 1080$ & 3 & | $3,12 \%$ \\
\hline & $1366 \times 768$ & 1 & $1,04 \%$ \\
\hline & $320 \times 570$ & 1 & $1,04 \%$ \\
\hline \multirow{2}{*}{\multicolumn{2}{|c|}{ 10. $357 \times 595$}} & 1 & | $1,04 \%$ \\
\hline & & & visualizar relatório \\
\hline
\end{tabular}

Figura 6 - Resoluções de tela a partir de tecnologias móveis - 09/06/15 a 08/07/15

Com efeito, o sistema disponibilizado em português, possibilita a aquisição de informações advindas das diversas publicações. Informações essas inter-relacionadas e não sequenciais que, de outra maneira seriam dificilmente obtidas. $O$ sistema permite ao usuário a comparação de discrepâncias entre publicações de diferentes organismos no que tange ao monitoramento das radiações ionizantes. Um exemplo é o valor recomendado para o nível de investigação. 0 Organismo Internacional de Energia Atômica [37] recomenda o valor de $6 \mathrm{mSva}^{-1}$, isto é, 3/10 do LAMAM (Limite Anual Máximo Admissível Médio). Já o valor do nível de investigação sugerido pela Comissão Internacional de Proteção Radiológica [38] é de 1/10 do LAMA. A CNEN adota o valor recomendado pelo OIEA. O sistema aborda ainda recomendações que não se encontram disponíveis nas atuais publicações, ainda que estas permaneçam válidas. Toma-se como exemplo os programas de monitoramento para a contaminação do ar que, de acordo com a publicação 75 da CIPR substitui a publicação 35 da mesma entidade. Ocorre que a publicação vigente não repete as informações sobre a estrutura geral, que diz continuar em vigor, mas descreve apenas as recomendações da estrutura mais conveniente. Estas informações, vitais e ainda válidas encontram-se somente disponíveis na publicação suprimida. Ainda, para a informatização dos programas de monitoramento das radiações ionizantes foi efetuada uma cuidadosa pesquisa nos conteúdos de otimização e monitoramento, de forma a inter-relacionar informações que remetem a recomendações e normas que tangem os programas de otimização da proteção radiológica dispostas em diversas publicações ou advindas de diversas fontes (ICPR, OIEA, CNEN). Outro ponto que acreditamos ter contribuído para o retorno dos 210 usuários do sistema foi o cuidado com a construção de um projeto de navegabilidade adequado, de forma a facilitar a busca de informações que nem sempre aparecem em ordem lógica ao longo das publicações. Toma-se como exemplo a árvore positiva publicada em 1990 pelo OIEA [47], considerada a árvore mais genérica e completa para um programa de proteção radiológica adequado e eficaz. O programa de informatização disponibiliza para o usuário os diversos passos desta árvore, partindo dos seis maiores constituintes do programa, até suas especificidades no que diz respeito ao monitoramento. Cada item ou sub-item remete a links correlatos advindos de outras publicações e que se encontram em áreas distintas do site. Quando tratamos, por exemplo, do programa de monitoramento do local de trabalho, indicamos a leitura da discussão sobre "controle eficaz da radiação no trabalho". O programa de monitoramento do local de trabalho, por sua vez, se subdivide em sete sub-itens. Cada um deles leva o usuário a diferentes 
assuntos correlacionados. O sub-item "adequação do monitoramento individual", por exemplo, indica ao leitor as seguintes leituras:

- monitoramento de rotina para radiação externa;

- monitoramento relacionado com a tarefa em caso de acidentes para radiação externa;

- objetivos do monitoramento individual para exposição Interna.

O sistema oferece ainda tópicos de discussões no intuito de ampliar o repertório dos profissionais do campo da proteção radiológica, suscitando novas reflexões. Trata-se dos temas desenvolvidos nesta tese, a saber: a necessidade de um monitoramento auditor e as discussões sobre as exposições potenciais, que foram desenvolvidos articulando novas possibilidades em relação às atuais publicações. Em relação ao monitoramento com função auditora, acreditamos que apresenta oportunidades de reflexões que possibilitem aliar a ampliação de ações a favor da segurança à uma proteção radiológica econômica e eficaz. Em relação às exposições potenciais, o sistema não se propõe a fornecer certezas ou respostas, mas sim discussões sobre possíveis cenários, a partir das publicações atuais. Entendemos que ampliar o repertório de informações e reflexões do trabalhador pode auxiliá-lo sobremaneira na tomada de decisões. No nosso entender, o que agrega valor ao trabalho de informatização dos programas de proteção radiológica é a capacidade de oferecer ao usuário a possibilidade de articular cada um dos itens com um ou vários outros tópicos constantes nas diversas publicações.

Desta maneira, um dos resultados desta tese foi a construção de cenários completos e corretos a partir dos exemplos abordados na publicação 76 da CIPR [21]. O primeiro cenário desenvolvido nesta tese trata da exposição potencial em irradiadores de grande porte. 0 irradiador com projeto antigo foi desconsiderado para os propósitos do presente estudo, uma vez que os sistemas de segurança daquele modelo não mais se aplicam aos irradiadores modernos em uso. O irradiador com projeto moderno, por sua vez, foi amplamente desenvolvido para além do que traz a publicação 76 [21], considerando três pontos falhos:

1. A publicação em questão apresenta sequências de eventos incompletas e reducionistas, trascurando as recomendações da publicação 102 do OIEA [47]; a sequência de eventos apresentada não segue os passos recomendados para um programa de proteção radiológica, econômico e eficaz.

2. A publicação 76 da CIPR [21] desconsidera as diretrizes recomendadas no IAEA TECDOC 430 [51], que traz as exigências e simbologias para o correto desenvolvimento da árvore porfiriana.

3. O exemplo apresentado considera unicamente as falhas de segurança em sistemas eletrônicos e mecânicos. A própria publicação [21], que em sua seção 2.4 quantifica a ocorrência de falhas humanas inferindo um valor de $10^{-3}$ a $10^{-2}$ para a sua ocorrência e apontando a falha humana como a mais provável de ocorrer, não inclui este quesito em sua árvore de falhas.

Entendemos que ao montar sua árvore de falhas de acordo com as especificidades de sua situação, a instalação deve obrigatoriamente levar em consideração os três itens supramencionados. Na árvore de falhas por nós desenvolvida, que consideramos mais completa e correta no que tange o monitoramento, articulamos todas essas questões, completando-as ainda com outras considerações não articuladas na publicação 76 da CIPR ou publicação 102 do 
OIEA. As figuras 7 a 14 trazem um recorte da árvore recomendada pela publicação 102, no que diz respeito às atividades de monitoramento, que nos serviu de guia para balizar este primeiro exemplo trabalhado da publicação 76 da CIPR. As figuras 15 a 19, por sua vez, trazem a árvore de falhas por nós desenvolvida, apontando por diferença de cores as referidas articulações: na cor branca, são apresentadas as sequências propostas pela publicação 76 da CIPR; na cor roxa, são apresentadas as recomendações encontradas na publicação 102 OIEA e na cor verde, são apresentadas outras abordagens que julgamos pertinentes, fruto deste trabalho de pesquisa, e que não se encontram em nenhuma das duas publicações ${ }^{5}$. Foram elementos fundamentais acrescentados na referida sequência, as falhas procedimentais e as falhas humanas. Além da insuficiência no monitoramento relacionado com a tarefa, que é referenciada na publicação 102 do OIEA, porém negligenciada na publicação 76 da CIPR, trazemos a importância da auditoria, sobretudo no que tange o elemento humano, sem o qual, qualquer sequência de eventos é insuficiente para se estabelecer parâmetros confiáveis que permitam comparar e quantificar probabilisticamente as ocorrências potenciais [21; $47 ; 51]$.

O segundo cenário desenvolvido na presente tese refere-se à exposição potencial de pacientes proveniente de aparelho de radioterapia gama. A publicação 76 da CIPR aborda neste exemplo uma análise das exposições potenciais a partir de um aparelho radioterápico emissor gama com 201 fontes de ${ }^{60} \mathrm{Co}$ para a irradiação de lesões intracranianas. A referida publicação considera possíveis problemas como: falhas de pressão hidráulica, ativação e desativação elétricas inadvertidas, falhas da fonte de tensão e de componentes eletrônicos e operações mecânicas incorretas. No que tange o fator humano, a publicação aborda a exposição do paciente à radiação ionizante, exposição da equipe médica durante as condições de emergência, e a exposição do público. Entretanto, assim como no cenário anterior, a publicação considera em sua árvore de falhas os aspectos físicos mecânicos, hidráulicos e elétricos, radioproteção e sistemas de segurança. Apesar de reconhecer em sua sessão 5.4.2 que o fator humano é o principal contribuinte para o risco de uma situação de emergência relacionada a muitas tarefas e subtarefas, a publicação 76 traz seu cálculo de probabilidades relativas de falhas desconsiderando os erros humanos. Entendemos que não é possível quantificar probabilisticamente as ocorrências potenciais a partir de uma sequência de eventos que considera apenas falhas físicas, sem que a elas sejam associadas justamente ao fator contribuinte de maior risco para as exposições potenciais: a falha humana. Uma vez que esta tese trata do monitoramento das radiações ionizantes, que é um dos itens abordados na árvore positiva do OIEA [47], desenvolvemos uma árvore de falhas que oferece caminhos mais amplos e abrangentes, considerando (i) elementos humanos e operacionais que podem desencadear eventos indesejáveis; (ii) as recomendações da publicação 102 do OIEA para a construção de uma árvore completa e eficaz; e (iii) as recomendações do IAEA TECDOC 430 [51], que possibilitam uma compreensão mais ampla e completa das sequências passíveis de ocorrerem. A CIPR sugere sequências de eventos e quantifica suas probabilidades de ocorrência, sem entretanto oferecer cenários completos. Entende-se justificável que se combinem os eventos "falha elétrica" e "falha do operador", conforme podemos observar na FIGURA 20; ou que se combinem "interrupção de emergência presa" e "necessária retração de emergência do paciente", conforme podemos observar ainda na FIGURA 20. Entretanto, no que tange as falhas

\footnotetext{
${ }^{5}$ Os símbolos lógicos utilizados nas árvores de falhas encontram-se nas questões de número 301 a 305 contidas no anexo da presente tese.
} 
das válvulas, por exemplo, não se pode combinar os itens "falha da válvula na linha dentro" e "falha da válvula na linha fora", sem que haja prejuízo nos cálculos de probabilidades das exposições potenciais. $O$ cálculo correto envolveria então necessariamente as três situações: falha na válvula da linha "dentro", falha na válvula da linha "fora", e falha simultânea em ambas as válvulas; esta última com probabilidade de ocorrência inferior às duas primeiras. Embora o exemplo escolhido seja bastante simples, o referido exemplo desconsidera, não apenas as falhas humanas, como também um possível aumento da radiação externa por razões de insuficiência ou falhas relativas à blindagem. Estes dois aspectos foram acrescentados na árvore de falhas, conforme observa-se na figura 19, resultando no acréscimo de duas outras ramificações a serem acrescentadas à árvore de falhas, conforme podemos observar nas figuras 21 e 22 . A figura 22 trata dos aspectos humanos e procedimentais, relativos ao monitoramento das radiações ionizantes, verificação da confiabilidade dos equipamentos, auditoria dos procedimentos, uso do detector e adequação, vigência e revisão da documentação [21; 47; 51].

O terceiro cenário por nós desenvolvido aborda a exposição potencial em um cíclotron, a partir do exemplo trazido na publicação 76 da CIPR. Os aceleradores são vastamente utilizados na indústria, medicina e na pesquisa, uma vez que feixes de elétron, prótons e íons de energia elevada são utilizados em aplicações industriais, agrícolas e radioterapia, dentre outros. 0 cenário de acidente no acelerador toma por referêncial um cíclotron que opera com energia de feixe de prótons de $30 \mathrm{MeV}$ e uma corrente de feixes de $250 \mu \mathrm{A}$. Localiza-se no interior de uma caverna blindada de concreto com paredes de $2 \mathrm{~m}$ de espessura. $O$ acesso se dá através de porta blindada de concreto, ativada por um motor. $\mathrm{O}$ cíclotron exige três tipos diferentes principais de fontes de tensão para a produção de um feixe de prótons: um para o magneto (MG), um para a fonte de íons (FI) e um terceiro para o gerador de frequência (GF). Uma árvore de falhas permite analisar a sensibilidade dos eventos desencadeadores e quantificar a probabilidade anual de exposição do operador. Entretanto, esta quantificação, considerando as falhas nas barreiras físicas, falhas mecânicas ou eletrônicas, não seriam as mesmas se combinadas às probabilidades de falhas humanas e procedimentais. Uma vez que o fator humano é um grande contribuinte para o desencadeamento de situações indesejáveis, a árvore de falhas deve obrigatoriamente inclui-los. De outra forma, a análise probabilística ficaria sempre aquém das reais probabilidades de ocorrência no cotidiano laboral. Entendemos que devem ser consideradas as falhas humanas e as ações empreendidas para minimizá-las. No que diz respeito ao escopo desta tese, as ações referem-se ao monitoramento das radiações ionizantes, assunto trascurado pela publicação 76 da CIPR [21], mas recomendado na publicação 102 do OIEA [47]. As figuras 23 a 26 mostram a árvore de falhas por nós desenvolvida, baseada no mesmo exemplo do cíclotron referenciado na publicação 76 da CIPR [21], porém mais completa e correta conforme recomendações das publicações 102 do OIEA e "IAEA TECDOC 430" [47; 51]. 


\subsection{Considerações para um programa adequado e eficaz de proteção radiológica}

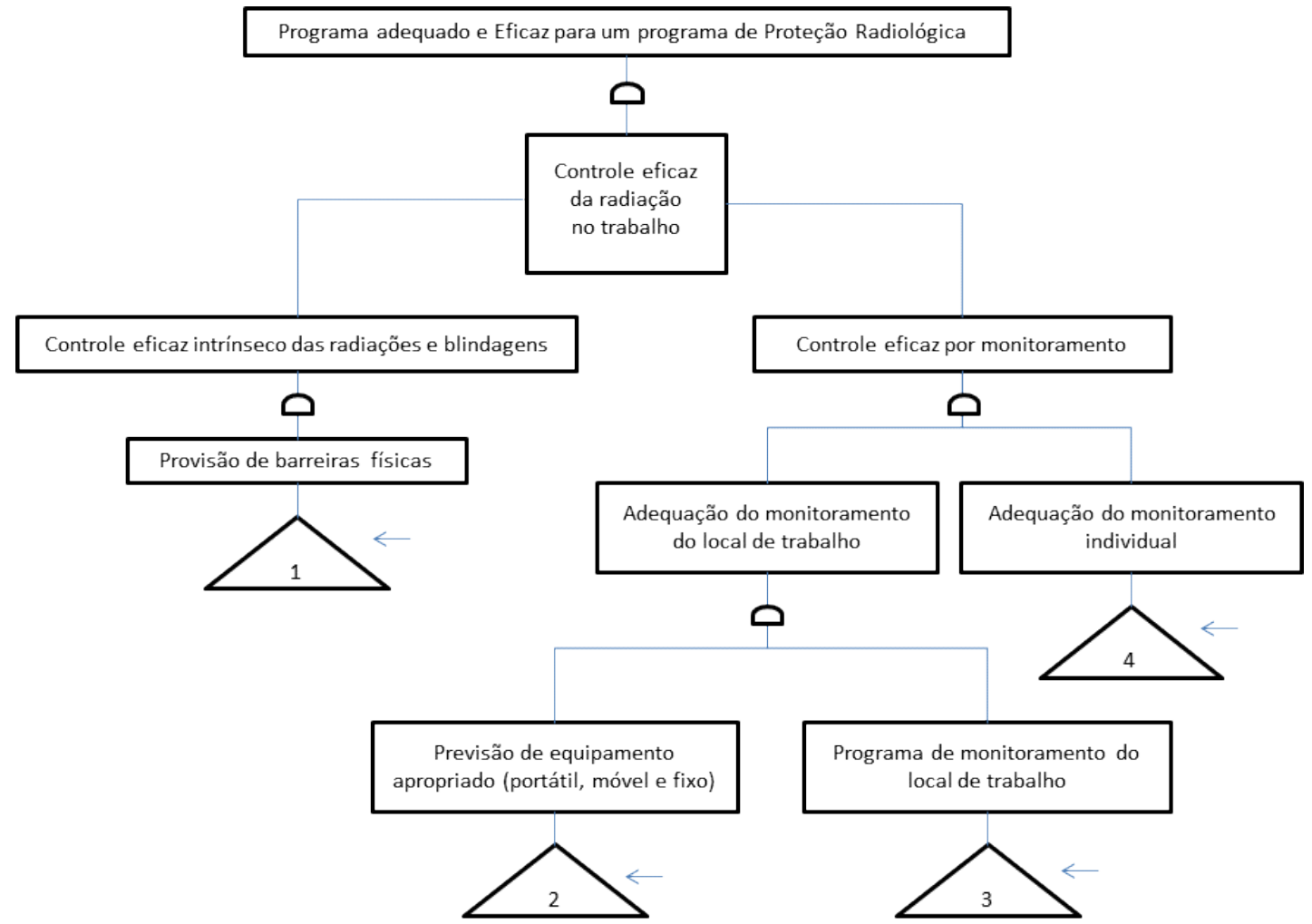

Figura 7 - Programa adequado e Eficaz para um programa de Proteção Radiológica

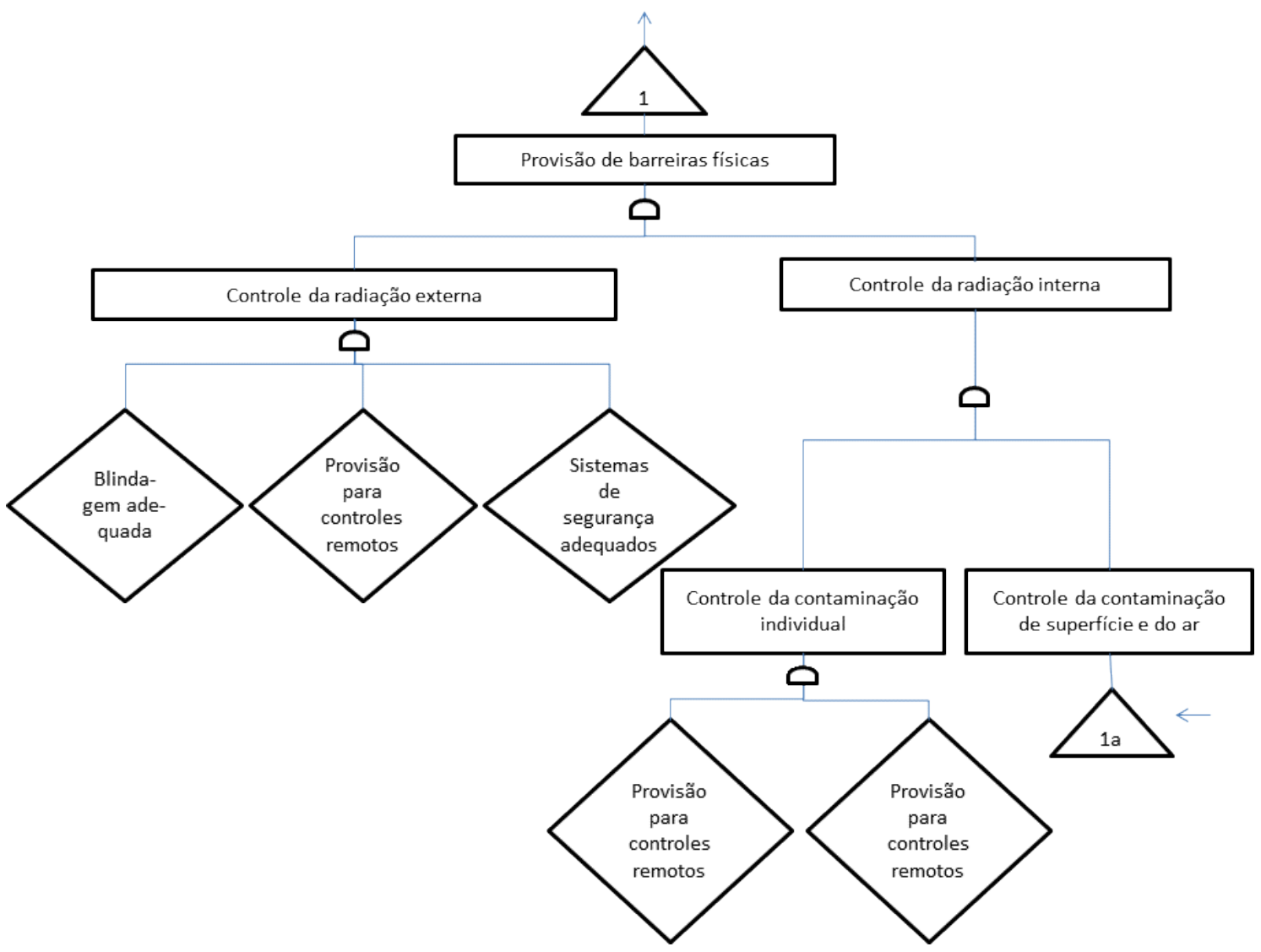

Figura 8 - Provisão de barreiras físicas 


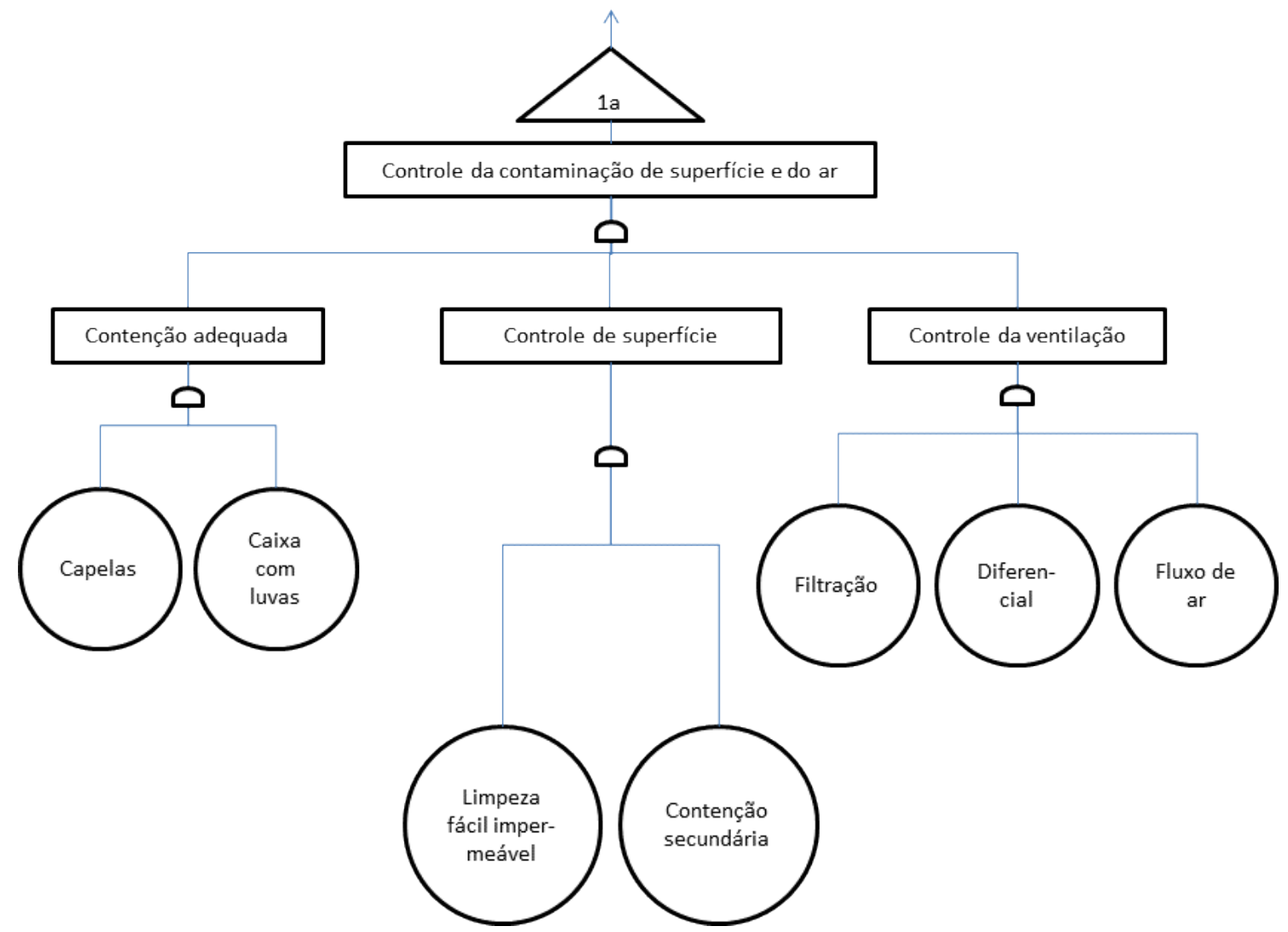

Figura 9 - Controle da contaminação de superfície e do ar

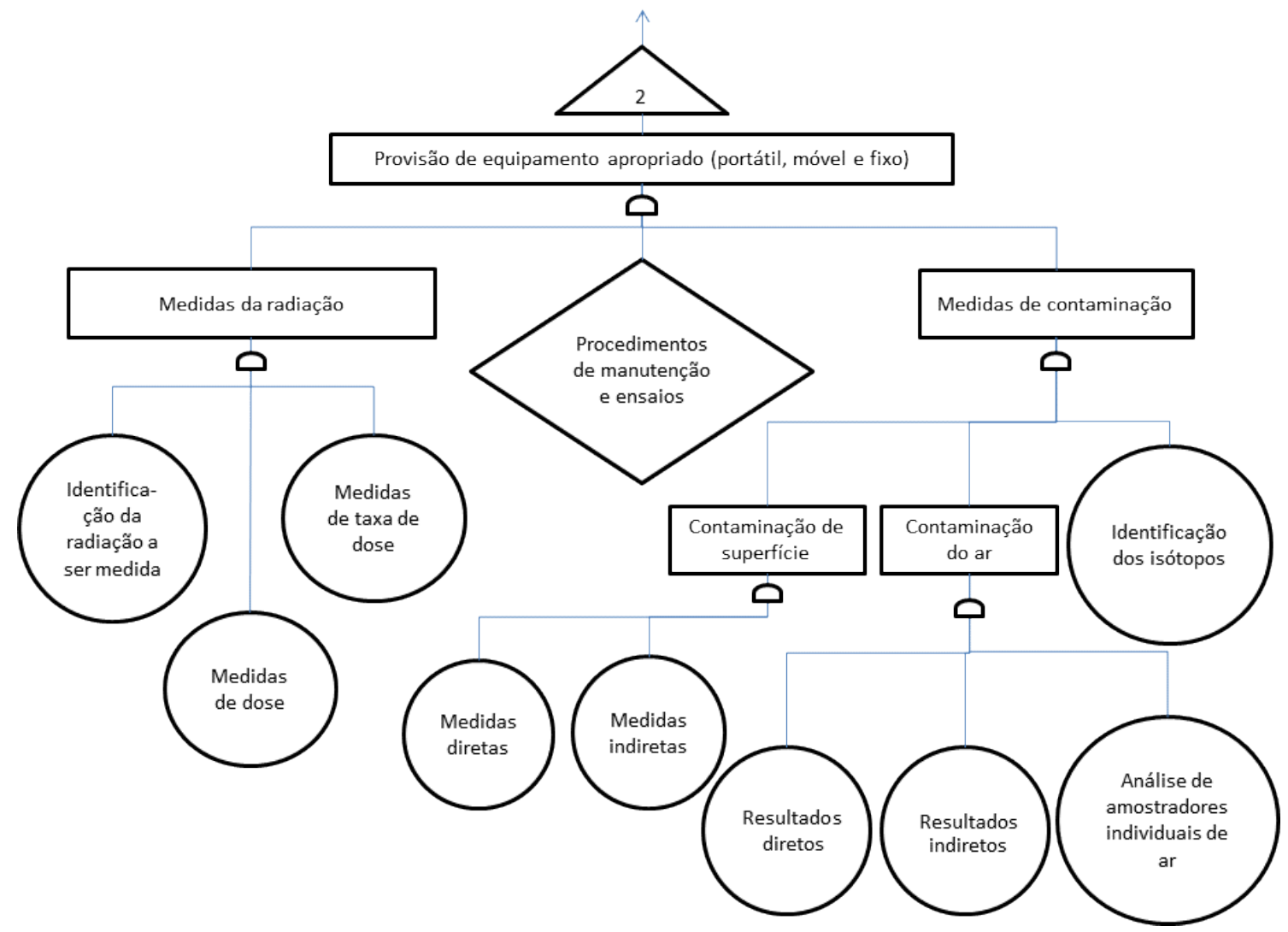

Figura 10 - Provisão de equipamento apropriado (portátil, móvel e fixo) 


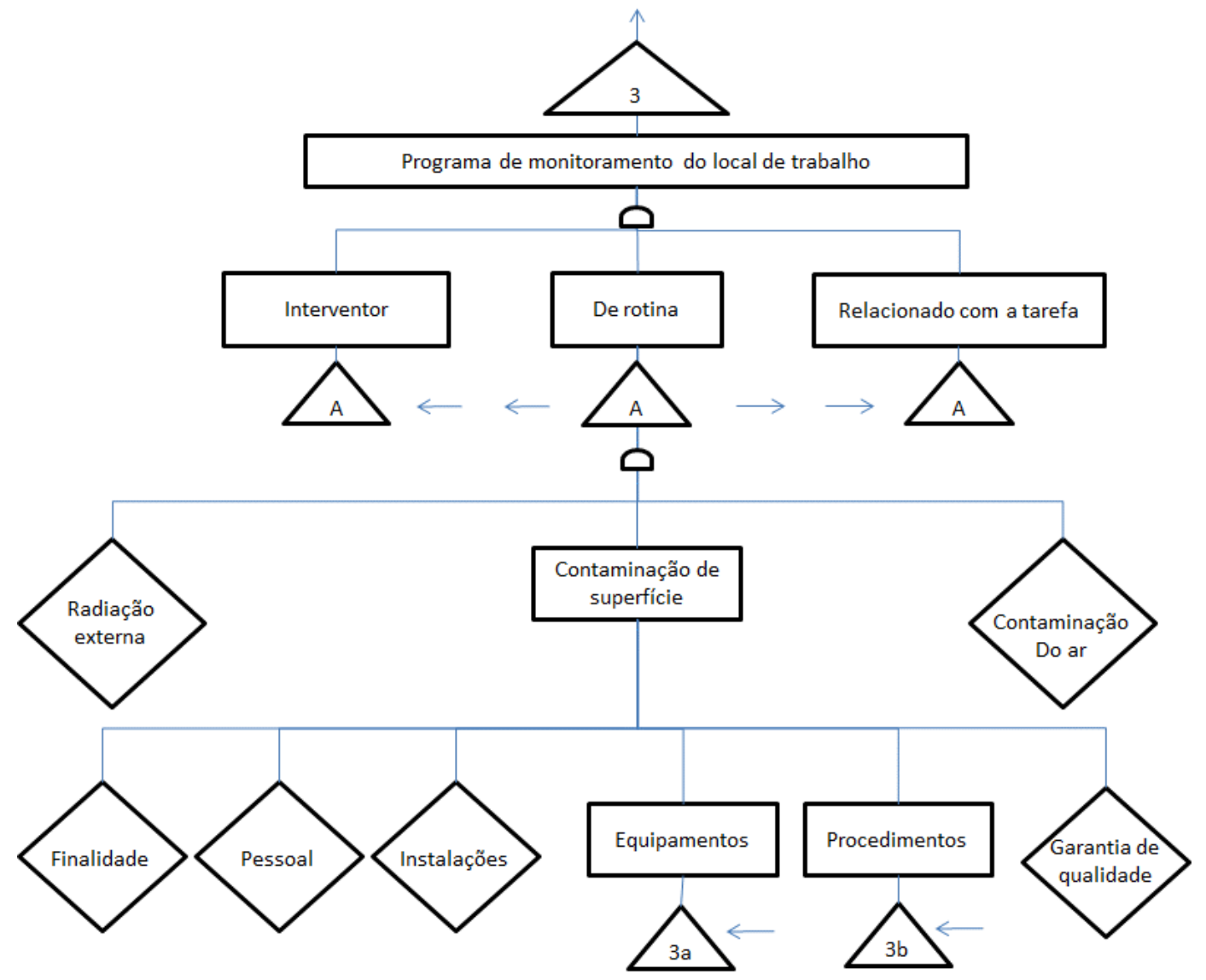

Figura 11 - Programa de monitoramento do local de trabalho

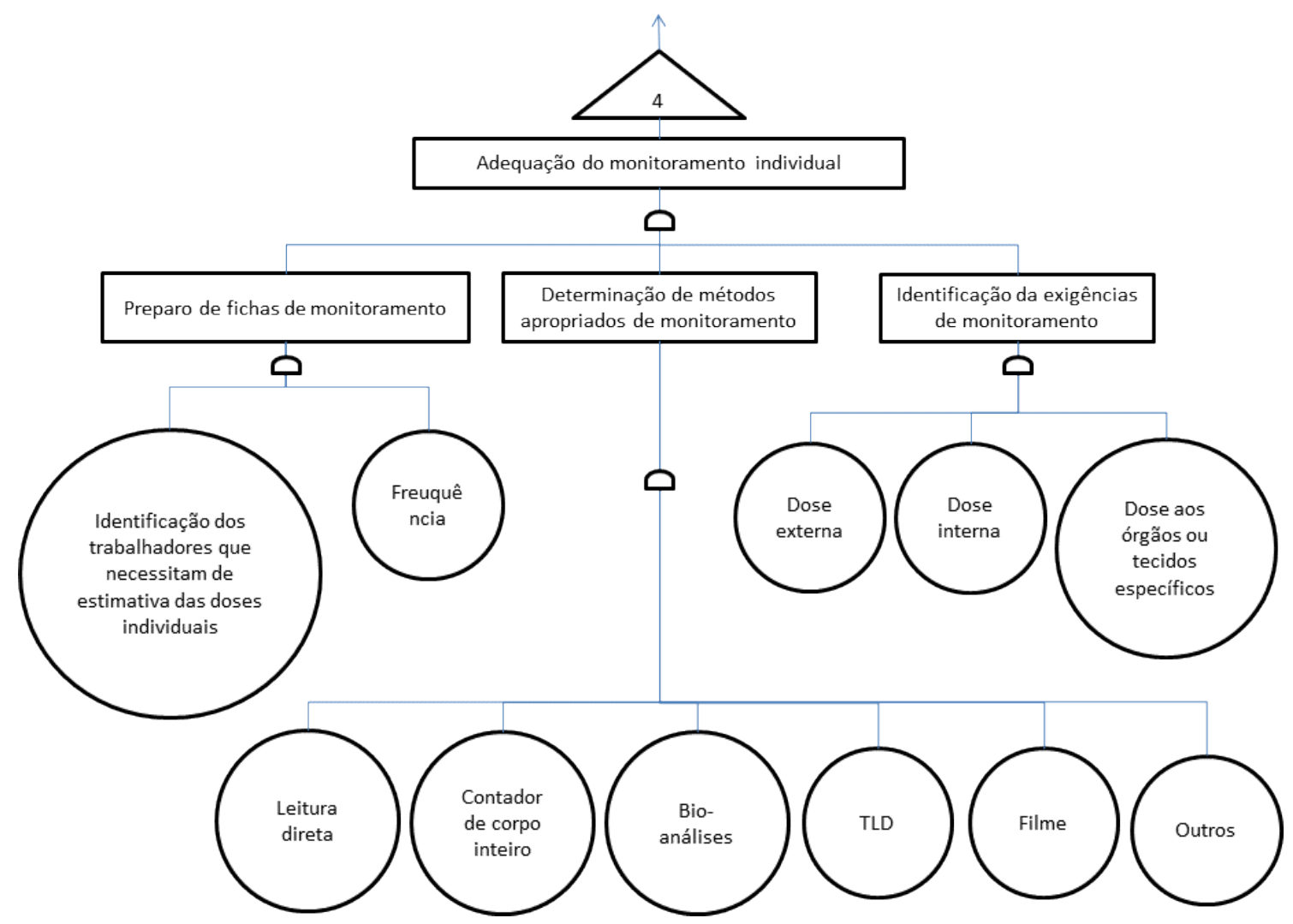

Figura 12 - Adequação do monitoramento individual 


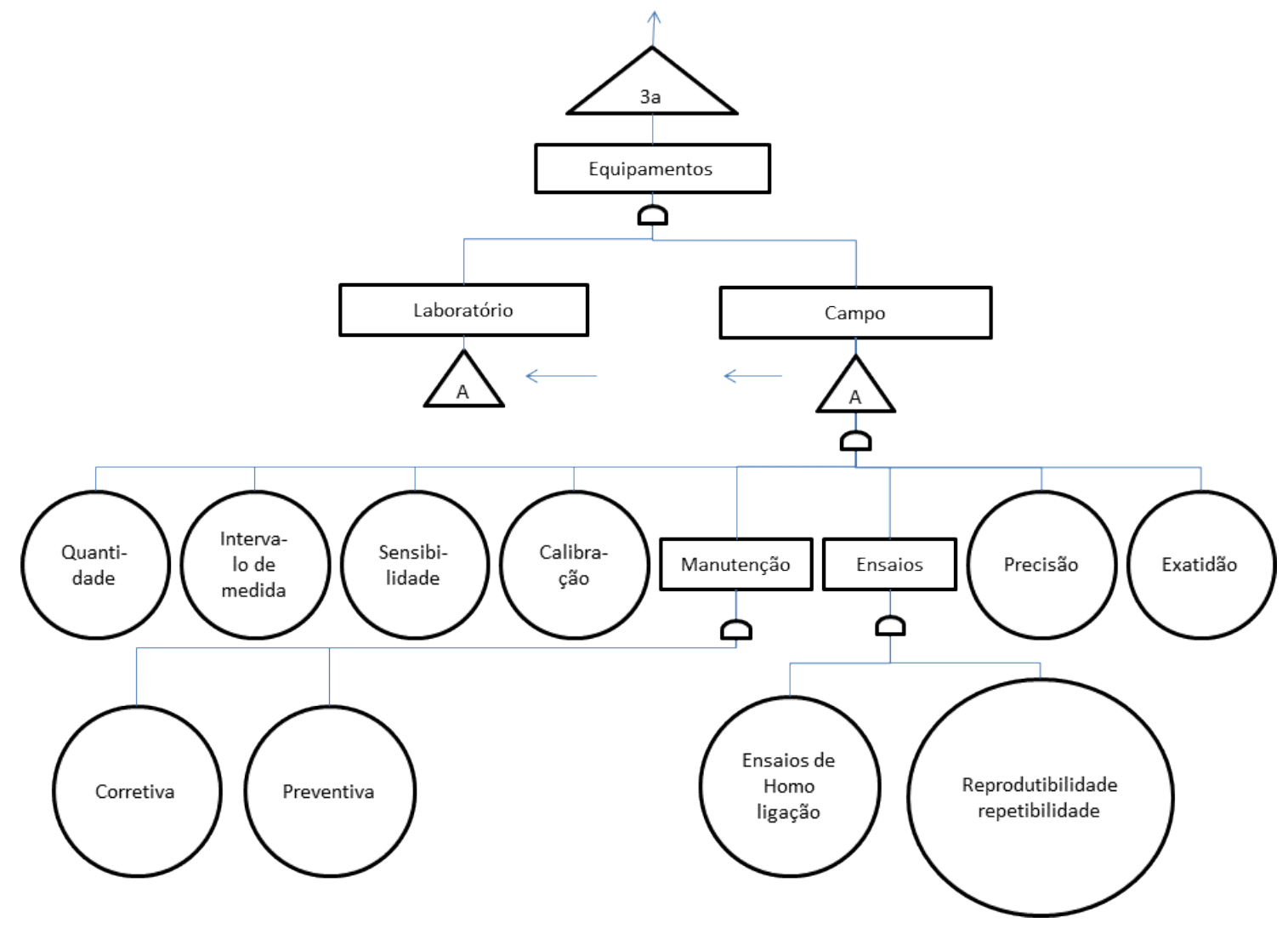

Figura 13 - Equipamentos

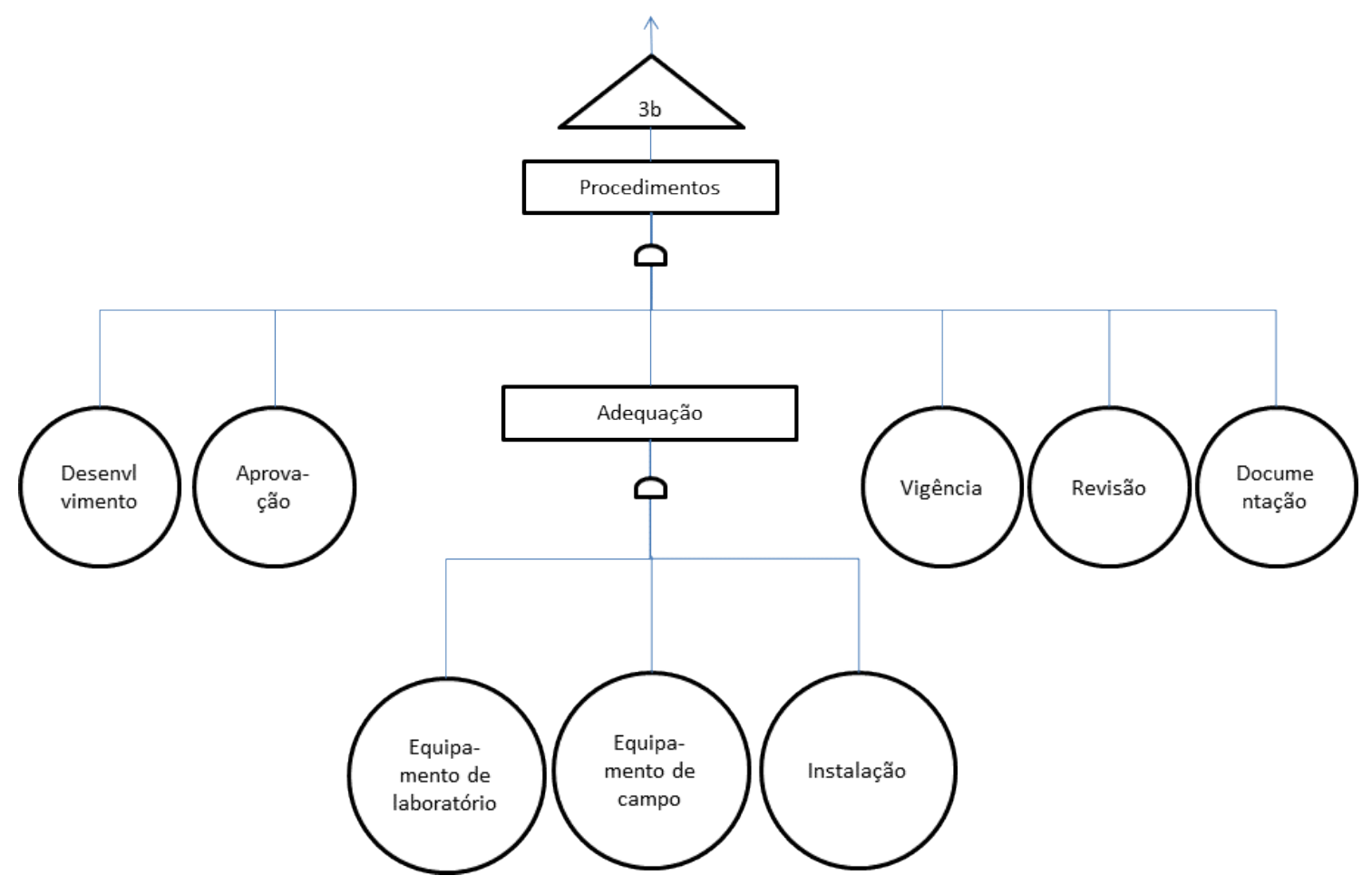

Figura 14 - Procedimentos 


\subsection{Cenário 1 - Exposição potencial em irradiador moderno}

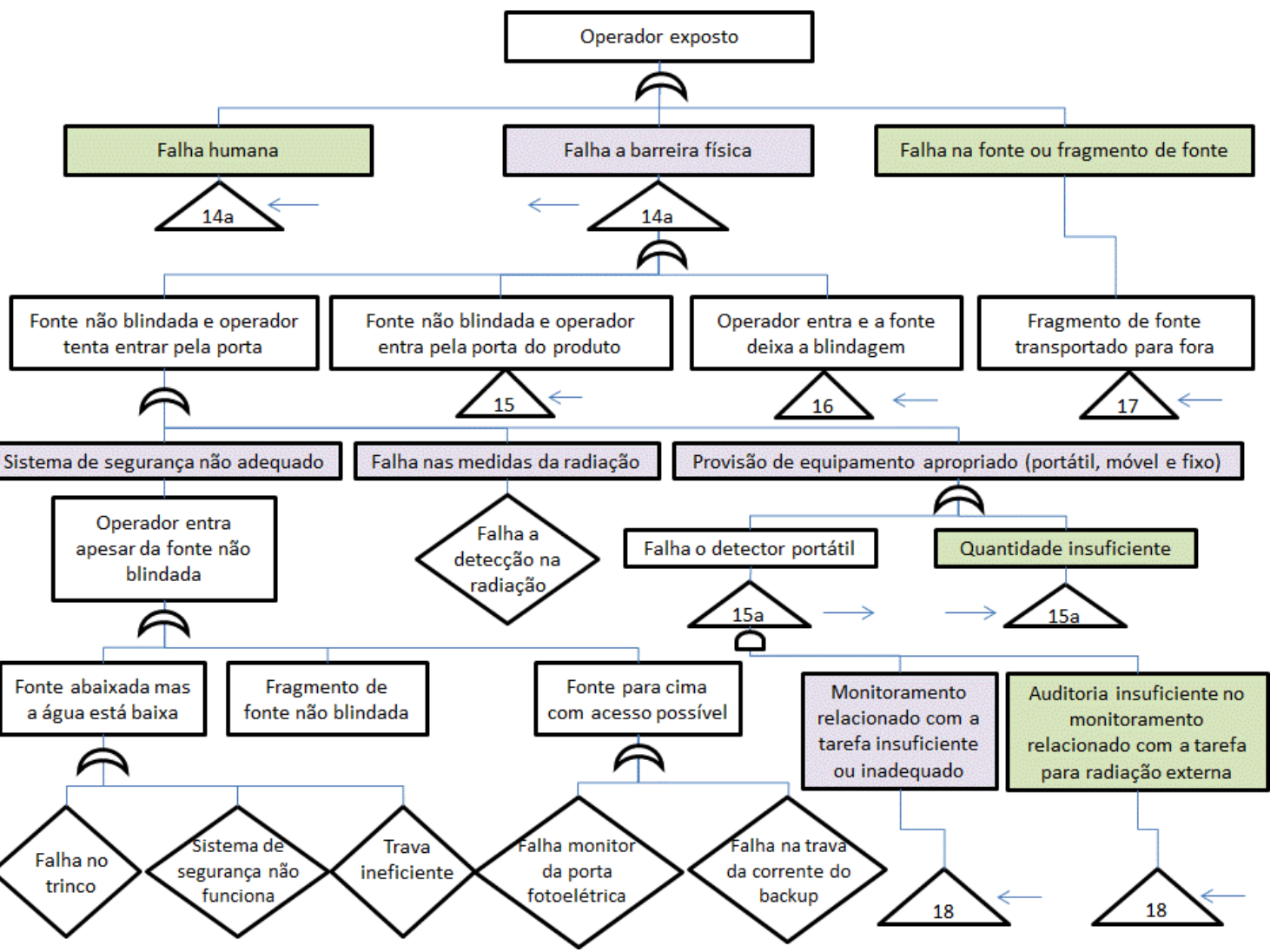

Figura 15 - Caso 1: Exposição potencial em irradiador moderno

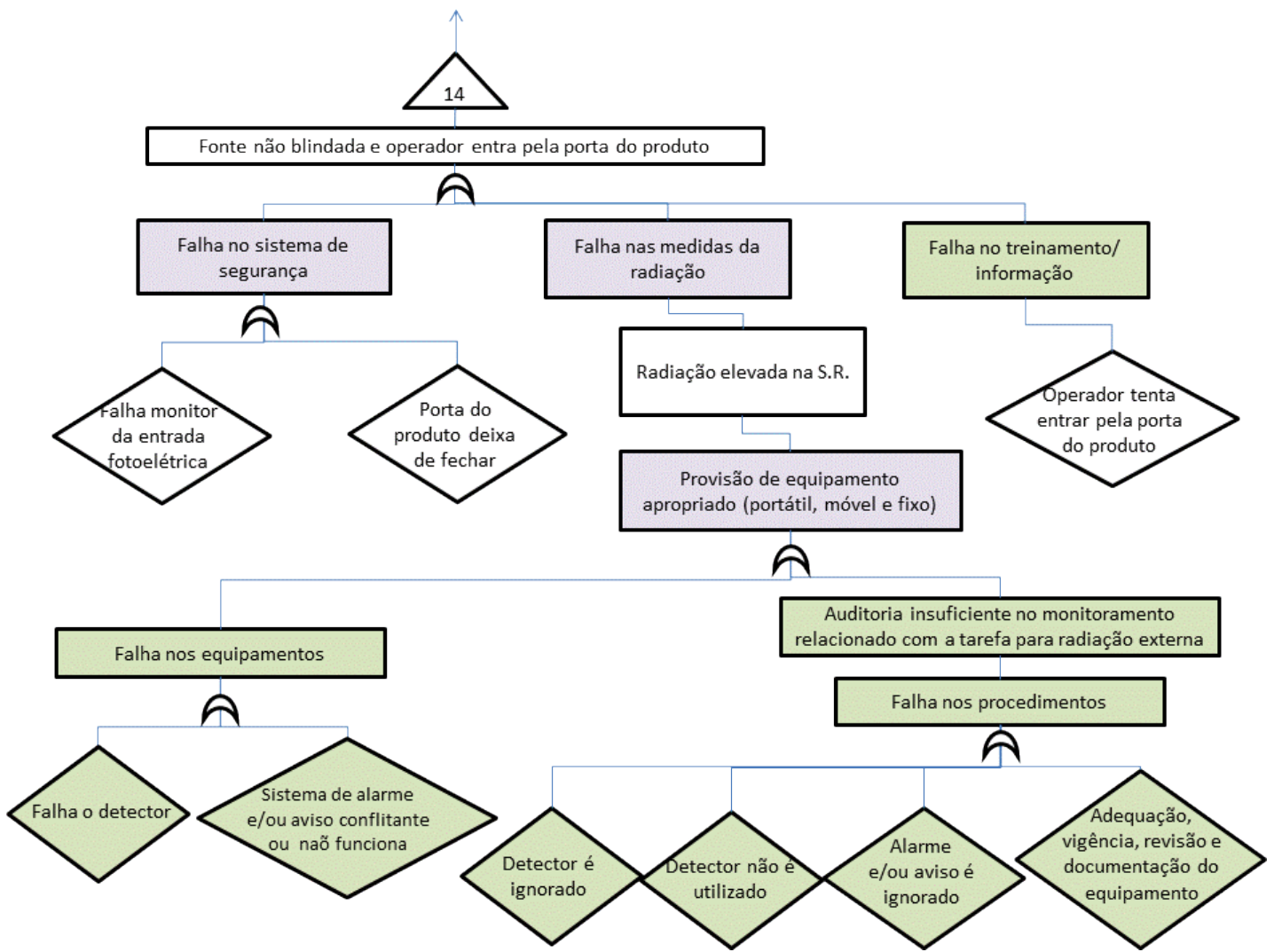

Figura 16 - Caso 1: Fonte não blindada e operador entra pela porta do produto 


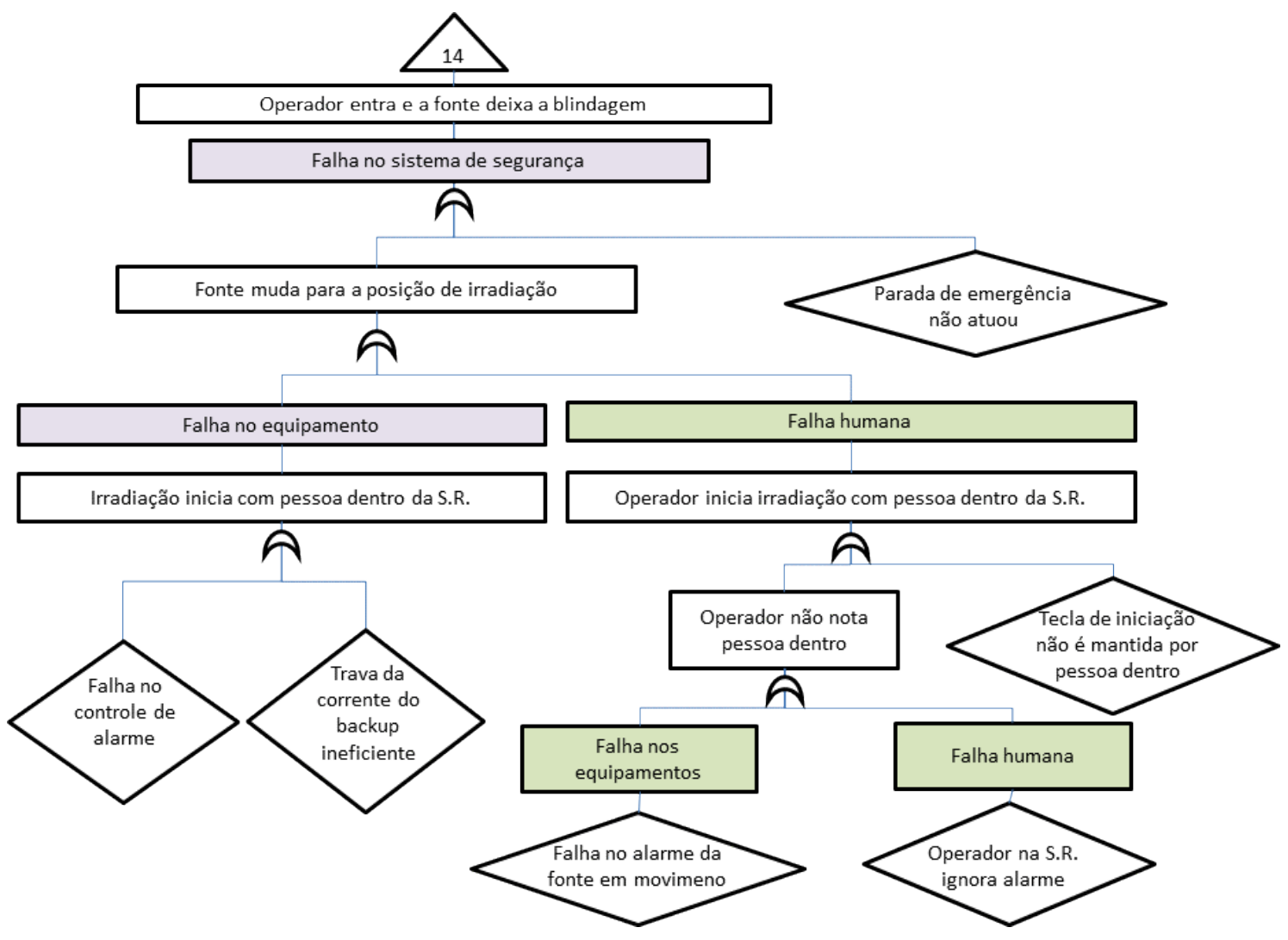

Figura 17 - Caso 1: Operador entra e a fonte deixa a blindagem

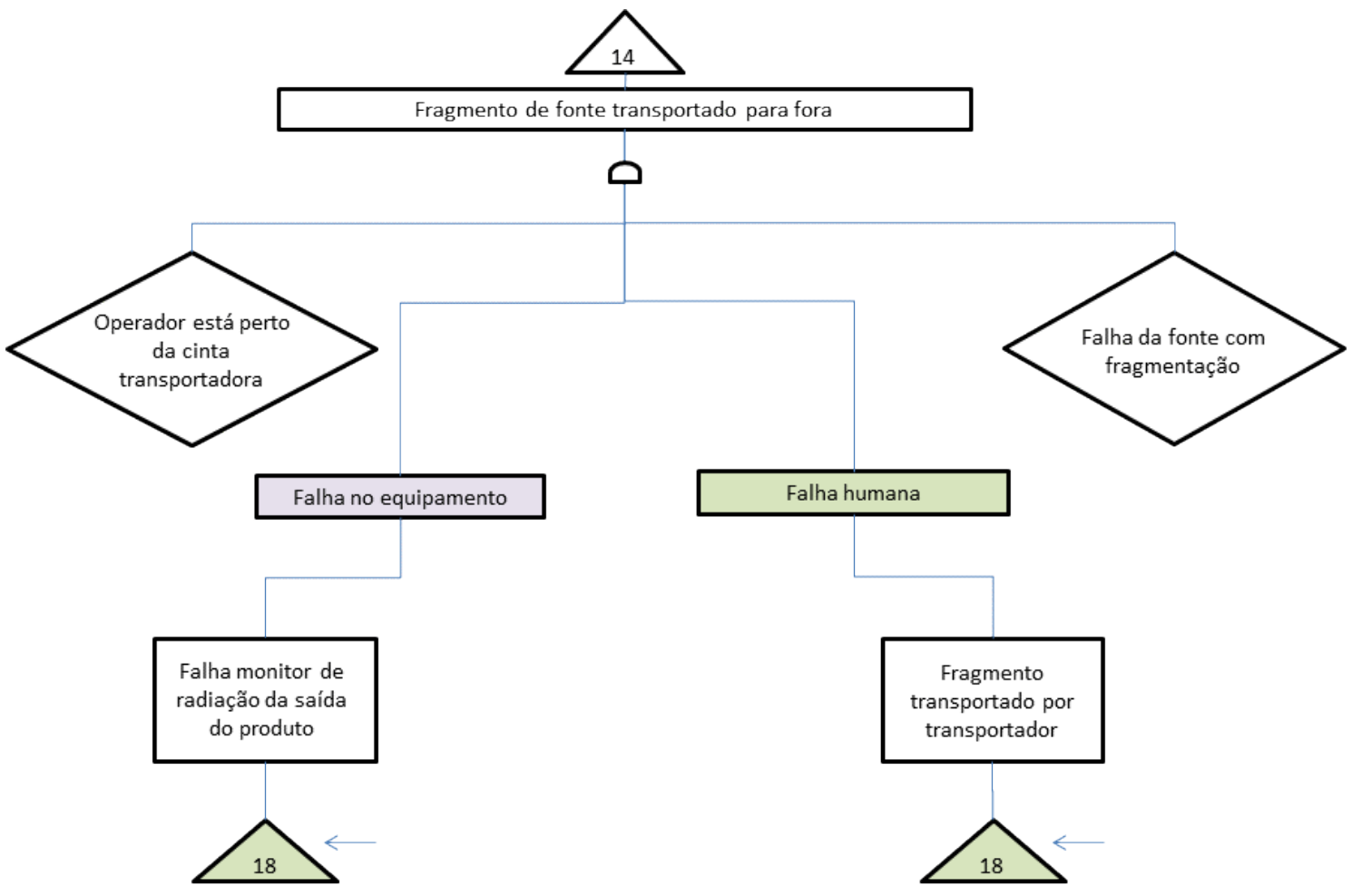

Figura 18 - Caso 1: Fragmento de fonte transportado para fora 


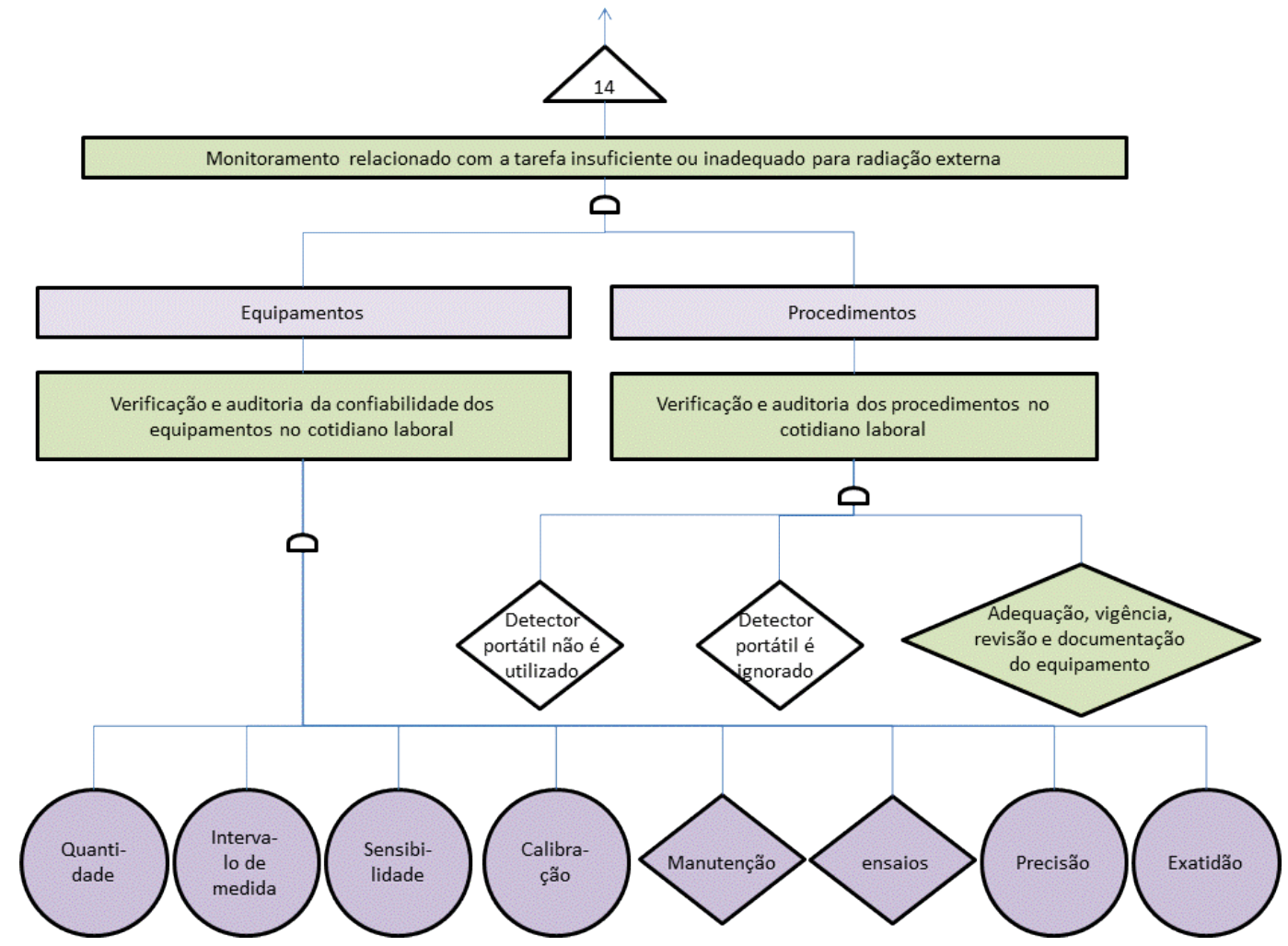

Figura 19 - Caso 1: Monitoramento relacionado com a tarefa para radiação externa

\subsection{Cenário 2 - Exposição potencial de pacientes por aparelho de radioterapia emissor gama}

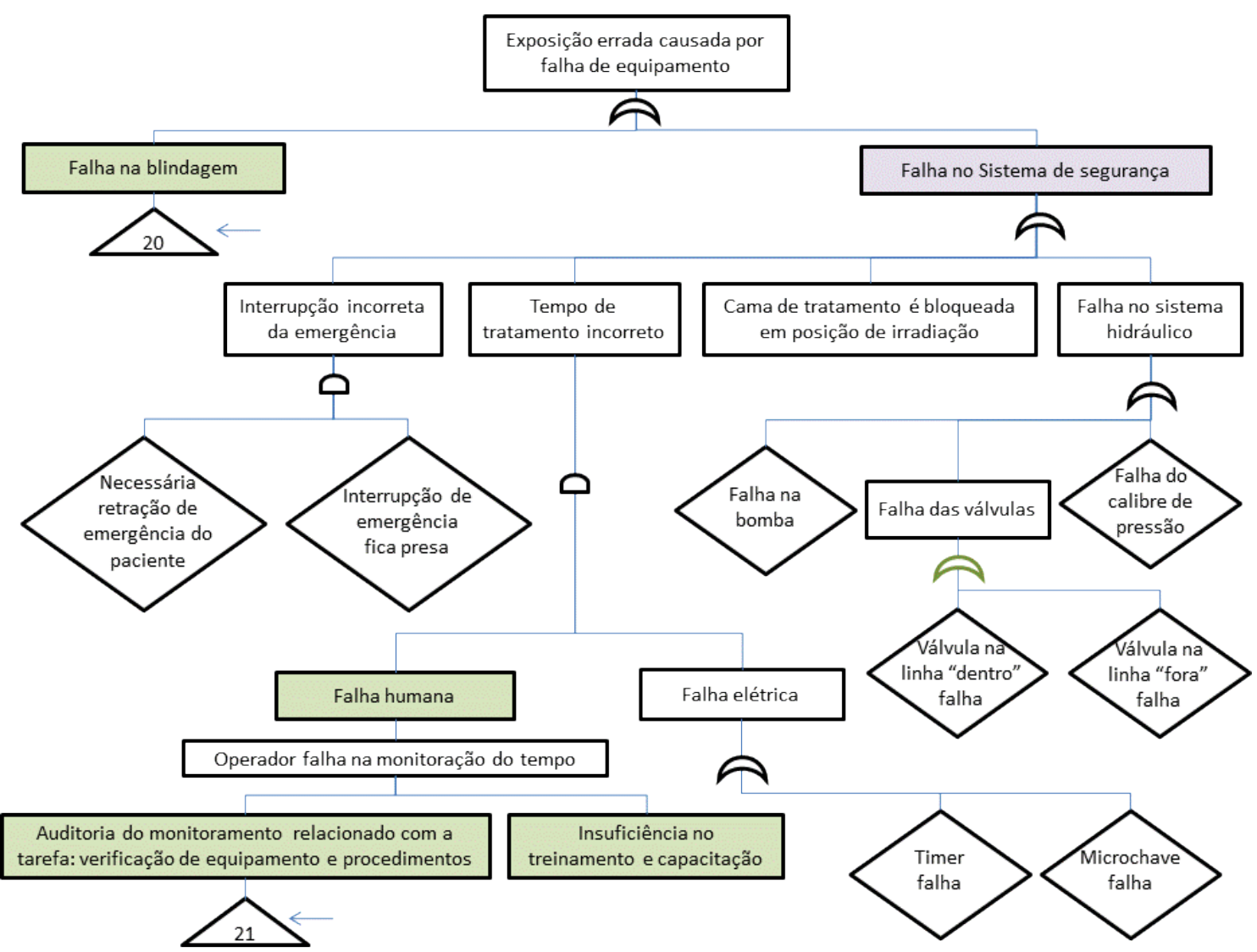

Figura 20 - Caso 2: Exposição potencial de pacientes por aparelho de radioterapia 


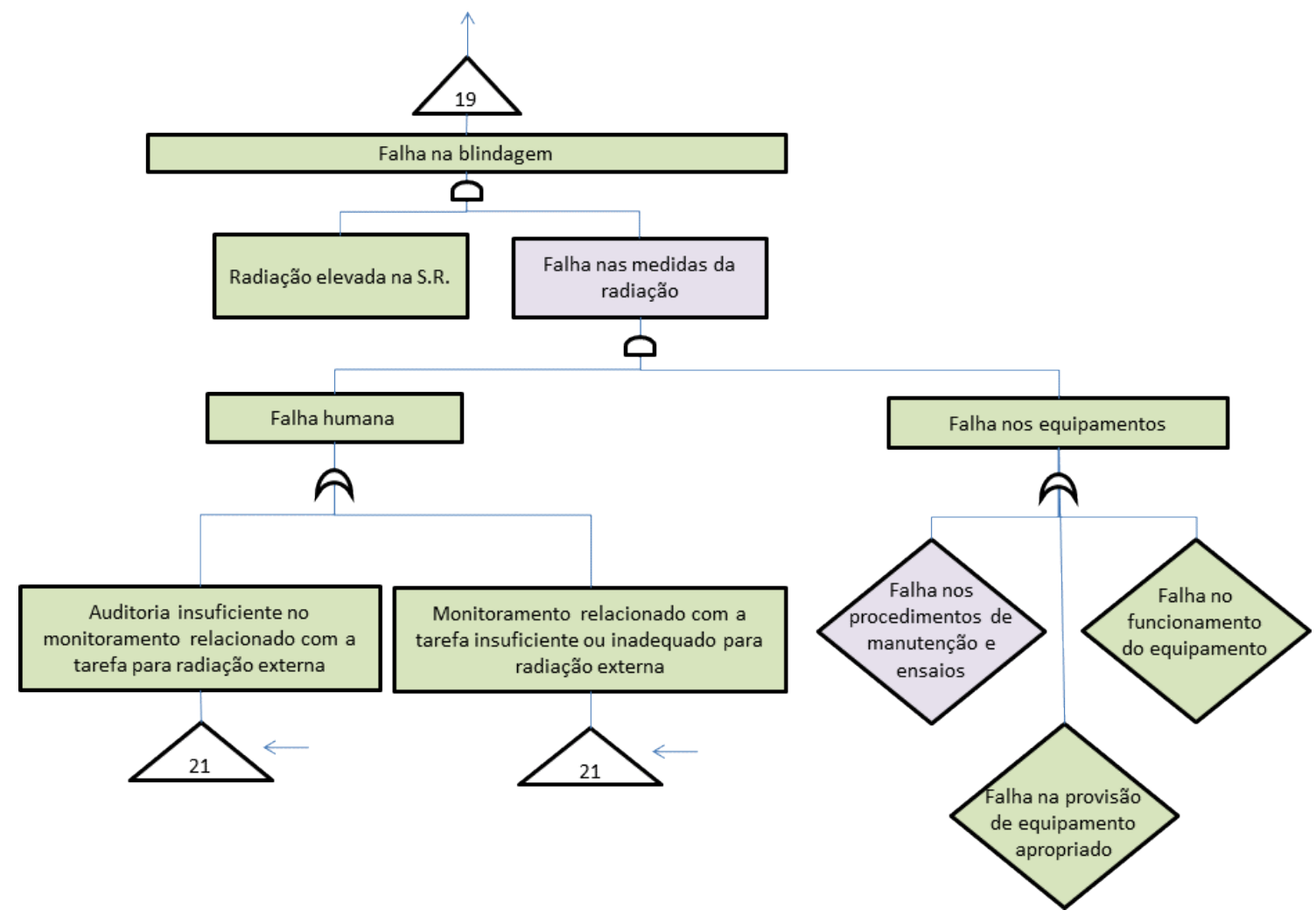

Figura 21 - Caso 2: Falha na blindagem

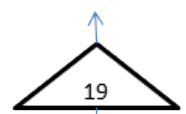

Auditoria do monitoramento relacionado com a tarefa: verificação de equipamento e procedimentos

○

Equipamentos
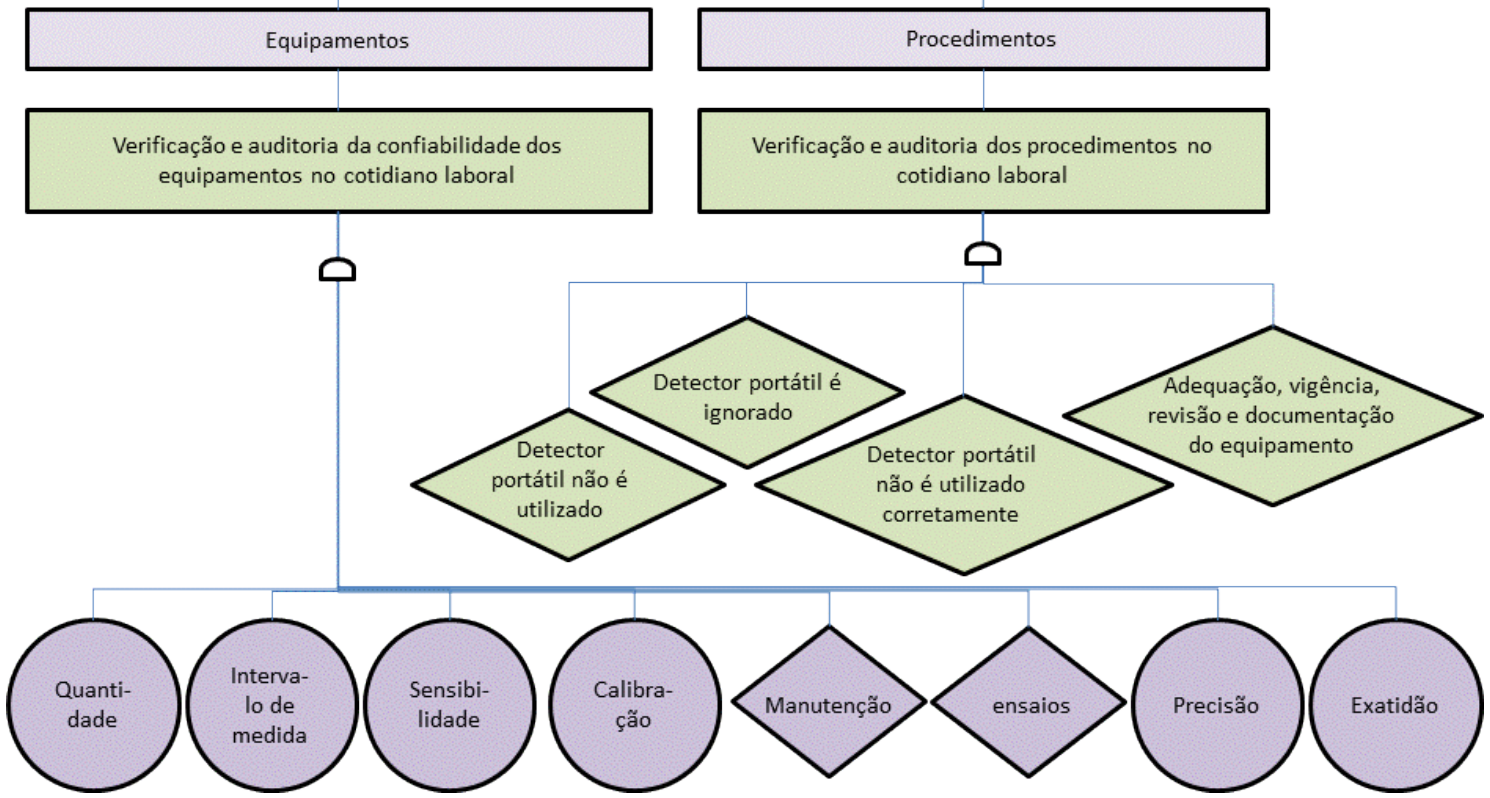

Figura 22 - Caso 2: Auditoria do monitoramento: equipamentos e procedimentos 


\subsection{Cenário 3: Exposição potencial em um cíclotron}

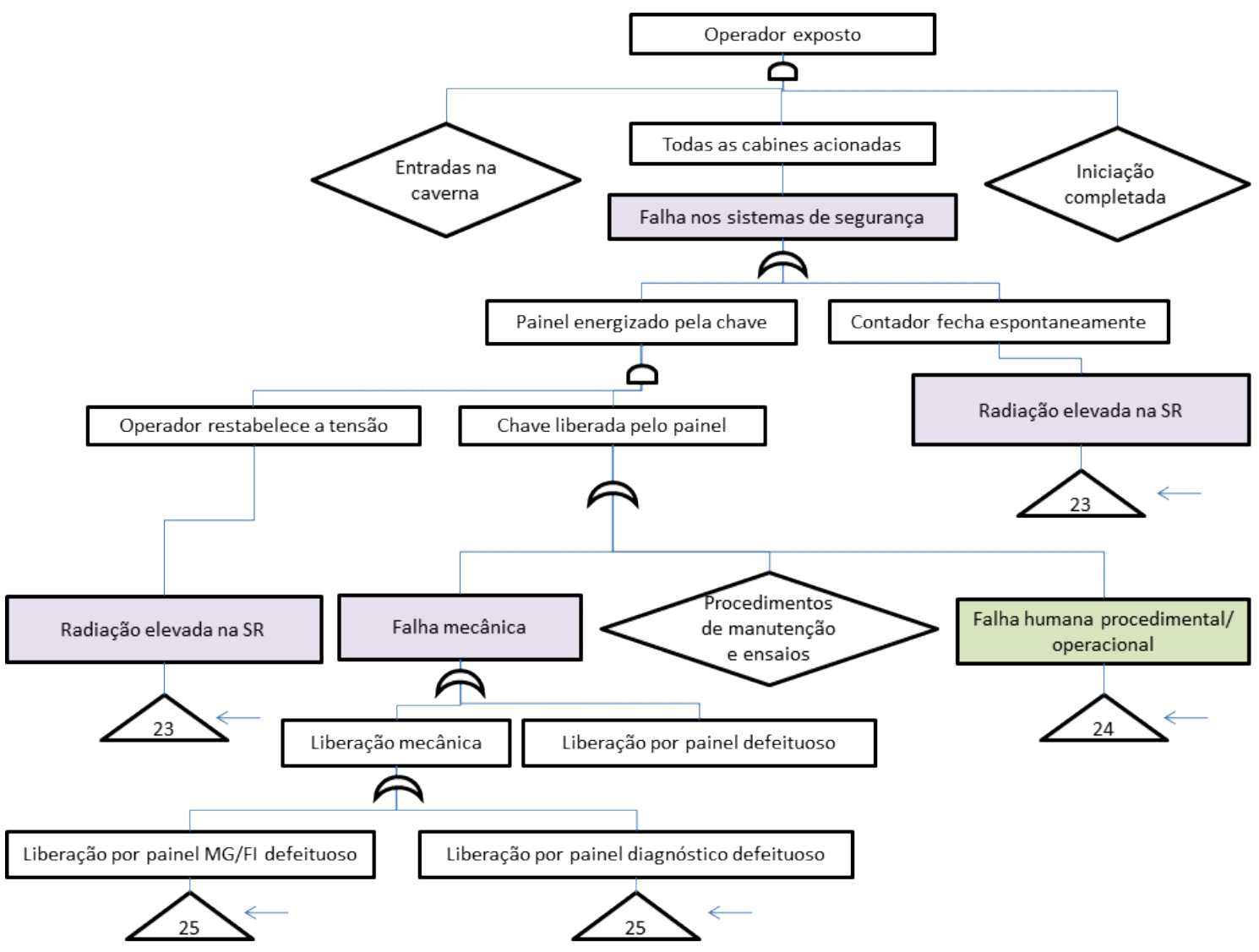

Figura 23 - Caso 3: Exposição potencial em um cíclotron

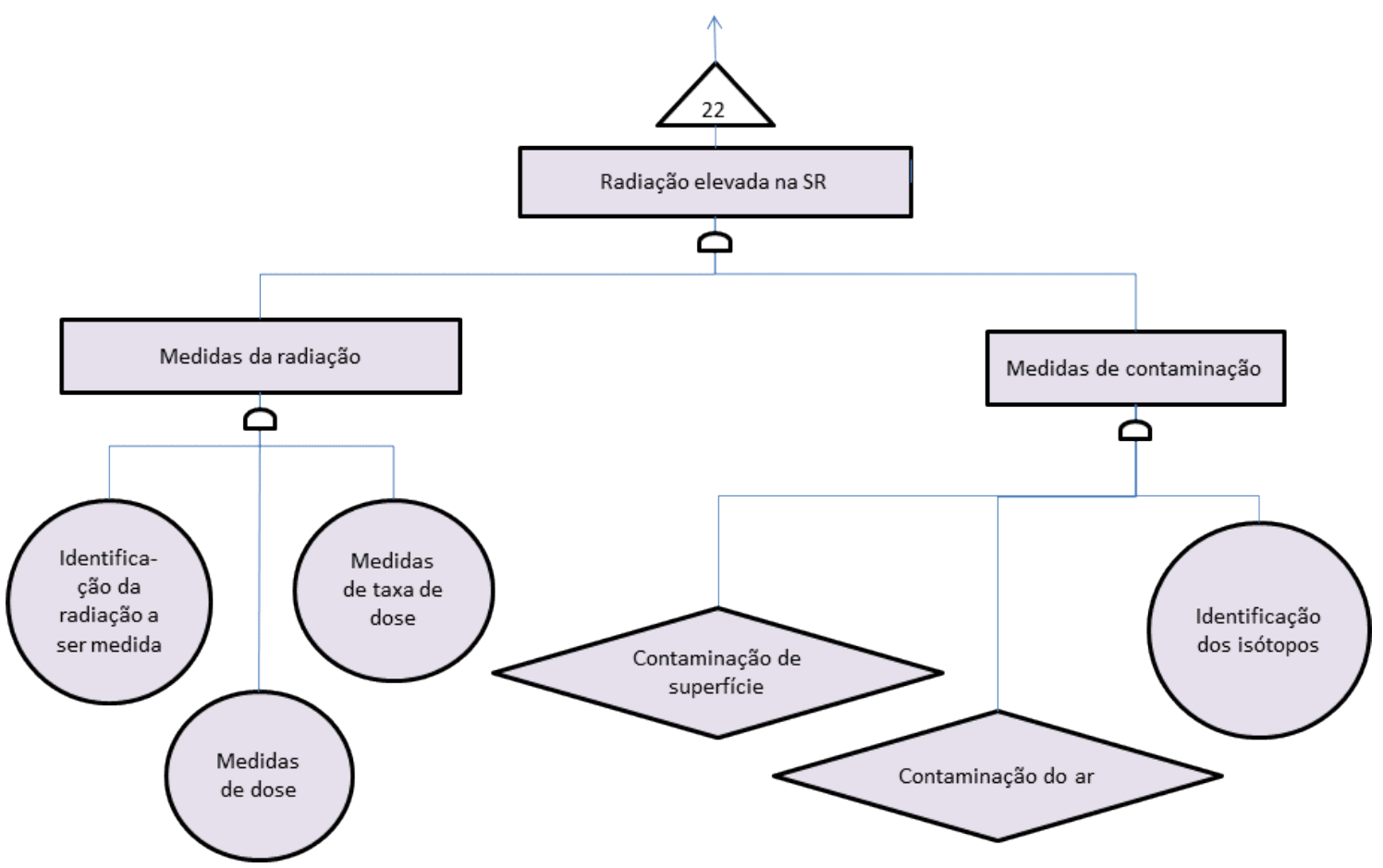

Figura 24 - Caso 3: Radiação elevada na Sala de Radiação 


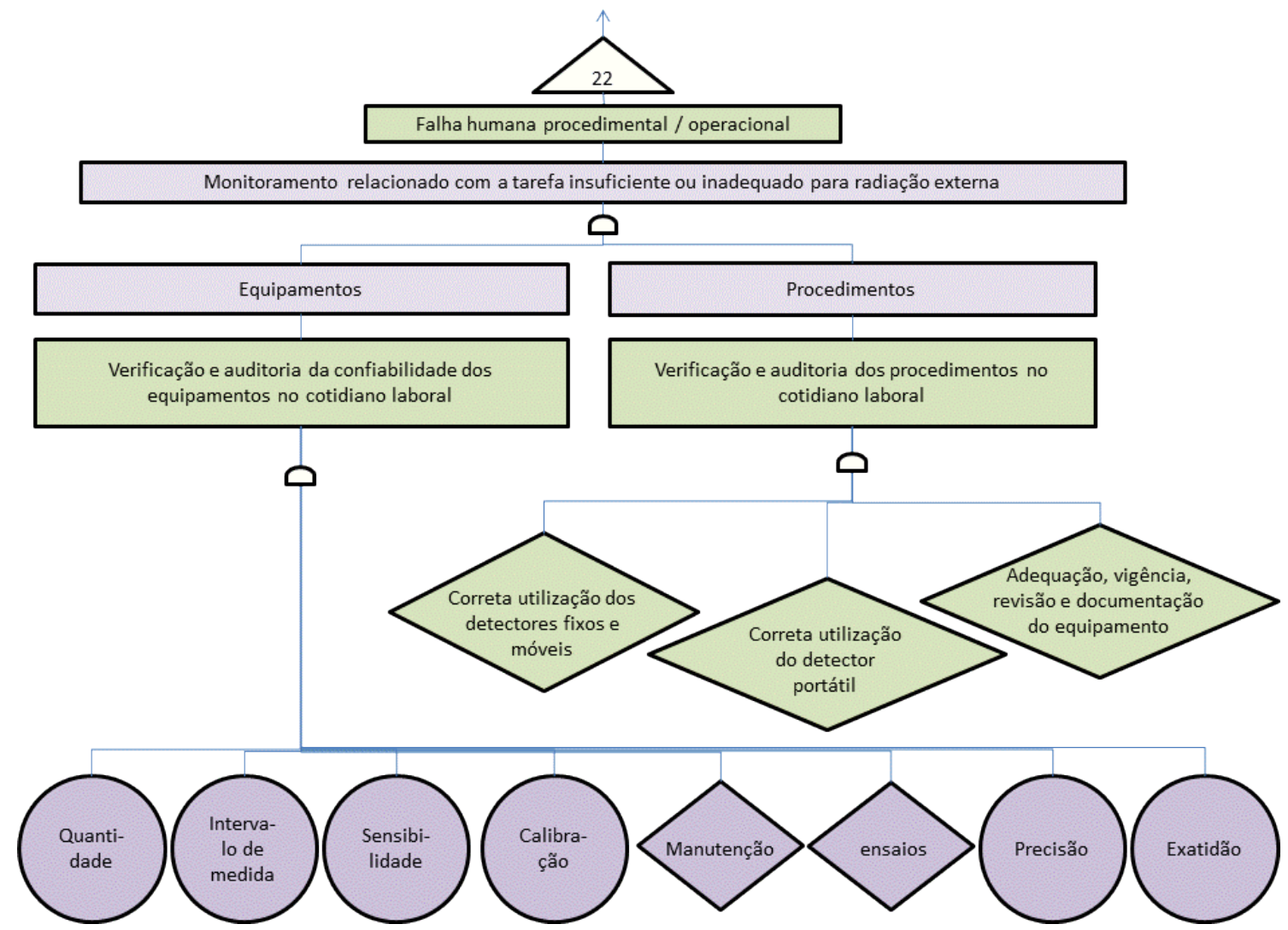

Figura 25 - Caso 3: Falha humana procedimental e/ou operacional

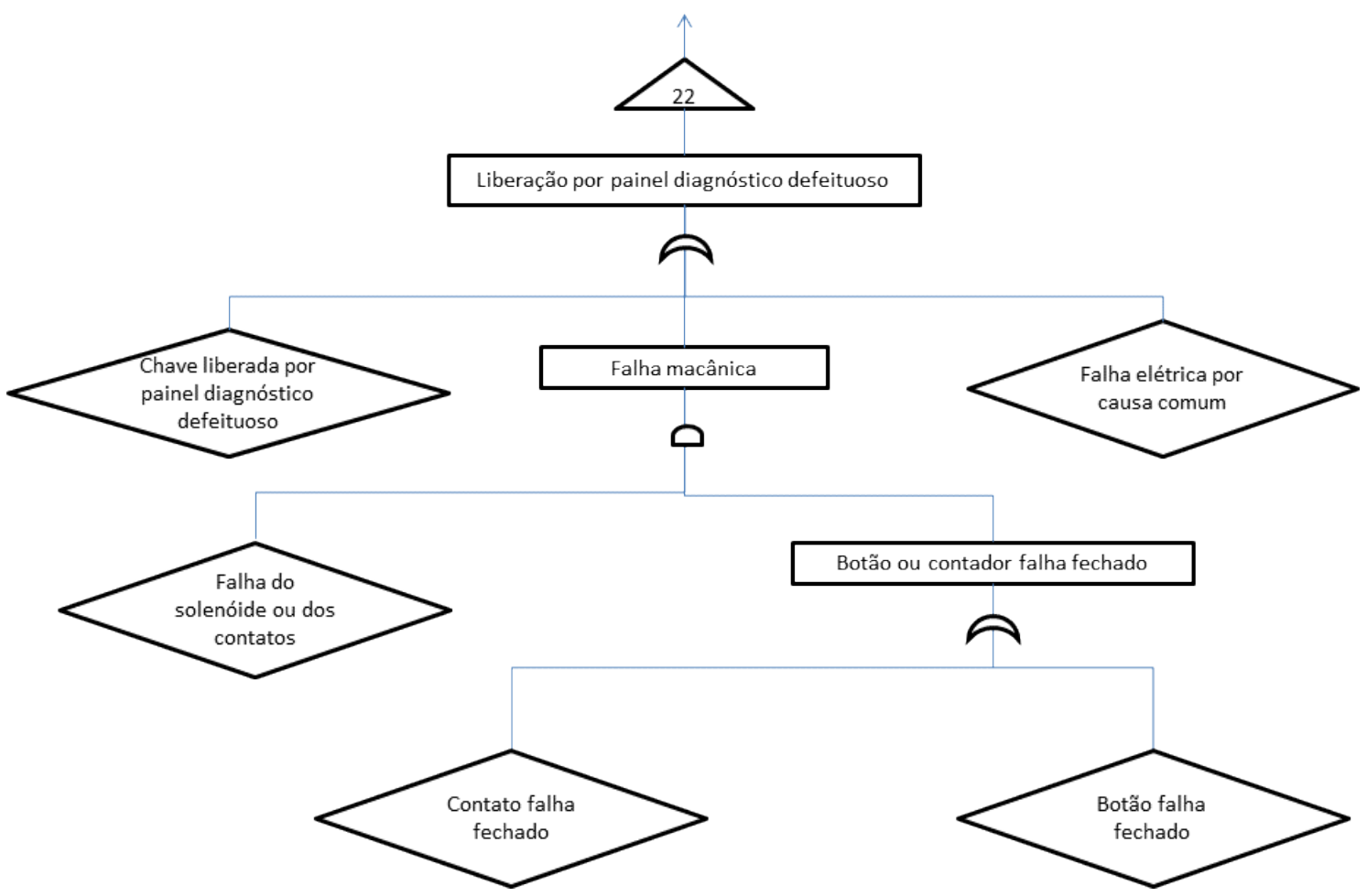

Figura 26 - Caso 3: Liberação por painel diagnóstico defeituoso 


\section{Conclusões}

Dado que a CIPR e o OIEA atualizaram recentemente as diretrizes básicas de proteção radiológica [2 - 3], o Brasil deve empreender nos próximos anos um trabalho de adequação de suas normas e resoluções, de acordo com as publicações internacionais. Os três princípios básicos de proteção radiológica, a saber: (i) justificação, (ii) otimização e (iii) limitação da dose foram ampliados para 10 princípios, conforme publicação do OIEA [3]:

1. Responsabilidade pela segurança: a principal responsabilidade para a segurança deve permanecer com a pessoa ou organização responsável pela instalação ou atividades que dão origem aos riscos da radiação.

2. Papel do governo: deve ser estabelecida e mantida uma estrutura governamental e legal eficaz para a segurança incluindo um órgão regulatório independente.

3. Liderança e gerência para a segurança: deve ser estabelecida uma liderança e gerência eficazes para a segurança em instalações e atividades pertinentes que dão origem aos riscos da radiação.

4. Justificação das instalações e atividades: as instalações e atividades que dão origem aos riscos de radiação devem fornecer um benefício global.

5. Otimização da proteção: a proteção deve ser otimizada para fornecer o grau mais elevado de segurança que possa ser racionalmente exequível.

6. Limitação dos riscos aos indivíduos: as medidas para o controle dos riscos da radiação devem assegurar que nenhum indivíduo arque com o risco de dano inaceitável.

7. Proteção à atual e futuras gerações: as pessoas e o ambiente, atuais e futuras devem ser protegidos aos riscos da radiação.

8. Prevenção dos acidentes: devem ser realizados todos os esforços práticos para evitar e mitigar acidentes nucleares e com radiação.

9. Prontidão e resposta à emergências: devem ser realizados arranjos para a prontidão e a resposta em emergências para incidentes nucleares e de radiação.

10. Ações protetoras para reduzir riscos da radiação existente ou não regulamentada: as ações de proteção para reduzir os riscos de radiação existente ou não regulamentada devem ser justificadas e otimizadas.

As reflexões propostas na presente tese vêm ao encontro das novas exigências internacionais, propondo ações cabíveis e passíveis de serem incorporadas na prática laboral. Dentro do escopo deste trabalho de pesquisa, foram abordadas as questões relacionadas ao monitoramento das radiações ionizantes e sua otimização em três diferentes aspectos: (i) a disseminação da informação em proteção radiológica, (ii) o desenvolvimento de um programa auditor para o monitoramento das radiações ionizantes e (iii) desenvolvimento de cenários para exposições potenciais. Cada um destes itens foi apresentado e justificado, de forma a possibilitar às instalações radiativas empreender ações consistentes e conscientes a favor da capacitação do seu efetivo e da segurança dos trabalhadores laboralmente expostos. As reflexões sobre a necessidade de um programa auditor de monitoramento abarcam os itens 1, 3, 4 e 5 das novas exigências internacionais. Os caminhos propostos para o desenvolvimento de cenários, permitindo prever uma certa probabilidade de ocorrência das exposições potenciais e a probabilidade de se atingir um determinado valor da dose, podem auxiliar a viabilizar os itens 6 
a 10 dos novos princípios de proteção radiológica, sobretudo no que tange os quesitos "prevenção contra acidentes" e "ações protetoras para reduzir riscos da radiação".

Dentro dos princípios da proteção radiológica, que deve ser econômica e eficaz, a implementação de um programa de monitoramento auditor permite avaliar se os critérios e ações previamente planejadas e/ou estabelecidas pelo Serviço de Proteção Radiológica estabelecidos estão sendo ou não atendidos foram implementados com eficácia e continuam adequados. Os fatos resultantes dos procedimentos de auditoria auxiliam a detectar deficiências no processo, possibilitando conclusões e recomendações diante de possíveis fatores desencadeadores de exposições indevidas. Por meio de exames cuidadosos e sistemáticos das atividades realizadas, em cada tipo de monitoramento, a auditoria infere segurança ao processo, respaldando o trabalhador na realização do monitoramento relacionado com a tarefa e a instalação que empreende ações responsáveis a favor da segurança.

Em relação às exposições potenciais, somente duas publicações da CIPR, a saber: a de no64 e 76 são expressivas e desenvolvem o assunto mas, ainda que forneçam a fundamentação teórica, são incompletas em seus exemplos, conforme demonstramos com a completeza das árvores de falhas elaboradas nesta tese. Destas duas publicações da CIPR, a respeito das exposições potenciais, verifica-se que a teoria fundamental necessita ser detalhada para cada tipo de atividade humana e cada tipo de fonte de radiação ionizante. Como a própria publicação 76 da CIPR menciona, existe ainda uma grande falta de conhecimento das probabilidades de falhas nos vários ramos da árvore de porfírio e atualmente constitui um vasto campo de pesquisa da proteção radiológica. $\mathrm{O}$ desenvolvimento deste campo de estudo das probabilidades de falhas nos vários ramos da árvore de porfírio pode ser bastante auxiliado pelas Tecnologias da Informação e Comunicação (TIC), que se encontram em franco crescimento, aproximando pesquisadores geograficamente distantes, promovendo o diálogo entre as comunidades internacionais e facilitando a disseminação do conhecimento de forma ampla e eficaz.

No que tange às instalações radiativas, dentro do escopo deste trabalho de pesquisa, a informatização dos programas de monitoramento da radiação ionizante e sua otimização é uma ferramenta de amplo alcance para a disseminação da informação e pesquisa. Uma vez que as novas diretrizes internacionais e futuras normas nacionais devem impactar diretamente no cotidiano laboral das instalações radiativas, a informatização e comunicação dos programas de proteção radiológica, fazendo uso das TIC, permitirão às instalações em todo o Território Nacional beneficiarem-se das informações mais atualizadas no que concerne o monitoramento das radiações ionizantes e a otimização da proteção. A tecnologia nuclear avança a passos largos nos mais diversos setores. $\mathrm{O}$ uso das radiações se faz cada vez mais presente na vida cotidiana. Baseada nas lições aprendidas do passado, nos desafios do presente e nas novas perspectivas para o futuro, esta tese buscou apresentar novos caminhos e ações a favor da segurança que possam contribuir, de forma justificada e eficaz, para a evolução da proteção radiológica diante dos novos paradigmas que buscam responder à complexidade dos novos cenários mundiais. 


\section{Trabalhos futuros}

\subsection{Como resultado direto deste trabalho}

No fim da sessão 1.1 sugerimos:

- Uma vez que os tipos e funções do monitoramento são os mesmos para as instalações radiativas e nucleares, este trabalho pode ser o princípio de um trabalho de pesquisa para a informatização dos RAS (Relatório de Análise de Segurança), que as instalações nucleares que devem confeccionar em substituição ao Plano de Proteção Radiológica.

Das sessões 6.1 e 6.2 sugerimos:

- Completar os ramos das árvores analíticas que permaneceram inexecutáveis representadas pelos losangos.

\subsection{Trabalhos decorrentes futuros}

Após dimensionamento, execução e avaliação de resultados do sistema operacional e trabalho de pesquisa dos programas de monitoramento da radiação ionizante e sua otimização, propomos como possibilidades de trabalhos futuros o que segue:

- O desenvolvimento de um sistema operacional integrado, que possa ser estendido a todos os itens exigidos no Plano de Proteção Radiológica. Para que se possa ter uma dimensão adequada do programa de proteção radiológica, sugerimos desenvolver minuciosamente os campos de atividades que podem ser adaptados a cada instalação em função das operações executadas e características das fontes de radiação ionizante utilizadas.

- Conforme a árvore de porfírio publicada em 1990 pelo OIEA, um dos itens a ser considerado e desenvolvido é o planejamento e preparo eficaz para emergência. Como atualmente os Planos de Proteção Radiológica trascuram tanto a auditoria do monitoramento relacionado com a tarefa como as ações para quantificação probabilística das exposições potenciais, sugerimos o desenvolvimento e informatização de árvores de falhas que possam refletir cenários abrangentes e fornecer caminhos para a identificação de fatores desencadeadores das ocorrências de exposições potenciais para os diferentes segmentos de atividades que envolvam as radiações ionizantes.

- Sugerimos a reavaliação da árvore de porfírio recomendada pelo OIEA em sua publicação 102 a partir de um estudo minucioso de diferentes árvores de eventos e árvores de falhas, que possibilite verificar se diferentes árvores se aplicam às diferentes falhas e atividades humanas envolvendo a radiação ionizante, conforme demonstrados em nossos exemplos. 


\section{Bibliografia}

1. COMISSÃO NACIONAL DE ENERGIA NUCLEAR. NN 3.01: Diretrizes Básicas de Proteção Radiológica. Rio de Janeiro, 2011

2. INTERNATIONAL COMMISSION ON RADIOLOGICAL PROTECTION. The 2007 Recommendations of the International Commission on Radiological Protection, publicação ICRP 103. Viena, 2007

3. INTERNATIONAL ATOMIC ENERGY AGENCY. Safety Standards for Protecting people and the environement - Radiation protection and safety of radiation sources: international basic safety Standards, General Safety Requirements - Part 3. Viena, 2014

4. INTERNATIONAL ATOMIC ENERGY AGENCY. The radiological accident in Soreq. Vienna, 1993.

5. COMITÊ GESTOR DA INTERNET NO BRASIL. Pesquisa Sobre o Uso das Tecnologias da Informação e da Comunicação no Brasil 2008, Núcleo de Informação e Coordenação do Ponto BR, São Paulo: 2009

6. COMITÊ GESTOR DA INTERNET NO BRASIL. Pesquisa Sobre o Uso das Tecnologias da Informação e da Comunicação no Brasil 2009, http://www.cetic.br/tic/2009/index.htm, acessado em 8 de junho de 2014

7. COMITÊ GESTOR DA INTERNET NO BRASIL. Pesquisa sobre o uso das Tecnologias de Informação e Comunicação no Brasil - TIC Domicílios e Empresas 2010, http://www.cgi.br/media/docs/publicacoes/2/tic-domicilios-e-empresas-2010.pdf, acessado em 8 de junho de 2014

8. COMITÊ GESTOR DA INTERNET NO BRASIL. Pesquisa sobre o uso das Tecnologias de Informação e Comunicação no Brasil - TIC Domicílios e Empresas 2011, http://www.cgi.br/media/docs/publicacoes/2/tic-domicilios-e-empresas-2011.pdf, acessado em 8 de junho de 2014

9. COMITÊ GESTOR DA INTERNET NO BRASIL. Pesquisa sobre o uso das Tecnologias de Informação e Comunicação no Brasil - TIC Domicílios e Empresas 2012, http://www.cgi.br/media/docs/publicacoes/2/tic-domicilios-e-empresas-2012.pdf, acessado em 8 de junho de 2014

10. LEVY, D. S., SORDI, G.M.A.A. Tecnología informática y radioprotección: informatización de la optimización y investigación del perfil de utilización. In: Simposio Internacional de Protección Radiológica - Encuentro Iberoamericano de Protección Radiológica, 2012, Cusco

11. GIRONZINI, E.M. Contribución de las redes sociales para el desarrollo de La protección radiológica. In: Simposio Internacional de Protección Radiológica Encuentro Iberoamericano de Protección Radiológica, 2012, Cusco

12. LEFAURE, C., BALDUYCK, S., BARBEY, P., BARRET, C., BARREY, N., BENQUE, B., FIGUEIRA, M., MOZZICONACCI, J.G., SEGUIN, B., TOURNEUX, C. A bottom up experience: the French RPO and qualified experts regional networks. In: 13th International Congress of the International Radiation Protection Association (IRPA), 2012, Glasgow 
13. GIRONZINI, E.M. Social Networking and Radiation Protection. In: 13th International Congress of the International Radiation Protection Association (IRPA), 2012, Glasgow

14. EVANS, S., DENMAN, A.R., GOLDSTONE, K., EVE, J. E-IRMER - An e-Learning package for Radiation Protection training of Health Staff. In: 13th International Congress of the International Radiation Protection Association (IRPA), 2012, Glasgow

15. HEATON, B., ZABIEREK, G., MOSELEY, T. Distance learning course in radiation protection. In: 13th International Congress of the International Radiation Protection Association (IRPA), 2012, Glasgow

16. ALBUQUERQUE, S. M.; LEVY, D. S.; SORDI, G. M. A. A.; LEVY, P. J. Informatization of Multi-Criteria Analysis Outranking: A Software to Improve Decision-Making in Radiological Protection Optimization Programs. In: 13th International Congress of the International Radiation Protection Association (IRPA), 2012, Glasgow

17. LEVY, D. S.; SORDI, G.M.A.A. Informatization and integration of radiological protection optimization programs. In: 13th International Congress of the International Radiation Protection Association (IRPA), 2012, Glasgow

18. INTERNATIONAL ATOMIC ENERGY AGENCY . IAEA ORPNET. http://wwwns.iaea.org/tech-areas/communication-networks/orpnet/ - acesso em 01 de março de 2014

19. INTERNATIONAL COMMISSION ON RADIOLOGICAL PROTECTION. Cost-Benefit Analysis in the Optimization of Radiation Protection, publicação ICRP 37 Ann. ICRP 10 (2-3). Viena, 1983

20. INTERNATIONAL COMMISSION ON RADIOLOGICAL PROTECTION. Optimization and Decision-Making in Radiological Protection, publicação ICRP 55 Ann. ICRP 20 (1). Viena, 1990.

21. INTERNATIONAL COMMISSION ON RADIOLOGICAL PROTECTION. Protection from Potential Exposures - Application to Selected Radiation Sources, publicação ICRP 76 Ann. ICRP 27 (2). Viena, 1997

22. INTERNATIONAL COMMISSION ON RADIOLOGICAL PROTECTION. General Principles of Monitoring for Radiation Protection of Workers, publicação ICRP 35. Viena, 1983

23. INTERNATIONAL COMMISSION ON RADIOLOGICAL PROTECTION. General Principles for the Radiation Protection of Workers, publicação ICRP 75. Viena, 1997

24. INTERNATIONAL ATOMIC ENERGY AGENCY. Basic Requirements for Personnel Monitoring, Safety Series n.14, Viena, 1980

25. INTERNATIONAL ATOMIC ENERGY AGENCY. Basic Principles for Occupational Radiation Monitoring, Safety Series n. 84, Viena, 1987

26. INTERNATIONAL COMMISSION ON RADIOLOGICAL PROTECTION. Recommendations of the International Commission on Radiological Protection, Publicação ICRP 1. Viena, 1958.

27. INTERNATIONAL COMMISSION ON RADIOLOGICAL PROTECTION. Report on Decision at the 1959 Meeting of the International Commission on Radiological Protection, Addendum to ICRP Publication 1 (1958 Recommendations), Publicação ICRP 2. Viena, 1959. 
28. Normas Básicas de Proteção Radiológica, resolução CNEN no 06/73 publicadas no Diário Oficial da União no 180 em 19 de setembro de 1973, secção I, parte II, pág. 3.129 a 3.175 .

29. SORDI, G.M.A.A. Evolução dos Paradigmas de Proteção Radiológica, Apostila didática para disciplina de pós-graduação Elementos Fundamentais de Proteção Radiológica. www.ipen.br/ensino - acessado em 13 de junho de 2015

30. INTERNATIONAL COMMISSION ON RADIOLOGICAL PROTECTION. Recommendations of the International Commission on Radiological Protection, publicação ICRP 9. Viena, 1965

31. INTERNATIONAL ATOMIC ENERGY AGENCY. Basic Safety Standards for Radiation Protection, Safety Series n.9, Viena, 1967

32. INTERNATIONAL COMMISSION ON RADIOLOGICAL PROTECTION. Implications of Commission Recommendations that Doses Be Kept as Low as Readily Achievable, publicação ICRP 9. Viena, 1973

33. INTERNATIONAL ATOMIC ENERGY AGENCY. Basic Safety Standards for Radiation Protection, 1982 Edition Safety Series no 9, Viena, 1982

34. INTERNATIONAL COMMISSION ON RADIOLOGICAL PROTECTION. Implications of Commission Recommendations That Dosis Be Kept as Low as Readily Achievable, publicação ICRP 22. Viena, 1973

35. INTERNATIONAL COMMISSION ON RADIOLOGICAL PROTECTION. Recommendations of the International Commission on Radiological Protection, publicação ICRP 26. Viena, 1977.

36. Diretrizes Básicas de Radioproteção, publicadas no Diário Oficial da União em 01 de agosto de 1988, Resolução CNEN no 12/88.

37. INTERNATIONAL ATOMIC ENERGY AGENCY. Intermational Basic Safety Standards for Protection Against lonizing Radiation and for the Safety of Radiation and for the Safety of Radiation Sources, Safety Series n.115, Viena, 1996

38. INTERNATIONAL COMMISSION ON RADIOLOGICAL PROTECTION. Recommendations of the International Commision on Radiological Protection Publication, publicação ICRP 60. Viena, 1991

39. INTERNATIONAL COMMISSION ON RADIOLOGICAL PROTECTION. Protection from Potential Exposure - A Conceptual Framework, publicação ICRP 64. Viena, 1993

40. UNIPRORAD Unificação dos Programas de Proteção Radiológica. www.uniprorad.com.br - acesso em 01 de julho de 2014

41. LEVY, D.S. Contribuição para informatização dos programas de proteção radiológica para instalações radiativas, Dissertação (mestrado), Instituto de Pesquisas Energéticas e Nucleares, São Paulo, 2012

42. RODRIGUES, D.L. Otimização no controle dos valores de radiação nas dependências do cíclotron de $\mathbf{3 0} \mathrm{MeV}$ do IPEN, Dissertação (mestrado), Instituto de Pesquisas Energéticas e Nucleares, São Paulo, 2002

43. World Wide Web Consortium, http://www.w3.org/ - acesso em 01 de março de 2014

44. Improving MySQL Query Analyser - Performance Optimization, http://www.mysql.com/ - acesso em 22 de agosto de 2010 
45. Sqlserver, Net Solutions, http://www.sqlserver.com/ - acesso em 01 de março de 2014

46. Php, http://www.php.net/ - acesso em 01 de março de 2014

47. INTERNATIONAL ATOMIC ENERGY AGENCY. Safety Series n. 102: Recommendation for the Safe Use and Regulation of the Radiation Source in Industry, Medicine and Teaching. Viena, 1990

48. INTERNATIONAL COMMISSION ON RADIOLOGICAL PROTECTION. Individual Monitoring for Internal Exposure of Workers, publicação ICRP 78, Ann. ICRP 27 (34). Viena, 1997

49. INTERNATIONAL COMMISSION ON RADIOLOGICAL PROTECTION. The optimization of the Radiological Protection: Broadening the Process, publicação ICRP 101b, Ann. ICRP 36 (3). Viena, 2006

50. SORDI, G.M.A.A. Equations proposal to determine risk limits for workers and for public individuals. In: 10 International congress of the international radiation protection association on harmonization of radiation, human life, and the ecossystem. Hiroshima, Japão. Proceedings: Tokyo. Japan Health Physics Society, 2000.

51. INTERNATIONAL ATOMIC ENERGY AGENCY. Procedures for the systematic appraisal of operational radiation protection programmes, publicação IAEA TECDOC 430. Vienna, 1987. 


\section{ANEXO A - Filosofia e Técnica para Monitoramento do Trabalhador para Radiação Ionizante}

A ferramenta de pesquisa UNIPRORAD disponibilizada perguntas e respostas que devem ser consideradas quando da elaboração de um programa de monitoramento, de maneira a satisfazer a todas as exigências nacionais e internacionais. $O$ referido sistema contém as informações detalhadas de cada tipo de monitoramento das radiações ionizantes, com referência às publicações utilizadas no desenvolvimento de cada tópico, bem como indicações dos inter-relacionamentos entre os diversos assuntos e publicações. As 349 questões por nós desenvolvidas, que permitem ao usuário responder a todas as questões cabíveis aplicadas à sua situação específica, encontram-se neste ANEXO.

\section{Conceitos fundamentais}

\section{1 - 0 que se entende por exposição laboral?}

Aquela contraída no trabalho como resultado de situações que podem razoavelmente ser relacionadas como sendo de responsabilidade do gerenciamento da operação.

\section{2 - Ser considerado trabalhador depende da função do servidor na empresa?}

Não, todos aqueles que trabalham em locais onde a exposição esta relacionada com a responsabilidade do gerente de operação são considerados como expostos laboralmente.

\section{3 - O que se entende por exposição normal e que tipo de exposição ela inclui?}

Aquela que pode ser razoavelmente considerada de ser recebida, inclui tanto as exposições oriundas de operações que são conduzidas como planejadas, como aquelas que não são pretendidas, mas que são oriundas de eventos de pequena consequência. Os eventos têm probabilidades iguais ou maiores do que $10^{-2} \mathrm{a}^{-1} \mathrm{e}$ as consequências obedecem os limites de dose anuais.

\section{4- O que se entende por exposição potencial?}

Aquela que não é pretendida, mas para a qual existe um potencial de ocorrência, ainda que não seja certa a sua realização. A exposição potencial pode ser prevista e a sua probabilidade de ocorrência estimada, mas não pode ser prognosticada em detalhes.

5 - Em que sistemas de proteção devem ser incluídas as exposições potenciais e como devem ser as probabilidades de ocorrência e as doses previsíveis?

As exposições potenciais devem ser incluídas nos sistemas de proteção referentes às práticas. As suas probabilidades de ocorrência devem ser inferiores a $10^{-2} \mathrm{a}^{-1}$ e as doses previsíveis não necessitam obedecer os limites de dose anuais. 


\section{6 - Qual é a finalidade da proteção radiológica?}

Proporcionar um padrão apropriado de proteção aos seres humanos em praticas que fazem uso das radiações ionizantes sem limitar indevidamente o beneficio prático proporcionado pela exposição à radiação.

7 - Como é direcionada a proteção radiológica com relação aos efeitos biológicos das radiações ionizantes?

É direcionada no sentido de evitar a ocorrência de efeitos determinísticos, pela conservação das doses abaixo dos limiares pertinentes e assegurar que todas as etapas racionais foram consideradas para reduzir a indução de efeitos estocásticos.

8 - Qual é o principal objetivo da proteção radiológica, segurança laboral e sua ascendente mais próxima, a saúde laboral?

É obter e manter um ambiente de trabalho aceitavelmente seguro e saudável.

9 - Qual é o intuito dos princípios básicos de proteção radiológica para a obtenção e manutenção de um ambiente de trabalho aceitavelmente seguro e saudável?

É o de evitar a exposição à radiação ionizante, de prevenir ou reduzir a possibilidade de exposições potenciais e de atenuar as consequências de incidentes e acidentes.

10 - Que limites de dose os trabalhadores devem obedecer em condições normais de trabalho?

Devem obedecer os limites de dose anuais, LDA, os limites de restrição das doses, LRD, e os limites autorizados, LDU.

\section{1 - O que a CIPR entende por responsabilidade?}

O dever de estabelecer os objetivos, fornecer as medidas necessárias para alcançar os objetivos propostos e garantir que estas medidas estão sendo conduzidas adequadamente.

12 - $O$ que a CIPR entende por autoridade?

O dever de possuir os recursos necessários para cumprir com as responsabilidades.

13 - De acordo com a CIPR quem deve deter a responsabilidade da proteção radiológica?

Aqueles indivíduos que possuem a autoridade.

14 - De acordo com a CIPR a responsabilidade prevê uma componente conhecida como prestação de contas. $O$ que esta ultima exige e no que implica?

A prestação de contas exige uma revisão continua do desempenho o ser obtido de tal modo que as falhas possam ser identificadas e sejam aplicadas as medidas para evitar uma nova ocorrência. A prestação de contas implica na necessidade de estabelecer um programa de verificação para determinar quão eficientemente estão sendo observados os objetivos iniciais. 
15 - A quem cabe dentro de uma instalação a responsabilidade principal para a obtenção e manutenção de um controle satisfatório de exposição à radiação ionizante?

Cabe aos grupos gerenciais de instalação que conduz a operação causadora das exposições.

16 - Qual é a estrutura recomendada pelo CIPR para o controle operacional das exposições à radiação ionizante em qualquer local de trabalho?

a. Deve-se efetuar uma avaliação radiológica inicial de todos os aspectos relacionados com a operação para identificar as fontes de exposição habituais e potenciais racionalmente previsíveis, para fazer previsões realistas das doses e para determinar as medidas de proteção radiológica necessárias para satisfazer o principio da otimização.

b. Deve-se estabelecer um programa de proteção radiológica operacional, proporcional ao grau de risco, para garantir o gerenciamento efetivo das medidas necessárias para satisfazer o principio da otimização.

17 - De acordo com a CIPR o que deve incluir um programa de proteção radiológica?

- Os métodos a serem utilizados no controle das exposições incluindo a designação das áreas controladas e supervisionadas

- As regras locais que os trabalhadores devem obedecer

- As disposições relacionadas com o monitoramento de trabalhadores e do local de trabalho

- As responsabilidades locais

- Qualquer necessidade quanto ao treinamento

18- 0 que se entende em proteção radiológica por área controlada?

Aquela área em que as condições normais de trabalho, incluindo a possível ocorrência de percalços menores, exigem que os trabalhadores sigam procedimentos e práticas muito bem estabelecidos, elaborados especificamente com o propósito de controlar as exposições à radiação ionizante.

19 - O que se entende em proteção radiológica por área supervisionada?

Aquela área em que as condições normais de trabalho são mantidas sob consideração, porém, normalmente não são necessários procedimentos especiais.

20 - Quais devem ser as condições de exposição à radiação ionizante fora das áreas demarcadas?

As taxas de dose causadas pelas fontes e o risco de contaminação pelos materiais radioativos sob forma não selada devem ser suficientemente pequenos para garantir que, em condições normais, o grau de proteção para aqueles que trabalham sob estas premissas, é comparável ao grau de Proteção necessário às exposições do público.

21 - Para a classificação das áreas que situações de exposição devemos considerar e nos casos em que não existem os problemas de contaminação como pode ser definida a área demarcada? 
Devemos considerar tanto as situações de exposição normal como potencial. As áreas demarcadas, quando não existem problemas de contaminação podem ser delimitadas pelos valores das taxas de dose.

\section{2 - Quando e porque torna-se necessário estabelecer uma área controlada?}

Torna-se necessário estabelecer uma área controlada quando são exigidos procedimentos operacionais específicos porque os controles de engenharia são considerados insuficientes ou não são confiáveis com suficiente segurança para proporcionarem o grau apropriado de proteção.

23 - Quando deve ser determinada a necessidade de estabelecer uma área controlada e no que deve estar baseada?

A necessidade de se estabelecer uma área controlada deve ser determinada durante a avaliação radiológica inicial e deve estar baseada no valor provável das exposições normais e na probabilidade a dimensão das exposições acidentais.

\section{4 - Quais são as exigências mínimas para uma área ser demarcada como controlada?}

a. Estarem adequadamente demarcadas.

b. Estarem devidamente sinalizadas para indicar aos trabalhadores, especialmente ao grupo de manutenção, que são aplicados procedimentos especiais na área e que podem existir fontes de radiação ionizante no local.

c. Os acessos sejam restringidos aos trabalhadores que foram treinados adequadamente de maneira que saibam reconhecer a necessidade ou estejam capacitados a implementar e manter os sistemas de procedimentos operacionais necessários para limitar as exposições.

25 - Em que condições pessoas não devidamente treinadas podem ter acesso a áreas controladas?

Podem ter acesso a áreas controladas todas as pessoas, como visitantes desde que estejam acompanhadas por alguém que recebeu o treinamento ou as instruções adequadas.

26 - No trabalho em presença de fontes radioativas não seladas quando e por que são necessários procedimentos especiais?

São necessários procedimentos especiais quando podem surgir contaminações no ar e nas superfícies que por sua vez podem provocar incorporações no trabalhador, uma vez que nem sempre é possível controlar as incorporações somente por meio da confiança nos controles de engenharia, particularmente no evento de um incidente ou acidente. Estes procedimentos especiais são necessários para evitar ou reduzir a possibilidade destas incorporações e para controlar a dispersão da contaminação.

\section{7 - Quando as áreas supervisionadas se tornam necessárias e qual é o seu propósito?}

a. Quando for necessário manter as condições de trabalho bob custódia.

b. Quando não for necessário definir procedimentos operacionais. 
O propósito delas é determinar se o comportamento da área deve ser alterado por causa, por exemplo, das circunstancias que foram imprevistas na avaliação radiológica inicial ou pela ocorrência de algum colapso no controle, seja de engenharia ou de procedimento, em qualquer área controlada adjacente.

28 - O que é necessário para adentrar a uma área supervisionada?

É necessário o mínimo de formalidades para que qualquer trabalhador possa adentrar nela.

29 - Pode-se trabalhar com material radioativo em uma área supervisionada?

Sim, exemplos:

a. Onde são manuseadas pequenas atividades de substancias radioativas sob forma não selada e onde existe um pequeno potencial para a incorporação.

b. Onde são utilizadas quantidades traçadoras de material radioativo, como em pesquisa.

c. Onde são manuseados materiais contendo radionuclídeos naturais em concentração pequenas.

30 - Em áreas supervisionadas quando são necessárias instruções de trabalho?

Onde pode haver dispersão de contaminação

31 - Quais são as exigências mínimas em uma área demarcada?

a. A existência de um programa de inspeção para detectar qualquer deterioração nas disposições de proteção.

b. Que sejam demarcadas com sinalização, sempre que factível .

32 - Quais são dois exemplos para os quais não é factível demarcar com sinalização as áreas supervisionadas?

Cabines de avião e determinados setores em hospitais.

33 - Que fatores devem ser considerados para determinar a limitação das áreas demarcadas considerando o uso de níveis de referência da taxa de dose ou contaminação do ar ou de superfície?

a. A não ser que as condições locais sejam estáveis devem ser considerados os valores futuros ao invés dos valores atuais.

b. Deve ser evitado o uso de valores derivados baseados em suposições cautelosas.

c. Todos os critérios usados para definir as zonas limítrofes devem estar baseados em suposições realísticas principalmente, em relação ao fator de ocupação que é pertinente à situação. 
34 - Quais são os objetivos em se estabelecer limites externos das áreas demarcadas?

Evitar o que segue:

a. Definição de áreas, sem necessidade.

b. Definição de áreas indevidamente grandes.

c. A necessidade de medir taxas de dose ou contaminação com valores pequenos ou desprezíveis.

35 - Para estabelecer as áreas demarcadas pode-se especificar áreas maiores do que as estritamente necessárias? Por que?

Sim, para que possam ser utilizadas as barreiras físicas existentes, como zona limítrofe.

36 - Qual é o propósito dos controles de engenharia e quando devem ser introduzidos?

O propósito é separar fisicamente a fonte do trabalhador e, portanto, evitar ou reduzir tanto as exposições a fontes externas como às incorporações. Os controles de engenharia devem ser introduzidos na fase de projeto e devem ser considerados antes da aplicação de outras medidas de proteção, porém podem tornar-se necessárias modificações e a introdução destes controles em uma fase posterior, onde a experiência mostra que são apropriados, no interesse da otimização da proteção.

37 - O que são incluídos nos principais sistemas de controle de engenharia relacionados com a proteção radiológica?

a. A blindagem;

b. Os sistemas de ventilação

c. Os sistemas para evitar adulterações de modo a restringir o acesso a uma fonte

d. Os alarmes de taxa de dose e de contaminação

e. Os depósitos, para controle de seu acesso.

38 - O que ocorre, com o transcorrer do tempo, com todo sistema de controle de engenharia relacionado com a proteção radiológica e como pode ser evitado?

O sistema deteriora-se e pode necessitar ser modificado por uma variedade de razões incluindo fatores operacionais não relacionados com a proteção radiológica. Esta deterioração pode ser evitada se forem realizadas revisões e verificações periódicas de sua eficácia. Esta última deve ser verificada onde as manutenções e modificações realizadas possam ter afetado a sua condição de operação.

39 - O que a CIPR sugere para apoiar o julgamento de se uma ação de proteção radiológica é razoável?

a. O bom senso, pois ele reflete a experiência, o conhecimento e o exercício de julgamentos profissionais como por exemplo um custo muito pequeno em uma mudança que reduza as doses, deve ser empreendido ainda que as doses já sejam bem pequenas. 
b. A boa prática, pois esta compara aquilo que foi ou é esperado ser obtido com aquilo que foi obtido em instalações ou práticas similares ou relacionadas. Deve-se ter o cuidado de garantir que seja mantida a racionalidade e que as ações desnecessárias não constituam norma.

40 - Quais são as grandezas físicas de proteção utilizadas nos limites primários anuais?

a. Dose equivalente num órgão ou tecido para radiação externa;

b. Dose equivalente comprometida para a radiação interna;

c. Dose efetiva para irradiação de corpo inteiro.

41 - Quais são as grandezas físicas de proteção utilizadas nos limites secundários anuais conhecidos, também, como grandezas operacionais?

a. Dose equivalente ambiente para o monitoramento de área para radiação penetrante.

b. Dose equivalente direcional para monitoramento de área para radiação pouco penetrante.

c. Dose equivalente pessoal para o monitoramento individual para exposição externa.

d. Dose incorporada para monitoramento individual para a radiação interna, também conhecida como contaminação interna.

\section{2 - Que tipo de estimativa das doses efetivas proporcionam as grandezas operacionais?}

Proporcionam valores que evitam a sub e sobre estimativa excessiva na maioria dos campos de radiação encontrados em situações práticas.

43 - A que tipo de procedimento estão ligados os limites de restrição de dose e constituem uma exigência explicita?

Estão ligados ao decréscimo nas doses efetivas para os indivíduos (restrição de dose) e dos riscos para os indivíduos no caso da exposição potencial (restrição de risco) e constituem uma exigência explicita do procedimento de otimização da proteção.

\section{4 - Qual é o propósito da restrição da dose?}

É limitar o intervalo de opções de proteção no procedimento da otimização. Neste caso todas as opções de proteção radiológica deverão apresentar valores de doses individuais máximas inferiores ou no máximo iguais aos valores das restrições de dose; portanto a restrição de dose tem um significado prospectivo para poder ajudar a evitar que os indivíduos venham a receber valores de dose inadequados ou estejam submetidos a valores de risco inadequados.

45 - As restrições de dose constituem parte integrante de que princípio básico e portanto com o que elas se relacionam?

Elas são relacionadas com o principio da otimização da proteção conhecido também como princípio ALARA e portanto estão relacionadas à fonte. 
46 - De onde se originam os limites otimizados e que valores assumem?

Os limites otimizados se originam nas maiores doses na opção de proteção radiológica considerada solução analítica pelo principio de otimização. Eles assumem valores de 20 a $25 \%$ maiores do que as maiores doses previstas da opção de proteção que constitui a solução analítica.

47 - Quem emite os limites autorizados e a quem se destinam?

São emitidos pela autoridade competente do país e eles se destinam a quem efetuar um processo de otimização ou um determinado grupo de instalações, portanto os limites autorizados não são gerais e nem genéricos.

48 - Os métodos de monitoramento de radiação ionizante para fins de proteção radiológica o que devem fornecer e por que?

Devem fornecer estimativas suficientemente exatas dos limites admitidos pela autoridade competente do país ou limites otimizados possibilitando a obtenção de:

a. Concordância com eles (limites)

b. Condições de obediência a eles (limites)

c. Graus de proteção indispensáveis

49 - Em que grandezas físicas devem ser expressos os resultados dos monitoramentos e quando isto não ocorrer o que se deve introduzir?

Os resultados do monitoramento devem ser expressos nas grandezas físicas utilizadas nos limites emitidos pela autoridade competente do país, como por exemplo: as grandezas físicas utilizadas nos limites primários e secundários. Quando isto não for possível deve-se introduzir um modelo dosimétrico que relacione a grandeza física medida com a grandeza física recomendada pela autoridade competente do país.

50 - Os modelos dosimétricos que relacionam as grandezas físicas medidas com as grandezas físicas recomendadas pela autoridade competente do país que tipos de relações podem apresentar?

Podem apresentar relações simples como o dosímetro portado sobre o corpo e relacionado com a dose efetiva ou a dose equivalente pessoal ou ainda relações complexas que podem envolver os movimentos do trabalhador, a geometria da irradiação, vias de irradiação etc. como por exemplo a medida da contaminação de superfície relacionada com os limites básicos anuais.

\section{1 - Do que dependem os monitoramentos individuais em situação normal de trabalho?}

a. Da probabilidade de irradiação, externa e interna, consideradas independentemente.

b. Um tipo de monitoramento não justifica o outro.

c. A introdução de ambos, irradiação externa e contaminação interna, só se justificam em algumas situações peculiares.

52 - Como deve ser o monitoramento individual em exposições potenciais quando elas ocorrerem com relação às situações normais de trabalho? 
a. Os programas de monitoramento devem ser mais detalhados do que em situações normais de trabalho.

b. Os programas de investigação devem ser mais detalhados.

c. As estimativas de doses equivalentes ou absorvidas ou ainda comprometidas nos vários órgãos ou tecidos devem ser mais precisas e exatas do que nas situações normais de trabalho.

53 - 0 que se entende por nível de referência em proteção radiológica?

Um valor pré-determinado, para qualquer grandeza física usada nos programas de proteção radiológica que, se for ultrapassado ou prevê-se que seja ultrapassado, exigirá que seja tomada uma ação, ou decisão previamente definida.

\section{4 - Quais são os níveis de referência sugerido pela CIPR?}

Os níveis de referência sugeridos são: Registro, Investigação, Intervenção e Ação

55 - Por quem é estabelecido o nível de registro e quais são suas características principais?

É estabelecido pela gerência operacional ou autoridade nacional, permite o registro excluindo informações triviais e consultoria, porém, deve ser aplicado consistentemente, aplica-se principalmente para exposição laboral, com ênfase principal ao monitoramento individual e do local de trabalho.

56 - Por quem é estabelecido o nível de investigação e quais são as suas características principais?

É estabelecido pelo gerente operacional, que solicita uma investigação local (geralmente muito simples) se for excedido. Aplica-se principalmente à exposição laboral.

57 - Por quem é estabelecido o nível de intervenção e quais são suas características principais?

É estabelecido pela autoridade regulatória, aplica-se à exposição do publico para dose que pode ser evitada por uma contramedida especifica, frequentemente é mandatório.

\section{8 - O que se entende por nível de registro em proteção radiológica?}

Um valor de dose equivalente ou de incorporação definido formalmente, acima do qual, qualquer resultado, de um programa de monitoramento, apresenta interesse suficiente para justificar o seu registro.

59 - 0 que se deve ser feito com os resultados inferiores ao nível de registro?

Devem ser ignorados. São tratados como zero para propósitos de proteção radiológica. Nos assentamentos declara-se inferior ao nível do registro. 
60 - Qual é a finalidade do nível de registro em proteção radiológica?

Eliminar o monitoramento onde as doses são muito pequenas e, portanto insignificantes com relação à proteção radiológica.

61 - Que valores de nível de registro, para o monitoramento individual, são sugeridos pelos órgãos internacionais?

O OIEA sugere uma dose efetiva não inferior a $1 \mathrm{mSv} \mathrm{a}^{-1} \mathrm{e}$ a CIPR uma dose equivalente anual de $1 / 10$ do limite de dose anual.

62 - Nas situações onde vários componentes contribuem significantemente para a dose total individual, como exposições externas e internas de vários órgãos específicos, como deve ser estipulado o nível de registro?

Deve ser estipulado um nível de registro menor do que aquele sugerido internacionalmente, para cada componente.

63 - No monitoramento individual para irradiação externa quando se torna útil o nível de registro?

Ele é útil para estabelecer o valor mínimo de deteç̧ão do dosímetro a ser relacionado para medir estas pequenas doses.

64 - Por que o nível de registro é útil no monitoramento individual interno?

Porque evita esforços desnecessários de interpretação para resultados de pequena importância, lembrando que a interpretação é onerosa, mesmo fazendo uso de modelos computadorizados, pois exige julgamentos específicos a cada situação.

65 - Quando se torna necessário em proteção radiológica introduzir o nível de investigação?

Quando as condições de trabalho deixam de ser satisfatórias e exigem uma ação mais eficaz que o simples ato de registro.

66 - 0 que se entende em proteção radiológica por nível de investigação?

Um valor da dose efetiva ou da incorporação, geralmente, estabelecido tomando por base uma única medida, acima do qual, o resultado torna-se suficientemente importante para justificar uma investigação posterior.

67 - Que valores a CIPR e o OIEA recomendam como nível de investigação para o monitoramento individual?

A CIPR sugere o intervalo de valores entre a região aceitável $\left(5 \mathrm{mSv} \mathrm{a}^{-1}\right)$ até o limite de dose anual média sobre 5 anos. O OIEA continua adotando a regra anterior em que o intervalo tem início nos 3/10 dos limites de dose anuais, isto é, $6 \mathrm{mSv}^{-1}$. 
68 - Em proteção radiológica o que se pretende com o estabelecimento do nível de investigação?

Pretende-se auxiliar na melhoria da proteção onde ela é necessária e atua como uma restrição nas condições de deterioração da proteção onde a situação já é bem gerenciada.

69 - o que se entende em proteção radiológica por nível de intervenção?

Um valor pré-estabelecido, de uma determinada grandeza física usada no monitoramento tal que se for excedido ou prevê-se que seja excedido, é obrigatória uma intervenção para a correção da situação em deterioração.

70 - Para que situações de exposição à radiação ionizante recomenda-se o estabelecimento do nível da intervenção?

Para situações de acidentes, incidentes e de exposição crônica onde ela persiste por um período de tempo grande, isto é, muitos anos e tornam-se necessárias ações reparadoras para reduzir ou evitar estas exposições.

71 - Quais são exemplos de exposição crônica à radiação ionizante para os quais recomendase o estabelecimento de níveis de intervenção?

Exposição à radiação natural de fundo, no caso do radônio e exposição a rejeitos de meia vida longa proveniente de atividades ou eventos ocorridos no passado.

72 - Quais são os princípios gerais do sistema de proteção radiológica recomendados pela CIPR para se empreender uma intervenção?

a. A intervenção proposta deve trazer mais benefícios que malefícios, isto é, a redução no detrimento resultante da redução na dose deverá ser suficiente para justificar os riscos e os custos, incluindo os custos sociais.

b. A forma, a dimensão e a duração da intervenção deverão estar otimizadas de tal maneira que o beneficio líquido na redução da dose, isto é, o beneficio na redução do detrimento causado pela radiação, menos o detrimento associado à intervenção, deverá estar otimizado.

73 - 0 que se entende em proteção radiológica por valor de intervenção?

Um valor de dose que pode ser evitada por meio de uma ação protetora ou reparadora específica em um caso de emergência ou de numa situação de exposição crônica.

74 - Em que situações uma prática ou uma fonte de uma prática pode ser isentada de ser considerada material radioativo independentemente de outras condições, para fins de proteção radiológica?

a. Quando a dose esperada de ser recebida por qualquer membro do público em virtude da fonte ou da prática isentada seja da ordem de $10 \mu$ Sv ou menor em um ano.

b. A dose comprometida efetiva coletiva em um ano de atuação da prática não seja superior a cerca de 1 Sv-pessoa.

c. Uma avaliação para otimização da proteção mostra que a isenção é a opção ótima. 
75 - Como foram derivados os valores de isenção de material radioativo e o que eles representam?

Os valores foram derivados usando um modelo restritivo baseado nos critérios para isenção adotados pela CIPR e em uma série de cenários de usos limitadores e de deposição. Eles representam os menores valores calculados para qualquer cenário para uma quantidade moderada de material, geralmente, uma tonelada.

\section{6 - 0 que a CIPR entende por nível de exclusão?}

A exclusão, da finalidade das recomendações e normas de proteção radiológica independentemente de outras considerações, de uma prática ou uma fonte de uma prática ou ainda uma situação existente.

\section{7 - Que exemplos de exclusão de material radioativo são sugeridos pela CIPR?}

a. As fontes de amerício de um para-raios

b. A deposição como rejeito das fontes de amerício dos para-raios,

c. Radiações naturais do ambiente

d. Fertilizantes com materiais radioativos naturais

e. Fosfogesso com materiais radioativos naturais

78 - O que pretendem refletir os níveis de referência utilizados pelo serviço de proteção radiológica?

Pretendem, por meio de um modelo (cenário), refletir os limites básicos anuais, os limites de restrição de dose ou ainda os limites autorizados emitidos pela autoridade competente do país ou, por fim, os níveis de referência, numa situação específica de um determinado trabalho.

79 - Do que depende a relação quantitativa entre a grandeza física medida em um programa de monitoramento e os limites emitidos pela autoridade competente do país?

a. Da exatidão da medida escolhida para representar a situação real

b. Em que grau o modelo representa o limite escolhido

80 - Na escolha de um nível de referência quais são as principais diferenças entre um nível mais genérico e um nível mais específico?

O nível mais genérico é aplicado em muitas situações, é mais usado, é mais restritivo e apresenta maiores incertezas, enquanto que o nível mais especifico é mais restrito à situação em consideração, é mais realista e é mais preciso e exato.

\section{1 - Qual é a finalidade em se estabelecer um nível de referência?}

Estabelecer um quadro, cuja aderência fornecerá virtual certeza da obediência aos limites de competência da autoridade regulatória do país ou dos limites ALARA. 
82 - O que significa a falha na obediência aos níveis de referência e como pode ser solucionada?

A falha não implica necessariamente em doses maiores aos limites emitidos pela autoridade competente do país e nem aos limites otimizados, mas significa falha na obtenção dos padrões de proteção pretendidos. A solução é: uma ação remediadora sempre que praticável, uma modificação no sistema operacional da instalação ou adoção de um novo nível de referência. Mas neste último, como deve ser lembrado, para se manter a confiança no significado do nível de referência as modificações não devem ser nem levianas e nem frequentes.

83 - O que deve ser lembrado para o estabelecimento de um nível de referência para o monitoramento individual?

a. Que na maioria das situações a radiação externa e interna podem ser consideradas separadamente, tornando desnecessário o ajuste de uma delas em relação à outra.

b. Que na incorporação de uma mistura de radionuclídeos os níveis de referência para cada um dos radionuclídeos devem ser ajustados em relação aos demais níveis, de maneira semelhante ao limite de material incorporado para vários radionuclídeos.

84 - Qual é o objetivo do monitoramento do local de trabalho e quando ele deixa de ser útil?

O objetivo é provar obediência aos padrões de proteção bem estabelecidos pela direção e ele deixa de ser útil para posterior avaliação dos trabalhadores individuais.

85 - Qual é o objetivo de registrar os monitoramentos individuais?

Manter um registro das atividades com radiação ionizante do indivíduo monitorado.

86 - Quais são os principais interesses da direção da instalação em manter a conservação de registros pessoais?

a. Manter e melhorar os padrões de projeto e operação.

b. Conseguir demonstrar a obediência às recomendações da CIPR e regulamentos nacionais.

87 - Que temas devem ser registrados em um programa de monitoramento da radiação
a. Detalhes do programa;
b. Detalhes dos métodos de medida;
c. Detalhes dos métodos de interpretação;
d. Resultados dos monitoramentos dos locais de trabalho;
e. Resultados do monitoramento individual.

88 - A quem deve estar disponível o programa de monitoramento da radiação ionizante?

a. Ao gerente operacional;

b. Aos consultores de proteção radiológica;

c. Aos consultores médicos;

d. À autoridade regulatória ainda que não seja uma exigência regulatória;

e. Ao próprio trabalhador no que diz respeito a ele, sob pedido. 
89 - 0 gerente da instalação pode disponibilizar os registros de dose individuais a um grupo de trabalhadores?

Em principio não, pois estes registros são considerados confidenciais, mas consultando a sua força de trabalho pode, desde que a finalidade seja encorajar o interesse para um melhor desempenho de sua própria proteção.

90 - Quais são as recomendações da CIPR em relação ao período de conservação dos assentamentos?

a. Os resultados que fornecem as avaliações de doses individuais devem ser mantidos por períodos comparáveis com a sobrevivência esperada para os indivíduos a não ser que exista uma exigência regulatória mais restritiva.

b. Não é necessária a retenção por mais de dois anos, para propósitos de proteção radiológica, daqueles dados de monitoramento obtidos somente por gerenciamento rotineiro das operações.

c. O gerente deve decidir quais são os dados que devem ser mantidos levando em conta a necessidade de se demonstrar a concordância com sua própria política e com as exigências regulatórias.

d. Deve ser evitada a necessidade de preservar todos os resultados do monitoramento durante muitos anos.

\section{Introdução ao Monitoramento}

91 - Qual é a finalidade de um programa de monitoramento da radiação ionizante para fins de proteção radiológica?

Avaliar o controle das exposições externas e internas dos indivíduos para as radiações ionizantes.

92 - Quais são as principais justificativas de um programa de monitoramento da radiação ionizante para fins de proteção radiológica?

a. Mostrar como o monitoramento auxilia na obtenção e demonstração de um grau de proteção adequado.

b. Comprovar que as condições de trabalho continuam adequadas com o transcorrer do tempo.

93 - Benefícios complementares de um programa de monitoramento de radiação ionizante para fins de proteção radiológica podem substituir as principais justificativas de sua introdução?

Os benefícios complementares de um programa de monitoramento não substituem as justificativas principais. Exemplo de áreas nas quais podem existir benefícios complementares:

a. Relações industriais

b. Relações públicas 
c. Pesquisa científica, por exemplo: epidemiologia

d. Determinação da responsabilidade no evento da manifestação de efeitos adversos causados à saúde em trabalhadores individuais

e. Confirmação na correteza da classificação dos locais de trabalho

f. Determinação das flutuações nas condições de trabalho

g. Nos programas de otimização fornecendo garantias nas previsões dos resultados ou fornecendo dados a serem utilizados nas revisões de suas programações (otimização)

94 - O que podemos citar como exemplo de três finalidades complementares do monitoramento da radiação ionizante para fins de proteção radiológica?

a. Reavaliações dos programas de monitoramento

b. Determinação do perímetro dos locais de trabalho demarcados

c. Determinação da forma e da intensidade da supervisão médica

95 - Por que se deve reavaliar os programas de monitoramento da radiação ionizante para fins de proteção radiológica?

a. Para torná-lo auto-ajustável

b. Identificar os bons e maus aspectos dos procedimentos de operação

c. Identificar os bons e maus aspectos das características do projeto

96 - Que atitude deve-se tomar após a obtenção de condições melhoradas com relação ao programa de monitoramento da radiação ionizante para fins de proteção radiológica?

Devem-se reconsiderar as necessidades e finalidade de um programa de um monitoramento contínuo.

97 - Que fatores predominantes devem ser considerados para determinar o perímetro dos locais de trabalho demarcados por meio do monitoramento da radiação ionizante para fins de proteção radiológica?

a. Para a radiação externa o fator predominante é o resultado do próprio monitoramento do local de trabalho

b. Para contaminação de superfície ou do ar o fator predominante é a probabilidade de ocorrência das contaminações

98 - Como o monitoramento da radiação ionizante para fins de proteção radiológica afeta a forma e a intensidade da supervisão médica?

Afeta a forma e a intensidade da supervisão médica considerando:

a. As doses equivalentes e as doses potenciais

b. As informações dos trabalhadores

c. As condições gerais encontradas nos locais de trabalho 
99 - Qual é a principal obrigação de um programa de monitoramento da radiação ionizante para fins de proteção radiológica?

Fornecer informações necessárias para avaliar a irradiação dos trabalhadores em termos daquelas grandezas em que foram expressos os limites básicos.

100 - Quais são as grandezas físicas de proteção radiológica utilizadas nos limites básicos anuais?

Para limites básicos primários são utilizadas as grandezas físicas:

- Dose equivalente no órgão ou tecido

- Dose efetiva para corpo inteiro

- Dose equivalente comprometida para a dose interna no órgão ou tecido

- Dose comprometida efetiva para a dose interna de corpo inteiro

Para limites básicos secundários são utilizadas as grandezas físicas:

- Dose equivalente ambiente para a exposição externa de corpo inteiro e para o monitoramento do local de trabalho

- Dose equivalente direcional para a exposição externa da pele para monitoramento do local de trabalho

- Dose equivalente pessoal para a exposição externa para o monitoramento individual

- Dose de incorporação para monitoramento individual interno

101 - Quais são as etapas de um processo de monitoramento da radiação ionizante para fins de proteção radiológica e qual é a sequência lógica para concluí-las?

As etapas são duas, a saber:

a. A medida propriamente dita

b. Interpretação do resultado da medida

A sequência lógica para levá-las a bom termo é:

Medida $\rightarrow$ Modelo $\rightarrow$ Resultado $\rightarrow$ Interpretação

102 - Na sequência lógica de um processo de monitoramento de radiação ionizante para fins da proteção radiológica quais são as principais funções do modelo que a partir da medida fornece o resultado?

As principais funções são:

a. Descrever de forma quantitativa a relação entre as grandezas medidas e aquelas que se desejam avaliar ou estimar.

b. Constituir um requisito para a seleção adequada dos procedimentos de medida.

103 - De acordo com a CIPR quais são os aspectos importantes de um programa de monitoramento da radiação ionizante para fins de proteção radiológica? 
a. A gerência de operação é a principal responsável no estabelecimento de um programa de monitoramento;

b. O programa de monitoramento deve ser projetado com base em uma avaliação radiológica prévia, em função de exigências regulatórias;

c. Os objetivos e o projeto de um programa de monitoramento devem ser claramente definidos e registrados;

d. O projeto de monitoramento deve incluir as bases estabelecidas para interpretação dos resultados em função dos objetivos da proteção.

104 - Por que todos os aspectos de um programa de monitoramento da radiação ionizante para fins e proteção radiológica devem ser periodicamente revisados?

Para garantir que o programa de monitoramento continua adequado.

105 - Como foram divididas as funções do monitoramento da radiação ionizante para fins de proteção radiológica e onde se aplicam?

As funções são três a saber:

a. Monitoramento de rotina

b. Monitoramento relacionado com a tarefa

c. Monitoramento interventor (especial)

Estas três funções se aplicam respectivamente a:

a. Operações continuas ou voluntarias das atividades da instalação

b. Uma operação especifica

c. Na necessidade de uma investigação

106 - Para que fins foi idealizado o monitoramento da radiação ionizante com função de rotina?

a. Para demonstrar que as condições de trabalho, inclusive os valores das doses individuais permanecem satisfatórios.

b. Para avaliar e estimar as doses dos trabalhadores e auditar o monitoramento relacionado com a tarefa.

c. Para atender às exigências regulatórias.

107 - Para que fins foi idealizado o monitoramento da radiação ionizante com função relacionada com a tarefa?

Para auxiliar na (o)

a. tomada de decisão imediata para condução da operação;

b. otimização da proteção;

c. sentido de evitar, detectar e tomar as primeiras medidas reparadoras em caso de desvios da situação normal de trabalho.

108 - Que tipo de situação envolve e para que fins foi idealizado o monitoramento da radiação ionizante com a função interventora (especial)? 
Tipicamente envolve uma situação no local de trabalho onde as informações são insuficientes para demonstrar um controle adequado. Ele foi idealizado para:

a. Fornecer informações detalhadas de modo que possa elucidar qualquer problema.

b. Definir procedimentos futuros.

109 - Quais as definições dos dois tipos de monitoramento da radiação ionizante utilizados pela proteção radiológica de trabalhadores e como são denominados seus resultados de acordo com o OIEA?

a. Monitoramento do local de trabalho, que envolve as medidas realizadas no ambiente de trabalho e seus resultados, de acordo com o OIEA, são considerados doses avaliadas.

b. Monitoramento individual que é implementado para obter as medidas por um equipamento portado pelo trabalhador ou por medidas das quantidades de materiais radioativos presentes no ou sobre seu corpo e a interpretação destas medidas e seus resultados, de acordo com o OIEA, são considerados doses estimadas.

110 - Como são denominadas as subdivisões dos dois tipos de monitoramentos realizados pela proteção radiológica para a radiação ionizante?

O monitoramento do local de trabalho é subdividido em:

a. Radiação externa;

b. Contaminação de superfície;

c. Contaminação de ar.

O monitoramento individual é subdividido em:

a. Exposição externa;

b. Contaminação de pele e roupa;

c. Exposição interna.

\section{Monitoramento do Local de Trabalho para Radiação Externa}

111 - Qual é a finalidade do monitoramento do local de trabalho para a radiação externa para fins de proteção radiológica?

Garantir a existência de condições satisfatórias de trabalho analisando o controle das exposições às radiações externas.

112 - Qual é o objetivo do monitoramento do local de trabalho para a radiação externa para fins de proteção radiológica?

Mostrar que o ambiente de trabalho é satisfatório para a radiação externa e que não sofreu mudanças que possam exigir uma reavaliação dos procedimentos de operação.

113 - O monitoramento de rotina para local de trabalho e para radiação externa, que tipo de medida envolve e que tipo de equipamento pode incluir? 
Envolve o uso de medidas de inspeção regularmente repetidas e pode incluir o uso de monitores instalados para identificar o inicio de condições anormais ou de emergência. Um exemplo deste último pode ser uma falha no retorno de uma fonte de radiografia para a sua blindagem.

114 - Quais os 3 cuidados que devem ser tomados na confecção de um programa de monitoramento de rotina para o local de trabalho e radiação externa com fins de proteção radiológica?

a. Deve ser cuidadosamente planejado

b. Não deve ser super elaborado

c. Que a geração de um grande número de resultados desnecessários é contra producente e pode mascarar a presença de resultados úteis e significativos

115 - Em que locais deve ser executado o monitoramento de rotina do local de trabalho para radiação externa com fins de proteção radiológica?

Deve ser efetuado nas posições onde permanecem os trabalhadores durante a execução das respectivas tarefas.

116 - Que casos devem ser considerados para determinar a frequência com que deve ser efetuado o monitoramento do local de trabalho com a função de rotina para a radiação externa e qual é a frequência associada a cada caso?

a. As variações de campo de radiação só ocorrem em decorrência de alterações apreciáveis nos arranjos de blindagem, nos controles ou nos processos realizados no local de trabalho. Frequência: é necessário somente um monitoramento ocasional no local para propósitos de comprovação.

b. As variações do campo de radiação são lentas e as consequências não são graves. Frequência: monitoramentos periódicos, normalmente proporcionarão informações de advertência suficientes e em tempo hábil sobre as condições de deterioração, principalmente para pontos pré-estabelecidos.

c. As variações do campo de radiação são rápidas e imprevisíveis a valores alarmantes. Frequência: no local de trabalho devem ser colocados instrumentos de aviso ou usados individualmente pelos trabalhadores.

117 - Características que os instrumentos devem possuir no caso do campo de radiação variar rapidamente e de modo imprevisível a valores alarmantes no caso do monitoramento de rotina do local de trabalho para radiação externa. 
a. Devem ser robustos e confiáveis.

b. Devem apresentar respostas adequadas para o tipo e a energia da radiação que se encontra no local de trabalho.

c. Deve ser dada uma atenção especial na escolha e calibração de instrumentos utilizados na medida de nêutrons ou fótons de penetração pequena.

d. Os instrumentos devem responder em unidades SI e devem ser calibrados nas grandezas operacionais do CIUR, geralmente, em dose equivalente ambiente ou dose equivalente direcional.

e. Os instrumentos antigos, graduados em unidades SI mas calibrados em dose absorvida no ar, geralmente, são adequados para medidas de fótons.

f. Ainda que a maioria dos instrumentos utilizados no monitoramento do local de trabalho meçam taxa de dose em vez de dose, existem circunstâncias onde é útil um dosímetro integrador simples como um DTL.

118 - No caso do monitoramento com função relacionado com a tarefa para o monitoramento do local de trabalho para radiação externa que características do instrumento são desejáveis?

a. Que seja portátil.

b. Que preveja as doses prováveis a serem acumuladas durante o desenvolvimento da tarefa.

119 - Em que casos e com que frequência devem ser realizados os monitoramentos com função relacionada com a tarefa do local de trabalho para a radiação externa?

Caso: os campos de radiação permanecem essencialmente constantes. Frequência:

- Um levantamento preliminar das taxas de dose na região a ser ocupada pelos trabalhadores, geralmente, é suficiente.

- Algumas vezes torna-se necessário repetir estes levantamentos antes de cada série de operações.

Caso: as operações interferem na taxa de dose e portanto os campos de radiação podem variar. Frequência:

- Devem ser realizadas medidas durante toda a operação.

120 - Quando e por que o monitoramento com função relacionada com a tarefa passa a ser incluído na função relacionada com a rotina para o monitoramento do local de trabalho para radiação externa?

O monitoramento com função relacionada com a tarefa, quando for realizado por equipamento fixo, passa para o controle do serviço de radioproteção. Portanto é incluído no monitoramento com função de rotina, pois pode ser controlado pela radioproteção por meio de uma estação repetidora das medidas e isto visa diminuir o volume de tarefas de radioproteção efetuadas pelo trabalhador, que tem a principal função de produção.

121 - No monitoramento com função relacionada com a tarefa para o local de trabalho para a radiação externa, como são escolhidos os locais de monitoramento? 
Devem se escolhidas as posições onde se pode detectar confiavelmente qualquer desvio da situação normal, procurando evitar que os trabalhadores recebam doses extras além daquelas previstas durante o trabalho normal. Nas posições de monitoramento não é necessária a presença dos trabalhadores.

122 - No monitoramento do local de trabalho para radiação externa, que cuidados devemos tomar quando se trabalha com radiação beta ou outro tipo de penetração pequena?

- Que manipulações realmente secundárias, como mudanças de orientação ou remoção de componente, podem causar mudanças muito grandes na taxa de dose.

- Como a maioria dos monitoramentos, especialmente aqueles que fornecem um aviso aos trabalhadores, estão baseados na detecção da radiação gama mais energética, estas alterações podem deixar de ser detectadas.

- Nas medidas de taxa de dose imediatamente adjacentes a superfícies ou em fontes puntiformes.

123 - Que vantagens poderiam ser oferecidas se os resultados de um programa de monitoramento do local de trabalho para radiação externa puderem ser registrados sincronizados com um vídeo?

- Esta ferramenta de investigação pode ajudar nas ações minúsculas que contribuem significativamente à dose.

- Fornecem informações à força de trabalho que, então, se torna hábil para sugerir melhorias ao modo pelo qual as operações são empreendidas.

124 - Quando se torna necessário um monitoramento do local de trabalho para radiação externa com função de rotina e que cuidados devem ser lembrados?

Quando as doses estimadas forem superiores a $1 / 10$ do limite anual. Deve ser lembrado que este valor limite anual deve ser calculado na fração de tempo de medida do instrumento e que a dose estimada refere-se ao monitoramento individual.

125 - A interpretação das medidas resultantes do monitoramento do local de trabalho para a radiação externa, em termos de dose efetiva e dose equivalente media em órgãos e tecidos, é extremamente complexa em virtude do que e como pode ser facilitada?

É extremamente complexa, principalmente em virtude de:

a. A taxa de fluência da radiação e sua qualidade variam no espaço e no tempo.

b. Os trabalhadores movimentam-se em seu ambiente, de maneira que não pode ser prevista nem exatamente conhecida ou registrada.

A intervenção pode ser facilitada pela calibração dos instrumentos de medida.

126 - O que ocorre com a calibração dos instrumentos de medida utilizados no monitoramento do local de trabalho para radiação externa com relação aos campos de radiação? 
Quando os campos de radiação forem unidirecionais, a maioria dos instrumentos podem ser calibrados para fornecerem uma avaliação de $E_{\mathrm{I}, \mathrm{d}}$. Quando os campos de radiação forem multidirecionais ou isotrópicos ocorrem erros em virtude:

- Da blindagem intrínseca do instrumento que superestima $E_{l, d}$, mas ela é inferior aos erros causados para relacionar $\mathrm{H}_{\mathrm{l}, \mathrm{d}}$ aos vários pontos no espaço e no tempo com a dose integrada recebida pelo trabalhador

- Da correlação entre o equipamento e o manequim e resulta que o instrumento superestima $\mathrm{E}_{\mathrm{I}, \mathrm{d}}$

127 - Quais são as sugestões da CIPR para facilitar a interpretação dos resultados do monitoramento do local de trabalho para radiação externa com função de rotina?

- Para doses efetivas próximas a 1/10 dos limites anual sugere supor que o trabalhador permaneça o tempo todo no ponto de maior dose equivalente.

- Para doses efetivas próximas a 3/10 dos limites anual, determinar e às vezes restringir o tempo de permanência nas áreas onde as taxas de $E_{1, d}$ são elevadas até que não forem efetuadas melhorias na proteção.

128 - Quais são as sugestões da CIPR para facilitar a interpretação dos resultados do monitoramento do local de trabalho para radiação externa com função relacionada com a tarefa?

Estabelecer um tempo de trabalho máximo dentro do qual o trabalhador não ultrapassa uma dose efetiva especificada que é função das doses recebidas nas demais tarefas executadas durante o mesmo período de tempo.

\section{Monitoramento do Local de Trabalho para a Contaminação de Superfície}

129 - No que repercute a dimensão de contaminação de superfície da radiação ionizante em qualquer instalação?

a. Na habilidade de contenção

b. Na eficácia dos controles nos procedimentos adotados

c. No comprometimento gerencial associado com a segurança fornecida àquela atividade

130 - Quais são as finalidades de um monitoramento da ionização de uma superfície provocado pela radiação ionizante?

a. Demonstrar que a contenção primária de material radioativo tem um padrão elevado de segurança e de controle gerencial.

b. Mostrar que há ausência de contaminação próxima de um determinado valor de referência. 
131 - Quais são os principais objetivos de um programa de monitoramento de contaminação de superfície provocado pela radiação ionizante?

a. Detectar falhas na contenção.

b. Detectar desvios dos bons procedimentos de operação.

c. Restringir a contaminação de superfície e valores ALARA.

d. Ajudar na prevenção da dispersão de contaminação.

e. Fornecer informações para: (i) planejamento de programas otimizados para monitoramento do ar e individual para exposição interna e (ii) definir os procedimentos e as instalações operacionais.

132 - Quais são as consequências se forem obedecidos os principais objetivos de um programa de monitoramento de contaminação de superfície provocado pela radiação ionizante?

a. Ausência de contaminação interna anormal do trabalhador.

b. O monitoramento do ar ou individual interno é desnecessário.

133 - Quais são as principais utilidades do monitoramento da contaminação de superfície provocada pela radiação ionizante?

a. Servir como indicador na eficácia de contenção do material radioativo tanto no passado como no presente.

b. Ser utilizada para delimitar áreas onde o monitoramento do local de trabalho para a contaminação do ar ou o monitoramento individual para exposição interna à radiação são necessários.

134 - Para que casos o monitoramento da contaminação de superfície provocada pela radiação ionizante não é útil e por quê?

- Ela não é útil para a irradiação dos trabalhadores, pois os mecanismos para a avaliação destas doses são muito complexos e portanto não são empregados com esta finalidade.

- Não é útil para delimitar as áreas onde são necessários os monitoramentos do ar ou individual interno para os radionuclídeos que se encontram na forma volátil.

135 - Quais as principais vias de exposição dos trabalhadores originadas pela contaminação de superfície provocada pela radiação ionizante?

- Para exposição à beta/gama são tanto a exposição externa como a interna.

- Para exposição à alfa é a exposição interna.

A principal via de exposição interna é a inalação para todos os radionuclídeos em virtude da ressuspensão da contaminação de superfície. Em algumas circunstâncias pode ser significativa a ingestão inadvertida e absorção pela pele (particularmente para o trítio neste último caso).

136 - Quais são os focos ou o que focaliza a proteção radiológica com o monitoramento da contaminação de superfície provocada pela radiação ionizante e o que devem possuir as áreas controladas para estes casos? 
A proteção radiológica se focaliza na:

a. Identificação das operações e das localizações onde se origina a contaminação.

b. Determinação das áreas afetadas.

As áreas controladas devem possuir uma identificação de onde pode ser provável a ocorrência de uma contaminação significativa.

137 - Na interpretação dos resultados do monitoramento da contaminação de superfícies se faz distinção entre os emissores beta/gama e alfa? Por quê?

Os instrumentos de medidas são diferentes.

- Para os emissores alfa é a inalação decorrente da ressuspensão é a principal via.

- Para emissores beta/gama é exposição externa é a principal via.

138 - Qual é a finalidade de um monitoramento de contaminação de superfície pela radiação ionizante com função de rotina?

A finalidade é detectar uma contaminação pois é difícil avaliar a dose individual a partir dela.

139 - Qual é o método convencional de medida e como é determinada a sua frequência do monitoramento de contaminação de superfície pela radiação ionizante com função de rotina?

O método convencional é monitorar uma fração representativa das superfícies de uma área por meio de um detector específico. Por exemplo: panqueca. A frequência do monitoramento é estabelecida pela prática.

140 - Que casos devemos considerar do que e como devemos monitorar uma contaminação de superfície pela radiação ionizante com função de rotina?

a. Monitoramentos mais frequentes - Neste caso devem-se ter pontos indicadores estratégicos como barreiras de controle e áreas com potencial elevado de contaminação.

b. Monitoramentos menos frequentes - Neste caso deve-se, representativamente, cobrir toda a área controlada em conjunto com algumas medidas a mais fora da área.

c. Monitoramento onde existe a probabilidade de ocorrência de uma grande contaminação, onde o individuo possa transferir uma quantidade significativa de atividade para fora da área controlada num único evento - Neste caso o monitoramento convencional deve ser complementado pelo uso de monitores instalados nas saídas externas as áreas controladas. Os monitores podem ser: sondas de varreduras, monitores de pés e mãos ou portais. Estes monitores podem ser adequados para a indústria nuclear (ciclo do combustível nuclear), mas raramente são necessários nas aplicações medicas e indústrias.

d. Uso de métodos alternativos para detecção de deteriorações lentas ou derrames - neste caso faz-se uma análise dos valores da contaminação em panos de chão, sacos de aspirador, outras superfícies nas áreas de saída, sapatos, luvas, bolsas etc. Esta análise fornece uma indicação genérica dos valores da contaminação mas não detecta a 
ocorrência isolada de pequenas quantidades de materiais radioativos e nem permite uma estimativa qualitativa dos valores da contaminação.

e. Instalações onde é necessária a troca de vestimentas - deve-se lembrar que são instalações que possuem áreas demarcadas com potencial para contaminação e que deve ser dada uma atenção especial ao monitoramento dos trabalhadores que saem da área. Neste caso os monitores para contaminação de superfície colocados no lado limpo da sala de troca normalmente são idealizados para uso pessoal, com a finalidade de garantir que as mãos, roupas e sapatos estejam limpos antes que os trabalhadores deixem estes locais. Como este monitoramento é realizado após terem sido lavadas as mãos e após a remoção das sapatilhas e outras roupas de proteção especiais deve ser relacionada como uma técnica adequada de verificação da contaminação geral no local de trabalho.

f. Itens retirados das áreas demarcadas com potencial para contaminação devem ser monitorados - Neste caso quando o monitoramento de tudo que sai da área é impraticável deve-se definir as áreas e itens para os quais o monitoramento de rotina é necessário e porque o é.

g. Distinção entre contaminação fixa e removível - Neste caso devemos considerar que esta distinção não é absoluta, pois a contaminação fixa pode se tornar removível, principalmente quando são aplicados processos abrasivos e ambas as formas de contaminação contribuem para a radiação externa, mas unicamente a removível pode tornar-se uma fonte de exposição interna.

141 - Em virtude de termos contaminações de superfície provocadas pela radiação ionizante fixas e removíveis que medidas de contaminação possuímos?

- Medidas diretas com sondas que detectam tanto a contaminação fixa como a removível.

- Uso do teste de esfregaços que detecta somente a contaminação removível.

142 - Por que a finalidade do monitoramento de contaminação de superfície com função de rotina é detectar uma contaminação e não avaliar a dose do trabalhador? Com que função do monitoramento ela se coaduna mais?

Porque é muito difícil avaliar a dose dos trabalhadores provocada por ela. Ela se coaduna mais com a auditoria do monitoramento relacionado com a tarefa. 
143- Do que se necessita e não se necessita na prevenção de contaminação por fontes de radiação ionizante seladas?

Não há necessidade do monitoramento de contaminação de superfície, mas há necessidade de um programa regular de testes de fuga, conhecidos como ensaios diretos.

144 - Do que depende a frequência dos ensaios diretos das fontes de radiação ionizante seladas, quando eles são realizados e que cuidado deve-se tomar?

A frequência dos ensaios depende da eficácia de contenção da fonte.

a. Normalmente são adequados ensaios regulares de um a dois anos. A CNEN adota a frequência anual.

b. Em fontes frágeis ou usadas em ambientes agressivos os ensaios de vazamento devem ter uma frequência maior.

Deve-se tomar o cuidado de manter as fontes contidas nos ensaios de vazamento de fontes frágeis e nas circunstâncias onde podem ocorrer contaminações, em virtude de perda de integridade da fonte.

145 - Que tipo de ensaios indiretos podem ser realizados nas fontes de radiação ionizantes seladas e o que deve ser incluído no resultado do ensaio?

a. Monitoramento do recipiente que acomoda a fonte.

b. Monitoramento dos produtos de decaimento de meia vida curta como no caso do radio que se detecta o escape do radônio pela amostragem do ar.

No resultado do ensaio deve ser incluída uma declaração cautelosa que indica a natureza limitada do ensaio e, em particular, que o acesso junto à fonte pode resultar na dispersão de contaminação.

146 - Que confiança deve fornecer um programa completo de monitoramento de contaminação de superfície provocada pela radiação ionizante?

Deve fornecer a confiança de que a possibilidade de ocorrência de uma contaminação significativa levada para fora de uma área controlada seja aceitavelmente pequena.

147 - Durante o desenvolvimento de uma atividade quais são os objetivos de um monitoramento de contaminação de superfície provocada por radiação ionizante com função relacionada à tarefa e que utilidades ela tem?

Os objetivos são:

- evitar a contaminação;

- limitar a sua dispersão.

Sua utilidade:

- em contenções parciais - exemplo: capelas com exaustão;

- durante ou imediatamente após um trabalho não rotineiro ou de manutenção. 
148 - Quais são as principais ações efetuadas pelo serviço de proteção radiológica no monitoramento de contaminação de superfície provocado pela radiação ionizante com função relacionada à tarefa?

- Manter a disposição do trabalhador equipamentos de monitoramento.

- Treinar o trabalhador para a utilização dos equipamentos de monitoramento a sua disposição.

149 - No monitoramento do local de trabalho para a contaminação de superfície pela radiação externa, por que a interpretação dos resultados é realizada separadamente para a radiação alfa e beta, que riscos são associados e o que não seve ser ignorado?

A interpretação é realizada separadamente porque as medidas são realizadas separadamente. Os principais riscos são: para os emissores alfa a inalação e para a radiação beta a irradiação externa em superfícies parcialmente blindadas. Não devem ser ignorados os perigos de incorporação dos emissores beta.

150 - Como escolher níveis de referência relacionados com os limites anuais ou restrições de dose para o monitoramento do local de trabalho para a contaminação de superfície, por que motivo e quais são as consequências à sua obediência?

Devem ser escolhidos valores arbitrários que levem a doses inferiores aos níveis de registro do monitoramento individual, pois há uma pequena correlação entre contaminação de superfície e irradiação dos trabalhadores. A aderência aos níveis de referência inferiores aos níveis de registro:

- Resulta em alto padrão de gerenciamento.

- Tornam-se desnecessárias outras formas de monitoramento, como: (i) do ar e (ii) de contaminação interna do trabalhador.

151 - Quando se torna importante estabelecer um nível de investigação no monitoramento de área para a contaminação de superfície pela radiação ionizante? Qual é a sua justificativa e o que limita seu valor?

Torna-se importante:

- Quando não há dificuldade em se manter os seus valores bem abaixo do nível de registro.

- Em áreas onde ocorrem contaminações gerais, pois a tendência dos resultados fornece um aviso antecipado da deterioração dos procedimentos.

Ela é justificada sempre que haja um pequeno aumento no valor da radiação de fundo no instrumento e o seu valor é limitado pela sensibilidade dos monitores de contaminação disponíveis.

152 - Qual é a importância de se estabelecer o nível de registro no monitoramento do local de trabalho para contaminação de superfície e do que depende seu valor? 
A importância é evitar o registro dos resultados do monitoramento da contaminação de superfície abaixo de um valor selecionado. O seu valor depende da sensibilidade do instrumento.

\section{Monitoramento do Local de Trabalho para a Contaminação do Ar}

153 - Quando se justifica o monitoramento do ar no local de trabalho para a radiação externa e quando ela se torna necessária?

Ela se justifica quando a rota mais importante de incorporação de material radioativo pelo trabalhador for a inalação. Ela se torna necessária em instalações onde são manuseadas grandes quantidades de material sob forma não selada, mil vezes ou mais do valor limite de incorporação anual pertinente.

154 - Para efeito de monitoramento da radiação com fins de proteção radiológica como é considerado o trítio?

Ele é considerado como um contaminante suspenso no ar que é diretamente absorvido através da pele.

155 - Para fins de proteção radiológica por que tipos de monitoramento pode ser substituído aquele referente ao ar?

- Monitoramento do local de trabalho para radiação externa;

- Monitoramento do local de trabalho para contaminação de superfícies;

- Monitoramento individual interno.

156 - Para fins de proteção radiológica qual é a finalidade do monitoramento da contaminação do ar?

É manter os valores de contaminação do ar no ambiente de um local de trabalho inferiores aos padrões de proteção e níveis de referência visando evitar o monitoramento individual interno.

157- Quais são os principais objetivos de um programa de monitoramento do local de trabalho para contaminação do ar provocada pela radiação ionizante?

a. Auxiliar no controle de exposição interna dos trabalhadores resultante da inalação para avaliação da maior quantidade de material radioativo provável de ser inalado.

b. Fornecer uma deteç̧ão imediata de condições de deterioração ou anormais, permitindo, desse modo, aplicação de ações corretivas ou de proteção, por exemplo, pelo uso de equipamento de proteção respiratória.

c. Fornecer informações para o planejamento de programas de monitoramento individual de trabalhadores para a contaminação interna.

158 - Do que depende a implementação de cada objetivo de um programa de monitoramento do local de trabalho para a contaminação do ar provocado pela radiação ionizante e que utilidade, às vezes, pode ter este tipo de monitoramento? 
A implementação de cada um desses objetivos depende da disponibilidade e extensão do monitoramento individual para a contaminação interna e a utilidade que este tipo de monitoramento às vezes pode ter é de ser útil unicamente como um aviso antecipado de eventuais contaminações internas.

159 - Quando o monitoramento do local de trabalho para contaminação do ar provocada pela radiação ionizante é quase sempre necessário?

a. Quando são manuseadas grandes quantidades de materiais gasosos ou voláteis, por exemplo, trítio e seus compostos em processos de produção em grande escala e em reatores à água pesada (produção de óxidos);

b. Na mineração, moagem e refino de urânio e tório;

c. Na fabricação e reprocessamento do combustível nuclear e na usinagem de urânio natural e enriquecido;

d. No processamento de plutônio e outros elementos transurânicos;

e. No uso de celas blindadas (quentes) em reatores e em instalações com criticalidade;

f. Em locais de trabalho onde o radônio é considerado parte da exposição laboral.

160 - Em um projeto de qualquer programa de monitoramento do local de trabalho para a contaminação do ar provocada por radiação ionizante, que considerações devem ser ponderadas?

a. Que as fontes, particularmente importantes de contaminação do ar, são: (i) liberação localizada e (ii) ressuspensão da contaminação de superfície.

b. Que ambas as fontes, liberação localizada e ressuspenção da contaminação de superfície podem ser geradas diretamente por atividades de trabalho realizadas por trabalhadores individuais.

c. Que a contaminação do ar, frequentemente, é localizada e transitória.

d. Que podem existir diferenças significativas entre a concentração de atividade na zona de respiração de um trabalhador e o valor medido em alguma localização fixa próxima. A concentração na zona de respiração, normalmente é maior. O estabelecimento desse fator de crescimento é de vital importância no projeto de qualquer programa de monitoramento de contaminação do ar.

161 - No projeto de um programa de monitoramento do local de trabalho para a contaminação do ar pela radiação ionizante existe uma estrutura geral útil para todos os tipos de monitoramento e uma estrutura mais conveniente para este tipo de monitoramento. Qual a definição desta estrutura mais conveniente em suas divisões?

a. Monitoramento de alerta - para detectar e advertir o início de uma contaminação significativa presente no ar.

b. Amostragem de área - para detectar tendências e variações nas contaminações presentes no ar em todo o local de trabalho.

c. Amostragem representativa - para quantificar a extensão da contaminação presente no ar à qual o trabalhador provavelmente estará exposto. 
162 - As funções do monitoramento do local de trabalho para a contaminação do ar pela radiação ionizante como seriam classificadas na estrutura geral das funções?

Os monitoramentos com função de alerta e de amostragem de área seriam classificadas com função relacionada com a tarefa e a função de amostragem representativa com função de rotina. Mas a amostragem de área também pode tornar-se com função de rotina.

163 - Quando o monitoramento de alerta pode ser útil? Que tipo de equipamento deve ser usado e onde deve estar localizado? Qual um exemplo de onde devem ser instalados e não instalados, no monitoramento do local de trabalho para a contaminação do ar provocado pela radiação ionizante?

Torna-se útil em operações ou desvios que podem causar liberações apreciáveis e inesperadas de materiais radioativos no local de trabalho. Neste caso devem ser usados equipamentos de aviso operando continuamente. Eles devem estar localizados em posições onde detectarão com confiabilidade uma liberação de material radioativo. Um exemplo é a Instalação do equipamento em/ou próximo a pontos de extração do ar em locais de trabalho e não devem ser colocados na extensão de sistemas fechados do tipo da capela com exaustão.

164 - Cite quatro locais em que é útil a colocação dos equipamentos para o monitoramento de alerta para o local de trabalho onde pode existir a contaminação do ar provocada por radiação ionizante.

a. Reatores;

b. Próximos a celas de processamento;

c. Áreas onde são manuseados plutônios e outros elementos transurânicos;

d. Locais onde são usadas quantidades apreciáveis de materiais sob forma não selada.

165 - Que considerações devem ser realizadas para a escolha do nível de alarme e neste caso que equipamento deve ser utilizado no monitoramento de alerta para contaminação do ar provocado pela radiação ionizante?

- Deve-se considerar o valor normal de atividade presente no ar e a sua esperada variação.

- Há a necessidade de se evitar alarmes frequentes desnecessários (incluindo os alarmes falsos).

- Há a necessidade de se efetuar a discriminação de contribuições que confundem como aquelas causadas pela radiação natural de fundo resultante dos produtos de decaimento do radônio.

- Os equipamentos utilizados são os monitores contínuos de ar providos de alarme de aviso.

166 - Qual é a utilidade, quais são os equipamentos utilizados e o que se considera para determinar a sua quantidade e localização na amostragem representativa do monitoramento do local de trabalho para a contaminação do ar provocada por radiação ionizante?

A utilidade da amostragem representativa é a obtenção de dados sobre a tendência dos valores da contaminação presente no ar. Os Equipamentos utilizados são amostradores de área 
estáticos, com ou sem qualquer equipamento de monitoramento de alerta. O número de equipamentos e a sua localização devem ser justificados e devem-se considerar o significado global da contaminação e seu grau de variação.

167 - 0 que se pretende, qual é a importância, como, com que equipamento e em que locais se torna importante a amostragem representativa do monitoramento do local de trabalho para a contaminação do ar provocada pela radiação ionizante?

Pretende colher amostras da atividade no ar respirado pelos trabalhadores e, portanto, pode ser usada para determinar a exposição recebida pelo trabalhador. A sua importância é fornecida pelo papel que desempenha no monitoramento com propósitos de controle operacional. Utilizam-se amostradores fixos em um determinado número de locais selecionados como representativos da zona de respiração dos trabalhadores. Denomina-se de ciclo completo de operações. Ela se torna importante em locais fixos de trabalho com grande ocupação e a amostra de ar, que representa a incorporação, pode ser convenientemente localizada próxima à zona de respiração.

168 - Como pode ser avaliada a incorporação de materiais radioativos no monitoramento do local de trabalho para a contaminação do ar provocada pela radiação ionizante considerando a estrutura conveniente?

Pode ser avaliada a partir dos resultados do monitoramento do local de trabalho tanto pela amostragem de área como representativa.

169 - Do que depende e como pode ser realizada uma interpretação acurada dos resultados de uma medida da contaminação do ar provocada pela radiação ionizante considerando a estrutura conveniente?

A interpretação acurada depende:

- das propriedades físicas e químicas do contaminante.

- do grau em que as amostras são realmente representativas do ar inalado pelos trabalhadores.

Ela pode ser realizada introduzindo hipóteses simplificadoras, particularmente, em relação à distribuição do tamanho e concentração de atividade das partículas do contaminante.

170 - Em que caso a amostragem representativa da contaminação do ar provocada pela radiação ionizante pode representar adequadamente a incorporação de cada trabalhador?

Em um ciclo completo de operações.

171 - Quando forem usados amostradores de área de modo rotineiro para avaliar a contaminação do ar provocado pela radiação ionizante, como pode ser determinada a quantidade incorporada pelo trabalhador?

Pode ser determinada pela introdução de um programa de monitoramento interventor (especial), frequentemente envolvendo amostradores de ar individuais e determinados fatores de conversão. 
172 - Os fatores de conversão determinados pelo monitoramento com função interventora introduzidos no monitoramento de área para a contaminação do ar provocado pela radiação ionizante são perenes?

Não, eles devem ser revisados de tempo em tempo e, sempre, após qualquer alteração significativa nas operações.

173 - Quais os exemplos de situações em que mesmo fazendo uso de fatores de correção no monitoramento da contaminação do ar provocado pela radiação ionizante falham em representar adequadamente a incorporação para cada trabalhador?

- Situações em que as fontes de contaminação são localizadas e variáveis com o tempo, frequentemente, provocadas pela própria ação ou movimento do trabalhador. Exemplo: fuga em uma cela com luvas.

- Situações em que a distribuição de atividade dentro do espectro de tamanhos de partículas não é uniforme, algumas partículas apresentam grande fração do LIA com relação às demais partículas.

174 - Do que depende a representatividade de uma amostra de contaminação do ar com relação ao ar inalado por um trabalhador?

A representatividade depende:

a. da taxa de amostragem do ar

b. das características de seleção do tamanho das partículas do ar amostrado

c. da circulação do trabalhador dentro do local de trabalho

175 - Qual é a solução sugerida pela CIPR e em que caso ela é válida quando os fatores de conversão falharem na representação da incorporação por cada trabalhador fazendo uso de amostradores de área para o monitoramento da contaminação do ar provocada pela radiação ionizante e em que casos o seu valor pode ser menor ou maior?

A solução sugerida pela CIPR é adotar um fator de $1 / 10$ sobre o resultado para estabelecer um nível de referência.

- Podem ser observados valores de 1/10 quando a calibração dos amostradores de área é grosseira e deficiente.

- Podem ser observados valores < 1/10 quando a contaminação suspensa no ar é resultante de fontes espalhadas.

- Podem ser observados valores $>1 / 10$ quando a principal fonte de contaminação resulta das ações do trabalhador.

176 - Como obter a determinação do nível de referência no caso da contaminação do ar provocado pela radiação ionizante conhecendo-se a sua frequência de contaminação?

Tomaremos por base o exemplo considerando 10 contaminações do ar por ano, onde:

- Nível de referência: NR igual ao nível de registro

- Limite de Incorporação Anual: LIA para uma dose de $20 \mathrm{mSv}^{-1}$ 
- Frequência de contaminação no ar: $10 \mathrm{a}^{-1}$

- Nível de Referência de concentração no ar por hora do contaminante: NRCA

$$
\begin{gathered}
\frac{N R}{\text { EVENTO }}=\frac{\frac{1}{4} \text { LIA }}{10 \frac{\text { EVENTOS }}{A N O}}=\frac{1}{40} \text { LIA } \\
N R C A=\frac{L I A}{2000 h} \text { ou LIA }=2000 \mathrm{NRCA}
\end{gathered}
$$

Substituindo (2) em (1) vem:

$$
\frac{N R}{E V E N T O}=\frac{2000 N R C A}{40}=50 N R C A
$$

Lembre: Assegure-se que a incorporação estará abaixo de 1/40 do LIA para cada operação, para um ano de 2000 horas.

177 - O que deve ser feito e que cuidados devem ser tomados quando os níveis da contaminação do ar provocado pela radiação ionizante forem ultrapassados?

Deve-se introduzir ou reintroduzir o monitoramento interventor fazendo uso dos amostradores de ar individuais. Os cuidados a serem tomados no uso de amostradores de ar individuais são:

- Que possuem uma taxa de amostragem muito inferior àquela taxa de respiração do trabalhador de tal modo que um resultado simples de um turno ou até mesmo de uma semana são muito sensíveis a tendências resultantes da amostragem de uma única partícula não expressiva.

- Que o efeito de uma única partícula não expressiva tem uma importância muito menor nos resultados médios a longo prazo e são estes resultados que deverão ser utilizados para avaliar a incorporação.

178 - Quando os limites de incorporação, LIA, e os níveis de referência de concentração no ar, NRCA são adequados nas medidas de contaminação do ar provocada pela radiação ionizante?

a. Quando o diâmetro aerodinâmico médio para atividade do aerossol padrão for igual a $5 \mu \mathrm{m}$.

b. Quando são expressos como atividade total ou concentração de atividade sobre todos os tamanhos de partículas, isto é as amostras do ar não são seletivas nas dimensões das partículas.

179 - O que deve ser feito nos LIA e NRCA se o diâmetro aerodinâmico médio para a atividade, DAMA, dos aerossóis for diferente de $5 \mu \mathrm{m}$ ?

Deverão ser aplicados fatores de correção e estes geralmente provocarão a introdução de um monitoramento interventor que é apropriado sempre que:

- Há a necessidade de se determinar a distribuição das dimensões das partículas dos aerossóis.

- Ocorrer um resultado elevado isolado numa amostragem de ar individual. 
180 - 0 que se deve fazer em operações singulares e em operações variadas no monitoramento da contaminação do ar provocada pela radiação ionizante com função de rotina?

a. Nas operações singulares devem ser usados amostradores de ar instalados em locais escolhidos, expressivos das zonas de respiração dos trabalhadores.

b. Nas operações variadas deve-se efetuar amostragens nas diferentes etapas das operações e avaliar a incorporação total para cada trabalhador em um ciclo completo de operações.

181 - No monitoramento da contaminação do ar provocada pela radiação ionizante com função relacionada com a tarefa qual é a técnica mais comum e por quê?

A técnica mais comum é fazer uso de amostradores com equipamento de detecção contínuo, pois fornece um aviso nas variações súbitas dos níveis de concentração.

182 - Onde devem ser localizados e quando são necessários os amostradores de ar contínuos com função relacionada à tarefa usados no monitoramento da contaminação do ar pela radiação ionizante?

Os monitores de ar contínuos devem ser localizados onde poderão detectar confiavelmente uma liberação de material radioativo. Eles são necessários em:

- Reatores de Pesquisa

- Locais aonde são manuseados plutônio e elementos transurânicos dentro de caixas com luvas

- Onde houver grandes liberações de material radioativo

183 - Que conhecimento se exige e que tipo de hipóteses devem ser assumidas para uma interpretação acurada dos resultados de um monitoramento de contaminação do ar provocada pela radiação ionizante?

Exige-se conhecer:

- As propriedades físicas e químicas do contaminante.

- $\quad$ grau em que as amostras expressam o ar inalado pelos trabalhadores.

Devem ser realizadas hipóteses simplificadoras, particularmente, com relação à distribuição das partículas do contaminante.

184 - No monitoramento da contaminação do ar provocada pela radiação ionizante, o que se entende por ciclo típico e que monitores são usados para poder comparar seus resultados com os limites pertinentes?

Considera-se como ciclo típico aquele que há uma ocorrência regular de contaminação do ar em operações normais num período prolongado. No monitoramento são usados monitores representativos. 
185 - No monitoramento da contaminação do ar provocado pela radiação ionizante o que se entende por ciclo atípico, que monitores são usados para poder comparar os seus resultados com os limites pertinentes e com que frequência o monitoramento deve ser realizado?

Considera-se como ciclo atípico aquele em que não há condições regulares e as contaminações de ar são inesperadas. No monitoramento são utilizados amostradores de área, localizados próximos à zona de respiração, pois fornecem dados que expressam adequadamente a incorporação de cada trabalhador. Com relação à frequência as amostragens de ar devem ser contínuas ou regulares e frequentes em vários pontos dentro do local de trabalho.

186 - No monitoramento da contaminação do ar provocada pela radiação ionizante por que é impraticável interpretar os resultados dos amostradores de área ou representativos para a avaliação da incorporação para resultados singulares de amostras que duram um único turno ou menos?

- Entre os amostradores de área ou representativos temos diferenças de duas ou três ordens de grandeza

- É inadequado estabelecer um nível de referência representativo do limite anual ou da restrição de dose em termos da incorporação provável dos trabalhadores para ser usado para os amostradores representativos.

187 - Como é impraticável interpretar os resultados singulares de amostras que duram um único turno ou menos apresentados pelos amostradores de área ou representativos na medida da contaminação do ar provocada pela radiação ionizante, o que a CIPR sugere e do que dependem os seus limites?

A CIPR sugere estabelecer um nível de investigação bastante pequeno para detectar qualquer anormalidade significativa, mas suficientemente grande para não ser ultrapassada frequentemente em situações normais tal que a investigação forneça resultados significativos. O ponto superior do intervalo depende das incertezas na frequência em que os acontecimentos poderão ocorrer e o ponto inferior do intervalo depende da forma provável de investigação.

188 - Quando a concentração da contaminação no ar provocado pela radiação ionizante é pequena existem fatores complicadores para se determinar o nível de investigação para resultados singulares de amostras que duram um único turno ou menos. Neste caso como pode ser determinada a escolha do nível de investigação? 
Pode ser determinada considerando a:

- Forma de investigação.

- Sensibilidade de detecção do método.

- Provável concentração no ar, natural ou causada pelo material a ser avaliado, normalmente presente no local de trabalho.

189 - No monitoramento da contaminação do ar provocada pela radiação ionizante quando se torna necessário introduzir ou reintroduzir o uso de amostradores de ar individuais?

Quando se deseja determinar a irradiação dos trabalhadores com maior acurácia, nos seguintes casos:

- Quando os resultados médios de amostragens de ar de longa duração, em um ciclo completo, típico ou atípico, excedem os LAs ou NRLs.

- Quando os resultados de curta duração em amostragens singulares excedem os níveis de investigação., pois há necessidade de se obterem amostras de ar mais expressivas, daquelas fornecidas pelos amostradores de área colocados nas zonas de respiração.

190 - O que nos permite o uso dos amostradores de ar individuais para a medida da contaminação do ar provocada pela radiação ionizante? Qual delas é mais importante, mas qual é o seu maior problema?

Se forem usados no longo prazo possibilitam a sua interpretação em termos dos níveis de referência de concentração no ar e se forem usados em curto prazos possibilitam alertar para a tomada de ações remediadoras a curto prazo. A função alertar é mais importante do que avaliar as condições no longo prazo. O problema que eles apresentam é que são muito sensíveis a desvios criados durante a coleta do ar, pois possuem taxa de amostragem pequena.

191 - Para os monitores individuais do ar, no monitoramento da contaminação do ar, provocada pela radiação ionizante, que outros propósitos pode ter o nível de investigação além do seu precípuo?

a. Mostrar a tendência em longo prazo.

b. Avaliar a incorporação anual pela medida no indivíduo ou pela média dos resultados individuais em um grupo de trabalhadores.

192 - No monitoramento da contaminação do ar provocada pela radiação ionizante fazendo o uso dos amostradores individuais, se o nível de investigação for excedido o que deverá ser realizado?

Deverá ser realizado um programa de monitoramento individual, possivelmente incluindo o monitoramento para o corpo inteiro ou parcial. Deverão ser realizadas medidas em amostras de: urina, fezes, muco nasal, ar exalado e sangue. Este último em casos extremos. 


\section{Monitoramento Individual para Radiação Externa}

193 - Quais são os principais objetivos de um programa de monitoramento individual para a radiação externa?

a. Obter uma avaliação da dose efetiva e, onde for adequada, a dose equivalente em tecidos apreciavelmente expostos, de modo tal que demonstre concordância com as exigências gerenciais e regulatórias;

b. Contribuir para o controle de operações e para o projeto da instalação;

c. No caso de sobrexposição em acidentes, fornecer informação valiosa para o inicio e auxilio de qualquer acompanhamento médico e tratamento de saúde apropriado.

194 - A quem cabe a escolha dos trabalhadores que devem ser individualmente monitorados para a radiação externa?

Cabe ao gerente operacional mas deve ser examinada pelo órgão regulatório.

195 - Quais fatores devem ser considerados na escolha dos trabalhadores que necessitam de monitoramento individual para radiação externa?

a. O valor da dose com relação ao limites pertinentes.

b. A probabilidade de variações nas doses.

c. A complexidade das medidas nos procedimentos de interpretação envolvidos no programa de monitoramento.

196 - Quem deve ser monitorado individualmente e quem deve ser dispensado para a radiação ionizante externa?

Deverão ser monitorados individualmente os indivíduos laboralmente expostos, ILE, desde que suas doses não possam ser determinadas de outro modo como no caso das tripulações dos voos aéreos. Devem ser dispensados os ILE que recebem doses "consistentemente pequenas" e aqueles cujas doses não excedem um valor identificado como no caso da tripulação de voos aéreos. Não devem ser monitorados os indivíduos que recebem doses abaixo do limite do público.

197 - Para os indivíduos que necessitam de um monitoramento individual para a radiação externa, a partir de que valor a CIPR recomenda que seja efetuado o monitoramento?

A CIPR sugere um valor selecionado entre 5 e $10 \mathrm{mSva}^{-1}$.

198 - Como é definida a quantidade e o tipo de dosímetro individual a ser usado para a radiação ionizante externa?

É definida pela complexidade e heterogeneidade do campo de radiação. Exemplos:

a. Nos campos de radiação envolvendo tanto radiação penetrante como pouco penetrante, por exemplo, radiação gama e beta, deve ser usado um dosímetro com dois componentes. 
b. Em campos de radiação complexos e heterogêneos frequentemente será necessário mais de um dosímetro.

c. Em operações envolvendo manipulações muito próximas das fontes de radiação pode ser necessário o uso de um dosímetro tipo anel.

199 - Quais são os principais problemas apresentados no monitoramento individual para exposição externa a nêutrons e que solução propõe a CIPR?

Problemas:

a. Os limites de detecção dos monitores individuais para nêutrons geralmente são maiores do que aqueles para monitores individuais para gama.

b. Frequentemente, os nêutrons contribuem unicamente com uma pequena fração da dose de radiação externa total causada pela exposição laboral.

A CIPR Propõe que a avaliação da dose usando o monitoramento individual de exposição a nêutrons só seja necessária em áreas controladas onde as exposições a nêutrons, provavelmente, seriam uma contribuinte significativo para a dose efetiva.

200 - Os dosímetros individuais para a radiação externa que dose devem fornecer e o que deve ser registrado?

Devem fornecer a dose acumulada durante o período de tempo em que o individuo está trabalhando excluindo a dose acumulada pelo dosímetro fora do serviço. As técnicas utilizadas com esta finalidade devem constar do projeto de registro do programa de monitoramento.

201 - Qual é o propósito dos critérios sugeridos para a seleção dos trabalhadores que necessitam do monitoramento individual para a radiação externa quando forem necessárias doses especificadas?

O propósito é sugerir valores da atividade que resulte numa grande probabilidade de que as doses equivalentes nos órgãos ou tecidos, as doses efetivas e equivalentes nas mãos permaneçam inferiores aos limites anuais de dose aplicando-se procedimentos elementares de proteção.

202 - Em que partes do corpo e para que função do monitoramento individual podem ocorrer falhas na determinação das doses equivalentes para radiação ionizante externa?

Podem ocorrer doses equivalentes maiores nas mãos e em áreas da pele, sem serem detectadas ou avaliadas adequadamente pelo monitoramento individual com função de rotina.

203 - Que nível de referência a CIPR sugere para o monitoramento individual para a radiação externa, com função de rotina quando for necessário especificar um valor de dose e que valor considera nos exemplos? Por que?

Ela sugere, para a dose efetiva um valor fixo entre 5 a $10 \mathrm{mSva}^{-1}$ mas nos exemplos de seleção de pessoal a ser monitorado usa o valor de $5 \mathrm{mSva}^{-1}$ por ser o valor limítrofe entre as regiões tolerável e aceitável. 
204 - Como determinar a dose efetiva por hora proposta pela CIPR para selecionar os trabalhadores que necessitam do monitoramento individual com função de rotina para radiação ionizante externa? Quais as equações que fornecem soluções aproximadas?

Consideremos as seguintes informações:

- Limite anual: $5 \mathrm{mSv}$

- Distância entre a fonte e o tronco do corpo: $1 \mathrm{~m}$.

- Carga de trabalho anual (em presença da fonte): $2000 \mathrm{~h}$

Solução:

Taxa de dose efetiva que exige o monitoramento individual é superior a:

$$
\frac{5000 \mu S v}{2000 h}=2,5 \mu S v h^{-1}
$$

As equações aproximadas são:

- $15 \mathrm{MBq} \cdot \mathrm{MeV}=1$

- $0,4 \mathrm{mCi} . \mathrm{MeV}=1$

205 - Em que situações para o equipamento fluoroscópico e radiográfico, emissores de raios $X$ e gama (médico e industrial) não necessita de monitoramento individual com função de rotina para a radiação ionizante externa?

Não exigem o monitoramento individual para radiação externa, desde que por uma inspeção ou um programa limitado de monitoramento, demonstrem que os procedimentos de operação são muito criteriosos. Exemplos:

a. Trabalho não radiológico em departamentos que lidam com radiografia gama ou X.

b. Radiografias dentárias.

c. Trabalhos operacionais em processos industriais envolvendo o controle ou a medida radiológica, como: medidores de nível ou espessura.

206 - Em que casos o equipamento radioterapêutico: emissores de radiação gama e $\mathrm{X}$ não é necessário monitoramento individual com função de rotina para radiação ionizante externa?

- Os procedimentos operacionais e os princípios mecânicos restringem o acesso às salas de radioterapia

- São garantidas doses pequenas

- Os procedimentos de operação possuem sistematicamente um padrão elevado de segurança

Como exemplo pode-se citar trabalhos não radiológicos em departamentos que lidam com terapia a base de radiação gama e $\mathrm{X}$. 
207 - Que função do monitoramento individual e que tipo de equipamento para a radiação ionizante externa é necessária no caso da teleterapia com radiação gama, $X$ e com aceleradores?

É necessário o monitoramento relacionado com a tarefa e são justificados monitores pessoais de aviso com a finalidade de reduzir a incidência de irradiações acidentais elevadas.

208 - O que é que pode limitar as exposições laborais causadas diretamente por um incidente ou acidente envolvendo radiação ionizante e qual deve ser o objetivo da proteção radiológica?

As exposições só podem ser limitadas pelo projeto da instalação e suas características de proteção e pelo estabelecimento de procedimentos de emergência. O objetivo da proteção radiológica deve ser conservar as doses dentro daquelas permitidas em condições normais. Ainda que isto às vezes seja possível, nem sempre ocorre em acidentes graves.

209 - Nas emergências envolvendo exposições significativas à radiação ionizante dos grupos de emergência são permitidas relaxações nos controles aplicados em situações normais sem diminuir o grau de proteção no longo prazo. No controle imediato e remediação urgente destes incidentes ou acidentes quais são os valores de exposição adotados?

Doses efetivas até 0,5 Sv exceto para ações de salvamento de vidas, que raramente, podem ser limitadas por avaliação dosimétrica. E dose equivalente na pele de até $5 \mathrm{~Sv}$, exceto novamente, para o salvamento de vidas.

210 - Com relação às ações necessárias após um acidente envolvendo a radiação ionizante e o público quais são as categorias que classificam as indicações de trabalhado?

São três, a saber:

- Categoria 1: Ação urgente no local do acidente.

- Categoria 2: Implementação das primeiras ações de proteção e condução das ações de proteção do público.

- Categoria 3: Operação de recuperação.

211 - Em que ações devem atuar os trabalhadores classificados como da categoria 1 empenhados na ação de urgência no local do acidente envolvendo radiação ionizante, qual é a sua origem institucional e que limites de dose devem ser recomendados?

Os trabalhadores da categoria 1 devem atuar para salvar vidas, para evitar enfermidades graves ou para evitar um aumento substancial nas doses potenciais para os membros do público. Geralmente são trabalhadores da própria instalação, mas, também, podem ser trabalhadores de serviços de emergência, como a brigada de incêndio. Para esta categoria de trabalhadores não é apropriado recomendar limites de doses rígidos. 
212 - Em que ações devem atuar os trabalhadores classificados como da categoria 2 empenhados na implementação das primeiras ações de proteção e na condução de ações de proteção do público envolvendo radiação ionizante, que atenção deve ser dada a eles e que limites de dose devem ser recomendados?

Os trabalhadores da categoria 2 devem atuar para evitar as doses no publico, como a força policial, pessoal médico, motoristas e manobristas de veículos usados para a evacuação e grupos similares. Para estes trabalhadores deve ser dada atenção para a otimização da proteção, se bem que de um modo simples ou direto. $O$ objetivo é, também, conservar suas doses inferiores aos limites laborais ainda que isto nem sempre seja possível.

213 - Em que ações devem atuar os trabalhadores classificados como da categoria 3 empenhados nas operações de recuperação envolvendo radiação ionizante e como este trabalho deve ser tratado com relação às doses individuais?

Os trabalhadores da categoria 3 devem atuar nas operações de recuperação, como reparações nas instalações e locais de disposição de rejeitos, descontaminação dos locais e do ambiente. Este trabalho deve ser planejado cuidadosamente. Deve ser tratado como uma prática e portanto, as doses devem ser mantidas inferiores aos limites laborais.

214 - Que tratamento deve ser fornecido aos trabalhadores classificados como categoria 1 empenhados na ação de urgência no local do acidente envolvendo radiação ionizan te?

a. Deverão receber treinamento apropriado e serão compreensivamente informados dos perigos e riscos com os quais provavelmente irão se deparar.

b. Deverão ser treinados nos tipos de ações que podem ser exigidas.

c. Deverão receber, sempre que necessário, informações e treinamento sobre o uso de medidas de proteção, como a proteção respiratória, roupas de proteção, mecanismos de blindagem etc.

d. Deverão possuir meios apropriados para controlar e quantificar suas exposições usando mecanismos apropriados para a situação em questão, tais como dosímetros de leitura direta e de alerta.

215 - Que tratamento deve ser fornecido aos trabalhadores classificados como categoria 2 empenhados na implementação das primeiras ações de proteção e na condução das ações de proteção do público envolvendo radiação ionizante?

a. Deverão ser informados sobre os riscos associados com as doses que eles podem receber e instruídos sobre as ações que se exige que eles executem para se protegerem e protegerem o público.

b. Não é necessário o monitoramento individual, pois os meios para a implementação das ações de proteção antecipadas devem considerar as doses que eles poderão receber e que, geralmente, não serão diferentes daquelas recebidas pelo público para o qual eles fornecerão a proteção.

c. Que sejam realizadas estimativas das doses que estes trabalhadores irão receber. 
216 - Que tratamento deve ser fornecido aos trabalhadores classificados como categoria 3 empenhados nas operações de recuperação envolvendo radiação ionizante?

a. O treinamento deve depender da situação real e não pode ser identificado antecipadamente.

b. O treinamento deve ter um padrão similar àquele exigido a todos os trabalhadores que estão laboralmente expostos e que seja proporcional ao grande risco ao qual estão expostos.

c. A avaliação das doses deve ser igual a qualquer trabalhador exposto laboralmente que esteja submetido ao sistema de proteção radiológica para as práticas.

217 - Que informações os trabalhadores envolvidos nas situações de emergência em presença da radiação ionizante devem receber com respeito às suas doses de radiação?

a. Devem ser prontamente informados sobre as doses recebidas e as possíveis consequências sobre a saúde.

b. Que as doses recebidas em situações de emergência não devem comprometer o futuro emprego do trabalhador na realização de tarefas com radiação ionizante.

c. Se a dose recebida na exposição de emergência for próxima ou acima do limiar para efeitos determinísticos, ele será encaminhado a um médico.

218 - 0 que deve ser registrado e como em relação às doses recebidas pelos trabalhadores das três categorias que atuaram nas situações de emergência após um acidente envolvendo radiação ionizante?

Para todos os trabalhadores classificados nas categorias 1 e 2 os assentamentos devem ter registros das doses recebidas em situação de emergência identificadas em separado daquelas recebidas rotineiramente por causa das diferentes condições nas quais foram recebidas. Devese também registrar:

a. A natureza e duração da exposição

b. O tipo e qualidade da radiação

Para os trabalhadores classificados na categoria 3 as doses devem ser registradas como exposições laborais normais.

219 - Como é avaliada a dose equivalente e efetiva para a radiação ionizante externa no monitoramento individual com função relacionada à tarefa em caso de acidentes?

a. Para acidentes de pequenas proporções ela é coberta pelo programa de monitoramento de rotina.

b. Para acidentes com exposições elevadas em circunstâncias não intencionais deve-se incluir no programa de monitoramento uma providencia para estimar estas doses elevadas no programa rotineiro.

c. Para acidentes com exposições elevadas ou em circunstancias deliberadas devem ser especificados mais dosímetros para as tarefas que os exigirem. Também, devem ser considerados dosímetros de leitura direta e instrumentos de taxa de dose individuais, algumas vezes com aviso sonoro. 


\section{Monitoramento Individual para Exposição Interna}

220 - Quais são os principais objetivos de um programa de monitoramento individual para a exposição interna?

a. Obter uma avaliação de dose comprometida efetiva e, sempre que adequado, a dose equivalente comprometida em tecidos apreciavelmente expostos, de tal modo que demonstre concordância com as exigências gerenciais e regulatórias.

b. Contribuir para o controle de operações e do projeto de instalações.

c. No caso de acidentes envolvendo sobrexposição, fornecer informações valiosas para o inicio e auxilio de qualquer acompanhamento médico e tratamento de saúde apropriado.

221 - Por que medidas é realizado o monitoramento individual para exposição interna com função de rotina?

a. Por medidas indiretas pela coleta e analise de amostras de escretas ou;

b. por medidas diretas da radiação emitida pelos radionuclídeos contidos nos órgãos ou tecidos internos ao corpo.

222 - Além da atividade incorporada, o que se deve conhecer para estimar a dose equivalente e efetiva no monitoramento individual para exposição interna com função de rotina?

a. A sua distribuição no instante da incorporação.

b. Modelos dosimétricos e biológicos padronizados necessários para calcular os coeficientes associados com a incorporação para determinar a dose equivalente $\mathrm{e}$ efetiva.

223 - Para quem deve ser efetuado o monitoramento com função de rotina para a incorporação de material radiativo?

Deve ser efetuado somente para os trabalhadores que estão empregados em áreas que foram demarcadas como áreas controladas, especificamente em relação ao controle da contaminação e onde existem variações que resultam em incorporações apreciáveis.

224 - Quais as operações em que a experiência mostrou que é necessário considerar o monitoramento para a exposição interna dos trabalhadores com função de rotina?

a. Manuseio de grandes quantidades de gases e materiais voláteis, por exemplo, trítio e seus compostos em processos de produção em grande escala, em reatores de água pesada em consequência da produção de óxidos e em processos de luminescência como pinturas;

b. Processamento de plutônio e outros elementos transurânicos;

c. Processamento de minérios de tório e seus compostos;

d. Mineração e beneficiamento de minério de urânio com teor elevado;

e. Processamento de urânio natural e levemente enriquecido e fabricação de combustível para reatores; 
f. Produção de grandes quantidades de radionuclídeos;

g. Locais de trabalho com grandes teores de radônio que excedem os níveis de ação;

h. Manuseio de grandes quantidades de ${ }^{131} \mathrm{I}$, por exemplo, para terapia.

225 - Como se pode avaliar a necessidade de se introduzir um programa de monitoramento individual interno com função de rotina?

a. Pelos resultados do monitoramento do local de trabalho para contaminação de superfície e do ar;

b. Pela experiência anterior em operações similares;

c. Pelo uso dos critérios específicos;

d. Pela introdução de um programa de monitoramento individual interventor.

226 - Em que situações pode ser dispensado o monitoramento individual interno com função de rotina para radiação ionizante?

a. Condições de trabalho satisfatórias, confirmadas pelo monitoramento com função de rotina do local de trabalho.

b. Deteriorações lentas das condições de trabalho, pois elas podem ser detectadas com medidas infrequentes de amostras adequadas. Medidas estas que não visam determinar as doses equivalentes individuais. A frequência destas medidas é determinada pelas condições de trabalho.

c. Materiais com meia vida efetiva muito curta, pois este tipo e função do monitoramento torna-se impraticável e para manter a confiabilidade deve ser substituído pelo monitoramento do local de trabalho.

227 - Quais são os fatores mais importantes que influenciam na referência das medidas para o monitoramento individual interno com função de rotina da radiação ionizante e o que deve satisfazer para a sua escolha?

Os fatores mais importantes são:

a. Variação observada na incorporação do material radioativo com o transcorrer do tempo;

b. Tempo de residência do contaminante no corpo;

c. Sensibilidade de detecção em relação aos níveis de investigação e de registro apropriados.

A sua frequência deve ser tal que todas as incorporações apreciáveis sejam detectadas. 
228 - De acordo com a CIPR, quais são as situações que podem provocar uma contaminação interna dos trabalhadores e como é distinguida a primeira situação da última?

As situações são:

a. Resultante de eventos poucos frequentes, normalmente ao acaso.

b. Variável, mas essencialmente contínua, como resultado de operações normais.

c. Descontínua, mas com certa frequência, como resultado de pequenas situações anormais.

A distinção entre primeira e terceira está na frequência. Frequência próxima à mensal coadunase com a terceira situação.

229 - Que resultados podemos usar para avaliar a necessidade de um monitoramento para a contaminação interna com função de rotina para a radiação ionizante?

Podemos utilizar os resultados do monitoramento do ar.

230 - Qual a necessidade de um monitoramento individual para a exposição interna com função de rotina na situação de uma contaminação interna provocada por eventos pouco frequentes, normalmente ao acaso?

Só se considera a possibilidade do monitoramento individual com doses superiores a 1/10 do LAMA e os resultados anteriores do trabalhador podem possibilitar esta avaliação. Em caso de duvida há a necessidade de se efetuar uma revisão geral das operações executadas considerando o aspecto experiência. Se a revisão confirmar que a possibilidade de incorporação acima de 1/10 do LAMA é pequena, não será necessário um monitoramento individual de rotina mas poderá ser necessário um programa de monitoramento individual interventor após a deteç̧ão da contaminação. Esta detecção da contaminação pode ser realizada pelo monitoramento do local de trabalho ou pela própria situação operacional.

231 - Qual a necessidade de um monitoramento individual para a exposição interna com função de rotina na situação de uma contaminação interna variável, mas essencialmente contínua, como resultado de operações normais?

A principal informação para se estabelecer a necessidade de um monitoramento individual para a exposição interna com função de rotina advêm dos resultados do monitoramento de ar realizado nas zonas de respiração dos trabalhadores. Se as incorporações individuais estiverem distribuídas em torno de um valor médio e o programa de monitoramento do ar for bem projetado e interpretado é possível prever que a incorporação não será superior a 3 vezes o valor médio estimado para o grupo. Neste caso se os resultados médios anuais para o monitoramento do ar, na zona de respiração, forem menores do que $1 / 30$ do LAMA, o monitoramento individual interno não será necessário. 
232 - Qual a necessidade de um monitoramento individual para a exposição interna com funcão de rotina na situação de uma contaminação interna descontinua, mas com certa frequência, como resultado de pequenas situações anormais?

Os resultados do monitoramento do ar, geralmente, são obtidos na corrente de ar e não nas zonas de respiração e neste caso, tipicamente, existe um fator de uma ordem de grandeza entre as medidas na corrente de ar e aquelas efetuadas próximas a zona de respiração. Em virtude disto se o resultado médio anual do monitoramento do ar for menor do que 1/100 do LAMA as incorporações dos trabalhadores não excederão os 1/10 do LAMA e não será necessário o monitoramento individual interno com função de rotina.

233 - O que deve ser feito no caso em que os resultados apresentados por alguns trabalhadores sugerirem incorporações de material radioativo superiores a 1/10 do LAMA?

Este fato não implica necessariamente na exigência de um monitoramento individual interno, mas que se torna necessário uma avaliação mais cuidadosa das radiações individuais. Isto pode ser conseguido por meio de:

a. um estudo experimental propagado durante um período limitado incluindo uma amostragem do ar mais prolongada;

b. algum monitoramento individual.

234 - No monitoramento individual para a exposição interna causada pela radiação ionizante, - modelo metabólico aplicado ao resultado de medida ao que se deve relacionar, que informações deve fornecer e no que deve estar baseado?

O modelo metabólico que relaciona o resultado da medida à grandeza física usada na interpretação, como dose por bequerel, limite autorizado, ou níveis de referência, deve ser compatível com o modelo metabólico usado para a grandeza física que define o limite ou o nível de referência. O modelo metabólico deve fornecer informações sobre:

a. Quantidades de radionuclídeos depositados nos órgãos ou tecidos

b. Taxa de excreção

Ele deve estar baseado na possibilidade de que a incorporação seja uniformemente distribuída com o transcorrer do tempo, correspondendo a uma fração mais ou menos constante do limite no meio do intervalo entre os tempos de monitoramento.

235 - Como pode ser determinado e quando deve ser efetuado o monitoramento individual para a radiação interna com função de rotina para a radiação ionizante?

a. Para avaliar as incorporações a médio ou longo prazo o monitoramento pode se efetuado em intervalos de tempo selecionados, não necessariamente relacionados com as incorporações conhecidas, pois elas raramente são contínuas e podem ocorrer a qualquer momento entre as medidas.

b. Se forem conhecidos os instantes de incorporação pode ser feito um cálculo mais acurado, porém só será necessário se existir a suspeita de uma incorporação apreciável. 
236 - Como pode ser definido um nível de investigação da dose efetiva para o monitoramento individual para a radiação interna com função de rotina para a radiação ionizante em obediência às normas da CNEN e as recomendações da CIPR?

a. Pelas normas da CNEN o nível de investigação deve ser definido como $6 \mathrm{mSva}^{-1} / \mathrm{h}$ em que $\mathrm{n}$ é o numero de períodos de amostragem por ano.

b. Pelas recomendações da CIPR, deve ser definido como $5 \mathrm{mSva}^{-1} / \mathrm{n}$ com $\mathrm{n}$ tendo o mesmo significado das normas da CNEN. Neste caso o nível de investigação coincide com o nível de registro.

237 - No monitoramento individual para a radiação interna com função relacionada com a tarefa quando ela não se torna necessária e em caso contrario por que função de monitoramento pode ser substituída?

a. Ela não se torna necessária em condições normais de trabalho quando for utilizada uma proteção individual adequada para a realização das tarefas, e

b. ela pode ser substituída por um monitoramento interventor se houver evidencias de falhas nos mecanismos de proteção.

\section{Monitoramento Individual para Contaminação de Pele e Roupa}

238 - A contaminação da pele e da roupa pela radiação ionizante para que tipo de irradiação do corpo humano contribuem?

Contribuem para:

- Irradiação externa e

- irradiação interna, se for absorvida abaixo da camada superficial da pele.

239 - Por que é muito difícil determinar o valor das doses externas e internas provocadas pela contaminação da pele e da roupa pela radiação ionizante?

- Pelo fato das contaminações não serem uniformes.

- Pelo fato de ocorrem em certas partes do corpo, principalmente nas mãos.

240 - Que solução podemos invocar para se sobrepor às dificuldades apresentadas na determinação das doses externas e internas ao corpo humano provocadas pela contaminação da pele e roupa?

Estabelecendo níveis de ação ou investigação, isto é, níveis de referência ou autorizados de contaminação inferiores ao nível de registro, pois neste caso não é necessário determinar doses equivalentes ou efetivas.

241- Para as doses individuais qual é o valor do nível de investigação sugerido no monitoramento para a contaminação da pele e roupas e em que dimensão de superfície deve ser medida? 
a. Para as doses individuais e sugerido o valor de, 1/10 do LAMA.

b. Ela deve ser medida em uma superfície de $100 \mathrm{~cm}^{2}$ para a pele e roupa exceção feita às mãos que a superfície deve ser de $300 \mathrm{~cm}^{2}$ isto é uma mão completa frente e verso.

242 - Quais são os principais objetivos de um monitoramento para a contaminação da pele e roupa pela radiação ionizante?

- Demonstrar concordância com os limites pertinentes.

- Detectar a contaminação que poderia ser transferida para fora de uma área controlada, pelo indivíduo.

- No caso de sobre exposição, fornecer informação valiosa para o início e auxílio de qualquer acompanhamento médico e tratamento de saúde apropriado.

243 - Se o nível de registro para a contaminação da pele e roupa pela radiação ionizante for ultrapassado, que considerações devem ser realizadas e que incertezas podemos ter no caso de contaminantes emissores de radiação alfa na pele?

Devemos procurar reduzir a contaminação e também investigar a causa que provocou. Para radiação alfa são comuns incertezas de até duas ordens de grandeza na estimativa da dose local na pele.

244 - Que equipamentos são utilizados no monitoramento com função relacionada com a tarefa para a contaminação da pele e roupa e como pode ser explicado seu uso?

- Equipamento móvel de bancada para a contaminação de superfície: geralmente é usado dentro do laboratório, passando o detector próximo à pele e à roupa.

- Monitor de pés, mãos e roupa: geralmente fixo e localizado em local conveniente.

- Portais: geralmente colocados na entrada dos banheiros para quem sai do laboratório. Sua principal finalidade é detectar contaminações que passarão despercebidas ao trabalhador evitando que sejam transferidas para áreas inativas.

\section{Monitoramento Interventor}

245 - Qual é a finalidade de um monitoramento interventor em trabalhos envolvendo a radiação ionizante e o que ele deve possuir?

A finalidade é proporcionar uma informação detalhada que elucide os problemas para a obtenção de um controle adequado. Portanto deve ter:

- Objetivos bem definidos e

- duração limitada no tempo.

246 - Como deve terminar um monitoramento interventor para a radiação ionizante, uma vez concluídos os seus objetivos? 
a. Para situações normais de trabalho deve terminar a favor de: (i) monitoramento de rotina; (ii) monitoramento relacionado com a tarefa; (iii) não necessidade de monitoramento.

b. Para situações anormais de trabalho ao retorno à situação normal.

247 - Quando se torna necessário em situações normais de trabalho o monitoramento interventor para a radiação ionizante?

Pode ser necessário:

a. No inicio da colocação em funcionamento de uma instalação.

b. Logo após alterações consideráveis realizadas nas instalações ou em procedimentos operacionais.

c. Para verificar a adequacidade dos programas de monitoramento de rotina.

d. Para validar ou melhorar os modelos envolvidos na interpretação dos dados do monitoramento.

248 - Em que situações anormais de trabalho pode se tornar necessário o monitoramento interventor?

Logo após a observação de um resultado inesperado, por exemplo, quando um nível de investigação ou de ação foi excedido.

Em um acidente. Neste caso os propósitos podem ser vários como: (i) definir as áreas afetadas e (ii) reconstruir as circunstâncias de um evento de modo a chegar a uma melhor estimativa de dose.

249 - Para o monitoramento interventor envolvendo radiação ionizante o que deve constar nos planos de emergência radiológica, PER?

a. Os objetivos do monitoramento interventor, especial para as circunstâncias específicas.

b. A quantidade de instrumentos necessários.

c. A disponibilidade dos instrumentos durante um tempo adequado.

d. A adequacidade dos instrumentos para os tipos, a qualidade e a intensidade dos campos de radiação que provavelmente serão encontrados.

250 - Em que casos torna-se importante realizar o monitoramento interventor envolvendo radiação ionizante para fontes moveis e para instalações?

a. Para fontes móveis: (i) em radiografias de tubulações e (ii) em perfurações para prospeç̧ão.

b. Para instalações, onde são utilizadas fontes intensas que podem deixar de retornar para a sua posição de proteção na blindagem, por falhas, após uso.

251 - O que deve ser lembrado para o monitoramento com função interventora no caso de exposição externa com possibilidade de doses superiores ao limites?

a. São necessárias avaliações precisas e confiáveis da exposição. 
b. Os instrumentos dosimétricos de rotina nem sempre têm capacidade de fornecer estas informações.

c. É justificável fornecer aos trabalhadores dosímetros especiais que fornecem informações confiáveis sobre a dose absorvida acima de cerca de 1Gy.

d. Em campos de nêutrons, medidas simples da atividade induzida no corpo dos trabalhadores expostos, ${ }^{24} \mathrm{Na} \mathrm{e}{ }^{38} \mathrm{Cl}$ podem fornecer informações úteis.

e. Que é valiosa a dosimetria biológica.

\section{2 - 0 que se mede pela dosimetria biológica?}

Medem as aberrações cromossômicas em linfócitos circulantes.

253 - O que obrigatoriamente devemos considerar no monitoramento interventor para pequenos acidentes envolvendo a radiação ionizante?

Que são considerados pequenos acidentes quando as doses previstas são de até 10 vezes os limites anuais.

Para ter estimativas mais realistas deve-se conhecer o espectro de energia e a orientação da energia incidente e que estas informações podem ser obtidas a partir do conhecimento da fonte produtora do espectro e dos métodos de trabalho.

Que para irradiações frequentes ou falta de dados necessita-se o uso de dosímetros de rotina ou relacionada com a tarefa que proporcionem a informação espectral e que se obtenha dados sobre a orientação do indivíduo no campo de radiação. Estes dados podem ser obtidos: (i) pelo uso de um dosímetro adequado, como o filme radiográfico; (ii) pelo uso de vários dosímetros; (iii) pela consulta aos trabalhadores.

254 - O que obrigatoriamente devemos considerar no monitoramento interventor para grandes acidentes envolvendo a radiação ionizante?

a. Que as doses absorvidas exigem uma atenção médica.

b. Que as estimativas de dose devem ser mais corretas do que aquela fornecida pelos dosímetros individuais com função de rotina, pois surgirão incertezas nas doses absorvidas pelo corpo com relação à sua distribuição e aos seus valores.

c. Que o dosímetro individual com função de rotina ou relacionada com a tarefa pode propiciar importantes pontos de referência.

d. Que o conhecimento do acidente pode aumentar o número pontos de referência.

255 - No monitoramento com função de rotina nos acidentes de criticalidade, o que devemos considerar em relação aos dosímetros?

a. Que devem incorporar componentes especiais com dependência energética.

b. Que devem ser colocados em posições estratégicas nos locais de trabalho para fornecerem informações quanto à orientação e a dimensão das irradiações.

256 - O que obrigatoriamente devemos considerar no monitoramento interventor em casos extremos envolvendo a radiação ionizante? 
a. A reconstrução dos campos de radiação.

b. A execução de medidas das características dos campos de radiação colocando dosímetros: (i) sobre um manequim natural; (ii) dentro de um manequim natural; e efetuando medidas diretas da dose absorvida, em vários pontos do campo com o manequim.

c. Que o cálculo da dose pode ser facilitado pelo conhecimento, em um certo número de pontos, da fluência e do espectro de energia.

d. Que estas medidas estão além do escopo de um dosímetro individual com função de rotina.

e. Que o dosímetro individual com função de rotina pode ajudar na reconstrução da ocorrência de maneira a simular corretamente o acidente original.

257 - Em que casos torna-se necessário um monitoramento interventor para a exposição interna à radiação ionizante e que testes simples podem ser efetuados para a verificação desta necessidade?

a. Quando os resultados do monitoramento do local de trabalho indicam que podem ter ocorrido incorporações apreciáveis.

b. Quando os trabalhadores forem envolvidos em incidentes com incorporações apreciáveis de material radioativo.

Testes simples de verificação da necessidade do monitoramento interno interventor podem ser realizados por medidas de contaminação na pele, na roupa e no muco nasal.

258 - Que vantagem possui o monitoramento interno da radiação ionizante com função interventora e o que a CIPR informa a respeito?

A vantagem é que possibilita o estudo do metabolismo humano dos radionuclídeos e a CIPR informa que:

a. Neste caso justificam-se valores de atividade menores daqueles de interesse direto no monitoramento individual interno.

b. Este tipo de estudo deve ser encorajado.

259 - Quais são os métodos de medida, no monitoramento das exposições internas provocadas pela radiação ionizante com função interventora?

a. In vivo, é a avaliação dos radionuclídeos presentes no corpo ou nos tecidos por medidas externas.

b. In vitro, é a análise de excretas ou amostras de fluídos do corpo.

260 - Do que depende a escolha do método de medida no monitoramento das exposições internas provocadas pela radiação ionizante, com função interventora?

a. Depende das radiações emitidas pelo contaminante. No caso da radiação $X$ e gama as medidas são in vivo mas no caso das demais radiações são in vitro, ainda que seja possível in vivo pela análise de bremsstrahlung, isto é, radiação de frenação.

b. Da facilidade de acesso ao serviço de monitoramento. 
c. Do serviço de monitoramento individual interno ser centralizado, pois pode ser mais fácil enviar amostras para análise do que trabalhadores para o local onde se encontra o equipamento de medida.

261 - 0 que deve ser considerado na interpretação do monitoramento interno com função interventora?

a. Que os métodos de interpretação são, basicamente, iguais àqueles do monitoramento com função de rotina.

b. Que geralmente há um número maior de informações acerca do tempo e modo de incorporação e da forma física e química do material radioativo.

c. Que, quando existentes, devem-se usar dados metabólicos individuais para o cálculo de: (i) doses equivalentes comprometidas nos órgãos e tecidos individualmente e (ii) doses comprometidas efetivas para comparação com os limites primários.

d. Que não há necessidade de se usar dados do homem referência.

e. A confiança na estimativa final da quantidade de material radioativo no corpo ou a dose equivalente no tecido deverá repousar em todos os resultados do monitoramento disponível, tanto individuais como do local de trabalho.

\section{Manutenção das Assentamentos}

262 - Os assentamentos dos programas de monitoramento da radiação ionizante devem incluir detalhes de que assuntos?

a. Do programa

b. Dos métodos de medida e de sua interpretação

c. Dos resultados do monitoramento do local de trabalho

d. Dos resultados do monitoramento individual

263 - A quem devem estar disponíveis os assentamentos relativos ao monitoramento da radiação ionizante?

a. Gerência operacional;

b. Consultores de proteção radiológica;

c. Consultores médicos;

d. O órgão regulador, a pedido, ainda que isso não seja uma exigência reguladora;

e. O trabalhador a respeito de seu próprio monitoramento, a pedido;

f. Grupos de trabalhadores, desde que a gerência consulte a sua mão de obra, com a finalidade de encorajar um interesse no desempenho de suas proteções.

264 - Os programas de monitoramento da radiação ionizante têm potencial para gerar enormes quantidades de dados. Qual é o interesse, como devem ser apresentados e como pode ser reduzida a sua quantidade?

O interesse é mantê-los sob exame minucioso com a finalidade de eliminar as medidas desnecessárias do programa de monitoramento. Os dados (com as suas grandezas e unidades 
pertinentes claramente expressadas) devem ser apresentados ao gerente numa forma que facilite o reconhecimento de uma deterioração apreciável nas condições. A quantidade a ser assentada pode ser reduzida pelo uso de um nível de registro.

265 - No programa de monitoramento da radiação ionizante o que deve ser assentado no caso das doses estimadas terem sido realizadas por métodos diferentes daqueles preconizados nos padrões de proteção radiológica?

a. Todas as medidas que contribuem para a avaliação formal da dose devem ser transcritas no assentamento do indivíduo.

b. Se a avaliação formal da incorporação estiver baseada em dados de amostragem do ar combinado com o fator de ocupação, as informações pertinentes serão adequadas, para o propósito de registro individual.

266 - Como devem ser tratadas nos assentamentos as doses individuais relacionadas com a tarefa?

a. Devem ser incluídas nos assentamentos individuais, mas não em substituição aos resultados de rotina durante o período de execução da tarefa.

b. Se os dados relacionados com a tarefa justificam uma reavaliação dos dados relativos à função de rotina, deve ser transcrita uma contribuição à dose anual, consultando o órgão regulador, quando necessário.

267 - Como devem ser tratadas as doses equivalentes na pele causadas por sua contaminação nos assentamentos?

a. Devem ser tratadas separadamente dos dados fornecidos pelo monitoramento com função de rotina para a radiação externa.

b. Somente quando for realizada com confiabilidade razoável é que será incluída no assentamento da dose individual.

268 - Com relação à manutenção dos registros dos monitoramentos da radiação ionizante, visando satisfazer os padrões de proteção radiológica, o que reza o parágrafo 277 da publicação 60 da CIPR?

Reza que: "Deve ser atingido um balanço entre a complexidade de dados de entradas iniciais, que podem comprometer a acurácia e a completeza e o possível uso futuro dos registros. A validade da maioria dos registros diminui com o passar do tempo, quanto a possibilidade de se tornarem necessários. Como orientação geral e sujeito a exigências regulamentares, os registros que fornecem os resultados das avaliações das doses individuais devem ser mantido por períodos comparáveis com a sobrevivência esperada para os indivíduos".

269 - Quem decide quais são os dados que devem ser conservados nos assentamentos do monitoramento da radiação ionizante, o que deve considerar e o que deve ser evitado?

O gerente, considerando a necessidade de se demonstrar a concordância com a sua própria filosofia e com as exigências regulamentares. Deve ser evitada a necessidade de se preservar todos os resultados do monitoramento durante muitos anos. 
270 - Como devem ser tratados os resultados do monitoramento do local de trabalho para a radiação ionizante quanto ao seu assentamento?

a. Os seus resultados junto com os dados dosimétricos referentes à função relacionada à tarefa devem ser mantidos de forma que possam ser disponibilizados prontamente quando for exigida uma reavaliação de sua interpretação.

b. Para propósitos de proteção radiológica, não deve ser necessária a retenção daqueles dados de monitoramento obtidos somente para gerenciamento rotineiro das operações, por mais do que alguns anos.

\section{Acurácia}

271 - De onde se originam os erros observados no uso do monitoramento da radiação ionizante para fornecer as estimativas das doses individuais?

- Nas medidas

- Nos modelos associados com as medidas

- Nas grandezas físicas necessárias

272 - Quais são as categorias gerais nas quais podem situar-se os erros que contribuem para a incerteza total no monitoramento da radiação ionizante?

As categorias são:

- Erros aleatórios na medida, por exemplo: estatística de contagem.

- Erros sistemáticos nas medidas, por exemplo: erros de calibração.

- Erros, principalmente sistemáticos em modelos dosimétricos e metabólicos, por exemplo: incertezas nos dados metabólicos.

- Erros, principalmente sistemáticos, mas nem sempre consistentes no uso de modelos, por exemplo: padronização nas características físicas e químicas de um radionuclídeo inalado.

273 - Quando as indivíduos são expostos à radiações ionizante por longos períodos de tempo e desta maneira a avaliação das doses passa a estar baseada em um determinado número de medidas realizadas durante estes períodos o que ocorre com os seus erros?

- A probabilidade de erros aleatórios é reduzida pelas múltiplas medidas.

- Os erros sistemáticos nos modelos resultam em uma propensão no sentido de sobre estimar a dose verdadeira para as múltiplas avaliações.

274 - Que acurácias são observadas no monitoramento da radiação ionizante quando existem boas condições de laboratório?

Para as medidas de campos de radiação uma acuraria de 10\% num nível de confiança de $95 \%$.

275 - Quais são os problemas encontrados e que ocorrências são observadas no monitoramento da radiação ionizante para as medidas, realizados no local de trabalho? 
Os problemas encontrados são:

a. Os espectros de energia e a orientação dos campos de radiação não são conhecidos.

b. As incertezas observadas em uma medida feita com dosímetro individual serão muito maiores.

c. A não conformidade e a incerteza dos campos de radiação introduzirão erros no uso de modelos padronizados.

As ocorrências observadas são:

a. Para fótons, na estimativa da dose efetiva ao redor do limite de dose anual pertinente, podem ser observadas incertezas dentro de um fator de 1,5 em cada direção com um nível de confiança de $95 \%$.

b. Para elétrons e nêutrons de energia desconhecida as incertezas totais podem ser bem maiores.

c. Para todos os tipos de radiação com doses efetivas pequenas as incertezas são maiores.

276 - Em que efeito no monitoramento das exposições internas da radiação ionizante as incertezas totais nas doses registradas tem probabilidades de serem maiores do que aquelas apresentadas para as exposições externas?

Foi observado no tempo de distribuição da incorporação. Exemplos:

a. No monitoramento de rotina, este tempo raramente é conhecido.

b. O modelo padronizado considera que este tempo é adequadamente representado por uma única incorporação ocorrida na metade do período entre duas amostragens sucessivas e se considera ser uma boa suposição para incorporações uniformes contínuas e para incorporações aleatórias frequentes.

277 - Com relação aos erros cometidos, qual é a frequência das medidas em um programa de monitoramento de radiação ionizante? A que valores podem chegar os erros e em que casos?

A frequência das medidas é escolhida para evitar erros maiores do que um fator 3. Para programas de monitoramento simples este erro pode predominar como, por exemplo, para o ${ }^{131}$ I ou o trítio sob forma de óxido. Para programas menos simples, outras incertezas podem aumentar o erro total em um valor de aproximadamente uma ordem de grandeza, como por exemplo, no caso do plutônio insolúvel.

278 - Em virtude de, na prática, raramente ser possível estimar a dimensão dos erros em um programa de monitoramento da radiação ionizante, o que a CIPR recomenda?

- Para o monitoramento de rotina o uso da "melhor estimativa" para os valores e os modelos.

- Para os monitoramentos com função relacionada à tarefa e interventora o uso de modelos não padronizados podem ser mais apropriados.

\section{Garantia de qualidade}


279 - Para os programas de controle e monitoramento da radiação ionizante, como é definida a garantia da qualidade e o que ela engloba?

São ações sistemáticas e planejadas, necessárias para proporcionarem uma confiabilidade adequada nos resultados de programas de controle e monitoramento. Ela engloba o controle de qualidade.

280 - 0 que se entende por controle da qualidade nos processos de monitoramento da radiação ionizante?

Ações que avaliam, em relação às exigências estabelecidas, a adequacidade dos equipamentos, instrumentos e procedimentos.

281 - Quais são os deveres da organização com relação à garantia de qualidade para o monitoramento da radiação ionizante?

- Verificar a conformidade com os seus próprios objetivos e procedimentos.

- O comprometimento da gerência para atender aos objetivos.

- Integrar em um completo arcabouço de garantia da qualidade da proteção radiológica a conformidade.

282 - Em um programa de monitoramento da radiação ionizante o que deve assegurar a garantia de qualidade?

Deve assegurar que:

- Os equipamentos e os instrumentos funcionem corretamente.

- Os procedimentos foram estabelecidos e implementados corretamente.

- As análises são executadas corretamente.

- Os erros sejam quantificados dentro dos limites aceitáveis.

- Os assentamentos são mantidos corretos, pontualmente e disponíveis.

283 - Quais são os fatores a serem considerados em um projeto de um programa de garantia de qualidade para o monitoramento da radiação ionizante?

- Qualidade dos equipamentos e instrumentos.

- Treinamento e experiência do pessoal.

- Verificação dos procedimentos, pela análise de averiguação, de amostras de controle usando métodos padronizados.

- Frequência de calibração e manutenção dos equipamentos e instrumentos.

284 - Que cuidados devemos tomar na confecção de um programa de garantia de qualidade para o monitoramento da radiação ionizante?

a. Que a instabilidade no sistema de medida é um aspecto importante que influi na frequência de calibração e manutenção dos equipamentos e instrumentos.

b. Na necessidade de que os resultados dos programas de monitoramento sejam acompanhados por um padrão nacional. 
c. Com relação à classe de documentação necessária para demonstrar que a qualidade exigida foi alcançada e é mantida.

285 - O que deve ser documentado em um programa da garantia da qualidade no monitoramento da radiação ionizante?

a. O programa de garantia de qualidade.

b. As verificações realizadas regularmente pelo controle da qualidade.

\section{Procedimentos Para apreciação sistemática dos Programas de Proteção Radiológica}

286 - O que se pretende com os "Procedimentos para apreciação sistemática dos programas de proteção radiológica"?

Fornecer um guia à gerência e organizações reguladoras sobre uma técnica a ser usada na avaliação sistemática dos programas de proteção radiológica operacional de modo que sejam determinadas, objetivamente, a sua adequacidade e a sua eficácia.

287-Qual é a base técnica e como pode ser usado o procedimento proposto para a apreciação sistemática dos programas de proteção radiológica?

A base técnica é a árvore porfiriana e pode ser usada para examinar o programa como um todo, para determinar se está completo e adequado, bem como para examinar um componente do programa com bastante detalhamento.

288 - Em que casos é recomendada uma apreciação sistemática dos programas de proteção radiológica?

Sempre que se deseja:

a. examinar o esforço global da proteção radiológica em uma organização, com o intuito de determinar se realmente é adequado e completo para os perigos potenciais envolvidos;

b. determinar se a gerência assumiu os compromissos necessários e forneceu os recursos para manter as exposições ALARA;

c. examinar em profundidade aspectos individuais do programa com o fim de determinar a sua eficácia.

289 - Quando e aonde se originou a técnica da árvore porfiriana e o que motivou o seu surgimento?

Ela originou-se na década de 1960 como "Análise da árvore de falhas, na indústria aeroespacial, como tentativa de eliminar imprevistos." Ela foi motivada principalmente para imprevistos nos sistemas de interface, pois resultaram em retro ajustes caros ou tempos de vida operacional desnecessariamente curtos para os sistemas que eram promissores. 
290 - Qual foi a orientação inicial da árvore porfiriana, como se mostrou promissora e como se desenvolveu o seu conceito uma década depois (1970)?

A orientação inicial da análise da árvore de falhas totalmente orientada a máquinas e mostrouse promissora como ferramenta analítica para a avaliação de sistemas que envolviam grande parte do desempenho humano. Uma década depois o conceito desenvolveu-se para Gerenciamento de Imprevistos e Árvore de Risco, GIAR, o que tornou realidade a aplicação da Árvore de Falhas a Sistemas de Gerenciamento.

291 - A partir do conceito GIAR em que direção se desenvolveu a análise da árvore de falhas?

Desenvolveu-se como ferramenta para a investigação de acontecimentos indesejáveis (como acidentes). Avaliação dos sistemas e programas existentes para a estimativa da sua eficácia.

\section{2 - Como é definida a árvore porfiriana?}

É uma exposição gráfica da informação para ajudar o usuário na condução de uma análise detalhada de um sistema ou programa (de máquina, humano ou ambiental) para determinar os caminhos críticos para o sucesso ou a falha.

\section{3 - 0 que pode identificar uma árvore porfiriana?}

Pode identificar os detalhes e as inter-relações que devem ser considerados para evitar os imprevistos e as omissões ou as redundâncias desnecessárias que levam a situações em que os programas tornam-se inferiores ao ótimo.

\section{4 - Que possibilidades a árvore porfiriana fornece ao analista?}

a. Identificar sistematicamente os caminhos possíveis desde os eventos básicos até as consequências previstas.

b. Expor um registro visual claro do processo analítico.

c. Identificar sistemas de gerenciamento robustos e fracos.

d. Fornecer uma base para a tomada de decisão racional, por parte da gerência, ou do órgão regulador.

295 - O que se entende por árvore positiva e negativa?

- Árvore positiva visa uma finalidade ou a meta desejada

- Árvore negativa visa um evento indesejável ou maléfico

296 - Quais são os passos realizados na confecção da árvore porfiriana e a quem compete resolver até que ponto deve ser desenvolvida?

Os passos são os que seguem:

a. Escolha do evento principal ou cabeça da árvore.

b. O evento cabeça é desmembrado em componentes necessários para alcançá-lo e estes componentes são listados numa segunda fila.

c. O processo é repetido para cada componente da segunda fila que é desmembrado em seus próprios componentes que são listados numa terceira fila. 
d. O processo é repetido até que os componentes revelem todos os itens, eventos, procedimentos, equipamentos necessários e suficientes para alcançar o evento cabeça.

Compete ao usuário da árvore decidir até onde uma árvore deve ser desenvolvida

297 - Qual é o significado e o propósito de se constituir uma árvore porfiriana?

Ela significa uma análise dedutiva de um programa gerencial ou de segurança que parte do geral para o específico ou do resultado para a fonte e responde à pergunta: "o que é necessário para que isto aconteça?" O seu principal propósito é modelar programas complexos.

298 - Após o desenvolvimento de uma árvore porfiriana como podemos usá-la?

a. Como uma ferramenta para ajudar na avaliação, investigação e melhoria do programa, tanto em situações normais como anormais.

b. Junto com indicadores apropriados para o controle no desenrolar do programa ou de um subprograma dele.

\section{9- Quão extensa deve ser uma árvore porfiriana?}

É muito variável, dependendo do tipo de instalação ou operação, da necessidade do usuário, do tipo de avaliação a ser empreendida e do problema a ser resolvido.

300 - Qual é o nosso escopo com a árvore porfiriana?

O nosso escopo é construir uma árvore analítica positiva para avaliar o programa de proteção radiológica.

301 - Como são divididos os símbolos lógicos utilizados na construção da árvore porfiriana?

São divididos em três categorias, a saber:

- Eventos

- Acessos

- Transferências

302 - Quais são os símbolos lógicos comumente utilizados em uma árvore porfiriana para denotar eventos, componentes ou condições?

São o retângulo, o circulo, o losango e a elipse.

303 - Qual a função de cada símbolo lógico utilizado nos eventos empregado na construção da árvore porfiriana?

- O retângulo denota um componente ou uma condição geral, ou ainda uma porta de saída do evento que resultou de uma combinação lógica de eventos, de constituintes ou de condições contribuintes que agiram através de uma porta lógica.

- O círculo denota um terminal básico, um componente específico, item ou constituinte, que não exige maior desenvolvimento. Localiza-se nos terminais dos ramos da árvore porfiriana. 
- O losango denota um componente terminal que não foi desenvolvido por algum motivo, como por exemplo, por falta de informação, de recursos ou para evitar redundância.

- A elipse denota um componente condicional no qual são aplicadas restrições sobre uma porta ou saída lógica.

304 - Qual a função de cada símbolo lógico utilizado nos acessos empregado na construção da árvore porfiriana?

O acesso "e" produz uma saída unicamente quando ocorrem todos os eventos entrada.<smiles>C1=CCCC=C1</smiles>

O acesso "ou" produz uma saída quando ocorre uma ou mais entradas.

305 - Qual a função de cada símbolo lógico utilizado nas transferências empregado na construção da árvore porfiriana?

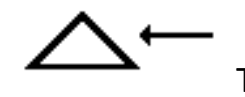

Transferência para dentro, com uma seta horizontal, significa uma transferência vinda de outra parte para esta.

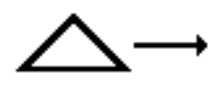

Transferência para fora, com uma seta horizontal, significa uma transferência desta parte da árvore para outra na direção da seta.

306 - qual é o propósito da revisão para a validação da árvore porfiriana e por quem deve ser executada?

O propósito da revisão da validação é confirmar que:

a. A árvore consegue os objetivos pretendidos.

b. O programa e suas funções foram completamente cobertos.

c. Os componentes e suas interações são necessários e suficientes para produzir o produto desejado.

A revisão deve ser executada por uma ou mais pessoas conhecedoras deverão rever os componentes da árvore e a lógica para acurácia e para ter certeza de que estão completos.

307 - Exemplo de uma árvore porfiriana positiva, usando os símbolos lógicos em que o evento cabeça e: "sentidos humanos todos funcionando", interrompendo todos exceto o paladar. 


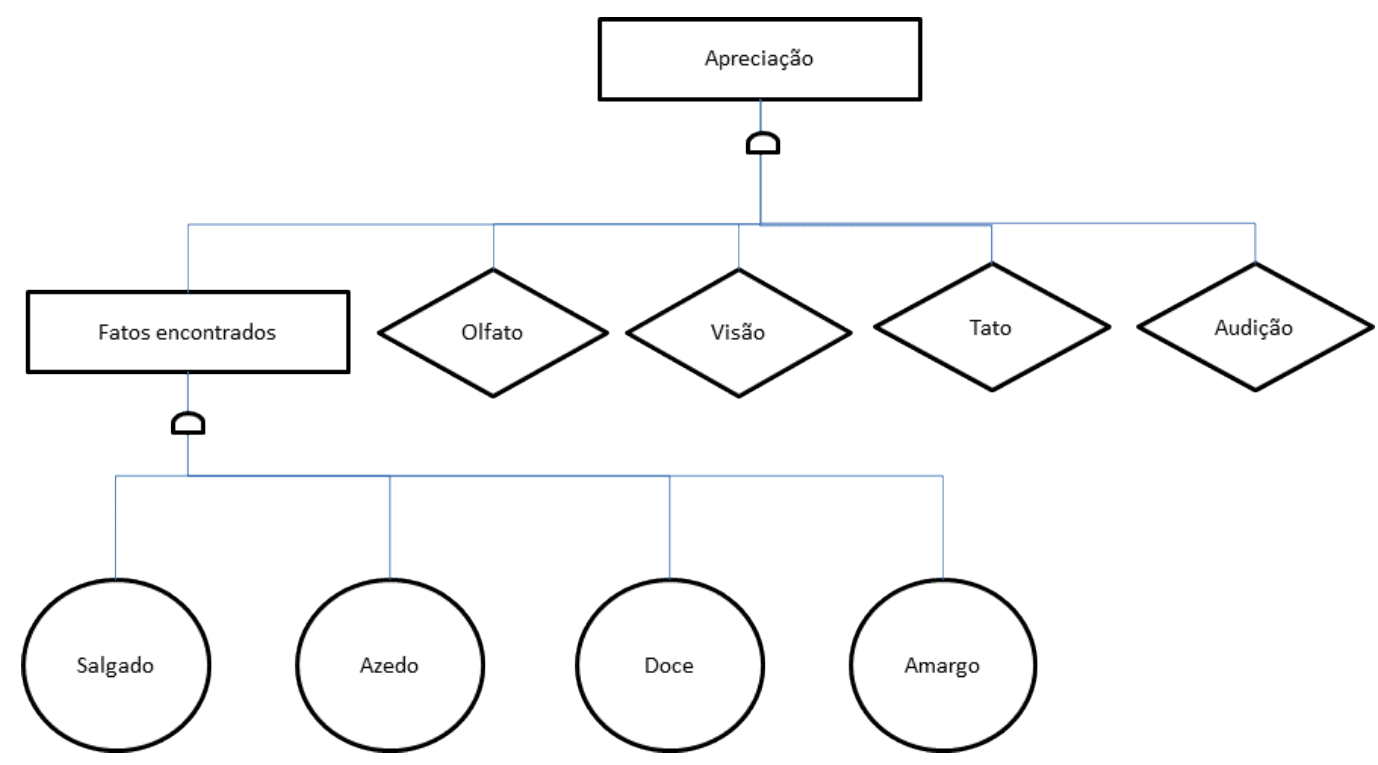

Figura 27 - Árvore porfiriana positiva e símbolos lógicos

308 - Exemplo de quatro aplicações gerais da árvore porfiriana.

a. Pode ser aplicada como uma ferramenta para manter clareza em um programa complexo, descrevendo os componentes necessários ao programa por meio de uma exposição gráfica lógica e completa.

b. Pode fornecer uma base para o estádio "fatos encontrados" na apreciação de um programa ou subprograma. Para isto usa-se a árvore analítica para identificar uma grande série de perguntas, cujas respostas fornecerão todos os fatos encontrados importantes à apreciação.

c. Pode ajudar participando na gerência do controle de programas complexos. A árvore porfiriana é utilizada para identificar os "indicadores" mais apropriados, representativos do desempenho dos subprogramas, num programa complexo.

d. Pode ser construída como uma árvore de falhas para participar na investigação de incidentes e acidentes. Para este tipo de investigação o evento cabeça é o incidente e a árvore ajuda a identificar as possíveis causas que puderam produzir ou contribuir para este incidente.

309 - Quatro exemplos de "indicadores de desempenho" de um programa de radioproteção.

a. Doses individuais, dose coletiva, taxa de dose ambiente, valores de contaminação.

b. Taxas instantâneas ou acumuladas das liberações de gases ou líquidos.

c. Frequência de falhas ou situações anormais reportáveis.

d. Frequências de falhas do equipamento ou instrumentação de radioproteção .

310 - Que tipos de Perguntas devem ser respondidas para identificar os componentes de uma árvore porfiriana?

- O que é necessário?

- De que tipo são? 
- Do que eles consistem?

- O que lhe é pertinente?

311 - Como pode ser desenvolvida até a terceira linha de uma árvore analítica, cujo acontecimento cabeça é "um programa adequado e eficaz de proteção radiológica" fazendose as perguntas pertinentes? Que diferentes usuários podem montar fileiras diferentes para 0 mesmo acontecimento?

Em um primeiro escrutínio pode-se formular a pergunta "do que consiste"? Neste caso deduzse: "pessoal", "instalações e equipamentos", "procedimentos", "controle da radiação laboral", "controle da radiação no publico" e "organização e gerenciamento" que vão todos na segunda linha.

Em um escrutínio mais apurado torna-se evidente que "o controle da radiação laboral" e o "controle da radiação no publico", são diferentes dos outros componentes, pois eles respondem preferencialmente, à pergunta: "o que lhe é pertinente?", isto é, o que é pertinente a um programa de proteção radiológica adequado e eficaz?

Como estes componentes respondem a duas perguntas diferentes, eles não podem ocupar a mesma fileira. Como o "Controle de radiação laboral" e o "Controle de radiação no público" são conceitos mais gerais do que os demais devem entrar numa fileira acima.

Como "Pessoal", "Instalações e Equipamentos", "Procedimentos" e "Organização e Gerenciamento" respondem à pergunta: "O que é necessário?" para o controle laboral e também para o controle da radiação no público, eles vão em uma ulterior fileira, como mostrado na FIGURA 28.

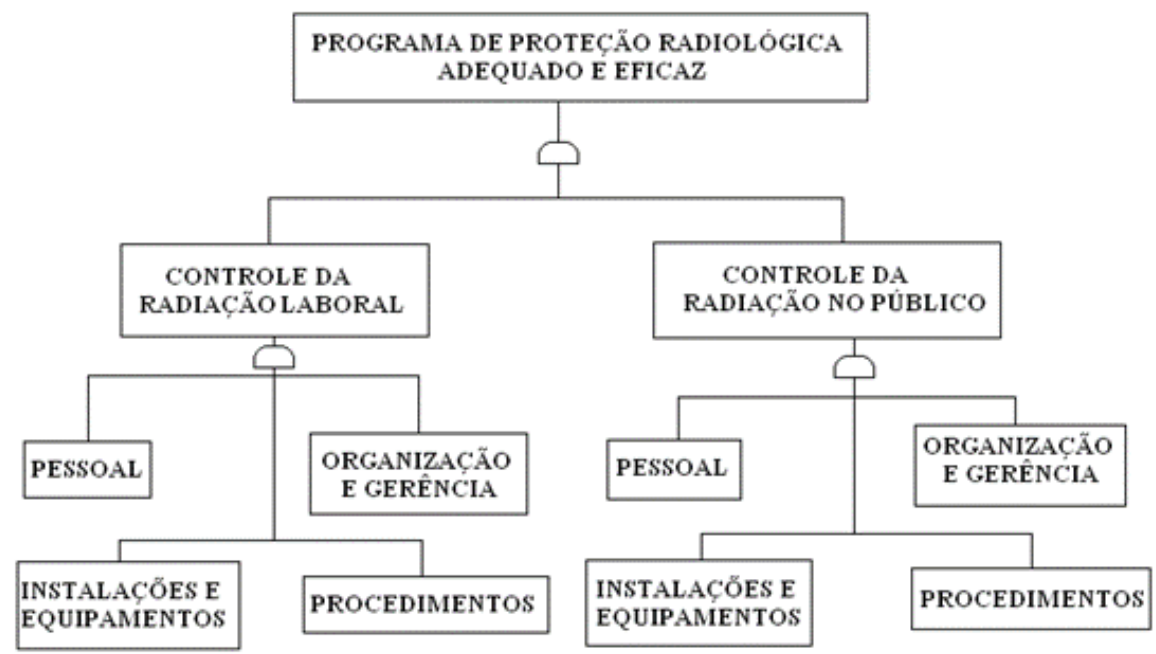

Figura 28 - Diferentes fileiras para um programa adequado e eficaz de proteção radiológica

Se for desenvolvido o ramo do controle da radiação laboral, a árvore deve ser modificada, conforme mostrado na FIGURA 29. 


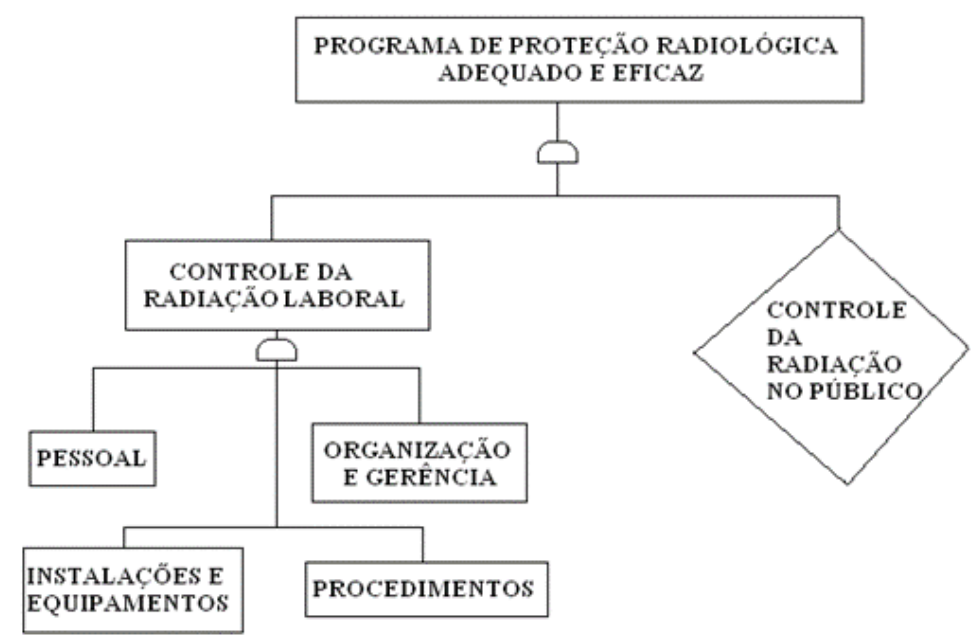

Figura 29 - Exemplo de árvore positiva para controle da radiação laboral

312 - Árvore analitica publicada na Safety Series $n^{\circ} 102$ do OIEA intitulada: "Recomendations for the safe use and Regulations of Radiation Sources in Industry, Medicine, Research and Teaching" publicada em 1990.

O sistema apresenta o recorte da árvore analítica publicada no OIEA, de acordo com o modelo apresentado nas FIGURAS 7 a 14 da presente tese.

313 - Qual a metodologia para formular perguntas a um determinado componente para formar as suas fileiras inferiores na árvore porfiriana?

Pode-se de formular perguntas fazendo uso de um componente com uma combinação de palavras como: “como?", “o que?", “quando?” “onde?", “com que frequência?”, "por quem?”. Exemplo: Com o componente "procedimentos" poderiam ser formuladas as seguintes perguntas:

a. Como estão desenvolvidos os procedimentos?

b. Quando os procedimentos estão desenvolvidos a contento?

c. Por quem foram desenvolvidos os procedimentos?

d. Que critérios foram utilizados?

e. Que justificativa tem?

f. Que tipo de aprovações são exigidas?

g. Que registros devem ser mantidos?

314 - O que é importante fazer a medida que se desenvolve a árvore porfiriana de um programa?

Agrupar os componentes em "subprogramas" ou "unidades" que executam funções ou propósitos específicos dentro do programa completo de proteção radiológica. Exemplos: "programa de monitoramento interno", "programa de monitoramento de efluentes gasosos" e "programa de monitoramento de área controlada". 
315 - O que pode ocorrer com o agrupamento em subprogramas do programa objeto de confecção da árvore porfiriana e o que sugere o CIPR?

Pode ocorrer que alguns componentes sejam repetidos em vários subprogramas, mas a CIPR sugere que eles devem ser incluídos se forem exigidos nos componentes do subprograma.

316 - Para a construção de uma árvore porfiriana pode ser útil uma seção de debates livres com um grupo de especialistas em proteção radiológica?

Sim, pois podem determinar os componentes que são necessários e suficientes para construir a árvore e fornecer as posições onde estes componentes devem ser colocados dentro da árvore.

317 - Como podemos melhorar as árvores porfiriana com o transcorrer do tempo?

Podemos melhorá-las com a experiência adquirida ou pelas lições aprendidas advindas de seu uso durante as apreciações, investigações de acidentes etc.

318- O que se pretende com uma apreciação detalhada e completa de um programa ou subprograma?

Pretende-se identificar os pontos robustos e fracos e fornecer bases para que as deficiências e omissões sejam corrigidas e, também, que os componentes desnecessários sejam eliminados .

319 - Qual é a finalidade de uma apreciação de um programa de proteção radiológica?

É fornecer uma completa avaliação de modo a verificar a adequacidade e a eficácia de um programa ou identificar as melhorias necessárias. Como resultado, as apreciações podem ajudar na otimização de um programa de proteção radiológica operacional.

320 - A necessidade de uma apreciação depende de muitos fatores? Que exemplos podemos citar?

a. O potencial de evitar mais dose.

b. O potencial de alcançar doses elevadas, provavelmente em condições de incidente ou acidente.

c. O tempo que se passou desde a última apreciação, pois em caso contrário, uma deterioração gradual nos padrões pode passar despercebida por um longo período de tempo.

d. A implementação de qualquer modificação importante que afete profundamente a dose individual ou coletiva.

e. A obtenção de algum nível de referência predeterminado que, talvez, possa ter sido escolhido para refletir a proteção radiológica otimizada.

321 - As técnicas de apreciação de um programa de proteção radiológica o que devem possibilitar ao avaliador?

- Identificar e documentar todos os componentes importantes de um programa do operador. 
- Documentar estes componentes de uma maneira tal que possa ser efetuada uma avaliação da adequacidade do: (i) programa completo e (ii) componentes individuais.

- Determinar se o programa: (i) é adequado e eficaz e (ii) pode ser usado como uma ajuda na sua otimização.

- Uma ajuda para assegurar que é mantido um programa adequado e eficaz.

322 - Como montar uma árvore analítica mostrando os componentes importantes na apreciação de um programa?

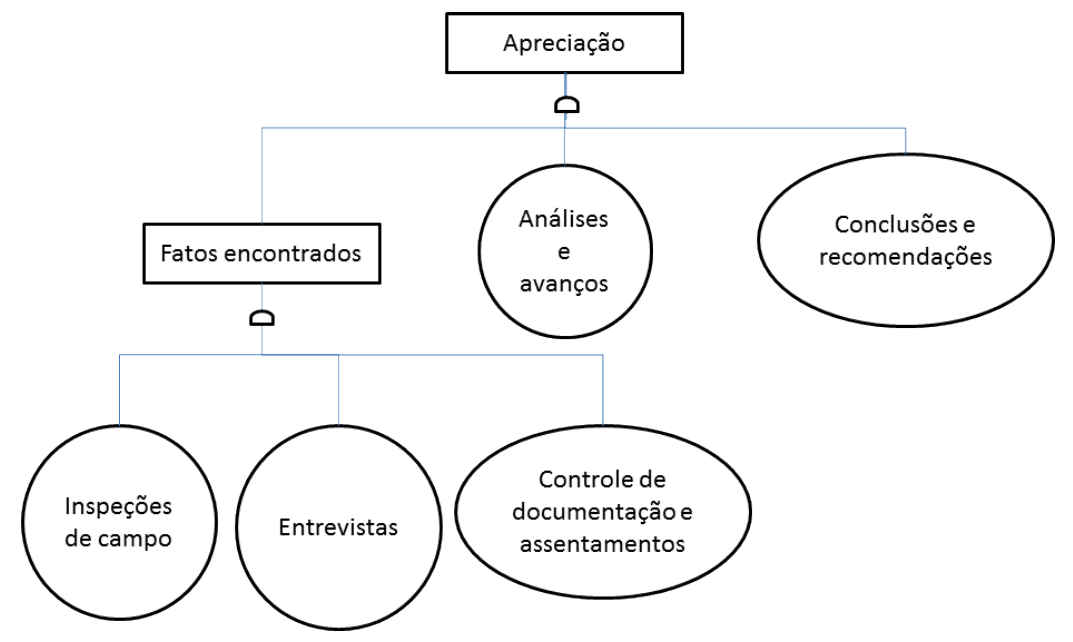

Figura 30 - Componentes importantes na apreciação de um programa

323 - O que a CIPR sugere que se realize com os fatos encontrados em uma apreciação de um programa ou uma operação?

- Um escrutínio para cada componente do programa ou subprograma.

- Que as informações obtidas podem ser submetidas a um julgamento profissional considerável e a comparações contra exigências e padrões regulamentares, bem como a princípios de boas práticas de proteção radiológica.

324 - A analise das avaliações subsequentes dos fatos encontrados na apreciação de um programa ou subprograma como podem ser facilitadas e que ferramentas podem participar dela?

Ela pode ser facilitada pelo uso de uma árvore porfiriana bem estruturada e podem participar ferramentas mais formais ligadas à otimização da proteção radiológica e fornecerem bases imputáveis para as conclusões e recomendações subsequentes.

\section{5 - Quem pode conduzir a apreciação de um programa ou subprograma?}

Pode ser conduzida pela ou por interesse da direção, da autoridade regulamentaria ou por uma terceira parte.

326 - Como fornecer um diagrama em bloco utilizado para condução de uma operação? 


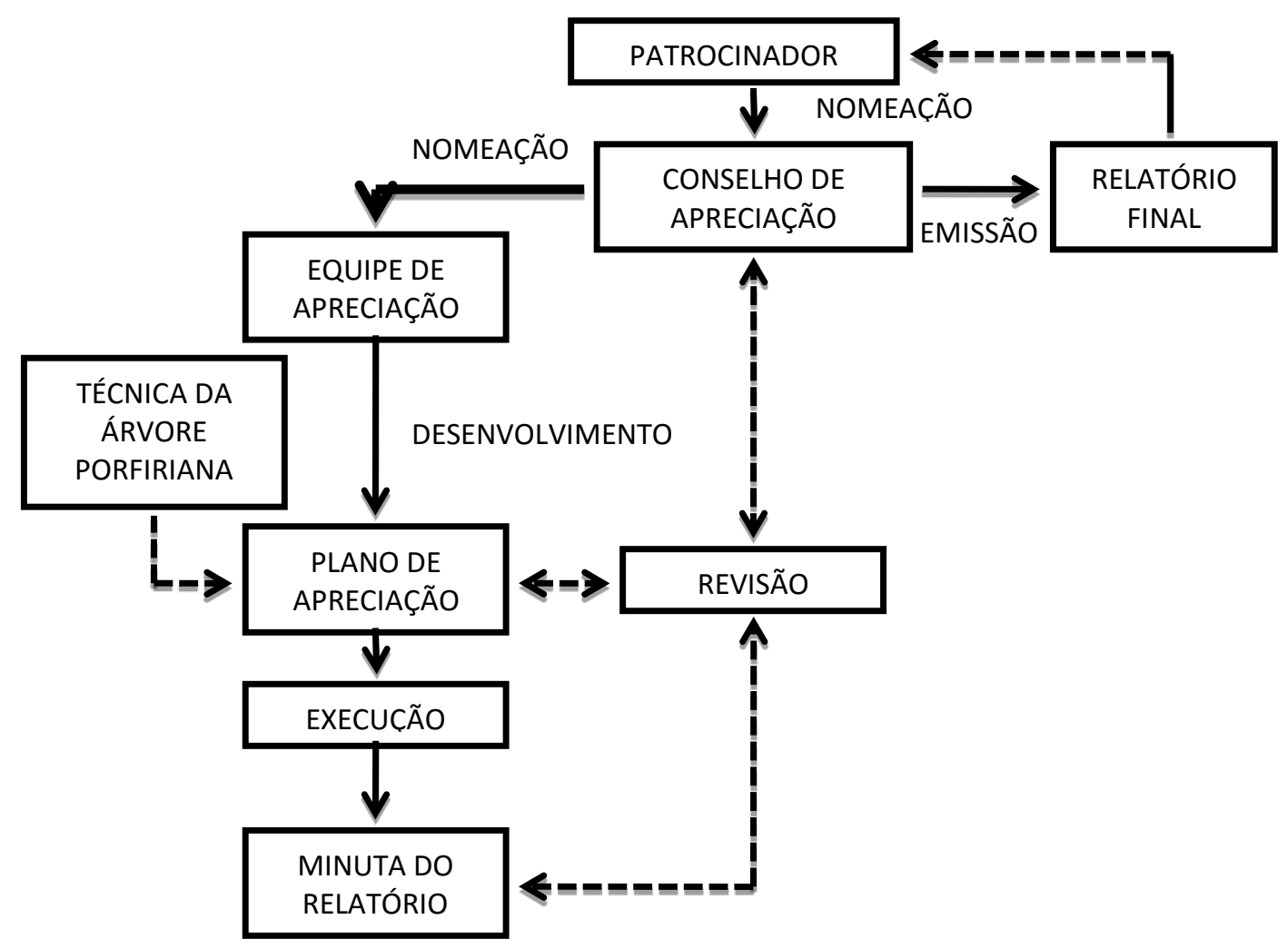

Figura 31- Diagrama em bloco para condução de uma operação

327 - Como devem ser escolhidos os representantes do conselho de apreciação de um programa ou subprograma?

Devem ser escolhidos dois ou mais representantes ou membros da direção que não sejam responsáveis diretos dos programas submetidos à apreciação. Eles, no máximo, podem ter uma responsabilidade gerencial indireta com relação ao programa.

328 - Que autoridade deverá ou poderá ter o conselho de apreciação de um programa ou subprograma?

a. Deverá ter autoridade para tomar decisões com respeito aos fatos encontrados e recomendações que resultam da apreciação.

b. Poderá, ou não, ter a autoridade para implementar as recomendações resultantes da apreciação.

329 - Quais são as principais responsabilidades do conselho de apreciação de um programa ou subprograma?

- Determinar quando seria executada a apreciação, qual o seu escopo, qual sua profundidade e qual o seu propósito

- Aprovar o plano de Apreciação

- Revisar o Relatório Minuta da apreciação submetida a ele pela Equipe de Apreciação

- Aprovar o Relatório Final 
330 - Que conhecimentos devem possuir os integrantes da equipe de apreciação?

Devem ser tecnicamente competentes para avaliarem as áreas funcionais atribuídas a eles.

331 - Por quantas pessoas deve ser constituída a equipe de apreciação de um programa ou subprograma e quais são as vantagens de se aumentá-la?

Deve ser constituída de pelo menos duas pessoas. As vantagens de aumentá-la são:

- Se a apreciação for externa poderá ser concluída em um tempo menor.

- O aumento no número de pessoas permite a seleção de indivíduos que tenham uma experiência mais específica nas áreas mais técnicas da apreciação.

332 - Quem deve e pode participar da Reunião de Planejamento necessária para o desenvolvimento do Plano de Aplicação de um programa ou subprograma?

Devem participar todos os membros da Equipe de Apreciação e pode, também, ser incluído um representante do conselho de Apreciação.

333 - O que deve satisfazer o plano de Apreciação desenvolvido na Reunião de Apreciação?

Deve satisfazer os propósitos, o escopo e a profundidade exigidos pelo conselho de Apreciação.

334 - A quem é submetido o plano minuta de apreciação e qual é a responsabilidade da equipe de apreciação após a sua aprovação?

R: Deve ser submetido ao Conselho de Apreciação e após sua aprovação a Equipe de Apreciação é responsável para implementá-lo e para completar a apreciação.

\section{5 - Como a Equipe de Apreciação desenvolve o plano de Apreciação?}

Primeiramente formaliza uma árvore porfiriana que descreve graficamente o programa, em uma profundidade apropriada que, em seguida, é usada como um guia lógico para desenvolver uma série de questões que servem de base para o Plano. Estas questões devem ser planejadas com a finalidade de guiar o apreciador nas áreas pertinentes para adquirir uma avaliação compreensiva dos vários aspectos do programa e devem fornecer os dados que são necessários a satisfazer o propósito da apreciação.

336 - A equipe de apreciação após ter desenvolvido o plano de apreciação o que deve realizar?

- Determinar o número de visitas e de entrevistas.

- Efetuar uma estimativa preliminar do tempo necessário para executar a apreciação real.

- Realizar todas as mudanças necessárias com relação ao itinerário inicial.

337 - Como devem ser planejados o itinerário das árvores e as questões de um plano de apreciação de um programa ou subprograma?

Devem ser planejados de forma flexível para cobrir outros aspectos que possam ter sido negligenciados durante o planejamento inicial, mas que foram descobertos durante $o$ desenvolvimento da apreciação. 
338 - 0 que é exigido de uma apreciação?

Um retrospecto da documentação, dos dados registrados e, das entrevistas e visitas realizadas.

339 - 0 que o apreciador deve observar, discutir e confirmar durante as visitas?

a. Deve observar pessoalmente e confirmar todos os aspectos do programa que não poderiam ser vislumbrados na revisão da documentação.

b. Deve discutir e confirmar detalhes do programa com a direção, o quadro de servidores e empregados na produção da instalação.

340 - 0 que deve ser registrado e o que se deve indicar de uma apreciação?

Devem ser registradas todas as respostas a questões relacionadas a cada componente da árvore que fosse desenvolvido e indicar se o componente está satisfeito, ou que requer uma ulterior análise. O propósito da apreciação é que determina a necessidade de uma ulterior análise de um fato encontrado, evento negativo.

\section{1 - Por que devem ser mantidos os registros de uma apreciação e o que podem incluir?}

Os registros devem ser mantidos para justificar o resultado de cada evento e podem incluir referências a procedimentos específicos, dados coletados das fontes da instalação, incluindo discussões com o pessoal e relatórios escritos das observações pessoais.

342 - Após o apreciador ter concluído as suas atribuições o que deve realizar e com que propósito?

Deve ser realizada uma reunião, para rever os resultados. O propósito da revisão é determinar se foram realizadas omissões na apreciação, como um todo, ou se é necessária uma ulterior avaliação para justificar completamente qualquer um dos fatos encontrados.

343 - Como deve ser estruturado o Relatório Minuta da apreciação, o que deve ser incluído nele e por quem deve ser confeccionado?

O relatório deve apresentar um resumo introdutório dos principais fatos encontrados que são importantes. Em seguida conter capítulos cobrindo cada uma das principais áreas funcionais inseridas no Plano de Apreciação e por fim um último capítulo apresentando as conclusões e recomendações. Nele devem ser incluídos todos os dados coletados para justificar os fatos encontrados da apreciação, e isto deve ser feito, por meio de referências ou em alguns casos como apêndices ao relatório. O Relatório Minuta deve ser confeccionado pelos membros da Equipe de Apreciação.

344 - 0 que deve ser feito e pode ser feito pela equipe de apreciação após o Relatório Minuta estar concluído?

Deve ser submetido ao conselho de Apreciação para revisão e uma cópia do Relatório Minuta pode ser submetida à direção da organização que está sendo apreciada, naquele instante, para a sua apreciação. A prática de fornecer uma copia à direção da organização desde os primeiros estágios da confecção da minuta pode reduzir más interpretações e erros por parte dos apreciadores. 
345 - Após a revisão inicial do Relatório Minuta da apreciação, que atitude deve tomar o conselho de Apreciação?

Deverá marcar uma reunião com a Equipe de Apreciação para resolver os comentários extraídos do Relatório Minuta.

346 - O que deverá ser efetuado se forem resolvidos, na reunião com a Equipe da Apreciação, todos os comentários realizados pelo Conselho de Apreciação? E se não forem resolvidos?

Se todos os comentários forem resolvidos, o conselho solicita que o relatório seja emitido em sua forma final para ser enviado ao patrocinador. Se existem problemas que não puderam ser resolvidos o conselho poderá:

a. Solicitar que sejam realizados novos esforços pela Equipe de Apreciação para coletar dados a fim de resolver o problema.

b. Se for constatado que será exigido um tempo considerável para se chegar a uma solução, pode ser emitido o Relatório Final contendo uma observação que defina claramente o problema não resolvido e a ação proposta para sua solução.

347 - Como é considerado o relatório final pela direção e que responsabilidades ela deve assumir?

É considerado como um documento de trabalho para direção para a tomada de decisão e ela se responsabiliza pelas conclusões e recomendações da apreciação de forma definitiva.

\section{8 - Que respostas a direção deverá fornecer ao Conselho de Apreciação?}

Apresentar um cronograma das ações para cada recomendação ou, caso se resolva não agir para uma determinada recomendação, deve informar as razões da decisão.

349 - Quais são as fases de um programa de apreciação?

São seis, a saber:

a. Identificar os propósitos e a finalidade da apreciação. Começar com uma árvore porfiriana genérica, adequada ao tipo de trabalho que está sendo empreendido.

b. Conhecendo a instalação e particularmente a finalidade e dimensão de suas operações, modificar a árvore porfiriana genérica para produzir uma árvore que seja inteiramente apropriada à instalação a ser avaliada.

c. Fazendo uso da árvore porfiriana dimensionada à instalação, construir uma série detalhada de questões que produzirão a fase "fatos encontrados" da apreciação.

d. Obter respostas detalhadas à série de questões.

e. Avaliar as informações obtidas comparando-as com padrões pré-determinados como: exigências regulamentares, princípios aceitos de otimização, princípios de boa proteção radiológica, um firme julgamento profissional.

f. Identificar os pontos robustos e fracos do programa e formular as recomendações apropriadas e se for necessário aplicar as técnicas analíticas de ajuda para a tomada de decisão mais formais, como aquelas usadas na otimização da proteção radiológica. 